\title{
The entanglement of NASH and atherosclerosis
}

Citation for published version (APA):

Jeurissen, M. L. J. (2017). The entanglement of NASH and atherosclerosis: shared features of a macrophage-specific response. [Doctoral Thesis, Maastricht University]. Maastricht University. https://doi.org/10.26481/dis.20170112mj

Document status and date:

Published: 01/01/2017

DOI:

10.26481/dis.20170112mj

Document Version:

Publisher's PDF, also known as Version of record

\section{Please check the document version of this publication:}

- A submitted manuscript is the version of the article upon submission and before peer-review. There can be important differences between the submitted version and the official published version of record.

People interested in the research are advised to contact the author for the final version of the publication, or visit the DOI to the publisher's website.

- The final author version and the galley proof are versions of the publication after peer review.

- The final published version features the final layout of the paper including the volume, issue and page numbers.

Link to publication

\footnotetext{
General rights rights.

- You may freely distribute the URL identifying the publication in the public portal. please follow below link for the End User Agreement:

www.umlib.nl/taverne-license

Take down policy

If you believe that this document breaches copyright please contact us at:

repository@maastrichtuniversity.nl

providing details and we will investigate your claim.
}

Copyright and moral rights for the publications made accessible in the public portal are retained by the authors and/or other copyright owners and it is a condition of accessing publications that users recognise and abide by the legal requirements associated with these

- Users may download and print one copy of any publication from the public portal for the purpose of private study or research.

- You may not further distribute the material or use it for any profit-making activity or commercial gain

If the publication is distributed under the terms of Article $25 \mathrm{fa}$ of the Dutch Copyright Act, indicated by the "Taverne" license above, 


\section{The Entanglement of NASH and Atherosclerosis}

Shared features of a macrophagespecific response 
(C) Mike Jeurissen, Maastricht 2016

Layout: Mike Jeurissen

Cover design: www.ThesisExpert.nl

Production: Ipskamp Printing

ISBN: 978-94-028-0460-7

Printing of this thesis was financially supported by the Nederlandse Vereniging voor Hepatologie

Financial support by the Dutch Heart Foundation for the publication of this thesis is gratefully acknowledged. 


\title{
The Entanglement of NASH and Atherosclerosis
}

\section{Shared features of a macrophage- specific response}

\author{
PROEFSCHRIFT \\ ter verkrijging van de graad van doctor aan de Universiteit Maastricht, \\ op gezag van de Rector Magnificus, Prof. Dr. Rianne M. Letschert \\ volgens het besluit van het College van Decanen, \\ in het openbaar te verdedigen op \\ Donderdag 12 januari 2017 om 10:00 uur
} door akkoord,

Mike Louis Johannes Jeurissen

Geboren te Lelystad op 15 November 1985 


\section{Promotor:}

Prof. Dr. R. Shiri-Sverdlov

Prof. Dr. J.F.C. Glatz

\section{Co-promotors:}

Dr. M.M. Donners

\section{Beoordelingscommissie:}

Prof. Dr. C.P. Reutelingsperger (Voorzitter)

Prof. Dr. S.M. Francque (University of Antwerp, Belgium)

Dr. S.E. Köhler

Prof. Dr. T. Lüdde (University of Aachen, Germany) 


\section{Contents}

$\begin{array}{ll}\text { Chapter 1: } & \text { General Introduction }\end{array}$

Chapter 2: Prevention of oxLDL uptake decreases 25

atherosclerosis in hematopoietic NPC1 ${ }^{\text {mut }}$

deficient $L d I r^{-1}$ mice

Atherosclerosis, 2016

Chapter 3: Bone marrow-specific caspase-1/11 deficiency 45 inhibits atherosclerosis development

in $L d l r^{-1-}$ mice

FEBS Journal, 2015

Chapter 4: Myeloid DLL4 does not contribute to the

65

pathogenesis of non-alcoholic steatohepatitis

in $L d l r^{-1-}$ mice

In press at PLoS One, 2016

Chapter 5: Hematopoietic overexpression of CYP27A1

reduces hepatic inflammation independently of 27-hydroxycholesterol levels in $\mathrm{LdIr}^{-/}$mice Journal of Hepatology, 2015

Chapter 6: General discussion

Summary

Samenvattting

Valorisation

Dankwoord

Curriculum vitae 

Chapter 1

General Introduction 


\section{Metabolic Syndrome}

The Metabolic Syndrome (MetS) is defined as a clustering of multiple metabolic risk factors that contribute to the development of non-alcoholic fatty liver disease (NAFLD), cardiovascular disease (CVD) and Type 2 diabetes (T2D) (1-4). The metabolic risk factors that are contributing to the disease are defined as a pro-inflammatory state, abdominal obesity, elevated glucose level or insulin resistance, hypertension and atherogenic dyslipidaemia (5). Obesity dramatically increases the prevalence of MetS. In both men and women, the prevalence of MetS was $6.8 \%-9.3 \%$ in normal weight, $29.8 \%-33.1 \%$ in overweight, and $65 \%-56.1 \%$ in obese individuals, respectively $(6,7)$. The expansion of visceral adipose tissues has been proposed to be the main trigger for MetS leading to insulin resistance and thereby contributing to other metabolic risk factors, like dyslipidaemia, hypertension and impaired glucose metabolism. When these conditions are not treated, MetS can develop into T2D which in turn is an important risk factor for $\operatorname{CVD}(5,8,9)$. Marchesini et al. proposed that NAFLD is the hepatic manifestation of MetS (2). Accordingly, NAFLD is associated with obesity, insulin resistance and dyslipidaemia which are all hallmarks of MetS. Next to that, NAFLD is an important risk factor for CVD since it contributes to the formation of atherosclerotic plaques (10-13). In addition, it has been claimed that NAFLD is the precursor of the metabolic syndrome, and there is accumulating evidence that NAFLD aggravates or contributes to the progression of the metabolic syndrome (14).

\section{Non-alcoholic steatohepatitis - the hepatic manifestation of the metabolic syndrome}

NAFLD is currently one of the most common liver diseases worldwide. NAFLD can be subdivided into two conditions, namely non-alcoholic fatty liver characterized by isolated steatosis, or non-alcoholic steatohepatitis with fat accumulation and inflammation (lobular inflammation and hepatic cellular ballooning) also known as NASH. Metabolic risk factors like obesity, insulin resistance, hypertension and dyslipidaemia are increasingly linked to NAFLD and NASH, and these are therefore considered to be the hepatic manifestations of the metabolic syndrome $(2,15)$. Conversely, NASH is also being considered to be the precursor of the metabolic syndrome (14). In a US cohort of middle-aged adults, the prevalence of NAFLD was estimated to be roughly $45 \%$, and that of NASH around $12 \%(16)$. In obese individuals that underwent bariatric surgery, the prevalence surged to $86 \%-96 \%$ for NAFLD and to $25 \%$ - $55 \%$ for NASH (17). In NASH, inflammation is a key feature of disease progression (fibrosis formation and eventually cirrhosis) whereas steatosis alone is considered a benign and reversible condition. It is still not known why some patients progress to hepatic inflammation while others only develop steatosis. The 
pathophysiology of NASH is currently explained by an altered lipid and glucose metabolism in visceral fat that initiates hepatic fat accumulation. As a consequence, pro-inflammatory processes trigger hepatic inflammation in steatotic livers leading to the vicious circle of inflammation described for atherosclerosis. Inflammation contributes to liver damage and subsequently progressive fibrosis, which eventually leads to cirrhosis. However, since the mechanisms leading to hepatic inflammation are not fully elucidated yet, therapeutic options are poor $(15,18-22)$.

\section{Atherosclerosis - a chronic inflammatory disease of the vessels}

In 2013, CVD was the second leading cause of mortality worldwide with about 17 million deaths. Atherosclerosis is one of the major causes for developing clinical complications of CVD, eventually resulting in myocardial infarction and stroke $(23,24)$. Relevantly, myocardial infarction and stroke are more pronounced in individuals with MetS compared to individuals without MetS (25). Atherosclerosis is a chronic inflammatory disease of the medium- and large-sized arteries. Endothelial activation by hypertension, diabetes, turbulent blood flow, blood composition, hyperlipidaemia or reduced elasticity of the blood vessel results in LDL accumulation and retention in the vessel wall. Simultaneously, the formation of radicals like reactive oxygen species (ROS) will lead to the modification of LDL into oxidized LDL (oxLDL). In addition, endothelium activation will lead to the expression of various adhesion molecules on the endothelial surface facilitating the attraction of monocytes and lymphocytes. Migrated monocytes will differentiate into macrophages and aid in the uptake of oxLDL thereby finally becoming foam cells. These processes contribute to the development of plaque formation in the vessel wall $(24,26-28)$. The accumulation of foam cells stimulates the production of cytokines and chemokines, thereby attracting more inflammatory cells. The production of chemokines also attracts smooth muscle cells $(S M C)$ resulting in fibrous cap formation. At the same time, due to extensive oxLDL uptake, foam cells will undergo apoptosis releasing oxLDL into the plaque compartment leading to more inflammation. Insufficient clearing of these apoptotic cells (efferocytosis) contributes to the formation of a necrotic/lipid core (23, 27-29). This ultimately initiates a vicious cycle of inflammation and apoptosis leading to more plaques and eventually contributing to the destabilization of atherosclerotic lesions due to the loss of extracellular matrix, intraplaque hemorrhaging, fissuring and calcification. Finally, plaque rupture and subsequent vessel occlusion due to thrombus formation result in the clinical complications of CVD (23). 


\section{A shared etiology between atherosclerosis and NASH}

As previously mentioned, the metabolic risk factors displayed in NASH are closely linked to the MetS and as a consequence afflicted individuals have an increased risk for CVD (10-14). Clinical studies investigating the link between NASH and CVD, with atherosclerosis as an actively contributing factor independent of other metabolic risk factors (30), have been reviewed by $X u$ et al. (13). The underlying mechanisms are, however, not yet fully elucidated. Increased oxidative stress due to lipid-induced steatosis, release of pro-inflammatory cytokines, oxidized LDL cholesterol and macrophage activation have been proposed as factors that link the development of atherosclerosis and NASH $(13,30,31)$. In addition, macrophages play a central role in atherosclerosis development through their uptake of oxLDL and their ensuing differentiation into foam cells $(32,33)$. A similar process has been observed in NASH where lipid-laden Kupffer cells (KCs) also display a foam cell phenotype (34). The uptake of oxLDL by macrophages is facilitated by the scavenger receptors $A(S R-A)$ and CD36, and absence of these receptors protects against atherosclerosis (33, 35-37). Those receptors are expressed on the cell surface of KCs (38). We have demonstrated that deletion of these scavenger receptors decreased hepatic inflammation in a mouse model for $\operatorname{NASH}(39,40)$. These findings provide evidence that oxLDL triggers scavenger receptor dependent uptake and subsequently induce inflammation contributing to hepatic inflammation and atherosclerosis. OxLDL is a strong contributor to atherosclerosis development, and accordingly, strong correlations have been found between atherosclerosis and levels of autoantibodies directed against modified LDL $(41,42)$. In line, prevention of oxLDL uptake by pneumococcal vaccination, which results in an increase of antibodies against oxLDL, decreases atherosclerosis development in hyperlipidemic mice (43). A similar strategy decreased hepatic inflammation in a mouse model for NASH (44). Overall, these studies have shown that foam cell formation and inflammation are shared characteristics of the two chronic inflammatory diseases NASH and atherosclerosis (Figure 1). Importantly, potential new treatment strategies could therefore be beneficial for both NASH and atherosclerosis. 


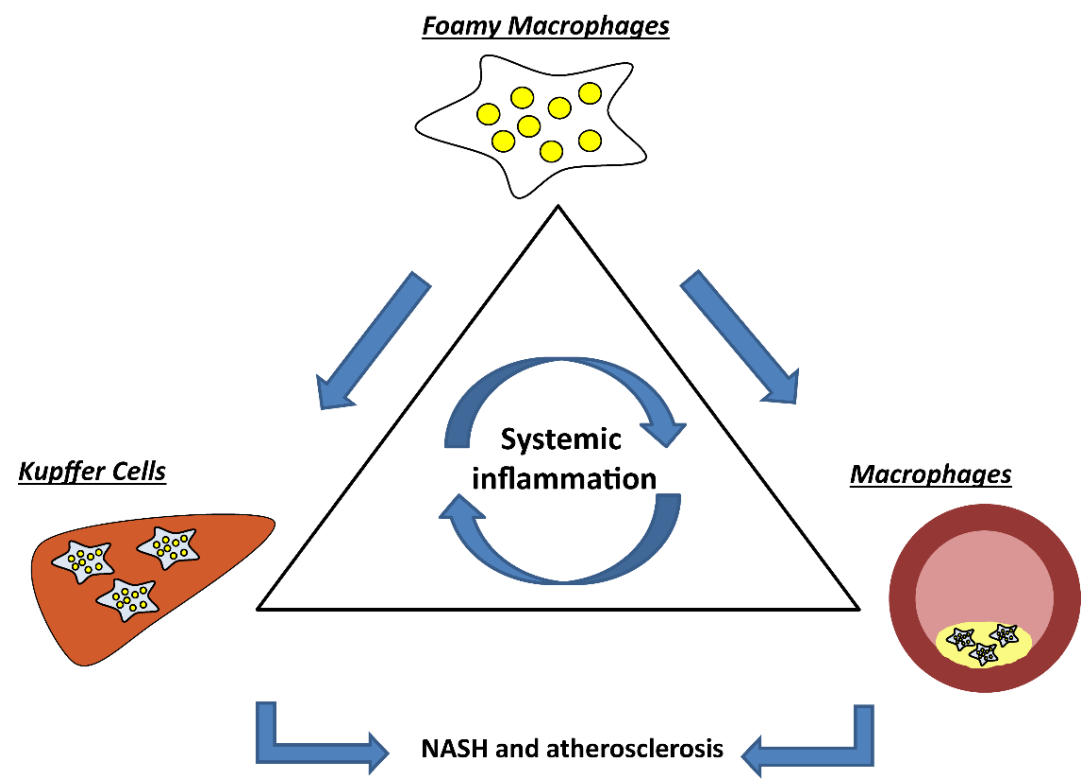

Figure 1: Shared mechanistic features of NASH and atherosclerosis. Foamy macrophages are key players in both NASH and atherosclerosis contributing to a vicious cycle of systemic inflammation leading to disease progression. Adapted from Bieghs et al (31).

\section{Atherosclerosis and NASH displays features of an acquired lysosomal storage defect}

Intracellular cholesterol metabolism is regulated by the internalization of cholesterol, which is then directed to the lysosomes for degradation. Lysosomes are membranebound cytoplasmic acidic organelles. Here, the cholesteryl esters within the lipid particles are hydrolysed, a process which is catalysed by lysosomal acid lipases. The transport of free cholesterol out of the lysosome into the cytoplasm is dependent on Niemann-Pick Type C (NPC) proteins (45-49). A mutation in these NPC proteins is characterized by the accumulation of cholesterol within the lysosomal compartment $(50,51)$ (Figure 2). Abnormal lysosomal lipid uptake has also been associated with aberrant lipid metabolism of foamy macrophages, which play a significant role in both atherosclerosis and NASH (52). In the seventies, it was observed for the first time that accumulated lipids within foamy cells were located in large, lipid-engorged lysosomes, which were identified by electron microscopy $(53,54)$. In the upcoming years, several studies demonstrated this also in human lesions as well as in numerous animal models of atherosclerosis (53-58). With regard to NASH, lysosomal cholesterol accumulation was found to be present within KCs and correlated well with hepatic inflammation 
and cholesterol crystal formation $(39,44,59)$. These observations clearly show that Iysosomal cholesterol accumulation is associated with inflammation and thereby crucial for both NASH progression and atherosclerosis development. It has been shown that it is mainly oxidized LDL that is trapped within lysosomes and resists efflux, whereas non-modified LDL is cleared normally $(52,60-62)$. These data suggest that the accumulation of oxLDL into the lysosomal compartment could be an important trigger for inflammation in NASH and atherosclerosis.

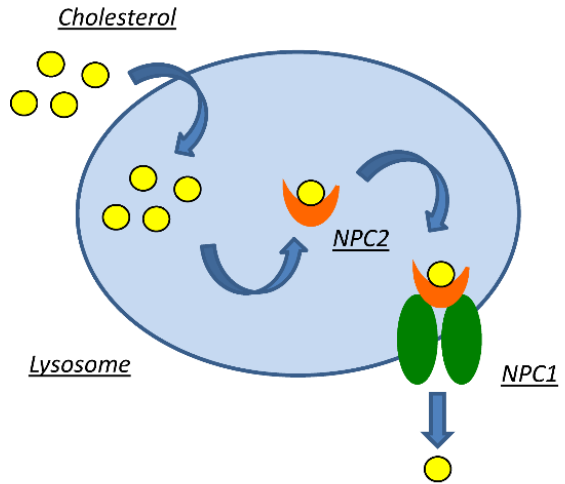

Normal Macrophage

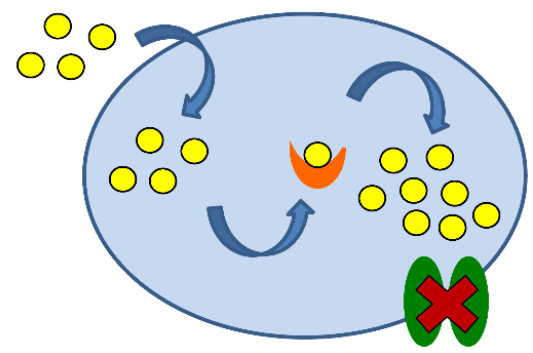

\section{NPC1 ${ }^{\text {mut }}$ Macrophage}

- Lysosomal cholesterol accumulation

- Increased inflammation

- Atherogenic

Figure 2: Schematic overview of normal and dysfunctional NPC1 protein in macrophages. Under normal conditions, cholesterol is initially directed to the lysosomes for hydroxylation by lysosomal enzymes and transported back in the cytosol by NPC1 proteins. NPC2 is necessary for the regulation of transport to the NPC1 protein. Dysfunctional NPC1 leads to increase in lysosomal cholesterol accumulation due to blockage of transport from the lysosome to the cytosol leading to more increased inflammation and atherogenesis. Adapted from Sugii et al. and loannou et al. $(48,49)$ 


\section{The downstream effects of foamy macrophages on inflammatory pathways and the modulation of cholesterol content}

\section{Inflammasome activation}

The inflammasomes are multi-protein complexes responsible for the activation of caspase-1 leading to the proteolytic cleavage and secretion of interleukin (IL)-1 $\beta$ and IL-18 (63-65). The uptake of oxLDL by macrophages will lead to an accumulation of cholesterol and the formation of cholesterol crystals within lysosomes, thereby inducing inflammation $(39,44,59)$, through the activation of the inflammasome $(66$, 67). In the context of NASH, we demonstrated that bone marrow specific caspase$1 / 11$ deficiency protects against cholesterol crystallization and hepatic inflammation in Ldl $^{-/}$mice, indicating a specific role for inflammasome activation in hepatic inflammation and thereby NASH progression. In addition, NLRP3 inflammasome activation has also been associated with uptake of oxLDL by macrophage $(68,69)$. Thus, inflammasome activation has not only been connected to NASH development but also plays a significant role in atherosclerosis development (70-72). Additionally, several studies have demonstrated that caspase-1 deficiency also protects against atherosclerosis development $(73,74)$. However, the specific contribution of hematopoietic caspases-1 and -11 to atherosclerosis development has never been investigated.

\section{Delta-Like-Ligand 4 (DLL4)-Notch signaling}

In addition, to lysosomal cholesterol accumulation, Notch signaling has been implicated to be an important regulator of metabolic processes (75). Upon interaction between Notch receptors (e.g. Notch-1, $-2,-3$ or -4 ) and their ligand (e.g. Jagged-1 (J1), Jagged-2 (J2), Delta-Like Ligand- 1 (DLL1), Delta-Like Ligand-3 (DLL3) or Delta-Like Ligand-4 (DLL4)), Notch receptors will undergo proteolytic cleavage by A disintegrin and metalloproteases (ADAM) and $\gamma$-secretases. Consequently, proteolytic cleavage leads to the release of the Notch intracellular domain (NICD) from the membrane and translocation to the nuclease where it subsequently interacts with Notch transcription factors inducing Notch target genes (Figure 3$)(76,77)$. With regard to the liver, Notch signaling is involved in liver development, liver repair and certain liver diseases (78). A specific role for Notch signaling has been indicated in a cohort of NAFLD patients where downstream targets of Notch are positively correlated with steatosis and inflammation (79). Additionally, Notch signaling has also been implicated in various cardiovascular pathological processes, like vascular calcification, neointimal hyperplasia and induces senescence in endothelial cells by stimulation of proinflammatory stimuli thereby promoting atherosclerosis development (80-83). Notch signaling is also involved in macrophage inflammation as co-localization of Notch 
receptors/ligands and macrophages is been demonstrated in human atherosclerotic lesions. Fung et al, demonstrated that specifically DLL4-Notch signaling plays a significant role in macrophages in vitro by inducing pro-inflammatory stimuli upon Notch-receptor binding (84). Remarkably, global inhibition of the Notch ligand DLL4 alters the macrophage-mediated inflammatory response, resulting in a reduction of atherosclerosis (85). It has been demonstrated that activation of (DLL4)-Notchsignaling also promotes a fatty liver (85-87). These observations suggest that Notch signaling could also be important in NASH progression. However, no direct causal relationships between DLL4-Notch signaling and macrophages in NASH have been demonstrated.

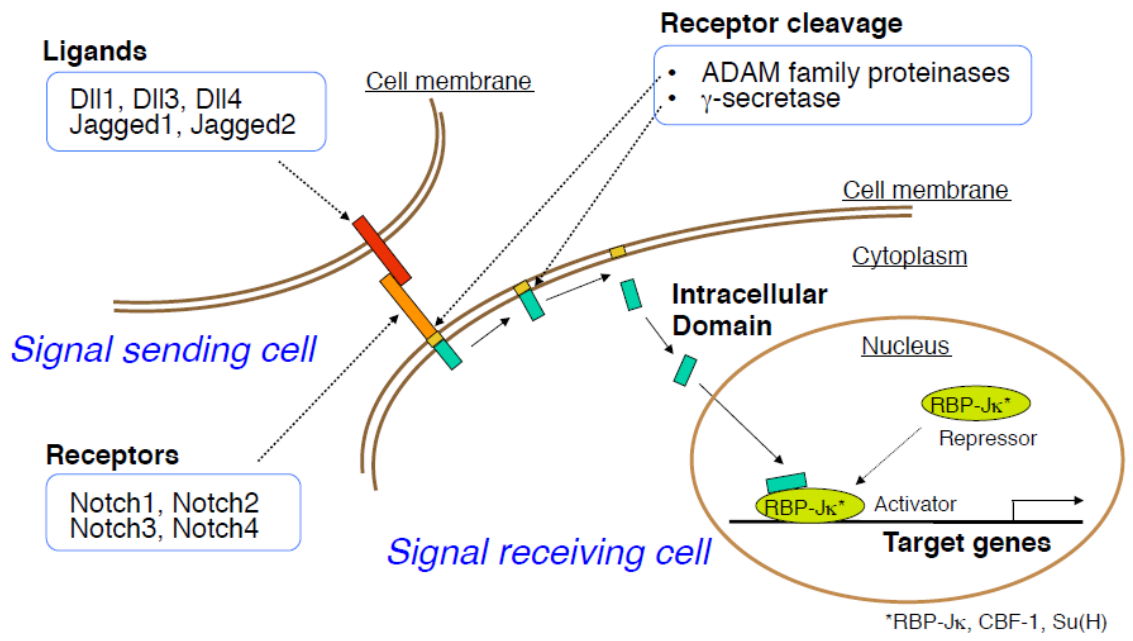

Figure 3: Notch signaling. A schematic overview of how Notch signaling is regulated via Notch-ligand interaction leading to target gene activation. Binding of a Notch ligand to a Notch receptor results in cleavage of the receptor and release of the Notch intracellular domain by $v$ secretase, which is then free to translocate to the nucleus where it acts as a transcriptional activator (83). (DLL; Delta-Like ligand), ADAM; a disintegrin and metalloprotease, RBP-JK; recombinant signal binding protein $\mathrm{JK}$; Figure taken from Fakuda et al. (83) 


\section{7-Hydroxycholesterol (27-HC)}

Previously, it was demonstrated that 27-HC can reduce both lysosomal cholesterol accumulation and cholesterol crystals within macrophages (59) and thereby potentially indirectly inhibit inflammasome activation. 27-HC is one of the most abundant oxysterols found in the human circulation and is produced by the mitochondrial enzyme CYP27A1 (88). 27-HC plays an important role in the bile acid synthesis pathway, which contains two major pathways, the classical and alternative pathway (89). In the classical pathway, within the liver, cholesterol is initially converted into $7-\alpha$-hydroxycholesterol $(7 \alpha-\mathrm{HC})$ by the rate-limiting enzyme CYP7A1, and is eventually converted to cholic acid (CD) (89). In extrahepatic tissue (e.g. macrophages) cholesterol is converted into $27-\mathrm{HC}$ by CYP27A1 via the alternative pathway. Subsequently, $27-\mathrm{HC}$ is converted by CYP7B1 into $7 \alpha-\mathrm{HC}$ leading to the production of chenodeoxycholic acid (CDCA) (Figure 4) (89). Remarkably, high concentrations of 27-HC are especially found in atherosclerotic lesions and in macrophage-derived foam cells and increased with the severity of the atherosclerotic lesions (88). Relevantly, NPC1 mutant fibroblasts have been shown to have reduced levels of $27-\mathrm{HC}$. Supplementing these cells with $27-\mathrm{HC}$ led to a reduction of the Iysosomal cholesterol pool (90). These observations suggest that $27-\mathrm{HC}$ has the ability to reduce lysosomal cholesterol accumulation in vitro and therefore has a protective function. In line with these findings, we have previously shown that $27-\mathrm{HC}$ reduces Iysosomal cholesterol accumulation and hepatic inflammation in Ld/r/ mice (59). However, the mechanism how $27-\mathrm{HC}$ is modulating intracellular cholesterols is not known.

\section{Classical Pathway:}

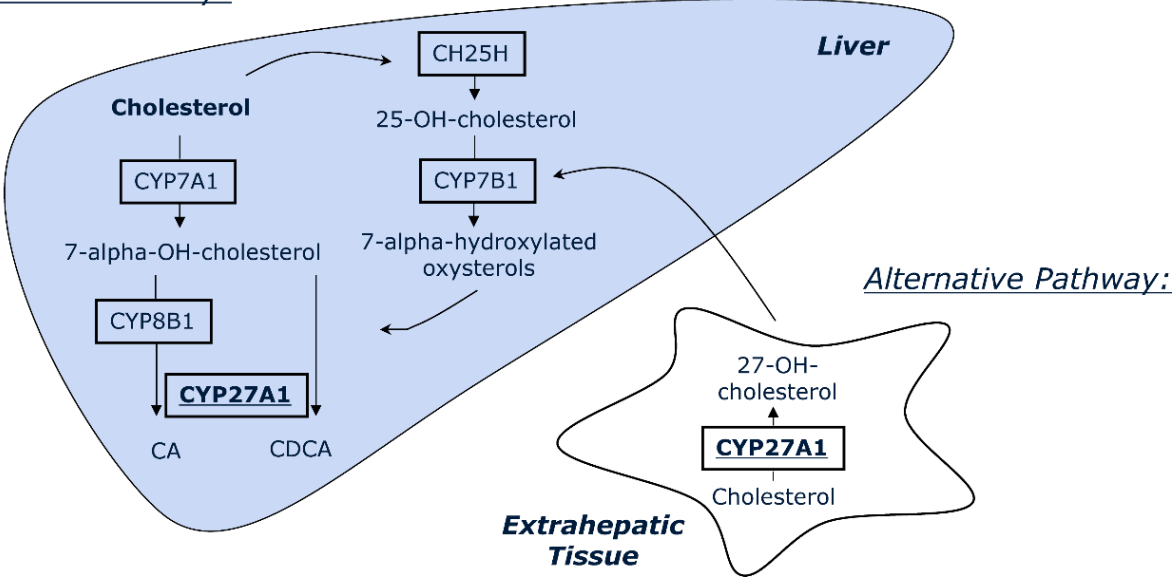


Figure 4: Bile acid synthesis pathway. Conversion of cholesterol into bile acids can be established via two pathways; the classical or alternative pathway. The classical pathway is defined were cholesterol is converted to $7 \alpha$-hydroxycholesterol by its rate-limited enzyme CYP7A1. In the alternative pathway, cholesterol can either be converted into oxysterols via CYP27A1 or $\mathrm{CH} 25 \mathrm{H}$ in extrahepatic tissues (e.g. macrophages) or liver, respectively. Further conversion of these oxysterols leads to the production of CA and CDCA. Adapted from Fuchs et al. and Li et al. $(89,91)$.

\section{Mouse model used for studying atherosclerosis and NASH}

Over the years, numerous animal models have been used to study the development of NASH and atherosclerosis $(26,92,93)$. In this thesis, we will make use of the lowdensity lipoprotein receptor knockout $\left(L d / r^{-/}\right)$mice, which lack the receptor for LDL $(94,95)$. The internalisation of APOB- and APOE- containing lipoproteins is mediated via the $L D L$ receptor $(\operatorname{LDLr})(96,97)$. As a consequence of a dysfunctional LDL receptor, these mice will display mild plaque growth when fed a cholesterol- and fat-enriched diet. In addition, these mice show mildly elevated plasma cholesterol levels, which are mostly, confined to the IDL/LDL fractions. As plasma cholesterol of humans with an LDLR deficiency mainly consists of the LDL fraction, this is physiologically comparable to the cholesterol profile of the $\mathrm{Ldll}^{-/}$mice (94). In addition, due to their increased sensitivity to oxLDL uptake, these mice also develop sustained hepatic inflammation and liver damage upon a long-term Western-type diet regime. Additionally, in contrast to $A p o e^{-/}$mice, Ldlr/- mice are also highly suitable for bone marrow transplantation (BMT) experiments (98). As APOE deficiency is rescued by the BMT cells, which produce APOE, transplanted mice are no longer susceptible to atherosclerosis $(98,99)$. After a BMT, bone marrow cells of the recipient are replaced with bone marrow of the donor, resulting in a new functional hematopoietic system. In this way, genes can be replaced and/or deleted in cells which originate from the bone marrow, such as monocytes and macrophages (100). As such, different potential inflammatory mechanisms in the hematopoietic system (e.g. Npc1 $1^{m u t}$, Caspase $1 / 11^{-1}$ and Cyp27a1 ${ }^{\text {over }}$ ) can be investigated on an $L d l r^{-/}$background. An alternative method to delete genes specifically in the myeloid linage (e.g. monocytes, macrophages, granulocytes, and dendritic cells) is to generate a conditional mouse model using the Cre-LoxP system. In that system, two separate mouse strains are generated carrying either a copy of the Cre recombinase gene or LoxP sites surrounding a gene or part of a gene. In the first mouse strain, Cre recombinase is under control of the promotor of a specific cell type or tissue (e.g. LysM-Cre for myeloid cells). Cre recombinase is an endonuclease that recognizes and cuts the specific loxP sites flanking the gene of interest (e.g. D/l4) in the second mouse strain. Crossing both strains consequently leads to a deletion of the loxP-flanked gene (part) in those cells or tissues that express the Cre recombinase. This system is ideal to investigate certain genes where a whole- 
body deletion would be lethal to avoid embryonic death (e.g. D/l4) (101). Overall, all these characteristics make this $L d l r^{-}$mouse model highly suitable to investigate not only atherosclerosis but also onset and progression of NASH (102).

\section{Outline of this thesis:}

The focus of this thesis will be on investigating the role of macrophage in both atherosclerosis and NASH by elucidating several mechanisms related to the crosstalk between lipids and inflammation.

In Chapter 1, a global overview was given about the pathophysiology of the metabolic syndrome and its two major contributors; NASH and atherosclerosis. Furthermore, the shared etiology of NASH and atherosclerosis is discussed in this chapter. Literature emphasizes that there is a strong association between lysosomal cholesterol accumulation and inflammation. However, the relative importance of lysosomal oxLDL accumulation during atherosclerosis, compared to non-modified LDL, has never been established in vivo. In Chapter 2, we aimed to demonstrate the contribution of lysosomal oxLDL accumulation to atherosclerosis in a mouse model for lysosomal storage disease. Several mechanisms are proposed as to how lysosomal cholesterol accumulation can induce inflammation. One of these mechanisms may be related to inflammasome activation leading to capase-1/11-mediated inflammatory processes. Therefore, the role of hematopoietic caspase-1/11 in Ldlr- mice was investigated in Chapter $\mathbf{3}$ in the context of atherosclerosis. Additionally, recent findings acknowledge Notch-signaling as a metabolic regulator and its involvement in macrophage inflammation. In Chapter 4, the causal role of myeloid DLL4 was investigated during NASH development. Modulation of lysosomal cholesterol accumulation may be beneficial to reduce foam cell formation and inflammation as 27-hydroxycholesterol has been shown to have beneficial effects on these processes. The underlying mechanisms of how 27-hydroycholesterol modulates these processes were tested by overexpressing the mitochondrial enzyme CYP27A1 in $\mathrm{Ldll}^{-/-}$mice, and are reported in Chapter 5. Finally, the overall conclusions of this thesis are discussed in Chapter 6. 


\section{References}

1. Grundy SM. Metabolic syndrome: connecting and reconciling cardiovascular and diabetes worlds. Journal of the American College of Cardiology. 2006;47(6):1093-100.

2. Marchesini G, Bugianesi E, Forlani G, Cerrelli F, Lenzi M, Manini R, et al. Nonalcoholic fatty liver, steatohepatitis, and the metabolic syndrome. Hepatology. 2003;37(4):917-23.

3. Paschos P, Paletas K. Non-alcoholic fatty liver disease and metabolic syndrome. Hippokratia. 2009;13(1):9-19.

4. Sarafidis PA, Nilsson PM. The metabolic syndrome: a glance at its history. Journal of hypertension. 2006;24(4):621-6.

5. Grundy SM, Brewer HB, Jr., Cleeman JI, Smith SC, Jr., Lenfant C, American Heart A, et al. Definition of metabolic syndrome: Report of the National Heart, Lung, and Blood Institute/American Heart Association conference on scientific issues related to definition. Circulation. 2004;109(3):433-8.

6. Ervin RB. Prevalence of metabolic syndrome among adults 20 years of age and over, by sex, age, race and ethnicity, and body mass index: United States, 2003-2006. National health statistics reports. 2009(13):1-7.

7. Sperling LS, Mechanick JI, Neeland IJ, Herrick CJ, Despres JP, Ndumele CE, et al. The CardioMetabolic Health Alliance: Working Toward a New Care Model for the Metabolic Syndrome. Journal of the American College of Cardiology. 2015;66(9):1050-67.

8. Aydin S, Aksoy A, Aydin S, Kalayci M, Yilmaz M, Kuloglu T, et al. Today's and yesterday's of pathophysiology: biochemistry of metabolic syndrome and animal models. Nutrition. 2014;30(1):1-9.

9. Welty FK, Alfaddagh A, Elajami TK. Targeting inflammation in metabolic syndrome. Translational research: the journal of laboratory and clinical medicine. 2015.

10. Targher G, Bertolini L, Padovani R, Rodella S, Tessari R, Zenari L, et al. Prevalence of nonalcoholic fatty liver disease and its association with cardiovascular disease among type 2 diabetic patients. Diabetes care. 2007;30(5):1212-8.

11. Yoo HJ, Choi KM. Hepatokines as a Link between Obesity and Cardiovascular Diseases. Diabetes \& metabolism journal. 2015;39(1):10-5.

12. Asrih M, Jornayvaz FR. Metabolic syndrome and nonalcoholic fatty liver disease: Is insulin resistance the link? Molecular and cellular endocrinology. 2015;418 Pt 1:55-65.

13. Xu X, Lu L, Dong $Q$, Li X, Zhang N, Xin Y, et al. Research advances in the relationship between nonalcoholic fatty liver disease and atherosclerosis. Lipids in health and disease. 2015;14:158.

14. Lonardo A, Ballestri S, Marchesini G, Angulo P, Loria P. Nonalcoholic fatty liver disease: a precursor of the metabolic syndrome. Digestive and liver disease: official journal of the Italian Society of Gastroenterology and the Italian Association for the Study of the Liver. 2015;47(3):181-90.

15. Parekh S, Anania FA. Abnormal lipid and glucose metabolism in obesity: implications for nonalcoholic fatty liver disease. Gastroenterology. 2007;132(6):2191-207.

16. Williams CD, Stengel J, Asike MI, Torres DM, Shaw J, Contreras M, et al. Prevalence of nonalcoholic fatty liver disease and nonalcoholic steatohepatitis among a largely middle-aged population utilizing ultrasound and liver biopsy: a prospective study. Gastroenterology. 2011;140(1):124-31.

17. Clark JM. The epidemiology of nonalcoholic fatty liver disease in adults. Journal of clinical gastroenterology. 2006;40 Suppl 1:S5-10. 
18. Kleiner DE, Brunt EM, Van Natta M, Behling C, Contos MJ, Cummings OW, et al. Design and validation of a histological scoring system for nonalcoholic fatty liver disease. Hepatology. 2005;41(6):1313-21.

19. Kopec KL, Burns D. Nonalcoholic fatty liver disease: a review of the spectrum of disease, diagnosis, and therapy. Nutrition in clinical practice : official publication of the American Society for Parenteral and Enteral Nutrition. 2011;26(5):565-76.

20. Rinella ME. Nonalcoholic fatty liver disease: a systematic review. JAMA. 2015;313(22):2263-73.

21. Portincasa P, Grattagliano I, Palmieri VO, Palasciano G. The emerging problem of nonalcoholic steatohepatitis (NASH). Rom J Gastroenterol. 2005;14(1):43-51.

22. Than NN, Newsome PN. A concise review of non-alcoholic fatty liver disease. Atherosclerosis. 2015;239(1):192-202.

23. Virmani R, Kolodgie FD, Burke AP, Farb A, Schwartz SM. Lessons from sudden coronary death: a comprehensive morphological classification scheme for atherosclerotic lesions. Arteriosclerosis, thrombosis, and vascular biology. 2000;20(5):1262-75.

24. Hansson GK. Inflammation, atherosclerosis, and coronary artery disease. N Engl J Med. 2005;352(16):1685-95.

25. Kazlauskiene L, Butnoriene J, Norkus A. Metabolic syndrome related to cardiovascular events in a 10-year prospective study. Diabetology \& metabolic syndrome. 2015;7:102.

26. Hansson GK, Libby $P$. The immune response in atherosclerosis: a double-edged sword. Nature reviews Immunology. 2006;6(7):508-19.

27. Libby P, Ridker PM, Hansson GK. Progress and challenges in translating the biology of atherosclerosis. Nature. 2011;473(7347):317-25.

28. Libby P. Atherosclerosis: the new view. Sci Am. 2002;286(5):46-55.

29. Schrijvers DM, De Meyer GR, Kockx MM, Herman AG, Martinet W. Phagocytosis of apoptotic cells by macrophages is impaired in atherosclerosis. Arteriosclerosis, thrombosis, and vascular biology. 2005;25(6):1256-61.

30. Targher G, Arcaro G. Non-alcoholic fatty liver disease and increased risk of cardiovascular disease. Atherosclerosis. 2007;191(2):235-40.

31. Bieghs V, Rensen PC, Hofker MH, Shiri-Sverdlov R. NASH and atherosclerosis are two aspects of a shared disease: central role for macrophages. Atherosclerosis. 2012;220(2):287-93.

32. Hansson GK, Hermansson A. The immune system in atherosclerosis. Nature immunology. 2011;12(3):204-12.

33. Greaves DR, Gordon S. The macrophage scavenger receptor at 30 years of age: current knowledge and future challenges. Journal of lipid research. 2009;50 Suppl:S282-6.

34. Wouters K, van Gorp PJ, Bieghs V, Gijbels MJ, Duimel H, Lutjohann D, et al. Dietary cholesterol, rather than liver steatosis, leads to hepatic inflammation in hyperlipidemic mouse models of nonalcoholic steatohepatitis. Hepatology. 2008;48(2):474-86.

35. Febbraio M, Guy E, Silverstein RL. Stem cell transplantation reveals that absence of macrophage CD36 is protective against atherosclerosis. Arteriosclerosis, thrombosis, and vascular biology. 2004;24(12):2333-8.

36. Febbraio M, Podrez EA, Smith JD, Hajjar DP, Hazen SL, Hoff HF, et al. Targeted disruption of the class B scavenger receptor CD36 protects against atherosclerotic lesion development in mice. The Journal of clinical investigation. 2000;105(8):1049-56.

37. Manning-Tobin JJ, Moore KJ, Seimon TA, Bell SA, Sharuk M, Alvarez-Leite JI, et al. Loss of SR-A and CD36 activity reduces atherosclerotic lesion complexity without abrogating foam cell formation in hyperlipidemic mice. Arteriosclerosis, thrombosis, and vascular biology. 2009;29(1):19-26. 
38. Naito M, Kodama T, Matsumoto A, Doi T, Takahashi K. Tissue distribution, intracellular localization, and in vitro expression of bovine macrophage scavenger receptors. Am J Pathol. 1991;139(6):1411-23.

39. Bieghs V, Verheyen F, van Gorp PJ, Hendrikx T, Wouters K, Lutjohann D, et al. Internalization of modified lipids by CD36 and SR-A leads to hepatic inflammation and lysosomal cholesterol storage in Kupffer cells. PloS one. 2012;7(3):e34378.

40. Bieghs V, Wouters K, van Gorp PJ, Gijbels MJ, de Winther MP, Binder CJ, et al. Role of scavenger receptor $A$ and $C D 36$ in diet-induced nonalcoholic steatohepatitis in hyperlipidemic mice. Gastroenterology. 2010;138(7):2477-86, 86 e1-3.

41. Karvonen J, Paivansalo M, Kesaniemi YA, Horkko S. Immunoglobulin M type of autoantibodies to oxidized low-density lipoprotein has an inverse relation to carotid artery atherosclerosis. Circulation. 2003;108(17):2107-12.

42. Tsimikas S, Brilakis ES, Lennon RJ, Miller ER, Witztum JL, McConnell JP, et al. Relationship of IgG and IgM autoantibodies to oxidized low density lipoprotein with coronary artery disease and cardiovascular events. Journal of lipid research. 2007;48(2):425-33.

43. Binder CJ, Horkko S, Dewan A, Chang MK, Kieu EP, Goodyear CS, et al. Pneumococcal vaccination decreases atherosclerotic lesion formation: molecular mimicry between Streptococcus pneumoniae and oxidized LDL. Nature medicine. 2003;9(6):736-43.

44. Bieghs V, van Gorp PJ, Walenbergh SM, Gijbels MJ, Verheyen F, Buurman WA, et al. Specific immunization strategies against oxidized low-density lipoprotein: a novel way to reduce nonalcoholic steatohepatitis in mice. Hepatology. 2012;56(3):894-903.

45. de Duve C. Lysosomes revisited. European journal of biochemistry / FEBS. 1983;137(3):391-7.

46. Dell'Angelica EC, Mullins C, Caplan S, Bonifacino JS. Lysosome-related organelles. FASEB journal : official publication of the Federation of American Societies for Experimental Biology. 2000;14(10):1265-78.

47. Kwon HJ, Abi-Mosleh L, Wang ML, Deisenhofer J, Goldstein JL, Brown MS, et al. Structure of Nterminal domain of NPC1 reveals distinct subdomains for binding and transfer of cholesterol. Cell. 2009;137(7):1213-24.

48. Sugii S, Reid PC, Ohgami N, Du H, Chang TY. Distinct endosomal compartments in early trafficking of low density lipoprotein-derived cholesterol. The Journal of biological chemistry. 2003;278(29):27180-9.

49. Ioannou YA. Multidrug permeases and subcellular cholesterol transport. Nature reviews Molecular cell biology. 2001;2(9):657-68.

50. Beltroy EP, Richardson JA, Horton JD, Turley SD, Dietschy JM. Cholesterol accumulation and liver cell death in mice with Niemann-Pick type C disease. Hepatology. 2005;42(4):886-93.

51. Loftus SK, Morris JA, Carstea ED, Gu JZ, Cummings C, Brown A, et al. Murine model of NiemannPick C disease: mutation in a cholesterol homeostasis gene. Science. 1997;277(5323):232-5.

52. Griffin EE, Ullery JC, Cox BE, Jerome WG. Aggregated LDL and lipid dispersions induce lysosomal cholesteryl ester accumulation in macrophage foam cells. Journal of lipid research. 2005;46(10):2052-60.

53. Haley NJ, Shio H, Fowler S. Characterization of lipid-laden aortic cells from cholesterol-fed rabbits. I. Resolution of aortic cell populations by metrizamide density gradient centrifugation. Laboratory investigation; a journal of technical methods and pathology. 1977;37(3):287-96.

54. Jerome WG. Advanced atherosclerotic foam cell formation has features of an acquired lysosomal storage disorder. Rejuvenation research. 2006;9(2):245-55.

55. Peters TJ, Muller M, De Duve C. Lysosomes of the arterial wall. I. Isolation and subcellular fractionation of cells from normal rabbit aorta. The Journal of experimental medicine. 1972;136(5):1117-39. 
56. Jerome WG, Lewis JC. Early atherogenesis in White Carneau pigeons. II. Ultrastructural and cytochemical observations. Am J Pathol. 1985;119(2):210-22.

57. Fowler S, Berberian PA, Shio H, Goldfischer S, Wolinsky H. Characterization of cell populations isolated from aortas of rhesus monkeys with experimental atherosclerosis. Circulation research. 1980;46(4):520-30.

58. Miller BF, Kothari HV. Increased activity of lysosomal enzymes in human atherosclerotic aortas. Experimental and molecular pathology. 1969;10(3):288-94.

59. Bieghs V, Hendrikx T, van Gorp PJ, Verheyen F, Guichot YD, Walenbergh SM, et al. The cholesterol derivative 27-hydroxycholesterol reduces steatohepatitis in mice. Gastroenterology. 2013;144(1):167-78 e1.

60. Jerome WG, Cash C, Webber R, Horton R, Yancey PG. Lysosomal lipid accumulation from oxidized low density lipoprotein is correlated with hypertrophy of the Golgi apparatus and transGolgi network. Journal of lipid research. 1998;39(7):1362-71.

61. Yancey PG, Jerome WG. Lysosomal cholesterol derived from mildly oxidized low density lipoprotein is resistant to efflux. Journal of lipid research. 2001;42(3):317-27.

62. Jerome WG, Cox BE, Griffin EE, Ullery JC. Lysosomal cholesterol accumulation inhibits subsequent hydrolysis of lipoprotein cholesteryl ester. Microscopy and microanalysis : the official journal of Microscopy Society of America, Microbeam Analysis Society, Microscopical Society of Canada. 2008;14(2):138-49.

63. Schroder K, Tschopp J. The inflammasomes. Cell. 2010;140(6):821-32.

64. Szabo G, Petrasek J. Inflammasome activation and function in liver disease. Nature reviews Gastroenterology \& hepatology. 2015;12(7):387-400.

65. Man SM, Kanneganti TD. Converging roles of caspases in inflammasome activation, cell death and innate immunity. Nature reviews Immunology. 2016;16(1):7-21.

66. Duewell P, Kono H, Rayner KJ, Sirois CM, Vladimer G, Bauernfeind FG, et al. NLRP3 inflammasomes are required for atherogenesis and activated by cholesterol crystals. Nature. 2010;464(7293):1357-61.

67. Rajamaki K, Lappalainen J, Oorni K, Valimaki E, Matikainen S, Kovanen PT, et al. Cholesterol crystals activate the NLRP3 inflammasome in human macrophages: a novel link between cholesterol metabolism and inflammation. PloS one. 2010;5(7):e11765.

68. Jiang $Y$, Wang $M$, Huang $K$, Zhang Z, Shao N, Zhang $Y$, et al. Oxidized low-density lipoprotein induces secretion of interleukin-1beta by macrophages via reactive oxygen species-dependent NLRP3 inflammasome activation. Biochem Biophys Res Commun. 2012;425(2):121-6.

69. Liu W, Yin Y, Zhou Z, He M, Dai Y. OxLDL-induced IL-1 beta secretion promoting foam cells formation was mainly via CD36 mediated ROS production leading to NLRP3 inflammasome activation. Inflammation research : official journal of the European Histamine Research Society [et al]. 2014;63(1):33-43.

70. Hansson GK, Klareskog L. Pulling down the plug on atherosclerosis: cooling down the inflammasome. Nature medicine. 2011;17(7):790-1.

71. Freigang S, Ampenberger F, Spohn G, Heer S, Shamshiev AT, Kisielow J, et al. Nrf2 is essential for cholesterol crystal-induced inflammasome activation and exacerbation of atherosclerosis. European journal of immunology. 2011;41(7):2040-51.

72. Masters SL, Latz E, O'Neill LA. The inflammasome in atherosclerosis and type 2 diabetes. Science translational medicine. 2011;3(81):81ps17.

73. Gage J, Hasu M, Thabet M, Whitman SC. Caspase-1 deficiency decreases atherosclerosis in apolipoprotein E-null mice. Can J Cardiol. 2012;28(2):222-9. 
74. Usui F, Shirasuna K, Kimura H, Tatsumi K, Kawashima A, Karasawa T, et al. Critical role of caspase-1 in vascular inflammation and development of atherosclerosis in Western diet-fed apolipoprotein E-deficient mice. Biochem Biophys Res Commun. 2012;425(2):162-8.

75. Bi $\mathrm{P}$, Kuang $\mathrm{S}$. Notch signaling as a novel regulator of metabolism. Trends in endocrinology and metabolism: TEM. 2015;26(5):248-55.

76. Kopan R. Notch signaling. Cold Spring Harbor perspectives in biology. 2012;4(10).

77. D'Souza B, Meloty-Kapella L, Weinmaster G. Canonical and non-canonical Notch ligands. Curr Top Dev Biol. 2010;92:73-129.

78. Geisler F, Strazzabosco M. Emerging roles of Notch signaling in liver disease. Hepatology. 2015;61(1):382-92.

79. Valenti L, Mendoza RM, Rametta R, Maggioni M, Kitajewski C, Shawber CJ, et al. Hepatic Notch signaling correlates with insulin resistance and nonalcoholic fatty liver disease. Diabetes. 2013;62(12):4052-62.

80. Shimizu T, Tanaka T, Iso T, Doi H, Sato H, Kawai-Kowase $K$, et al. Notch signaling induces osteogenic differentiation and mineralization of vascular smooth muscle cells: role of Msx2 gene induction via Notch-RBP-Jk signaling. Arteriosclerosis, thrombosis, and vascular biology. 2009;29(7):1104-11.

81. Li Y, Takeshita K, Liu PY, Satoh M, Oyama N, Mukai Y, et al. Smooth muscle Notch1 mediates neointimal formation after vascular injury. Circulation. 2009;119(20):2686-92.

82. Liu ZJ, Tan Y, Beecham GW, Seo DM, Tian R, Li Y, et al. Notch activation induces endothelial cell senescence and pro-inflammatory response: implication of Notch signaling in atherosclerosis. Atherosclerosis. 2012;225(2):296-303.

83. Fukuda D, Aikawa M. Expanding role of delta-like 4 mediated Notch signaling in cardiovascular and metabolic diseases. Circ J. 2013;77(10):2462-8.

84. Fung E, Tang SM, Canner JP, Morishige K, Arboleda-Velasquez JF, Cardoso AA, et al. Delta-like 4 induces Notch signaling in macrophages: implications for inflammation. Circulation. 2007;115(23):2948-56.

85. Fukuda D, Aikawa E, Swirski FK, Novobrantseva TI, Kotelianski V, Gorgun CZ, et al. Notch ligand delta-like 4 blockade attenuates atherosclerosis and metabolic disorders. Proceedings of the National Academy of Sciences of the United States of America. 2012;109(27):E1868-77.

86. Niida T, Lok LL, Zheng CY, Koga JI, Fukuda D, Banks A, et al. Delta-like 4/Notch Signaling Promotes Fatty Liver Disease in Mice. Circulation. 2013;128(22).

87. Pajvani UB, Qiang L, Kangsamaksin T, Kitajewski J, Ginsberg HN, Accili D. Inhibition of Notch uncouples Akt activation from hepatic lipid accumulation by decreasing mTorc1 stability. Nature medicine. 2013;19(8):1054-60.

88. Brown AJ, Jessup W. Oxysterols and atherosclerosis. Atherosclerosis. 1999;142(1):1-28.

89. Fuchs M. Bile acid regulation of hepatic physiology: III. Regulation of bile acid synthesis: past progress and future challenges. American journal of physiology Gastrointestinal and liver physiology. 2003;284(4):G551-7.

90. Frolov A, Zielinski SE, Crowley JR, Dudley-Rucker N, Schaffer JE, Ory DS. NPC1 and NPC2 regulate cellular cholesterol homeostasis through generation of low density lipoprotein cholesterolderived oxysterols. The Journal of biological chemistry. 2003;278(28):25517-25.

91. Li T, Chiang JY. Bile acid signaling in metabolic disease and drug therapy. Pharmacological reviews. 2014;66(4):948-83.

92. Hebbard L, George J. Animal models of nonalcoholic fatty liver disease. Nature reviews Gastroenterology \& hepatology. 2011;8(1):35-44.

93. Kapourchali FR, Surendiran G, Chen L, Uitz E, Bahadori B, Moghadasian MH. Animal models of atherosclerosis. World journal of clinical cases. 2014;2(5):126-32. 
94. Ishibashi S, Brown MS, Goldstein JL, Gerard RD, Hammer RE, Herz J. Hypercholesterolemia in low density lipoprotein receptor knockout mice and its reversal by adenovirus-mediated gene delivery. The Journal of clinical investigation. 1993;92(2):883-93.

95. Moore KJ, Tabas I. Macrophages in the pathogenesis of atherosclerosis. Cell. 2011;145(3):341-55.

96. Ikonen E. Cellular cholesterol trafficking and compartmentalization. Nature reviews Molecular cell biology. 2008;9(2):125-38.

97. Choi SY, Fong LG, Kirven MJ, Cooper AD. Use of an anti-low density lipoprotein receptor antibody to quantify the role of the LDL receptor in the removal of chylomicron remnants in the mouse in vivo. The Journal of clinical investigation. 1991;88(4):1173-81.

98. Wouters K, Shiri-Sverdlov R, van Gorp PJ, van Bilsen M, Hofker MH. Understanding hyperlipidemia and atherosclerosis: lessons from genetically modified apoe and Idlr mice. Clinical chemistry and laboratory medicine. 2005;43(5):470-9.

99. Fazio S, Babaev VR, Burleigh ME, Major AS, Hasty AH, Linton MF. Physiological expression of macrophage apoE in the artery wall reduces atherosclerosis in severely hyperlipidemic mice. Journal of lipid research. 2002;43(10):1602-9.

100. de Winther MP, Heeringa P. Bone marrow transplantations to study gene function in hematopoietic cells. Methods in molecular biology. 2011;693:309-20.

101. Kos $\mathrm{CH}$. Cre/loxP system for generating tissue-specific knockout mouse models. Nutrition reviews. 2004;62(6 Pt 1):243-6.

102. Bieghs V, Van Gorp PJ, Wouters K, Hendrikx T, Gijbels MJ, van Bilsen M, et al. LDL receptor knock-out mice are a physiological model particularly vulnerable to study the onset of inflammation in non-alcoholic fatty liver disease. PloS one. 2012;7(1):e30668. 



\section{Chapter \\ 2}

\section{Prevention of oxLDL uptake leads to decreased atherosclerosis in hematopoietic NPC1-deficient}

LdIr/- mice

M.L.J. Jeurissen*, S.M.A. Walenbergh*, T. Houben, M.J.J. Gijbels, J. Li, T. Hendrikx, Y. Oligschlaeger, P.J. van Gorp, C.J, Binder, M.M.P.C. Donners, R. Shiri-Sverdlov

*These authors contributed equally to this work

Atherosclerosis 255 (2016) 59-65 


\section{Abstract}

Atherosclerosis is a chronic inflammatory disease of medium and large vessels and is typically characterized by the predominant accumulation of low-density lipoprotein (LDL)-cholesterol inside macrophages that reside in the vessel walls. Previous studies clearly demonstrated an association between specifically the oxidized type of LDL (oxLDL) and atherosclerotic lesion formation. Further observations revealed that these atherosclerotic lesions displayed enlarged, lipid-loaded lysosomes. By increasing natural antibodies against oxLDL, pneumococcal vaccination has been shown to reduce atherosclerosis in $L D L$ receptor knockout $\left(L d l r^{-/}\right)$mice. Relevantly, loss of the lysosomal membrane protein Niemann-Pick Type C1 (NPC1) led to lysosomal accumulation of various lipids and promoted atherosclerosis. Yet, the importance of lysosomal oxLDL accumulation inside macrophages, compared to non-modified LDL in atherosclerosis has never been established. By transplanting NPC1 bone marrow into lethally irradiated $L d l r^{-1-}$ mice, a hematopoietic mouse model for lysosomal cholesterol accumulation was created. Through injections with heat-inactivated pneumococci, we aimed to demonstrate the specific contribution of lysosomal oxLDL accumulation within macrophages in atherosclerosis development. While there were no differences in plaque morphology, a reduction in plaque size and plaque inflammation was found in immunized NPC1 ${ }^{\text {mut }}$-transplanted mice, compared to non-immunized NPC1 ${ }^{\text {mut }}$ transplanted mice. Thus, lysosomal oxLDL accumulation inside macrophages contributes to murine atherosclerosis. 


\section{Introduction}

In 2013, cardiovascular disease (CVD) was a major cause of mortality worldwide causing approximately 17 million deaths (1). One of the major underlying pathologies of CVD is atherosclerosis. Atherosclerosis is a chronic inflammatory disease of medium and large vessels, which is characterized by the accumulation of both lipid droplets and inflammatory cells in the vessel wall (2-4). Macrophages are abundantly present in atherosclerotic lesions and play an important role in the clearance of modified, oxidized low-density lipoproteins (oxLDL). These lipid-laden macrophages, also known as foam cells, are one of the main drivers of atherosclerosis development. Eventually, plaque rupture may occur, causing thrombosis and/or stroke, which are hallmarks of CVD (5-7, 49). Over the years, an increasing amount of evidence showed the importance of immune activation in atherosclerotic lesions $(4,8)$. Previously, natural antibodies targeted at oxLDL were shown to be abundantly present within atherosclerotic lesions $(9,10)$. In line, our group and others demonstrated that a pneumococcal-induced immune response against the phosphorylcholine (PC) epitope present on oxLDL, lead to diminished atherosclerosis development and hepatic inflammation $(11,12)$. Also, an elegant study by Hörkkö et al. clearly demonstrated that these antibodies specifically prevent binding, uptake and degradation of oxLDL by macrophages (9). These results demonstrate the importance of the uptake of oxLDL in macrophages in the context of atherosclerosis development. In general, after uptake by macrophages, cholesterol is initially directed to the lysosomes for hydrolysis. Inside these lysosomes, lysosomal enzymes mediate the hydrolysis of cholesteryl esters into free cholesterol that can be transported out of the lysosomes into the cytoplasm via Niemann-Pick Type C (NPC) proteins (13-16). As trafficking of free cholesterol from the lysosome to the cytoplasm is mainly regulated by NPC proteins, the dysregulation of these NPC proteins plays an important role in atherosclerosis development. Indeed, dysfunctional NPC1 leads to excessive accumulation of various lipids, including both non-modified as well as modified oxLDL, inside lysosomes $(17,18)$. Despite the fact that several studies found that NPC1 plays an important role in atherosclerosis, and that a number of in vitro studies clearly demonstrated that it is specifically oxLDL that accumulates inside lysosomes of macrophages $(19,20)$, the specific contribution of lysosomal oxLDL compared to non-modified LDL was neglected in these studies and has never been established in vivo (21-23). In the current study, we aimed to demonstrate the contribution of lysosomal oxLDL accumulation to atherosclerosis using a macrophage-specific NPC1 mutant (NPC ${ }^{\text {mut }}$ ) mouse model in combination with pneumococcal immunization. In this study, we showed that pneumococcal immunization of $\mathrm{NPC}^{\text {mut }}$-transplanted (-tp) mice led to a decrease in plaque lesion size, independently of cholesterol levels, and a decline in plaque inflammation. Together, our results indicate that lysosomal oxLDL accumulation inside macrophages contributes to atherosclerosis. 


\section{Materials and Methods}

\section{Mice, bone marrow transplantation, immunization, and diet}

All animals were housed under standard conditions and had access to food and water ad libitum. All animal experiments were approved by the committee for Animal Welfare of Maastricht University and were performed according to the Dutch regulations. The immunogen, Streptococcus pneumoniae (heat-inactivated pneumococci, R36A strain, Birmingham, AL) was prepared as described previously (24). Niemann-Pick type C1m1N mutant (NPC1 ${ }^{\text {mut}}$ ) mice on a C57BL/6 background (were a kind gift from Prof. Dr. Lieberman from University of Michigan Medical School). Ldlr/- mice were obtained from our in-house breeding. Bone marrow transplantation and pneumococcal immunizations were performed as described previously $(11,25)$. A detailed Materials and Methods section, concerning the methodology for the histological analysis, immunohistochemistry, RNA isolation and qPCR, is available in the Supplemental Materials and Methods. The primer sequences can be found in Table 1. Groups were compared with the two-way ANOVA for repeated measurements or by two-tailed unpaired t-test using GraphPad Prism (Version 5.03). Outliers were determined using Grubbs' Test.

Table 1: Primer sequences

\begin{tabular}{|c|c|c|}
\hline Gene & Primer forward & Primer reverse \\
\hline Cyclophilin A & TTCСTCСTTTCACAGAATTATTCCA & CCGCCAGTGCCATTATGG \\
\hline$T n f-\alpha$ & САTСTTCTCAAAATTCGAGTGACAA & TGGGAGTAGACAAGGTACAACCC \\
\hline Itgam & ACTTTCAGAAGATGAAGGAGTTTGTCT & TGTGATCTTGGGCTAGGGTTTC \\
\hline Cd68 & TGACCTGCTCTCTCTAAGGCTACA & TCACGGTTGCAAGAGAAACATG \\
\hline Ccr2 & CAGGTGACAGAGACTCTTGGAATG & GAACTTCTCTCCAACAAAGGCATAA \\
\hline Caspase-1 & GGGACCCTCAAGTTTTGCC & GACGTGTACGAGTGGTTGTATT \\
\hline II-18 & GACTCTTGCGTCAACTTCAAGG & CAGGCTGTCTTTTTGTCAACGA \\
\hline
\end{tabular}




\section{Results}

\section{Plaque formation is reduced in NPC1 ${ }^{\text {mut }}$-tp mice after immunization, independently of plasma lipid levels.}

We used $L d l r^{-/}$mice that were lethally irradiated and subsequently transplanted with bone marrow from NPC1 ${ }^{\text {mut }}$ mice as a tool to induce lysosomal cholesterol accumulation in hematopoietic cells. To provoke an immune response to oxLDL, mice were immunized with heat-inactivated Streptococcus pneumoniae. (See Figure 1 for the experimental set-up).
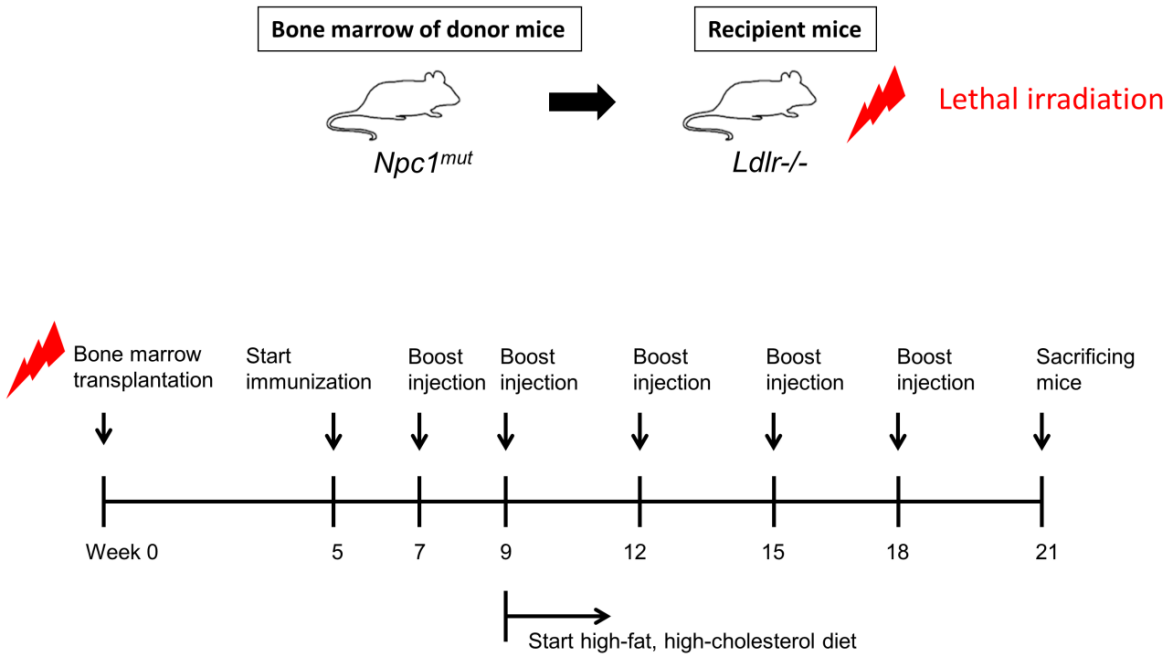

Figure 1: Experimental set-up. Briefly, lethally irradiated $L d / r^{/-}$mice were transplanted (-tp) with bone marrow from mutant NPC1 (NPC1 ${ }^{\text {mut}}$ ) mice. These mice develop lysosomal cholesterol accumulation specifically in the macrophages. To induce high levels of anti-oxLDL antibodies, NPC1 ${ }^{\text {mut }}$-tp mice were immunized with pneumococci every two weeks $(n=10)$, whereas control mice received PBS injections $(n=12)$. After four weeks of immunization, all mice were fed a high-fat, high-cholesterol diet (HFC) for twelve weeks and then were given immunizations every three weeks, until the end of the experiment. 
To confirm previous studies that successfully demonstrated elevated anti-oxLDL IgM titers after pneumococcal immunization $(11,12)$, we analysed the IgM antibody titers in the plasma of non-immunized and immunized NPC1 ${ }^{\text {mut }}$-tp mice at different time points. Immunization with heat-inactivated pneumococci led to a strong elevation of IgM autoantibodies directed against oxLDL (EO6) compared to non-immunized mice (Figure 2). IgM antibodies directed against copper-oxLDL (Cu-oxLDL) were also increased in immunized mice compared to control at different time points (Figure 2). Moreover, the anti-oxLDL IgM responses were sustained over time until the end of the experiment. Plasma lipid levels were not significantly different between immunized and non-immunized mice (Table 2).

$\lg M(E O 6)$

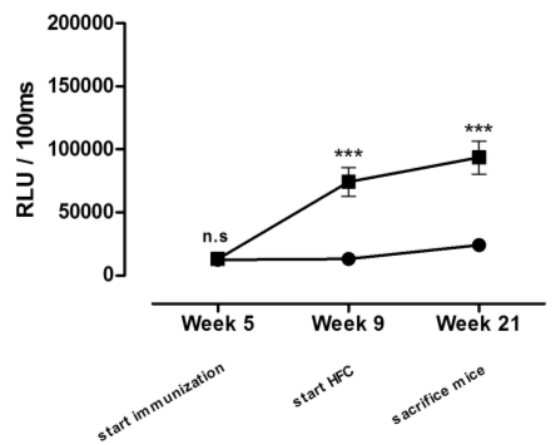

$\lg M(C u-O x L D L)$

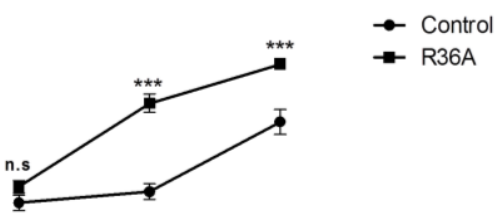

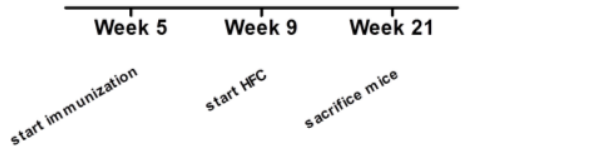

Figure 2: $\quad$ IgM auto-antibodies in plasma of NPC1 ${ }^{\text {mut }}$-tp mice. Mice were immunized with Streptococcus pneumoniae strain R36A or treated with PBS (control). IgM auto-antibodies targeted at oxLDL (EO6 and copper (Cu)-oxLDL) were measured in the plasma of immunized and non-immunized

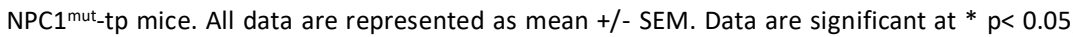
$* * p<0.01, * * * p<0.001$.

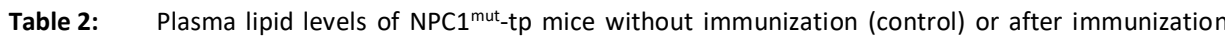
with Streptococcus pneumoniae, strain R36A were determined at the end of the experiment after sacrifice (21 weeks). No significant changes were observed.

\begin{tabular}{lcc}
\hline & \multicolumn{2}{c}{ NPC1 $^{\text {mut }}$-tp } \\
\cline { 2 - 3 } & Control & $R 36 A$ \\
\hline Plasma & & \\
Cholesterol $(\mathrm{mmol} / \mathrm{l})$ & $22.10( \pm 1.10)$ & $20.81( \pm 0.78)$ \\
Triglycerides $(\mathrm{mmol} / \mathrm{l})$ & $1.42( \pm 0.15)$ & $1.42( \pm 0.13)$ \\
Free fatty acids $(\mathrm{mmol} / \mathrm{l})$ & $0.96( \pm 0.05)$ & $0.98( \pm 0.03)$ \\
\hline
\end{tabular}


Immunization of NPC1 ${ }^{\text {mut }}$-tp mice resulted in a trend $(p=0.055)$ towards a reduced plaque area $(-17 \%)$ in the aortic root (Figure $3 \mathrm{~A}$ and $\mathrm{B}$ ). In the aortic arch, gene expression of $C d 68$, a macrophage marker often used as surrogate marker for plaque size $(26,27)$, was significantly reduced $(-43 \%$ compared to control) (Figure 3C), independently of plasma lipid levels.

A

NPC1 ${ }^{\text {mut }}$-tp - PBS

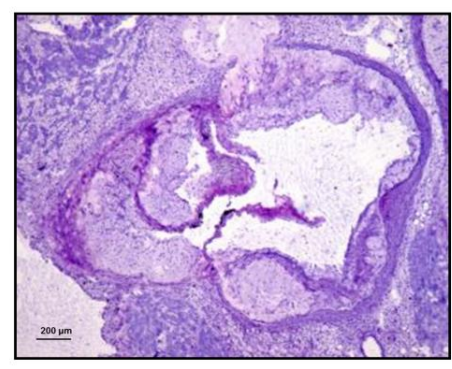

B

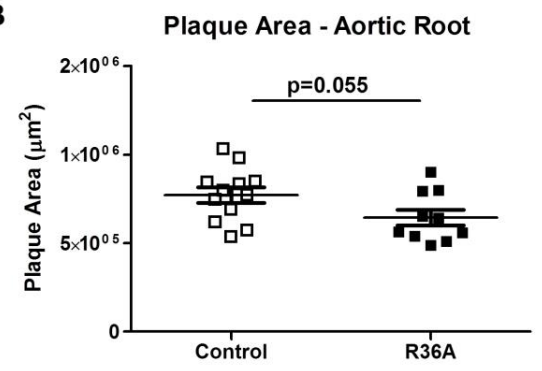

NPC1 $^{\text {mut }}$-tp $-R 36 A$

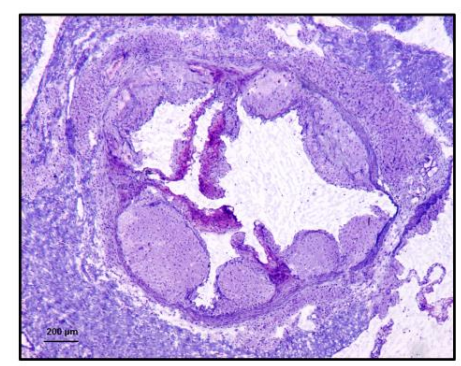

C

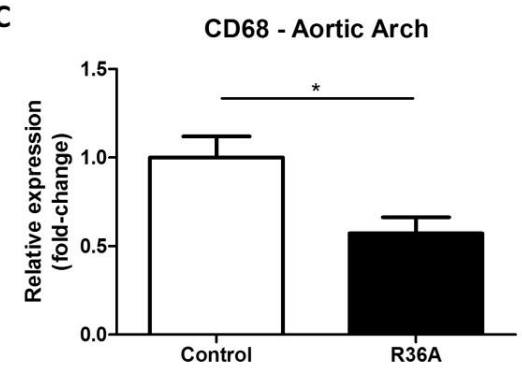

Figure 3: Histological analysis of plaque area in (non)-immunized NPC1 ${ }^{\text {mut }}$-tp mice. Representative pictures of the toluidine staining $(A)$ and quantification of the total plaque area of the aortic root in (non)-immunized NPC1 ${ }^{\text {mut }}$-tp mice (B). Gene expression of Cd68 in the aortic arch corrected for cyclophilin A expression (C). All data are represented as mean +/- SEM. Data are considered to be significant at $* p<0.05, * * p<0.01, * * * p<0.001$. 


\section{Inflammatory gene expression is reduced in the aortic arch of NPC1 ${ }^{\text {mut }}$-tp mice.}

To investigate whether immunization with heat-inactivated pneumococci led to alterations in plaque morphology, we analysed monocyte/macrophage and collagen content, as well as necrosis and apoptosis in the aortic root plaques of (non)immunized NPC1 ${ }^{\text {mut }}$-tp mice. Immunohistological staining for monocyte/macrophage content revealed no significant differences between immunized and non-immunized mice (Figure 4A). Similarly, collagen content assessed by Sirius Red staining, as well as the amount of necrosis and apoptosis were not different between the two groups (Figure 4B-D).
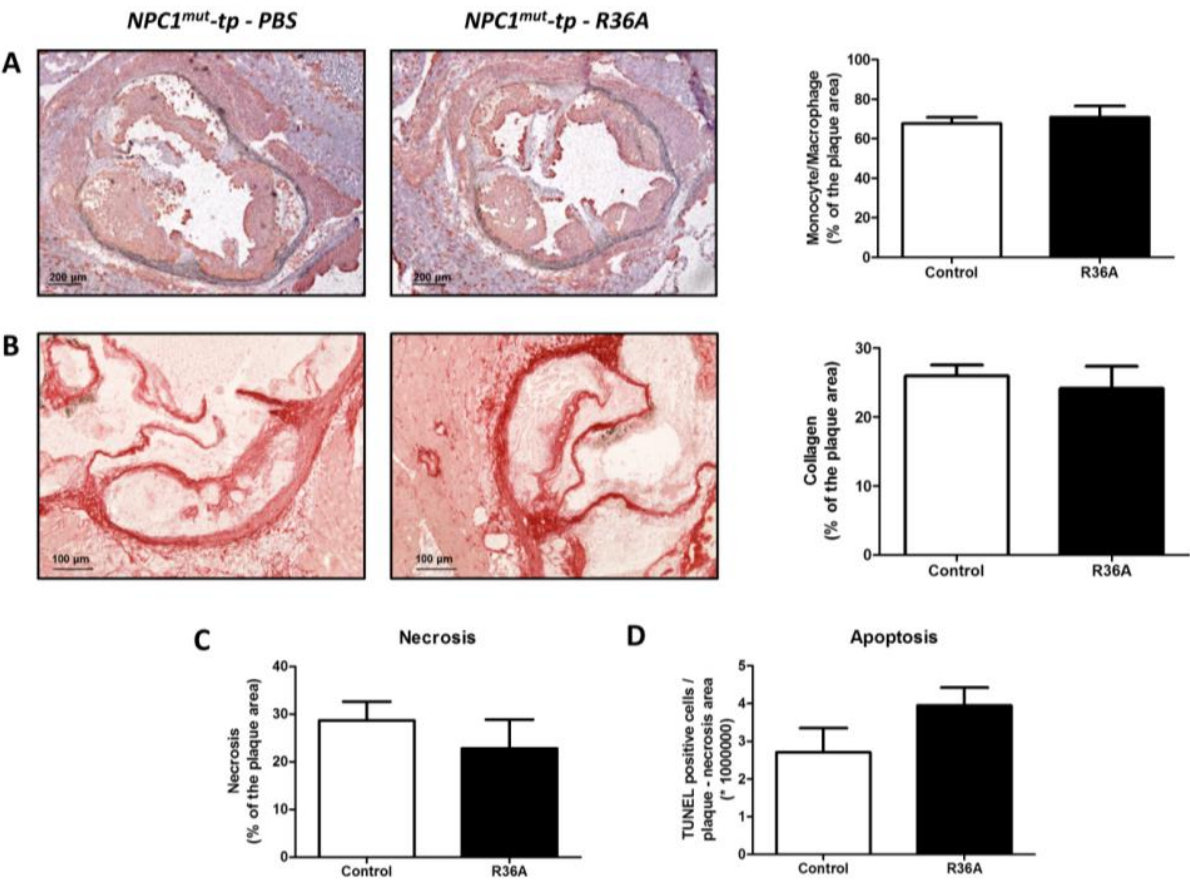

Figure 4: Quantification of plaque morphology of (non)-immunized NPC1 ${ }^{\text {mut-tp }}$ mice in the aortic root. Representative pictures and quantification of the MOMA-2 (A) and collagen (B) staining in NPC1 ${ }^{\text {mut_tp }}$ mice immunized with R36A or control injections with PBS. Quantification of necrosis (C) and apoptosis as demonstrated by a TUNEL staining (D) in (NPC1 ${ }^{\text {mut-tp mice }}$ immunized with R36A or control injections with PBS. All data are represented as mean +/SEM. 
To examine whether immunization with heat-inactivated pneumococci led to reduced plaque inflammation, inflammatory gene expression levels were determined in the aortic arch of NPC1 ${ }^{\text {mut }}$-tp mice. Gene expression of the inflammatory markers tumor necrosis factor-alpha (Tnf $\alpha), \mathrm{C}-\mathrm{C}$ chemokine receptor type 2 (Ccr2) and integrin Alpha $\mathrm{M}$ (Itgam) showed a trend towards reduced expression in immunized NPC1 ${ }^{\text {mut }}$-tp mice but were not considered significant when compared to control (Figure 5A-C). Inflammasome activation, triggered by oxLDL crystals, is involved in atherosclerosis development and can be measured by one of its downstream targets, namely caspase-1 that in turn activates interleukin-18 (IL-18) (27). Caspase-1 gene expression was significantly reduced in the aortic arch of immunized NPC1 ${ }^{\text {mut }}$-tp mice, whereas no changes in gene expression of II-18 were observed (Figure 5D and E). Overall, these results show that plaque inflammation is reduced and that plaque stability is not affected in immunized NPC ${ }^{\text {mut }}$-tp mice). Despite a clear reduction in Caspase-1 mRNA expression in the aortic arch, we did not observe any changes in caspase-1 activity in the aortic root between immunized and non-immunized NPC1 ${ }^{\text {mut }}$-tp mice, most likely due to the presence of large necrotic areas (Supplementary Figure 1).
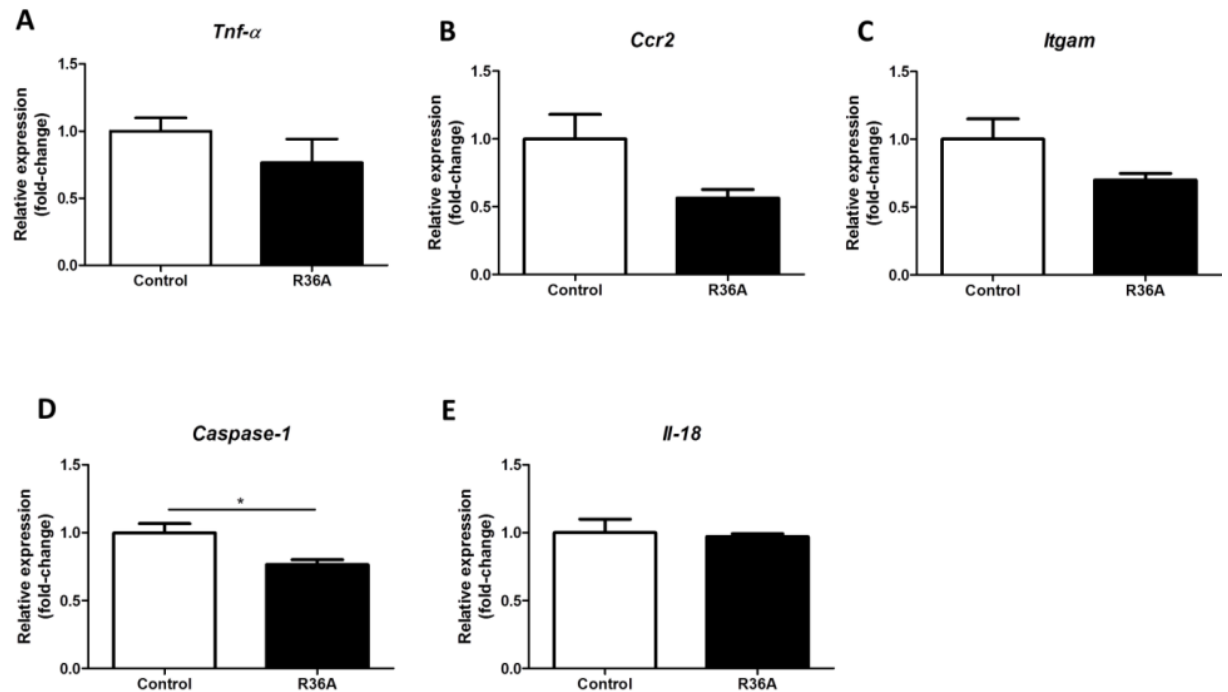

Figure 5: Quantification of plaque inflammation in (non)-immunized NPC1 ${ }^{\text {mut }}$-tp mice in the aortic arch. Relative gene expression of Tnfo, Caspase-1, CCr2, Itgam and II-18 in NPC1 ${ }^{\text {mut }-t p ~ m i c e ~}$ immunized with R36A or control injections with PBS (A-E). All data are represented as mean + - SEM. Data are significant at * $p<0.05, * * p<0.01, * * * p<0.001$. 
To expand our analyses of inflammation, we performed additional stainings for macrophages (MAC-1), neutrophils (NIMP) and T-cells $\left(\mathrm{CD}^{+}\right)$. No differences were observed in the number of MAC-1 positive cells between the two experimental groups and showed that MAC-1 is mainly expressed on foam cells, which is in line with our MOMA staining, which is also expressed on macrophages (Supplementary Figure 2). Next, immunohistological stainings for neutrophils and T-cells were performed on frozen tissue sections of the aortic root of immunized and non-immunized NPC1 ${ }^{\text {mut }}$-tp mice. No differences in the amount of neutrophils between immunized and nonimmunized NPC1 ${ }^{\text {mut }}$-tp mice were observed. In contrast, a significant increase in the amount of T-cells was observed in immunized NPC1mut-tp mice (Supplementary Figure 3). However, it that is important to note that increased T-cell amounts could constitute a reaction to dampen inflammasome activation (28) which could explain these findings. 


\section{Discussion}

Our results demonstrate that pneumococcal immunization can modulate atherogenesis in hematopoietic NPC1-deficient $\mathrm{Ldll}^{-/}$mice. While previous studies showed that pneumococcal immunization led to reduced lysosomal cholesterol accumulation (12), the current findings demonstrate the specific importance of oxLDL within lysosomes in atherosclerosis development.

The aim of this study was to demonstrate the contribution of lysosomal oxLDL accumulation, rather than non-modified LDL, to atherosclerosis, by exclusively preventing the macrophage-mediated uptake and subsequent storage of oxLDL in NPC $1^{\text {mut }}$-tp mice. We show that upon induction of anti-oxLDL antibodies, atherosclerosis development is reduced in NPC1 ${ }^{\text {mut }}$-tp mice compared to nonimmunized mice. In vitro, it has been shown that, unlike LDL, oxLDL is retained in the lysosomes and is resistant to efflux into the cytoplasm (29-31). Stimulation of murine macrophages with oxLDL led to increased production of TNF and IL-6 in response to LPS stimuli (32). Studies also demonstrated that oxLDL uptake by macrophages led to a release of pro-inflammatory cytokines via reactive oxidant species (ROS)-dependent inflammasome activation thereby promoting foam cell formation $(33,34)$. These in vitro findings clearly demonstrated the major contribution of oxLDL to foam cell formation and inflammation, thereby influencing atherosclerosis development. In line, despite a similar relative monocyte/macrophage content, gene expression analysis of the aortic arch revealed that caspase-1 expression was significantly reduced in immunized NPC1mut-tp mice in the current study. Indeed, numerous studies have shown that caspase-1 plays an important role in atherosclerosis $(27,35,36)$. In previous studies, we already demonstrated that pneumococcal immunization resulted in reduced lysosomal cholesterol accumulation and cholesterol crystal formation (12). In line with these findings, others observed that cholesterol crystal-induced inflammasome activation contributes to the development of atherosclerosis via caspase-1 mediated activation (37). These observations indicate that blocking oxLDL uptake in macrophages of immunized NPC1 ${ }^{\text {mut }}$-tp mice results in a reduced caspase-1mediated inflammatory response. 
Uptake of oxLDL is mainly facilitated by CD36 and macrophage scavenger receptor 1 (MSR1) and contributes to foam cell formation (38). Previous research of our group demonstrated that, while there was a clear reduction in inflammation, foam cell formation was unaltered in $\mathrm{Cd} 36^{-\%}$-tp, Msr1- - tp and $\mathrm{Cd} 36^{\%} / \mathrm{Msr} 1^{-}$-tp mice compared to Wt-tp mice $(25,39)$. Further detailed analysis revealed that specifically oxLDL is internalized by macrophages, and this has been shown to be associated with lysosomal cholesterol accumulation and increased inflammation. Prevention of oxLDL uptake led to a reduction of lysosomal cholesterol accumulation and a decrease in inflammation in vivo $(39,40)$. Overall, these data indicate that it is not the total amount of cellular cholesterol, but rather the specific accumulation of lysosomal oxLDL that contributes to atherosclerosis development and inflammation.

Although lipid-lowering agents are the primary treatment for atherosclerosis and other CVDs, the residual risk for a cardiovascular event remains present in these patients (41-43). As not total cholesterol, but rather the uptake of oxLDL is contributing to the development of atherosclerosis, lowering LDL alone may not be efficient. In the past, numerous in vitro and in vivo studies have shown that antioxidants could be beneficial in reducing atherosclerotic lesions (44). Surprisingly, despite some observational studies that showed a correlation between anti-oxidants and atherosclerosis, primary and secondary intervention clinical randomized studies failed in humans (44). The fact that cholesterol can undergo oxidation within lysosomes could be important to explain why these studies failed (45) and why we have observed only a moderate reduction in atherosclerotic lesion size within this study. Besides oxLDL, other cholesterol products such as aggregated LDL, sphingomyelin and cholesteryl ester-rich lipid dispersions can also accumulate inside lysosomes $(29,46,47)$. This could also explain the moderate reduction in plaque size in the current study when compared to previous findings by Binder et al. who performed similar pneumococcal immunizations in hyperlipidemic mice without an NPC1 mutation (11). Taking into account the negligible plasma oxLDL concentrations relative to LDL (48), the reduction in plaque size and inflammation exceeded our expectations and underlines the importance of oxLDL in atherosclerosis development. Future intervention strategies should focus specifically on preventing oxLDL, rather than non-modified LDL, from being internalized into lysosomes. Such an intervention can have an additive effect to current existing treatments against atherosclerosis. 


\section{References}

1. Bowry AD, Lewey J, Dugani SB, Choudhry NK. The Burden of Cardiovascular Disease in Low- and Middle-Income Countries: Epidemiology and Management. Can J Cardiol. 2015;31(9):1151-9.

2. Libby P, Ridker PM, Hansson GK, Leducq Transatlantic Network on A. Inflammation in atherosclerosis: from pathophysiology to practice. Journal of the American College of Cardiology. 2009;54(23):2129-38.

3. Hansson GK, Libby P. The immune response in atherosclerosis: a double-edged sword. Nature reviews Immunology. 2006;6(7):508-19.

4. Hansson GK, Hermansson A. The immune system in atherosclerosis. Nature immunology. 2011;12(3):204-12.

5. Libby P, Ridker PM, Hansson GK. Progress and challenges in translating the biology of atherosclerosis. Nature. 2011;473(7347):317-25.

6. Mallat Z. Macrophages. Arteriosclerosis, thrombosis, and vascular biology. 2014;34(12):2509-19.

7. Berliner JA, Watson AD. A role for oxidized phospholipids in atherosclerosis. N Engl J Med. 2005;353(1):9-11.

8. Binder CJ, Chang MK, Shaw PX, Miller YI, Hartvigsen K, Dewan A, et al. Innate and acquired immunity in atherogenesis. Nature medicine. 2002;8(11):1218-26.

9. Horkko S, Bird DA, Miller E, Itabe H, Leitinger N, Subbanagounder $G$, et al. Monoclonal autoantibodies specific for oxidized phospholipids or oxidized phospholipid-protein adducts inhibit macrophage uptake of oxidized low-density lipoproteins. The Journal of clinical investigation. 1999;103(1):117-28.

10. Yla-Herttuala S, Palinski W, Butler SW, Picard S, Steinberg D, Witztum JL. Rabbit and human atherosclerotic lesions contain IgG that recognizes epitopes of oxidized LDL. Arterioscler Thromb. 1994;14(1):32-40.

11. Binder CJ, Horkko S, Dewan A, Chang MK, Kieu EP, Goodyear CS, et al. Pneumococcal vaccination decreases atherosclerotic lesion formation: molecular mimicry between Streptococcus pneumoniae and oxidized LDL. Nature medicine. 2003;9(6):736-43.

12. Bieghs V, van Gorp PJ, Walenbergh SM, Gijbels MJ, Verheyen F, Buurman WA, et al. Specific immunization strategies against oxidized low-density lipoprotein: a novel way to reduce nonalcoholic steatohepatitis in mice. Hepatology. 2012;56(3):894-903.

13. de Duve C. Lysosomes revisited. European journal of biochemistry / FEBS. 1983;137(3):391-7.

14. Dell'Angelica EC, Mullins C, Caplan S, Bonifacino JS. Lysosome-related organelles. FASEB journal : official publication of the Federation of American Societies for Experimental Biology. 2000;14(10):1265-78.

15. Kwon HJ, Abi-Mosleh L, Wang ML, Deisenhofer J, Goldstein JL, Brown MS, et al. Structure of Nterminal domain of NPC1 reveals distinct subdomains for binding and transfer of cholesterol. Cell. 2009;137(7):1213-24.

16. Sugii S, Reid PC, Ohgami N, Du H, Chang TY. Distinct endosomal compartments in early trafficking of low density lipoprotein-derived cholesterol. The Journal of biological chemistry. 2003;278(29):27180-9.

17. Beltroy EP, Richardson JA, Horton JD, Turley SD, Dietschy JM. Cholesterol accumulation and liver cell death in mice with Niemann-Pick type C disease. Hepatology. 2005;42(4):886-93.

18. Loftus SK, Morris JA, Carstea ED, Gu JZ, Cummings C, Brown A, et al. Murine model of NiemannPick C disease: mutation in a cholesterol homeostasis gene. Science. 1997;277(5323):232-5.

19. Jerome WG, Cash C, Webber R, Horton R, Yancey PG. Lysosomal lipid accumulation from oxidized low density lipoprotein is correlated with hypertrophy of the Golgi apparatus and trans-Golgi network. Journal of lipid research. 1998;39(7):1362-71. 
20. Yancey PG, Jerome WG. Lysosomal cholesterol derived from mildly oxidized low density lipoprotein is resistant to efflux. Journal of lipid research. 2001;42(3):317-27.

21. Feng B, Zhang D, Kuriakose G, Devlin CM, Kockx M, Tabas I. Niemann-Pick C heterozygosity confers resistance to lesional necrosis and macrophage apoptosis in murine atherosclerosis. Proc Natl Acad Sci U S A. 2003;100(18):10423-8.

22. Zhang JR, Coleman T, Langmade SJ, Scherrer DE, Lane L, Lanier MH, et al. Niemann-Pick C1 protects against atherosclerosis in mice via regulation of macrophage intracellular cholesterol trafficking. The Journal of clinical investigation. 2008;118(6):2281-90.

23. van Tits LJ, Stienstra R, van Lent PL, Netea MG, Joosten LA, Stalenhoef AF. Oxidized LDL enhances pro-inflammatory responses of alternatively activated $M 2$ macrophages: a crucial role for Kruppel-like factor 2. Atherosclerosis. 2011;214(2):345-9.

24. Briles DE, Forman C, Hudak S, Claflin JL. Anti-phosphorylcholine antibodies of the T15 idiotype are optimally protective against Streptococcus pneumoniae. The Journal of experimental medicine. 1982;156(4):1177-85

25. Bieghs V, Wouters K, van Gorp PJ, Gijbels MJ, de Winther MP, Binder CJ, et al. Role of scavenger receptor $A$ and $\mathrm{CD} 36$ in diet-induced nonalcoholic steatohepatitis in hyperlipidemic mice. Gastroenterology. 2010;138(7):2477-86, 86 e1-3.

26. Goossens P, Vergouwe MN, Gijbels MJ, Curfs DM, van Woezik JH, Hoeksema MA, et al. Myeloid IkappaBalpha deficiency promotes atherogenesis by enhancing leukocyte recruitment to the plaques. PLoS One. 2011;6(7):e22327.

27. Hendrikx T, Jeurissen ML, van Gorp PJ, Gijbels MJ, Walenbergh SM, Houben T, et al. Bone marrow-specific caspase-1/11 deficiency inhibits atherosclerosis development in Ldlr(-/-) mice. The FEBS journal. 2015;282(12):2327-38.

28. Guarda G, Dostert C, Staehli F, Cabalzar K, Castillo R, Tardivel A, et al. T cells dampen innate immune responses through inhibition of NLRP1 and NLRP3 inflammasomes. Nature. 2009;460(7252):269-73.

29. Griffin EE, Ullery JC, Cox BE, Jerome WG. Aggregated LDL and lipid dispersions induce lysosomal cholesteryl ester accumulation in macrophage foam cells. Journal of lipid research. 2005;46(10):2052-60.

30. Jerome WG, Lewis JC. Early atherogenesis in White Carneau pigeons. II. Ultrastructural and cytochemical observations. Am J Pathol. 1985;119(2):210-22.

31. Jerome WG, Yancey PG. The role of microscopy in understanding atherosclerotic lysosomal lipid metabolism. Microscopy and microanalysis : the official journal of Microscopy Society of America, Microbeam Analysis Society, Microscopical Society of Canada. 2003;9(1):54-67.

32. Groeneweg M, Kanters E, Vergouwe MN, Duerink H, Kraal G, Hofker MH, et al. Lipopolysaccharide-induced gene expression in murine macrophages is enhanced by prior exposure to oxLDL. Journal of lipid research. 2006;47(10):2259-67.

33. Jiang $\mathrm{Y}$, Wang $\mathrm{M}$, Huang $\mathrm{K}$, Zhang Z, Shao N, Zhang $\mathrm{Y}$, et al. Oxidized low-density lipoprotein induces secretion of interleukin-1beta by macrophages via reactive oxygen species-dependent NLRP3 inflammasome activation. Biochem Biophys Res Commun. 2012;425(2):121-6.

34. Liu W, Yin Y, Zhou Z, He M, Dai Y. OxLDL-induced IL-1 beta secretion promoting foam cells formation was mainly via CD36 mediated ROS production leading to NLRP3 inflammasome activation. Inflammation research : official journal of the European Histamine Research Society [et al]. 2014;63(1):33-43.

35. Usui F, Shirasuna K, Kimura H, Tatsumi K, Kawashima A, Karasawa T, et al. Critical role of caspase1 in vascular inflammation and development of atherosclerosis in Western diet-fed apolipoprotein E-deficient mice. Biochem Biophys Res Commun. 2012;425(2):162-8.

36. Gage J, Hasu M, Thabet M, Whitman SC. Caspase-1 deficiency decreases atherosclerosis in apolipoprotein E-null mice. Can J Cardiol. 2012;28(2):222-9. 
37. Duewell P, Kono H, Rayner KJ, Sirois CM, Vladimer G, Bauernfeind FG, et al. NLRP3 inflammasomes are required for atherogenesis and activated by cholesterol crystals. Nature. 2010;464(7293):1357-61.

38. Pennings M, Meurs I, Ye D, Out R, Hoekstra M, Van Berkel TJ, et al. Regulation of cholesterol homeostasis in macrophages and consequences for atherosclerotic lesion development. FEBS letters. 2006;580(23):5588-96.

39. Bieghs V, Verheyen F, van Gorp PJ, Hendrikx T, Wouters K, Lutjohann D, et al. Internalization of modified lipids by CD36 and SR-A leads to hepatic inflammation and lysosomal cholesterol storage in Kupffer cells. PloS one. 2012;7(3):e34378.

40. Bieghs V, Walenbergh SM, Hendrikx T, van Gorp PJ, Verheyen F, Olde Damink SW, et al. Trapping of oxidized LDL in lysosomes of Kupffer cells is a trigger for hepatic inflammation. Liver Int. 2013;33(7):1056-61.

41. Lim S, Park YM, Sakuma I, Koh KK. How to control residual cardiovascular risk despite statin treatment: focusing on HDL-cholesterol. International journal of cardiology. 2013;166(1):8-14.

42. Ahn $\mathrm{CH}$, Choi SH. New drugs for treating dyslipidemia: beyond statins. Diabetes \& metabolism journal. 2015;39(2):87-94.

43. National Cholesterol Education Program Expert Panel on Detection E, Treatment of High Blood Cholesterol in A. Third Report of the National Cholesterol Education Program (NCEP) Expert Panel on Detection, Evaluation, and Treatment of High Blood Cholesterol in Adults (Adult Treatment Panel III) final report. Circulation. 2002;106(25):3143-421.

44. Salvayre R, Negre-Salvayre A, Camare C. Oxidative theory of atherosclerosis and antioxidants. Biochimie, 125 (2016), pp. 281-296 http://dx.doi.org/10.1016/j.biochi.2015.12.014

45. Wen Y, Leake DS. Low density lipoprotein undergoes oxidation within lysosomes in cells. Circulation research. 2007;100(9):1337-43.

46. Jerome WG, Cox BE, Griffin EE, Ullery JC. Lysosomal cholesterol accumulation inhibits subsequent hydrolysis of lipoprotein cholesteryl ester. Microscopy and microanalysis : the official journal of Microscopy Society of America, Microbeam Analysis Society, Microscopical Society of Canada. 2008;14(2):138-49.

47. Maor I, Mandel H, Aviram M. Macrophage uptake of oxidized LDL inhibits lysosomal sphingomyelinase, thus causing the accumulation of unesterified cholesterol-sphingomyelin-rich particles in the lysosomes. A possible role for 7-Ketocholesterol. Arteriosclerosis, thrombosis, and vascular biology. 1995;15(9):1378-87.

48. Holvoet P, Kritchevsky SB, Tracy RP, Mertens A, Rubin SM, Butler J, et al. The metabolic syndrome, circulating oxidized LDL, and risk of myocardial infarction in well-functioning elderly people in the health, aging, and body composition cohort. Diabetes. 2004;53(4):1068-73.

49. Di Pietro N, Formoso G, Pandolfi A. Physiology and pathophysiology of oxLDL uptake by vascular wall cells in atherosclerosis. Vascul Pharmacol. 2016;84:1-7. 


\section{Supplementary Materials}

\section{Histological and morphological analysis}

For histological analysis, aortic roots of (non)-immunized NPC1mut-tp mice were cross-sectional cryo-embedded in Tissue-Tek ${ }^{\circledR}$ (Sakura Finetek Europe B.V., Alphen aan den Rijn, The Netherlands). When the aortic valves were visible, serial sections (7 $\mu \mathrm{m})$, on a series of twenty-four slides, was collected. For quantification of plaque area, slides were stained with Toluidine Blue in order to visualize the atherosclerotic lesions inside the aortic root. Atherosclerosis development was determined as described before (1). Monocytes and/or macrophages, as well as collagen content in atherosclerotic plaques, were assessed by means of MOMA-2 and Sirius red staining, respectively. Sirius red staining was performed according to standard protocol as described previously (2).

\section{Immunohistochemistry}

Cryosections of the aortic root were dried and fixed in 100\% dry acetone for $15 \mathrm{~min}$. To block endogenous peroxidase activity, tissues were incubated with $3 \% \mathrm{H} 2 \mathrm{O} 2$ solutions for about $5 \mathrm{~min}$. Tissues were afterward treated with Avidin/Biotin solution (Vector; SP2001) for 30 minutes to block endogenous biotin. Next, tissues were incubated for 1 hour at room temperature with primary antibody for monocyte/macrophages (MOMA-2; 1:50; supernatant; Rat Hybridoma; Isotype Rat IgG2b, MAC-1 (M1/70, 1:500), NIMP (Neutrophils, 1:100, supernatant), CD3 (KT3 $1: 100$ ). Subsequently, tissue sections were incubated with secondary antibody (Rabbit anti-Rat IgG Biotin (6180-08), SouthernBiotech, Birmingham, AL, USA) for 1 hour at RT. To enhance signaling amplification of secondary antibody, tissues were incubated for $30 \mathrm{~min}$ in Peroxidase Vectastain Elite ABC solution (Vector Laboratories, PK-6100, Peterborough, United Kingdom)). For detection of the secondary antibody, Peroxidase Substrate kit AEC (Vector Laboratories, SK-4200, Peterborough, United Kingdom) was used. Slides were counterstained with hematoxylin. Pictures were taken with a Nikon digital camera DMX1200 and ACT-1 v2.63 software (Nikon Instruments Europe, Amstelveen, The Netherlands). The intensity of MOMA-2 positive area was used to determine the amount of monocyte/macrophages within the atherosclerotic lesions. TUNEL staining for apoptosis was performed on frozen liver sections according to the manufacturers' protocol (In situ Cell Death Detection Kit, Roche Applied Science) in which the number of TUNEL positive cells / plaque area determined the amount of apoptosis. Caspase-1 activity was measured in the aortic root of both Wt-tp and caspase-1/11-/--tp mice via Fluorescent Labeled Inhibitors of Caspases (FLICA). Sections were fixed and then stained for $2 \mathrm{hrs}$ at room temperature with a fluorescent 
probe for active caspase-1. (FAM-FLICA ${ }^{\mathrm{TM}}$ Caspase-1 Kit, ICT097, Biorad). Caspase-1 activity was calculated by the percentage of FLICA positive area relative to the total plaque size.

\section{RNA isolation and quantitative polymerase chain reaction}

Total RNA was isolated from the aortic arch of (non)-immunized NPC1-tp mice with the RNeasy micro kit, (74004, QIAGEN, Venlo, The Netherlands), according to manufacturer's instructions. First-strand complementary DNA (cDNA) was made from 100 ng total aortic arch RNA (iScript ${ }^{\mathrm{TM}}$ CDNA Synthesis Kit (170-8891), Bio-Rad, Veenendaal, The Netherlands), according to manufacturer's protocol. Relative quantitative gene expressions of inflammatory markers were measured by quantitative polymerase chain reaction (qPCR) on an SDS 7900HT using SensiMix SYBR HIROX (Cat No QT605-05 Bioline, London UK) and $10 \mathrm{ng}$ of cDNA template. For normalization, Cyclophilin A was used as a reference gene. Primers sets, as shown in table 1, were developed with Primer Express version 2.0 (Applied Biosystems) using default settings. Data from qPCR were analyzed with the LinReg PCR, (Analysis of RTPCR data, Version 2015.3)

\section{Reference}

1. Kanters E, Pasparakis M, Gijbels MJ, Vergouwe MN, Partouns-Hendriks I, Fijneman RJ, et al. Inhibition of NF-kappaB activation in macrophages increases atherosclerosis in LDL receptordeficient mice. J Clin Invest. 2003;112(8):1176-85.

2. Bieghs V, Wouters K, van Gorp PJ, Gijbels MJ, de Winther MP, Binder CJ, et al. Role of scavenger receptor $A$ and $\mathrm{CD} 36$ in diet-induced nonalcoholic steatohepatitis in hyperlipidemic mice. Gastroenterology. 2010;138(7):2477-86, 86 e1-3. 


\section{Supplementary Figures}

DAPI
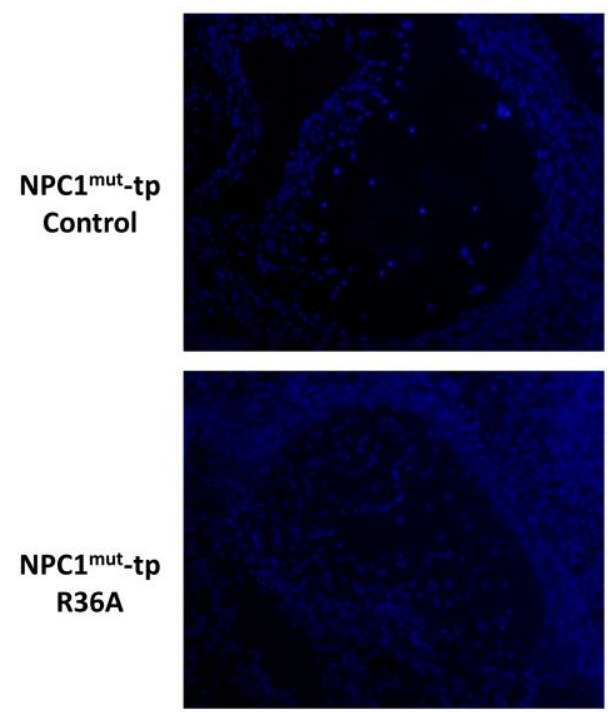

FLICA
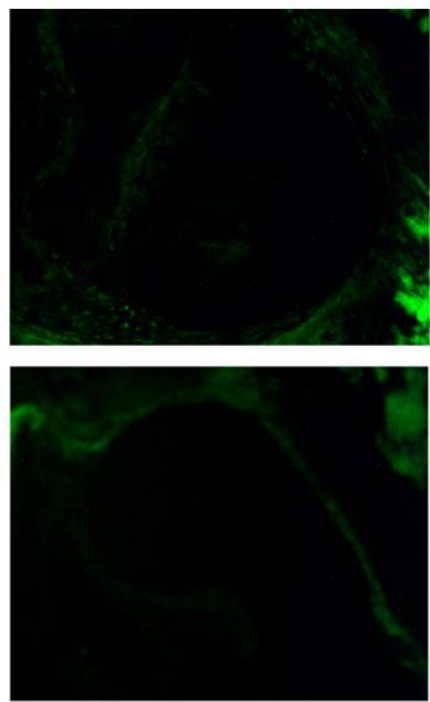

Supplementary Figure 1: $\quad$ Caspase-1 activity measured in the aortic root of (non) immunized NPC1 ${ }^{\text {mut }}$ tp mice. Representative pictures of caspase-1 activity (FLICA assay) in the aortic root of (non)-immunized NPC1 ${ }^{\text {mut-tp mice. }}$

A

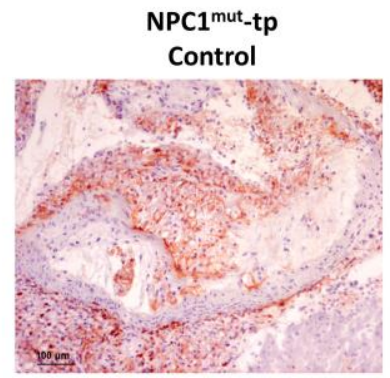

B

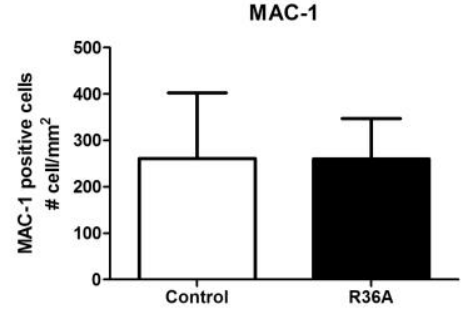

NPC1 ${ }^{\text {mut }}$-tp

R36A

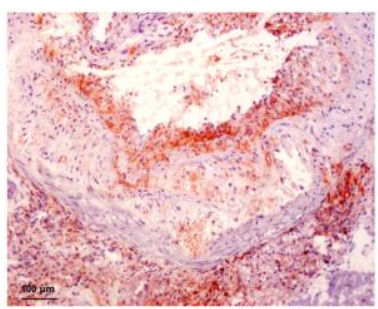


Supplementary Figure 2: MAC-1 staining in the aortic root of (non)-immunized NPC1 mut-tp mice. Representative pictures of MAC-1 staining in the aortic root of (non)immunized NPC1 ${ }^{\text {mut }}$-tp mice (A). Quantification of the MAC-1 staining by counting MAC-1 positive cells in (non)-immunized NPC1 ${ }^{\text {mut }}$-tp mice (B). All data are represented as mean + /- SEM.
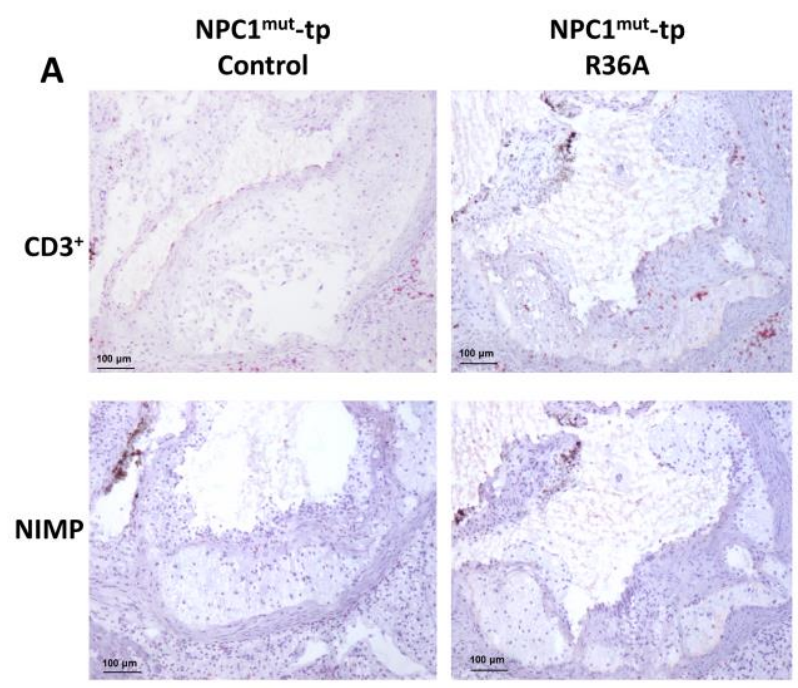

B
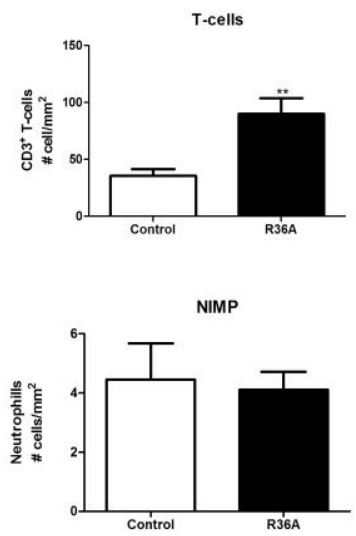

Supplementary Figure 3: $\quad \mathrm{CD} 3+$ and neutrophil staining in the aortic root of (non)-immunized NPC1 ${ }^{\text {mut }}$-tp mice. Representative pictures of $\mathrm{CD} 3+$ and neutrophils staining in the aortic root of (non)-immunized NPC1mut-tp mice (A). Quantification of the $\mathrm{CD} 3+$ and neutrophils staining by counting MAC-1 positive cells in (non)immunized NPC1mut-tp mice (B). All data are represented as mean +/- SEM. Data are significant at $* p<0.05, * * p<0.01, * * * p<0.001$ 



\section{Chapter 3}

Bone marrow-specific caspase-1/11 deficiency inhibits atherosclerosis development in $\mathrm{LdII}^{-/-}$mice

M.L. J. Jeurissen*, T. Hendrikx*, P. J. van Gorp, M.J J. Gijbels, S. M. A. Walenbergh, T. Houben, R. van Gorp, C.C. Pöttgens, R. Stienstra, M.G. Netea, M.H. Hofker, M. M. P. C. Donners and R. Shiri-Sverdlov

*These authors contributed equally to this work

FEBS Journal 282 (2015) 2327-2338 


\section{Abstract}

Recent investigations have suggested that inflammasome activation plays an important role during atherosclerosis. Upon activation, the inflammasome induces processing and release of pro-inflammatory cytokines interleukin $1 \beta$ (IL-1 $\beta$ ) and interleukin 18 (IL-18) via activation of caspase-1/11. Previously, it was shown that complete caspase-1 deficiency is protective against atherosclerosis development. However, while macrophages are the main inflammatory cells involved in atherosclerosis, the exact role of macrophage- specific caspase-1/11 activation during development of cardiovascular disease has never been investigated. We hypothesized that hematopoietic caspase-1/11 deficiency leads to reduced atherosclerosis development. To investigate the specific contribution of hematopoietic caspase- $1 / 11$ activation to atherosclerosis development, $\mathrm{Ldll}^{-/}$mice received a transplant (tp) of wild-type $(\mathrm{Wt})$ or caspase- $1 / 11^{-}$bone marrow, to create $\mathrm{Wt}$-tp mice and caspase$1 / 11^{-/}$-tp mice, and fed a high-fat, high cholesterol diet for 12 weeks. Our results showed an increase in anti-inflammatory blood leukocytes in caspase-1/11/-tp mice compared with Wt-tp mice, as indicated by a decreased level of Ly6Chigh monocytes and an increased level of Ly6Clow monocytes. In line with our hypothesis, hematopoietic deletion of caspase $1 / 11$ resulted in a strong reduction in atherosclerotic plaque size. Furthermore, necrotic core content was dramatically decreased in caspase-1/11\%-tp mice. Our data indicate that hematopoietic caspase$1 / 11$ activation is involved in vascular inflammation and atherosclerosis, and plays an important role in cardiovascular disease progression. 


\section{Introduction}

Atherosclerosis is one of the leading causes of death worldwide. The main characteristic of atherosclerosis is the development of plaques in the vessel wall due to accumulation of lipid-laden macrophages (foam cells). Although the exact mechanisms that drive atherosclerosis are complex and still not fully understood, inflammation and cell death are known to play a pivotal role (1). Recent studies have indicated the involvement of inflammasomes in progression of atherosclerosis (2-4). Phagocytosis of oxidized low density lipoproteins, the most important risk factor for atherosclerosis, by macrophages was shown to activate the NOD-like receptor family, pyrin domain containing 3 (NLRP3) inflammasome (5). Furthermore, cholesterol crystals, which are characteristic of advanced plaques, were found to activate NLRP3 inflammasomes, thereby triggering the inflammatory response during atherosclerosis (6). Upon activation by various stimuli, the inflammasome induces the processing and release of the pro-inflammatory cytokines interleukin 1 beta (IL-1 $\beta$ ) and interleukin 18 (IL-18) via caspase-1. Whereas caspase-1 is involved in the canonical pathway of inflammasome activation, caspase-11 was found to trigger caspase-1-dependent IL-1 $\beta$ and IL-18 release in response to non-canonical inflammasome activators $(7,8)$. Previously, complete caspase- 1 deficiency was described as protective against atherosclerosis development, as reduced plaque size was observed in $\mathrm{ApoE}^{-\%}$ caspase$1^{\%}$ mice compared with $A p o E^{-}$mice receiving a Western type diet $(9,10)$ Furthermore, the reduction in plaque area was associated with fewer macrophages and vascular smooth muscle cells present in the plaques, and lower levels of the interleukins IL-1 $\beta$ and IL-6, plus the chemokine (C-C motif) ligand 2 (CCL2) and the cytokine tumor necrosis factor a (TNF $\alpha$ ), in the plasma of double knockout mice (10). However, so far, the specific contribution of hematopoietic caspase-1/11 activation to atherosclerosis development has not been established. We hypothesized that hematopoietic caspase-1/11 deficiency leads to reduced atherosclerosis development. To test this hypothesis, bone marrow cells from wild-type $(\mathrm{Wt})$ donor mice or mice lacking caspase- $1 / 11$ were transferred into lethally irradiated hyperlipidemic LdIr $^{-1}$ recipient mice to create Wt-tp mice and caspase- $1 / 11^{-/-t p}$ mice that were then put on a high-fat, high-cholesterol diet (HFD) for 12 weeks. In line with our hypothesis, hematopoietic deletion of caspase-1/11 resulted in a substantial reduction in atherosclerotic plaque size. Additionally, caspase- $1 / 11^{-/}$-tp mice showed reduced cell death in the plaque area compared with controls. Our data indicate that hematopoietic caspase-1/11 activation plays an important role in vascular inflammation and atherosclerosis. 


\section{Material and Methods}

\section{Mice, diet and bone marrow transplantation}

Mice were housed under standard conditions, and given unlimited access to food and water. Animal experiments were performed according to Dutch regulations, and approved by the Committee for Animal Welfare of Maastricht University. Female 10 12-week-old $L d l r^{-/}$mice were lethally irradiated and transplanted with $\mathrm{Wt}$ or caspase$1 / 11^{-/}$bone marrow as previously described (11). Caspase- $1 / 11^{-/}$mice were a kind gift from Mihai Netea (Department of Medicine, Radboud University Nijmegen Medical Centre and Nijmegen Institute for Infection, Inflammation and Immunity, Nijmegen, The Netherlands). All mice were back-crossed with C57BL/6J mice for 10 generations, and age-matched wild-type $\mathrm{C} 57 \mathrm{BI} / 6 \mathrm{~J}$ mice were used as controls throughout the experiments. Besides caspase-1, these mice are also deficient in caspase-11. The efficiency of bone marrow transplantation was approximately $98 \%$ (data not shown). After 9 weeks of recovery, mice were given HFD for 12 weeks ( $\mathrm{n}=$ 12 for Wt-tp mice; $n=14$ for caspase-1/11/ -tp mice). The HFD contained $21 \%$ milk butter, $0.2 \%$ cholesterol, $46 \%$ carbohydrates and $17 \%$ casein. Collection of blood and tissue specimens, biochemical determination of plasma lipids, RNA isolation, cDNA synthesis and quantitative PCR were performed as described previously (12-15).

\section{Histological analysis and morphological analysis}

For histological analysis, cross-sections of aortic roots of Wt-tp and caspase- $1 / 11^{-/}$-tp mice were sectioned $(7 \mu \mathrm{m})$ and collected on a series of 24 slides. For quantification of atherosclerotic plaque formation, slides were stained with toluidine blue for visualization of the atherosclerotic lesions inside the aortic root. Atherosclerosis development was determined as described previously (16). Furthermore, lesions in atherosclerotic plaques were classified as early, moderate or advanced as described previously (17). Monocyte/ macrophage levels and collagen content in atherosclerotic plaques were assessed by immunohistochemistry using MOMA-2 (monocyte) macrophage) and Sirius Red, respectively, according to standard protocols. Caspase-1 activity was measured in the aortic root of Wt-tp and caspase- $1 / 11^{-/}$-tp mice using fluorescent-labelled inhibitors of caspases (FLICA). Sections were fixed and then stained for $2 \mathrm{~h}$ at room temperature using a fluorescent probe for active caspase-1 (FAM-FLICA $^{\text {TM }}$ caspase-1 kit; Bio-Rad, California, CA, USA). Caspase-1 activity is represented as the positive area for fluorescent-labelled inhibitors of caspases relative to the total plaque size. 


\section{Fluorescence-activated cell sorting}

Blood was drawn from the tail vein of Wt-tp and caspase-1/11 $1^{--}$-tp mice at week 12 of HFD. Staining was performed using Trucount beads (BD Biosciences, San Jose, CA, USA) according to the manufacturer's instructions. In short, CD16/32 antibody (eBioscience, San Diego, CA, USA; (1:100)) was added to anti-coagulated whole blood to block the Fc-receptor and incubated for $10 \mathrm{~min}$ in the dark at room temperature (RT). All antibodies were diluted in FACS buffer (PBS, 0.1\% BSA, 0.01\% sodium azide) and were then added to the blood, shaken gently and incubated for $20 \mathrm{~min}$ in the dark at RT. To lyse the red blood cells, erylysis solution (8.4 g NH4Cl/0.84 g NaHCO solution in $1 \mathrm{~L}$ Milli-Q; 7.2-7.4 pH) was added and incubated for $15 \mathrm{~min}$ in the dark at RT. Samples were measured within $1 \mathrm{~h}$ by FACS (BD FACSCanto II flow cytometer). The following stainings were performed: Leukocytes: CD45 ${ }^{+}$, Monocytes: Ly6G CD11 ${ }^{+}$and the inflammatory status of the monocytes via Lys $6 \mathrm{C}^{+}$.

\section{Cytokine analysis}

The cytokine profile in pooled plasma samples of Wt-tp and caspase- $1 / 11^{-/}$-tp mice was determined using a cytometric bead array mouse inflammation kit (BD Biosciences) according to the manufacturer's instructions. Beads coated with specific capture antibodies for IL-6, IL-10, CCL2, interferon- $\gamma$, TNF- $\alpha$ and IL-12 were mixed together and incubated for $2 \mathrm{~h}$ with standard or test samples in the presence of a phycoerythrin-conjugated detection antibody. Concentrations of these cytokines were determined by measuring the mean fluorescence intensity using a BD FACSCalibur $^{\mathrm{TM}}$ (BD Biosciences) and comparing them with a standard curve. IL-18 levels were determined using an ELISA kit (mouse IL-18/IL-1F4 ELISA; R\&D Systems, Minneapolis, MN, USA) according to the manufacturer's instructions.

\section{Western blotting}

Pro- and mature IL-1 $\beta$ levels were measured via western blot analysis. The total protein concentration was measured using a Pierce ${ }^{\circledR}$ (Waltham, MA, USA) BCA protein assay. Equal amounts of protein $(60 \mu \mathrm{g})$ were loaded on the gel. After SDS/PAGE, proteins were transferred on nitrocellulose membrane (Bio-Rad). The membrane was blocked with $4 \%$ non-fat dry milk for $1 \mathrm{~h}$ at room temperature. For detection, the membrane was incubated with an antibody against IL-1 $\beta$ (1:1000 dilution; Cell Signalling Technology, Danvers, MA, USA) overnight at $4{ }^{\circ} \mathrm{C}$ followed by $1 \mathrm{~h}$ of incubation with donkey anti-rabbit antibody at room temperature (Jackson Laboratories, Bar Harbor, ME, USA). Signal was detected on autoradiograms by 
enhanced chemoluminescence. $\beta$-actin was used as a housekeeping protein (diluted 1:100 000; MP Biomedicals, Santa Ana, CA, USA).

\section{Efferocytosis assay}

Bone marrow cells were isolated from the bones of the hind limbs of $\mathrm{Wt}$ and caspase$1 / 11^{\%}$ mice. Cells were cultured for 8 days in RPMI-1640 cell culture medium supplemented with $10 \%$ fetal bovine serum, $1 \%$ Penicillin and Strep (P/S), 1\% Lglutamine, 20 mM HEPES (GIBCO/ Invitrogen, Breda, The Netherlands) and 20\% L929 cell-conditioned medium containing Macrophage colony stimulating factor to stimulate differentiation into bone-marrow derived macrophages (BMDMs). BMDMs of $\mathrm{Wt}$ and caspase- $1 / 11^{\%}$ mice were seeded into a 24 -well plate in quadruplicate $\left(0.2 \times 10^{6}\right.$ cells per well). Jurkat cells were labelled using Calcein-AM ( $1 \mathrm{mg}^{*} \mathrm{~mL}-1$, 1:2000 dilution; Invitrogen) and incubated for $1 \mathrm{~h}$ at $37^{\circ} \mathrm{C}$. To induce apoptosis, Jurkat cells were exposed to UV light (UVS-26; Fisher Scientific (Waltham, MA, USA); $254 \mathrm{~nm}$, $6 \mathrm{~W}$ bulb, $0.02 \mathrm{~J}^{*} \mathrm{~s}^{-1} \mathrm{~cm}^{-2}$ ) for $15 \mathrm{~min}$. After a $4 \mathrm{~h}$ recovery period, BMDMs of $\mathrm{Wt}$ or caspase-1/11\% mice were added to the apoptotic Jurkat cells for $45 \mathrm{~min}$. After washing for $1 \mathrm{~min}$ at room temperature with medium, the amount of efferocytosis was determined by FACS analysis by measuring the percentage of macrophages that incorporated Jurkat cells that are positively labelled for cell death with Calcein-AM.

\section{Statistical analysis}

The data were analysed using GRAPHPAD PRISM 4.0.3 (GraphPad Software Inc., La Jolla, CA, USA). An unpaired t test was performed to compare Wt-tp and caspase$1 / 11^{-\%}$-tp mice for each diet group. For FACS data, one-way ANOVA was performed with Tukey's multiple comparison test. 


\section{Results}

Increased anti-inflammatory blood leukocyte profile in caspase-1/11/-tp mice compared with Wt-tp mice after 12 weeks of a high-fat, high cholesterol diet

As shown previously, after 12 weeks of HFD, no differences were observed in the levels of triglycerides $(2.372 \pm 0.2378$ versus $1.938 \pm 0.1937 \mathrm{mM})$, free fatty acids $(1.120 \pm 0.084$ versus $1.121 \pm 0.099 \mathrm{mM})$ or cholesterol $(40.14 \pm 3.88$ versus $34.32 \pm$ $2.69 \mathrm{mM}$ ) in the plasma of Wt-tp and caspase-1/11/-tp mice (18). To elucidate the systemic effects of hematopoietic caspase-1/11 deficiency, fluorescence-activated cell sorting was performed to characterize the blood leukocyte profile of Wt-tp and caspase-1/11/-tp mice after 12 weeks of chow or HFD. There were no differences in the numbers of leukocytes between Wt-tp and caspase-1/11 $1^{--}$-tp mice (Figure $1 \mathrm{~A}$ ). Interestingly, when examining leukocyte subsets, the population of total monocytes was found to increase 1.6 -fold in caspase- $1 / 11^{-/}$-tp mice compared with Wt-tp mice receiving $H F D$, but no difference was observed between the groups receiving chow versus HFD (Figure 1B). Monocytes, which are precursors of macrophages, have various monocyte sub-populations with diverse functions, represented by the proinflammatory Ly6C ${ }^{\text {high }}$ monocyte population and the residential Ly6Clow monocyte population. In caspase-1/11\%-tp mice, the level of pro-inflammatory Ly $6 \mathrm{C}^{\text {high }}$ monocytes decreased upon chow and HFD feeding compared with Wt-tp mice (Figure 1C). Further, the level of Ly6Clow monocytes dramatically increased in caspase-1/11 $1 /$-tp mice receiving HFD compared with Wt-tp mice (Figure 1D). These data indicate that hematopoietic deletion of caspase-1/11 results in reduced systemic inflammation after HFD.

A

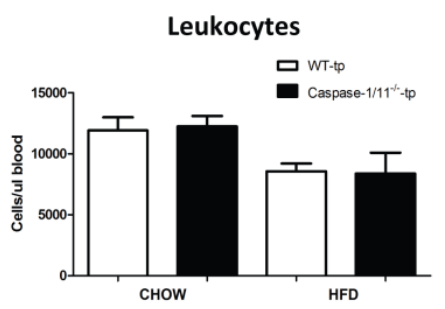

C

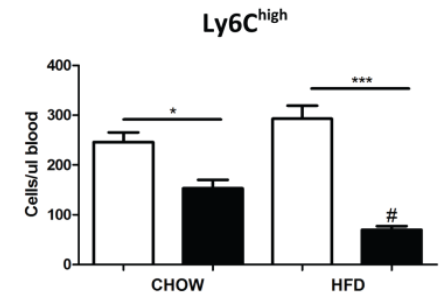

B Monocytes

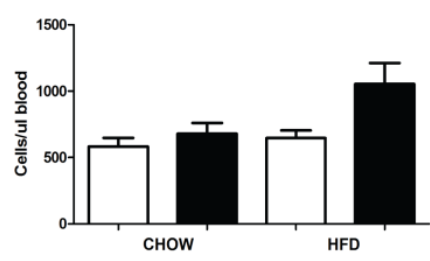

D

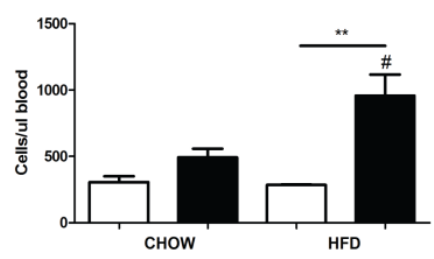


Figure 1: Blood leukocyte profile. Populations of leukocytes (A) and monocytes (B) after 12 weeks on chow or HFD in Wt-tp and caspase-1/11\%-tp mice. Sub-populations of Ly6 $\mathrm{C}^{\text {high }}$ monocytes (C) and Ly6 $6 \mathrm{C}^{\text {low }}$ monocytes $(D)$ in the blood of Wt-tp and caspase-1/11\%-tp mice receiving chow or HFD for 12 weeks. Values are means \pm SEM. Asterisks indicate values that are statistically significantly different between Wt-tp and caspase-1/11\%-tp $\left(* \mathrm{P}<0.05,{ }^{*} \mathrm{P}<0.01, * * * \mathrm{P}<\right.$ $0.001)$. The hash symbols (\#) indicate values that are statistically significantly different between mice receiving chow and those receiving HFD $(P<0.05)$.

To further define the inflammatory status of the experimental groups, plasma protein levels of the inflammatory cytokines CCL2, IL-12, TNF $\alpha$, IL-6, IL-10 and interferon- $\gamma$ $($ IFN- $\gamma$ ) were measured. Protein levels of CCL2 were significantly reduced in caspase$1 / 11^{-/}$-tp mice compared with Wt-tp mice (Figure $2 \mathrm{~A}$ ), but no differences in the protein levels of other inflammatory cytokines were observed (Figure 2B-F). These data indicate that hematopoietic caspase-1/11 deficiency results in reduced production of CCL2, thereby potentially leading to less atherosclerosis.

A

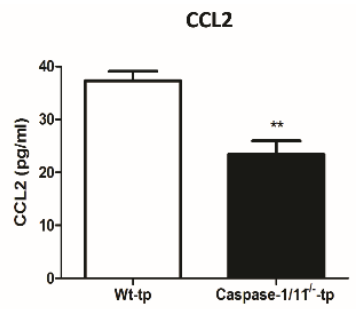

D

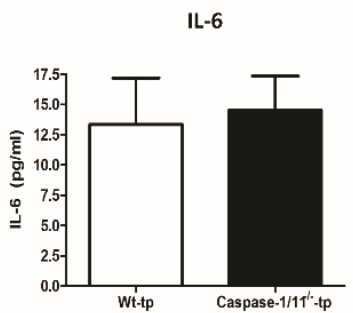

B

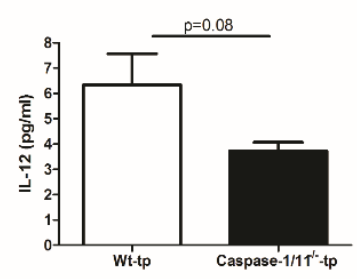

E

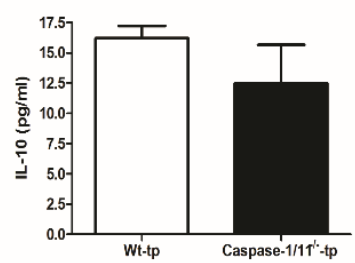

C

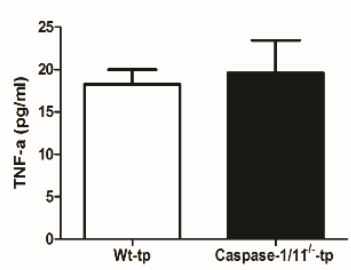

$\mathbf{F}$

IFNy

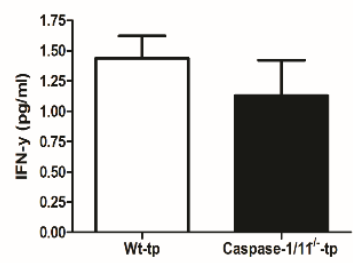

Figure 2: Circulatory cytokine analyses. Plasma protein levels of the inflammatory cytokines CCL2 (A), IL-12 (B), tumor necrosis factor $\alpha$ (C), IL-6 (D), IL-10 (E) and interferon $\gamma(F)$ after 12 weeks of HFD feeding in Wt-tp and caspase-1/11-tp mice, respectively. Values are means \pm SEM. Asterisks indicate a statistically significantly difference compared with Wt-tp mice $\left({ }^{* * P}<0.01\right)$. 


\section{Hematopoietic caspase-1/11 deficiency leads to a substantial reduction in atherosclerotic plaque size and affects plaque development}

To examine the effect of hematopoietic caspase-1/11 deficiency on atherosclerosis development, we analysed histological sections of the aortic root of Wt-tp and Caspase-1/11\%-tp mice receiving HFD. The aortic roots were stained with toluidine blue to determine plaque size (Figure $3 \mathrm{~A}$ ). Caspase- $1 / 11^{-/}$-tp mice showed a significant (1.5-fold) reduction in plaque size compared with Wt-tp mice (Figure 3B). Next, gene expression analysis for macrophage marker CD68 was performed in the aortic arches as the amount of macrophages present can give an indication of plaque size. A clear trend towards reduced expression of the $C d 68$ gene in the aortic arch was observed in caspase-1/11/--tp mice compared with Wt-tp mice (Figure 3C). However, it is important to bear in mind that atherosclerosis development in the aortic arch is slower than in the aortic roots $(19,20)$, which may explain why $C d 68$ expression was not reduced significantly. In addition, atherosclerotic lesions were classified as early, moderate and advanced lesions. This classification indicated that caspase- $1 / 11^{-/}$-tp mice had more moderate and fewer advanced atherosclerotic lesions compared with Wt-tp mice (Figure 3D).

A

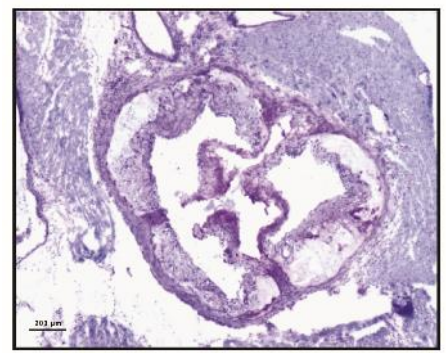

C CD68

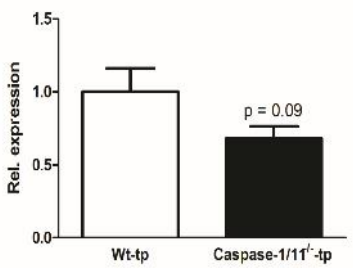

Caspase-1/11 - -tp

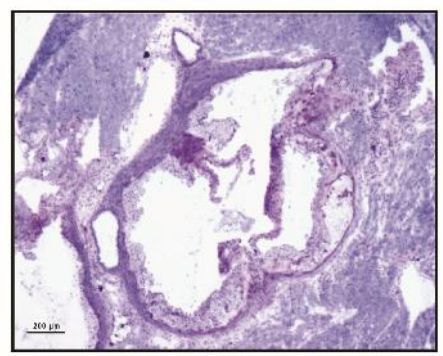

D

Plaque Progression
B Plaque Size
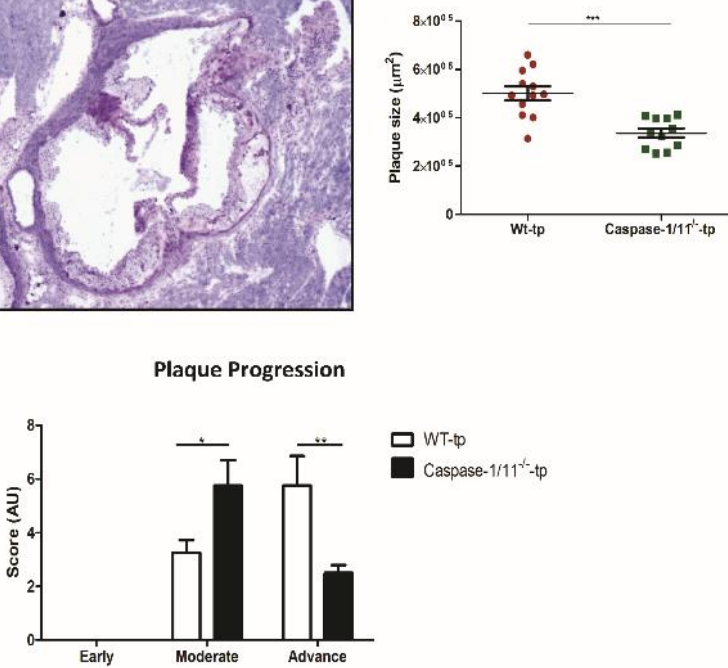
Figure 3: Analysis of atherosclerotic plaque size. Representative images of toluidine blue staining of aortic roots in Wt-tp and caspase-1/11\%-tp mice, respectively (A). Quantification of the total plaque size(B). Expression of $C d 68$ in the aortic arch of Wt-tp and caspase- $1 / 11^{\%}$-tp mice ( $\mathrm{n}=$ 12 for Wt-tp mice and $n=13$ for caspase-1/11-tp mice) (C). Classification of atherosclerotic lesions in Wt-tp and caspase-1/11\%--tp as early, moderate and advanced lesions. Values are means \pm SEM, and are relative to values in Wt-tp mice (D). Asterisks indicate values that are statistically significantly different from Wt-tp ( $P P<0.05, * * P<0.01, * * * P<0.001)$.

Analysis of expression of the IL-1 $\beta$, IL-18 and IL-33 genes in the aortic arch did not reveal any differences between Wt-tp and caspase-1/11- - tp mice (Figure $4 \mathrm{~A}-\mathrm{C}$ ). Circulating protein levels of IL-1b and IL-18 in plasma samples of Wt-tp and caspase$1 / 11^{-/}$-tp mice were determined. Whereas IL-1 $\beta$ was undetectable, IL-18 levels showed a trend towards reduced levels in caspase-1/11 $1^{-}$-tp compared with Wt-tp mice (Figure $4 \mathrm{D}$ and $\mathrm{E}, \mathrm{P}=0.06$ ). Further, expression of the NLRP3 and absent in melanoma 2 (AIM2) genes, encoding two well-known components of the inflammasome, revealed no difference in the expression of these genes in the aortic arch of Wt-tp and caspase- $1 / 11^{-/}$-tp mice (Figure $4 \mathrm{~F}$ and $\mathrm{G}$ ). Taken together, these data indicate that atherosclerotic plaque development is considerably reduced in hematopoietic caspase-1/11-deficient mice and lack of the caspases does not affect other parts of the inflammasome.

A

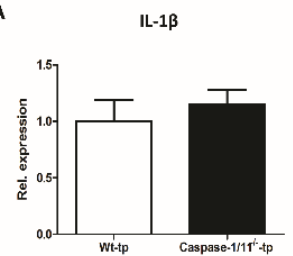

B

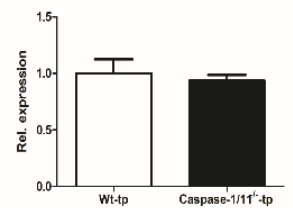

C

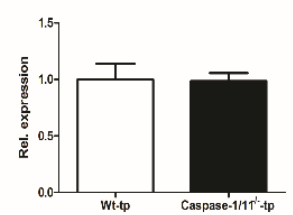

D

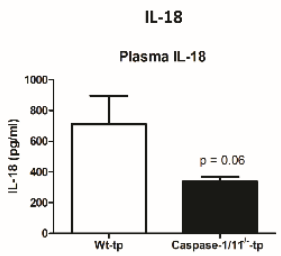

$\mathbf{F}$

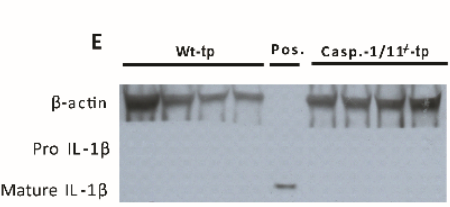

NLRP3

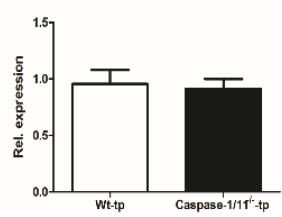

G

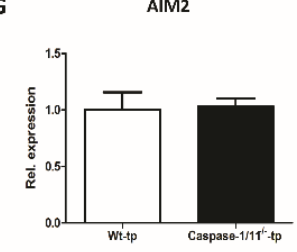

Figure 4: Expression of inflammatory genes. Expression of IL-1 $(A), I L-18(B)$ and IL-33 (C) in the aortic arch of Wt-tp and caspase-1/11\%-tp mice after 12 weeks of HFD. (D) Plasma IL-18 protein levels in Wt-tp and caspase-1/11\%-tp mice. Western blot analysis of pro- and mature IL-1 $\beta$ levels (E). Gene expression of NLRP3 (F) and AIM2 (G) in Wt-tp and caspase-1/11\%-tp mice. Values are means \pm SEM, and are relative to values in Wt-tp mice. 


\section{Reduced necrotic core content in mice with hematopoietic deletion of caspase-1/11}

To determine the effects of hematopoietic deletion of caspase-1/11 on plaque phenotype, (immuno)-histological staining for various aspects of atherosclerosis was performed. Although no changes were seen in the relative amount of monocytes/macrophages (data not shown), we observed a significant reduction in the absolute amount of monocytes/macrophages in caspase-1/11 $1^{-/}$-tp mice compared with Wt-tp mice (Figure 5A). In contrast, no changes were seen in relative collagen deposition (Sirius Red, Figure 5B) or foam cell formation (Figure 5C). Interestingly, the relative amount of necrosis in the plaque area (as determined by necrotic core measurement) was significantly reduced (1.7-fold) in caspase- $1 / 11^{-/-}$-tp mice compared with Wt-tp mice receiving HFD (Figure 5D and E). These data indicate that hematopoietic deletion of caspase-1/11 affects plaque composition by reducing the necrotic core content.

A

Monocyte/Macrophage

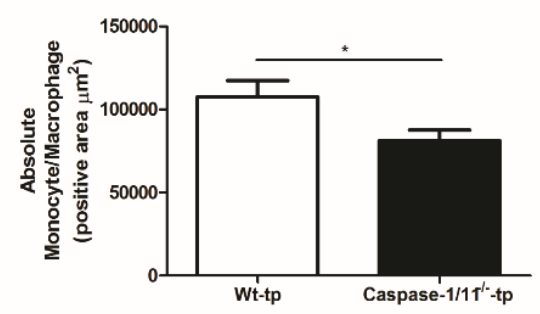

C

Foam cell size

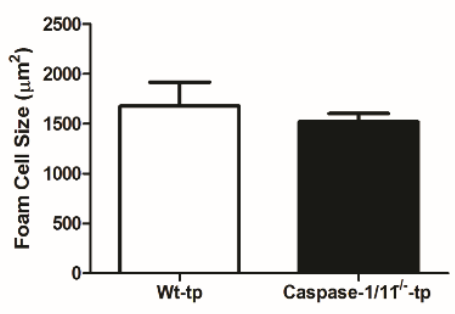

B Collagen

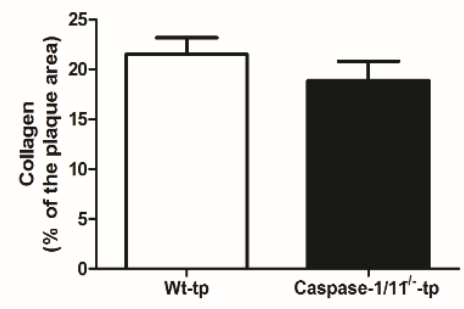

D Necrosis

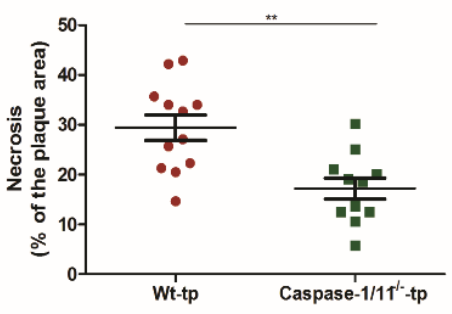


$\mathbf{E}$

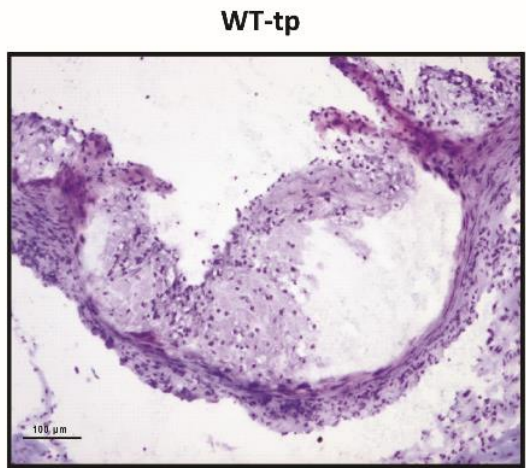

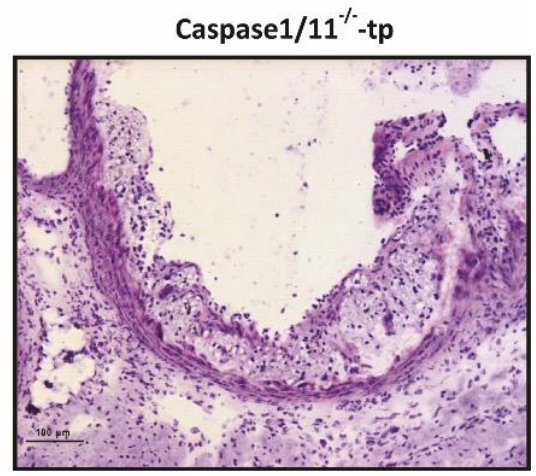

Figure 5: Plaque phenotype analysis. Quantification of (A) MOMA-2 staining for
monocytes/macrophages (absolute), Sirius Red staining for collagen deposition (B), and (C) foam cell formation in Wt-tp and caspase-1/11\%-tp mice. Quantification (D) and representative images $(E)$ of necrosis in Wt-tp and caspase-1/11\%-tp mice. Values are means \pm SEM. Asterisks indicate values that are statistically significantly different from Wt-tp (*P< $0.05, * * P<0.01)$.

\section{Hematopoietic deletion of caspase-1/11 reduces apoptosis, but not as a result of increased efficiency of efferocytosis}

To determine whether hematopoietic deletion of caspase-1/11 also affects apoptosis, TUNEL staining on cryo-sections of the aortic root of Wt-tp and caspase- $1 / 11^{--}$-tp mice was performed. As expected, TUNEL-positive stained area was significantly reduced (2.5-fold) in atherosclerotic plaques of caspase-1/11 $1^{--}$-tp mice compared with Wt-tp mice (Figure 6A and B). To investigate whether the reduction in apoptosis in the atherosclerotic plaques was due to an increase in the efficiency of clearance of apoptotic cell debris, an efferocytosis assay was performed. The capacity of bone marrow-derived macrophages (BMDMs) from Wt and caspase- $1 / 11^{-/}$mice to take up apoptotic cells was analysed in an in vitro assay. Despite the reduction in apoptosis seen in atherosclerotic plaques, no significant difference in efferocytosis was observed between $\mathrm{Wt}$ and caspase-1/11/- BMDMs (Figure 6C). To investigate whether reduced cell death is partly related to pyroptosis (caspase-1-mediated cell death), expression of the caspase- 1 gene in the aortic arch and caspase-1 activity in the aortic root in Wttp and caspase-1/11/ -tp mice were assessed. A significant reduction in caspase-1 expression was found in the aortic arch in caspase-1/11\%-tp mice compared with Wttp mice (Figure 6D), but no difference in caspase-1 activity was observed (Figure 6E). 
A

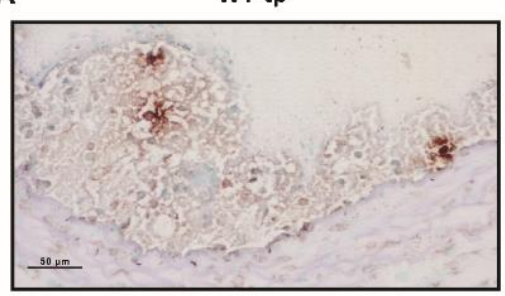

B Apoptosis

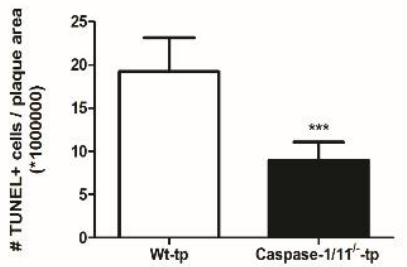

D Caspase-1

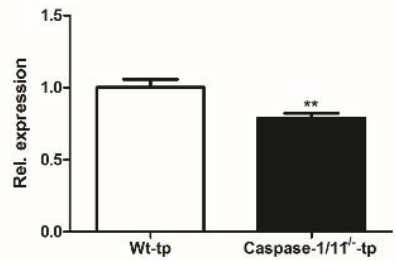

Caspase-1/11- -tp

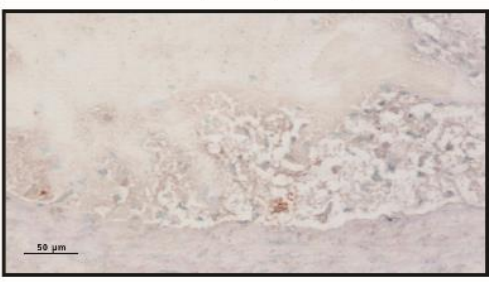

C

Efferocytosis

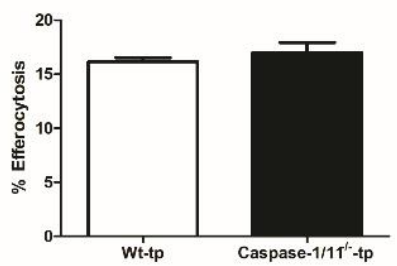

E Caspase-1 activity

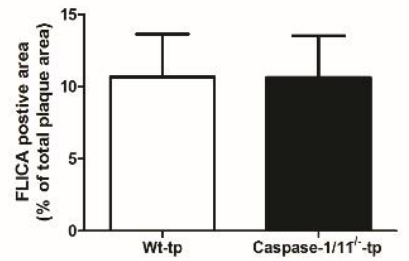

Figure 6: TUNEL staining, efferocytosis analysis and analysis of expression of the caspase-1 gene and caspase-1 activity. Representative images of TUNEL staining after 12 weeks of HFD feeding in Wt-tp and caspase-1/11\%-tp mice (A). Quantification of TUNEL staining for apoptosis (B). In vitro efferocytosis assay of WT and caspase-1/11\%-BMDMs (C). Expression of the caspase-1 gene in the aortic arch in Wt-tp and caspase-1/11\%-tp mice (D). Quantification of caspase-1 activity (FLICA assay) in the aortic root of Wt-tp and caspase-1/11\%-tp mice (E). Values are means \pm SEM, Asterisks indicate values that are statistically significantly different from Wt-tp $\left({ }^{* * \mathrm{P}}<0.01,{ }^{* * *} \mathrm{P}<0.001\right)$. 


\section{Hematopoietic deletion of caspase-1/11 does not affect platelet activation}

Infiltration of platelets into the plaque is aggravated by initiation of plaque rupture and formation of intra plaque haemorrhages inside these atherosclerotic lesions. Toluidine staining of slides of the aortic root of Wt-tp and caspase- $1 / 11^{-/-}$-tp mice was performed to assess the presence of intra plaque haemorrhages. No intra plaque haemorrhages were identified in either Wt-tp or caspase-1/11 $1^{--}$-tp mice (data not shown). In addition, May-Grünwald Giemsa staining was performed to assess the proportion of platelets inside the plaque. In line with previous data, staining revealed that no platelets were present in plaques of Wt-tp and caspase- $1 / 11^{-/}$-tp mice (data not shown). To determine whether platelet activation occurred in the atherosclerotic lesion, we performed gene expression analysis for platelet activation markers in the aortic arch the Wt-tp and caspase- $1 / 11^{-/}$-tp mice. The results showed no significant differences in the expression of $\mathrm{C}-\mathrm{C}$ chemokine receptor type 2 ( $\mathrm{Ccr} 2), \mathrm{C}-\mathrm{C}$ chemokine receptor type 5 ( $\mathrm{C}$ Cr5) and $\mathrm{C}-\mathrm{X}-\mathrm{C}$ chemokine receptor type 4 ( $\mathrm{CxCr} 4), \mathrm{C}-\mathrm{C}$ chemokine

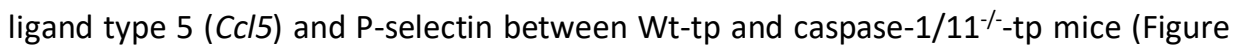
$7 A-E)$. While we cannot exclude the potential involvement of platelet activation, these data suggest that platelet activation is not a major mechanism associated with plaque development in these mice.

A

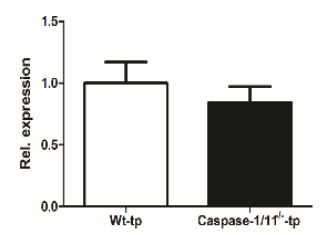

D

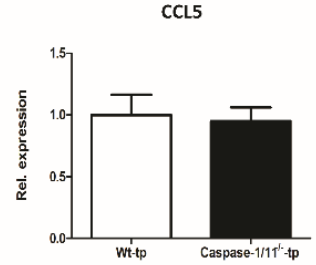

B

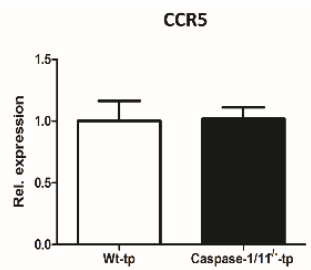

$\mathbf{E}$

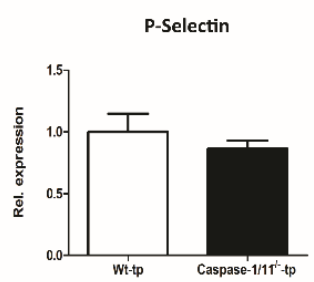

C

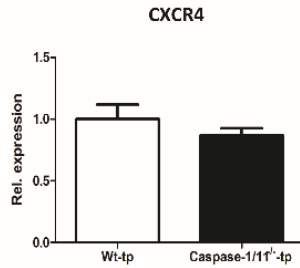

Figure 7: Gene expression analysis for platelet activation markers. Expression of genes encoding $\mathrm{Ccr} 2$ (A), Ccr5 (B), Cxcr4 (C), Cc/5 (D) and P-selectin (E) in the aortic arch of Wt-tp and caspase-1/11 -tp mice after 12 weeks of HFD. Values are means \pm SEM, and are relative to values in Wt-tp mice. 


\section{Discussion}

Atherosclerosis is one of the major risk factors for developing the clinical complications of cardiovascular disease. Our aim was to investigate the role of hematopoietic caspase-1/11 activation during atherosclerosis development. We hypothesized that hematopoietic caspase-1/11 deficiency is protective against vascular inflammation, leading to reduced atherosclerosis. Here, we show that hematopoietic caspase-1/11 deficiency leads to a substantial reduction in atherosclerotic plaque size and necrotic core formation. Our data indicate that hematopoietic caspase-1/11 activation plays an important role in vascular inflammation and atherosclerosis.

Previously, inflammasomes were shown to contribute to the development of atherosclerosis, potentially via activation by cholesterol crystals $(6,21)$. Interestingly, cholesterol crystals were found to be present in atherosclerotic lesions, and were shown to induce inflammasome activation in human macrophages (21). More recently, it was found that the scavenger receptor CD36 coordinates ligands towards inflammasome activation, providing a potential mechanism for the role of inflammasomes in atherosclerosis (22). The role of caspase-1 during atherosclerosis development has been described previously $(9,10,23)$. Using ApoE ${ }^{-/}$caspase- $1^{-/}$double knockout mouse models, it was shown that caspase-1 plays a critical role in vascular inflammation, and promotes atherosclerosis by enhancing inflammation in the lesion as reduced numbers of macrophages and vascular smooth muscle cells were found in the plaques compared with $\mathrm{ApoE}^{-/-}$mice $(10,23)$. Furthermore, ApoE ${ }^{-/}$caspase $-1^{-/}$ mice had significantly reduced plaque areas compared with controls, and lower plasma levels of inflammatory cytokines i.e. IL-1 $\beta$, CCL2 and TNF $\alpha$ (10). Despite these observations, one study claimed that atherosclerosis progresses independently of the inflammasome (23). A possible explanation for the differences in the findings may be the different mouse models used to study atherosclerosis. Although both models are known to efficiently develop atherosclerotic lesions, ApoE ${ }^{-/-}$mice are generally more hypercholesterolemic and spontaneously develop atherosclerosis, whereas $\mathrm{Ldll}^{-/-}$mice do not (16). However, the specific role of caspase-1/11 in hematopoietic cells was not described in these studies. In the present study, we show that hematopoietic deletion of caspase-1/11 reduces atherosclerosis development, indicating that macrophagespecific inflammasome activation plays an important role in cardiovascular disease. In addition, we observed a significant change in the monocyte subsets in circulation. Ly $6 \mathrm{C}^{\text {high }}$ monocytes are known to be inflammatory, and migrate to injured or infected sites $(24,25)$. On the other hand, Ly6C low monocytes patrol the resting vasculature and participate in resolution of inflammation (26). As Ly6C ${ }^{\text {high }}$ monocytes differentiate into cells that resemble $\mathrm{M} 1$ macrophages (pro-inflammatory), and cells derived from Ly6Clow monocytes exhibit $\mathrm{M}_{2}$ characteristics (anti-inflammatory), this may lead to a different macrophage phenotype within the plaque $(26,27)$. The mechanism by which caspase-1/11 affects the circulatory monocyte subsets is currently not understood. 
Potential mechanisms include altered conversion of inflammatory monocytes, increased survival of resident monocytes, or differences in monocyte trafficking. We showed that protein levels of CCL2 were significantly reduced in caspase-1/11/ -tp mice compared with Wt-tp mice. CCL2 is a key chemokine that regulates migration and infiltration of monocytes/macrophages. Further, CCL2 was shown to be involved in atherosclerosis by regulating migration of monocytes from the bloodstream across the vascular endothelium (28). In addition, it was shown that the higher the expression of either CCL2 or its receptor CCR2, the higher the likelihood of developing atherosclerosis in genetically modified animals (29). Follow-up studies are required to further investigate the mechanisms by which caspase-1/11 modulates monocyte subsets in the circulation, as our data suggest that atherosclerosis development may be diminished by such modulation towards anti-inflammatory monocytes.

Although apoptosis is well documented in atherosclerosis, recent studies showed that pyroptosis also plays an important role in atherosclerosis and plaque stability $(30,31)$. Pyroptosis is a caspase-1-dependent apoptotic process characterized by the presence of inflammatory cytokines. In the present study, no change in caspase-1 activity was observed in caspase- $1 / 11^{-/}$-tp mice compared with Wt-tp mice. These data suggest that cell death occurred mainly via apoptosis and not via pyroptosis. Recent studies have shown that the chemokine CCL2 plays a major role in apoptotic processes in various diseases (32-34). In vitro, it was shown that CCL2-primed macrophages are cytotoxic and enhance pro-apoptotic capacity (32). These data are in line with our observation that CCL2 is reduced in the plasma of caspase- $1 / 11^{-1-}$-tp mice, and suggest that apoptotic cell death in atherosclerotic plaques of these mice is CCL2-dependent. In conclusion, we have shown that hematopoietic caspase-1/11 contributes to atherosclerosis development. The mice used lacked caspase-11 in addition to caspase1. Whereas caspase-1 is a key player in canonical inflammasome activation, caspase11 has been found to be important in non-canonical inflammasome activation. The non-canonical caspase-11 inflammasome may interact with caspase- 1 via the caspase recruitment domains (8). Further, caspase-11, but not caspase-1, is a major sensor of lipopolysaccharides, and is mainly involved in inflammation driven by Gram-negative bacteria (7). In addition, inflammasomes have been shown to control sterile low-grade inflammation independently of non-canonical caspase-11 activation (35). As inflammasome activation by cholesterol crystals during atherosclerosis was shown to be caspase-1-dependent (21), it is most likely that caspase-11 plays a minor role in this process. Therefore, caspase- 1 may be a promising target for the improvement of future therapy options. 


\section{References}

1. Libby, P. (2012) Inflammation in atherosclerosis, Arterioscler Thromb Vasc Biol. 32, 2045-51.

2. Freigang, S., Ampenberger, F., Spohn, G., Heer, S., Shamshiev, A. T., Kisielow, J., Hersberger, M., Yamamoto, M., Bachmann, M. F. \& Kopf, M. (2011) Nrf2 is essential for cholesterol crystalinduced inflammasome activation and exacerbation of atherosclerosis, Eur J Immunol. 41, 2040 51.

3. Hansson, G. K. \& Hermansson, A. (2011) The immune system in atherosclerosis, Nat Immunol. 12, 204-12.

4. Masters, S. L., Latz, E. \& O'Neill, L. A. (2011) The inflammasome in atherosclerosis and type 2 diabetes, Sci Transl Med. 3, 81ps17.

5. Jiang, Y., Wang, M., Huang, K., Zhang, Z., Shao, N., Zhang, Y., Wang, W. \& Wang, S. (2012) Oxidized low-density lipoprotein induces secretion of interleukin-1beta by macrophages via reactive oxygen species-dependent NLRP3 inflammasome activation, Biochem Biophys Res Commun. 425, 121-6.

6. Duewell, P., Kono, H., Rayner, K. J., Sirois, C. M., Vladimer, G., Bauernfeind, F. G., Abela, G. S., Franchi, L., Nunez, G., Schnurr, M., Espevik, T., Lien, E., Fitzgerald, K. A., Rock, K. L., Moore, K. J., Wright, S. D., Hornung, V. \& Latz, E. (2010) NLRP3 inflammasomes are required for atherogenesis and activated by cholesterol crystals, Nature. 464, 1357-61.

7. Kayagaki, N., Warming, S., Lamkanfi, M., Vande Walle, L., Louie, S., Dong, J., Newton, K., Qu, Y., Liu, J., Heldens, S., Zhang, J., Lee, W. P., Roose-Girma, M. \& Dixit, V. M. (2011) Non-canonical inflammasome activation targets caspase-11, Nature. 479, 117-21.

8. Wang, S., Miura, M., Jung, Y. K., Zhu, H., Li, E. \& Yuan, J. (1998) Murine caspase-11, an ICEinteracting protease, is essential for the activation of ICE, Cell. 92, 501-9.

9. Gage, J., Hasu, M., Thabet, M. \& Whitman, S. C. (2012) Caspase-1 deficiency decreases atherosclerosis in apolipoprotein E-null mice, Can J Cardiol. 28, 222-9.

10. Usui, F., Shirasuna, K., Kimura, H., Tatsumi, K., Kawashima, A., Karasawa, T., Hida, S., Sagara, J., Taniguchi, S. \& Takahashi, M. (2012) Critical role of caspase-1 in vascular inflammation and development of atherosclerosis in Western diet-fed apolipoprotein E-deficient mice, Biochem Biophys Res Commun. 425, 162-8.

11. Bieghs, V., Wouters, K., van Gorp, P. J., Gijbels, M. J., de Winther, M. P., Binder, C. J., Lutjohann, D., Febbraio, M., Moore, K. J., van Bilsen, M., Hofker, M. H. \& Shiri-Sverdlov, R. (2010) Role of scavenger receptor $\mathrm{A}$ and $\mathrm{CD} 36$ in diet-induced nonalcoholic steatohepatitis in hyperlipidemic mice, Gastroenterology. 138, 2477-86, 2486 e1-3.

12. Bieghs, V., Hendrikx, T., van Gorp, P. J., Verheyen, F., Guichot, Y. D., Walenbergh, S. M., Jeurissen, M. L., Gijbels, M., Rensen, S. S., Bast, A., Plat, J., Kalhan, S. C., Koek, G. H., Leitersdorf, E., Hofker, M. H., Lutjohann, D. \& Shiri-Sverdlov, R. (2013) The cholesterol derivative 27hydroxycholesterol reduces steatohepatitis in mice, Gastroenterology. 144, 167-178 e1.

13. Bieghs, V., van Gorp, P. J., Walenbergh, S. M., Gijbels, M. J., Verheyen, F., Buurman, W. A., Briles, D. E., Hofker, M. H., Binder, C. J. \& Shiri-Sverdlov, R. (2012) Specific immunization strategies against oxidized low-density lipoprotein: a novel way to reduce nonalcoholic steatohepatitis in mice, Hepatology. 56, 894-903.

14. Bieghs, V., Verheyen, F., van Gorp, P. J., Hendrikx, T., Wouters, K., Lutjohann, D., Gijbels, M. J., Febbraio, M., Binder, C. J., Hofker, M. H. \& Shiri-Sverdlov, R. (2012) Internalization of modified lipids by CD36 and SR-A leads to hepatic inflammation and lysosomal cholesterol storage in Kupffer cells, PLoS One. 7, e34378.

15. Wisse, E., Braet, F., Duimel, H., Vreuls, C., Koek, G., Olde Damink, S. W., van den Broek, M. A., De Geest, B., Dejong, C. H., Tateno, C. \& Frederik, P. (2010) Fixation methods for electron microscopy of human and other liver, World J Gastroenterol. 16, 2851-66. 
16. Kanters, E., Pasparakis, M., Gijbels, M. J., Vergouwe, M. N., Partouns-Hendriks, I., Fijneman, R. J., Clausen, B. E., Forster, I., Kockx, M. M., Rajewsky, K., Kraal, G., Hofker, M. H. \& de Winther, M. P. (2003) Inhibition of NF-kappaB activation in macrophages increases atherosclerosis in LDL receptor-deficient mice, J Clin Invest. 112, 1176-85.

17. Donners, M. M., Wolfs, I. M., Stoger, L. J., van der Vorst, E. P., Pottgens, C. C., Heymans, S., Schroen, B., Gijbels, M. J. \& de Winther, M. P. (2012) Hematopoietic miR155 Deficiency Enhances Atherosclerosis and Decreases Plaque Stability in Hyperlipidemic Mice, PLoS One. 7, e35877.

18. Hendrikx, T., Bieghs, V., Walenbergh, S. M., van Gorp, P. J., Verheyen, F., Jeurissen, M. L., Steinbusch, M. M., Vaes, N., Binder, C. J., Koek, G. H., Stienstra, R., Netea, M. G., Hofker, M. H. \& Shiri-Sverdlov, R. (2013) Macrophage specific caspase-1/11 deficiency protects against cholesterol crystallization and hepatic inflammation in hyperlipidemic mice, PLoS One. 8, e78792.

19. Ma, Y., Wang, W., Zhang, J., Lu, Y., Wu, W., Yan, H. \& Wang, Y. (2012) Hyperlipidemia and atherosclerotic lesion development in Ldlr-deficient mice on a long-term high-fat diet, PLoS One. 7, e35835.

20. Paigen, B., Morrow, A., Holmes, P. A., Mitchell, D. \& Williams, R. A. (1987) Quantitative assessment of atherosclerotic lesions in mice, Atherosclerosis. 68, 231-40.

21. Rajamaki, K., Lappalainen, J., Oorni, K., Valimaki, E., Matikainen, S., Kovanen, P. T. \& Eklund, K. K. (2010) Cholesterol crystals activate the NLRP3 inflammasome in human macrophages: a novel link between cholesterol metabolism and inflammation, PLoS One. 5, e11765.

22. Sheedy, F. J., Grebe, A., Rayner, K. J., Kalantari, P., Ramkhelawon, B., Carpenter, S. B., Becker, C. E., Ediriweera, H. N., Mullick, A. E., Golenbock, D. T., Stuart, L. M., Latz, E., Fitzgerald, K. A. \& Moore, K. J. (2013) CD36 coordinates NLRP3 inflammasome activation by facilitating intracellular nucleation of soluble ligands into particulate ligands in sterile inflammation, Nat Immunol. 14, 812-20.

23. Menu, P., Pellegrin, M., Aubert, J. F., Bouzourene, K., Tardivel, A., Mazzolai, L. \& Tschopp, J. (2011) Atherosclerosis in ApoE-deficient mice progresses independently of the NLRP3 inflammasome, Cell Death Dis. 2, e137.

24. Swirski, F. K., Libby, P., Aikawa, E., Alcaide, P., Luscinskas, F. W., Weissleder, R. \& Pittet, M. J. (2007) Ly-6Chi monocytes dominate hypercholesterolemia-associated monocytosis and give rise to macrophages in atheromata, J Clin Invest. 117, 195-205.

25. Tacke, F., Alvarez, D., Kaplan, T. J., Jakubzick, C., Spanbroek, R., Llodra, J., Garin, A., Liu, J., Mack, M., van Rooijen, N., Lira, S. A., Habenicht, A. J. \& Randolph, G. J. (2007) Monocyte subsets differentially employ CCR2, CCR5, and CX3CR1 to accumulate within atherosclerotic plaques, J Clin Invest. 117, 185-94.

26. Nahrendorf, M., Swirski, F. K., Aikawa, E., Stangenberg, L., Wurdinger, T., Figueiredo, J. L., Libby, P., Weissleder, R. \& Pittet, M. J. (2007) The healing myocardium sequentially mobilizes two monocyte subsets with divergent and complementary functions, J Exp Med. 204, 3037-47.

27. Geissmann, F., Manz, M. G., Jung, S., Sieweke, M. H., Merad, M. \& Ley, K. (2010) Development of monocytes, macrophages, and dendritic cells, Science. 327, 656-61.

28. Deshmane, S. L., Kremlev, S., Amini, S. \& Sawaya, B. E. (2009) Monocyte chemoattractant protein-1 (MCP-1): an overview, Journal of interferon \& cytokine research: the official journal of the International Society for Interferon and Cytokine Research. 29, 313-26.

29. Coll, B., Alonso-Villaverde, C. \& Joven, J. (2007) Monocyte chemoattractant protein-1 and atherosclerosis: is there room for an additional biomarker?, Clinica chimica acta; international journal of clinical chemistry. 383, 21-9.

30. Chang, W., Lin, J., Dong, J. \& Li, D. (2013) Pyroptosis: an inflammatory cell death implicates in atherosclerosis, Med Hypotheses. 81, 484-6. 
31. Lin, J., Shou, X., Mao, X., Dong, J., Mohabeer, N., Kushwaha, K. K., Wang, L., Su, Y., Fang, H. \& Li, D. (2013) Oxidized low density lipoprotein induced caspase-1 mediated pyroptotic cell death in macrophages: implication in lesion instability?, PLoS One. 8, e62148.

32. Wang, Q., Ren, J., Morgan, S., Liu, Z., Dou, C. \& Liu, B. (2014) Monocyte chemoattractant protein1 (MCP-1) regulates macrophage cytotoxicity in abdominal aortic aneurysm, PLoS One. 9, e92053.

33. Yang, D., Elner, S. G., Chen, X., Field, M. G., Petty, H. R. \& Elner, V. M. (2011) MCP-1-activated monocytes induce apoptosis in human retinal pigment epithelium, Investigative ophthalmology \& visual science. 52, 6026-34.

34. Nam, B. Y., Paeng, J., Kim, S. H., Lee, S. H., Kim do, H., Kang, H. Y., Li, J. J., Kwak, S. J., Park, J. T., Yoo, T. H., Han, S. H., Kim, D. K. \& Kang, S. W. (2012) The MCP-1/CCR2 axis in podocytes is involved in apoptosis induced by diabetic conditions, Apoptosis: an international journal on programmed cell death. 17, 1-13.

35. Youm, Y. H., Grant, R. W., McCabe, L. R., Albarado, D. C., Nguyen, K. Y., Ravussin, A., Pistell, P., Newman, S., Carter, R., Laque, A., Munzberg, H., Rosen, C. J., Ingram, D. K., Salbaum, J. M. \& Dixit, V. D. (2013) Canonical Nlrp3 inflammasome links systemic low-grade inflammation to functional decline in aging, Cell metabolism. 18, 519-32. 



\section{Chapter 4}

Myeloid DLL4 does not contribute to the pathogenesis of Non-Alcoholic Steatohepatitis in

Ldll/' mice

M.L.J. Jeurissen, S.M.A. Walenbergh, T. Houben, T. Hendrikx, J. Li, Y. Oligschläger, P. J. van Gorp, M.J.J. Gijbels, A. Bitorina, I. Nessel, F.Radtke, M. Vooijs, J. Theys,

R. Shiri-Sverdlov

In press at PloSOne 


\section{Abstract}

Non-alcoholic steatohepatitis (NASH) is characterized by liver steatosis and inflammation. Currently, the underlying mechanisms leading to hepatic inflammation are not fully understood and consequently, therapeutic options are poor. Nonalcoholic steatohepatitis (NASH) and atherosclerosis share the same etiology whereby macrophages play a key role in disease progression. Macrophage function can be modulated via activation of receptor-ligand binding of Notch signaling. Relevantly, global inhibition of Notch ligand Delta-Like Ligand-4 (DLL4) attenuates atherosclerosis by altering the macrophage-mediated inflammatory response. However, the specific contribution of macrophage DLL4 to hepatic inflammation is currently unknown. We hypothesized that myeloid DLL4 deficiency in low-density lipoprotein receptor knockout $\left(L d / r^{\prime-}\right)$ mice reduces hepatic inflammation. Irradiated $L d / r^{-/}$mice were transplanted (tp) with bone marrow from wild type $(\mathrm{Wt})$ or $\mathrm{DLL}^{\mathrm{f} / \mathrm{f}} \mathrm{LysMCre}^{+/ 0}$ (DLL4 ${ }^{\text {del) }}$ mice and fed either chow or high fat, high cholesterol (HFC) diet for 11 weeks. Additionally, gene expression was assessed in bone marrow-derived macrophages

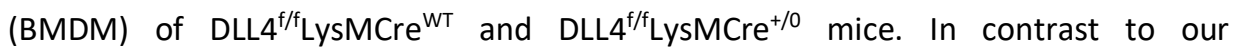

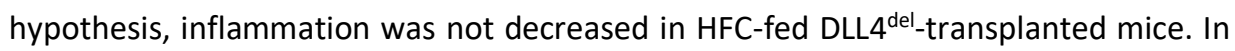
line, in vitro, there was no difference in the expression of inflammatory genes between DLL4-deficient and wildtype bone marrow-derived macrophages. These results suggest that myeloid DLL4 deficiency does not contribute to hepatic inflammation in vivo. Since, macrophage-DLL4 expression in our model was not completely suppressed, it can't be totally excluded that complete DLL4 deletion in macrophages might lead to different results. Nevertheless, the contribution of nonmyeloid Kupffer cells to notch signaling with regard to the pathogenesis of steatohepatitis is unknown and as such it is possible that, DLL4 on Kupffer cells promote the pathogenesis of steatohepatitis. 


\section{Introduction}

NASH is characterized by an increase in fat accumulation (steatosis) and inflammation in the liver. The prevalence of steatosis is estimated to be ranging from $84 \%$ to $96 \%$ whereas in this population the prevalence of NASH is ranging from $25 \%$ to $55 \%$ (1). Although steatosis is a rather benign and reversible condition, the presence of inflammation is the key feature of $\mathrm{NASH}$, which can lead to further disease progression and eventually lead to liver cirrhosis $(2,3)$. The exact mechanisms leading to hepatic inflammation are unknown and more insights are needed in order to discover novel therapeutic strategies. Current research recognizes the critical role of Notch signaling in the context of immune cells (4). Notch signaling occurs upon interaction of Notch receptors (e.g. Notch-1, $-2,-3$ or -4 ) on signal receiving cells and their membrane ligands (e.g. Jagged-1 (J1), Jagged-2 (J2), Delta-Like Ligand-1 (DLL1), Delta-Like Ligand-3 (DLL3) or Delta-Like Ligand-4 (DLL4)) on signal sending cells. Notch signaling has been implicated in the innate and adaptive immunity, which play an important role in various metabolic disorders (4-7). An increasing amount of evidence point towards the existence of a shared inflammatory etiology between NASH and atherosclerosis with a central role for macrophages (8). Fukuda et al. showed that global inhibition of DLL4 ameliorates atherosclerosis by altering macrophage-induced inflammatory responses, suggesting the importance of DLL4 on macrophage-mediated vascular inflammation $(9,10)$. In NASH, Kupffer cells (KCs), the resident macrophages of the liver, play a central role in the initiation of hepatic inflammation and disease progression $(8,11,12)$. Relevantly, it was shown that Notch downstream targets are positively correlated with steatosis and inflammation in a cohort of non-alcoholic fatty liver disease (NAFLD) patients (13). Furthermore, hepatic Notch activation lead to lipogenic gene expression and steatosis in chow fed mice whereas (DLL4)-Notch signaling promotes a fatty liver $(9,10,14)$. So far, the exact contribution DLL4-Notch in macrophages has not been investigated in the context of NASH. We hypothesized that myeloid DLL4 deficiency in low-density lipoprotein receptor knock-out ( $\left(\mathrm{dll}^{-/}\right)$mice reduces hepatic inflammation. To test this hypothesis, bone marrow of wild-type (Wt) or myeloid DLL4-deficient (DLL4 ${ }^{\text {del) }}$ ) mice was transplanted (-tp) into lethally irradiated $L d l r^{-1}$ recipient mice and were fed chow or HFC for 11 weeks after a recovery period of 9 weeks. In contrast to our expectations, myeloid deletion of DLL4 did not reduce hepatic inflammation. These results suggest that myeloid DLL4 deficiency does not contribute to hepatic inflammation in vivo. Since, macrophage-DLL4 expression in our model was not completely suppressed, it can't be totally excluded that complete DLL4 deletion in macrophages might lead to different results. Nevertheless, the contribution of non-myeloid Kupffer cells to notch signaling with regard to the 
pathogenesis of steatohepatitis is unknown and as such it is possible that, DLL4 on Kupffer cells promote the pathogenesis of steatohepatitis.

\section{Materials and Methods}

\section{Mice, bone marrow transplantation and diet}

All animals were housed under standard conditions and had access to food and water ad libitum. The animal experiments were approved by the committee for Animal Welfare of Maastricht University and were performed according to Dutch regulations. The DLL4 ${ }^{\text {flox/flox }}$ mice were kindly donated by Prof. Freddy Radtke (15), and crossbred with LysMCre mice (16) to generate the myeloid DLL4 specific knock-out mice. Ld/rmice were obtained from in-house breeding. To generate the myeloid DLL4 deficient $\mathrm{Ldlr}^{-/}$mice, bone marrow transplantation was performed. $L d / r^{-/}$mice received one week before and four weeks after irradiation antibiotic water containing $100 \mathrm{mg} / \mathrm{l}$ neomycin (Gibco, Breda, the Netherlands) and 6*104 U/I polymycin B Sulphate (Gibco, Breda, the Netherlands). One day before and on the day of the transplantation $\mathrm{Ldlr}^{-1}$ mice were lethally irradiated with 6 Gray of $\gamma$-radiation, thus receiving 12 Gray in total. Lethally irradiated $L d l r^{-}$mice were then injected with $1^{*} 107$ bone marrow cells donated from DLL4 ${ }^{f / f}$ LysMCre ${ }^{W T}(W t)$ or DLL4 ${ }^{f / f} L_{\text {sMMCre }}^{+/ 0}$ (DLL4 ${ }^{\text {del }}$ ) mice. In order the fully ensure bone marrow replacement mice had a nine weeks recovery period. After nine weeks of recovery, transplanted (-tp) mice received either a chow (Wt-tp: $n=12$, DLL4del-tp: $n=12$ ) or HFC (Wt-tp: $n=20$, DLL4del-tp: $n=20$ ) diet, containing $21 \%$ butter and $0.2 \%$ cholesterol (diet 1635; Scientific Animal Food and Engineering, Villemoissonsur-Orge, France) for 11 weeks. Blood was collected form the tail vein at the end of the experiment and mice were sacrificed afterwards. Liver tissue was harvested and snap-frozen in liquid nitrogen or fixed in $4 \%$ formaldehyde/PBS.

\section{Bone marrow efficiency}

In order to determine of the chimerism in the transplanted mice, we used donor bone marrow which has an LdlrWT origin, whereas recipient bone marrow an Ldlr/- origin. Genomic DNA was isolated using the PureLink ${ }^{\circledR}$ Genomic DNA (K182002; ThermoFisher Scientific). A standard curve was generated by mixing DNA from $\mathrm{Ldll}^{-1}$ and $L d l r^{W T}$ bone marrow cells at different ratios. Chimerism was determined by quantifying the amount of $L d l r^{-1}$ DNA in samples from $70 \mu \mathrm{L}$ peripheral blood. To standardize for the amount of input DNA, the non-relevant p50 gene was quantified. Samples were assayed in duplicate on a $7900 \mathrm{HT}$ real-time PCR system by using $25 \mathrm{ng}$ DNA, SensiMix ${ }^{\text {TM }}$ Sybr \& Fluorescein kit (QT615-05, Bioline), according to the manufacturer's instructions. 
Ldlr $^{-1}$ specific primers are forward 5'-GCTGCAACTCATCCATATGCA-3' and reverse 5'GGAGTTGTTGACCTCGACTCTAGAG-3. Forward and reverse p50-specific primers are 5'ACCTGGGAATACTTCATGTGACTAA-3' and 5'ACACCAGAAGTCCAGGATTATAGC-3', respectively. A standard curve was generated by plotting the mean threshold cycle (Ct) $\Delta \mathrm{Ct}$ ( Ct p50 - Ct Ldlr ${ }^{-/}$) against the logarithm of the percentage $\mathrm{Ldll}^{-/}$and calculation of a regression line. Chimerism was calculated from the percentage of Ldlr / DNA in the blood samples (representing the remaining recipient bone marrow), determined by applying the mean $\Delta \mathrm{Ct}$ of the sample to the standard curve. Efficiency of the bone marrow transplantation in both groups was approximately 99\% (data not shown).

\section{Plasma/Liver Lipid measurements}

Plasma cholesterol and triglycerides were measured via enzymatic colorimetric assay according to the manufacturer protocol (Cholesterol Liquicolor CHOD_PAD; Human \#10028, Instruchemie, Delfzijl) (Sigma Triglyceride (GPO Trinder) kit (Sigma Tr0100)). Absorbance was measured with the BioRad Benchmark Plate Reader (170-6750XTU; Bio-Rad, Hercules, CA). To measure liver cholesterol and triglycerides, liver homogenates were made. About 40-50 mg of frozen liver tissue was homogenized in 1 $\mathrm{ml} \mathrm{SET} \mathrm{buffer} \mathrm{(250} \mathrm{mM} \mathrm{Sucrose,} 2$ mM EDTA, 10 mMTris) with $1 \mathrm{~mm}$ glass beads (art. 11079110) on the max setting of the Biospec Mini Bead Beater-1. Afterwards, samples underwent two freeze-thaw cycles for complete cell destruction. To optimize cell destruction, samples were taken through a $25 \mathrm{G} \times 5 / 8$ " needle several times and a final thaw cycle was added. Total protein content was measured via bicinchoninic acid (BCA) assay (23225; Pierce, Rockford, IL). Liver cholesterol and triglycerides were measured via enzymatic colorimetric assay (Cholesterol Liquicolor CHOD_PAD; Human \#10028, Instruchemie, Delfzijl) (Triglyceride Liquicolor CHOD_PAD; Human \#10724, Instruchemie, Delfzijl)

\section{Liver histology}

Livers of Wt-tp and DLL4del-tp mice were embedded in paraffin and sections of $4 \mu \mathrm{m}$ thick were cut. H\&E staining was performed according to the manufacturer's protocol. Slides were scored for steatosis and liver cell injury (e.g. necrosis, inflammation, bile duct formation) by an experienced mouse pathologist (MJJG). For immunohistological stainings, frozen mouse liver tissue was cryo-embedded in Tissue-Tek ${ }^{\circledR}$ (Sakura Finetek Europe B.V., Alphen aan den Rijn, The Netherlands) and sections of $7 \mu \mathrm{m}$ thick were cut. For immunohistological stainings, cryosections of the liver were dried and fixated in dry acetone for $15 \mathrm{~min}$. To block endogenous peroxidase activity, sections were incubated with $3 \% \mathrm{H}_{2} \mathrm{O}_{2}$ solution for about $5 \mathrm{~min}$. Tissue sections were also 
treated with Avidin/Biotin solution (Vector; SP2001) for 30 min. Afterwards, sections were incubated for 1 hour at room temperature (RT) with primary antibody for infiltrated macrophages (MAC-1; MAB1124; clone M1/70; 1:500) or Neutrophils (NIMP-1; rat anti-mouse Ly6-C, supernatant; clone: NIMP-R14, 1:100). Subsequently, tissue sections were incubated with secondary antibody (Rabbit anti-Rat IgG Biotin (6180-08), SouthernBiotech, Birmingham, AL, USA) for 1 hour at RT. To amplify the signal, sections were incubated for $30 \mathrm{~min}$ in Peroxidase Vectastain Elite $A B C$ solution (Vector Laboratories, PK-6100, Peterborough, United Kingdom). For detection of the secondary antibody, the Peroxidase Substrate kit AEC (Vector Laboratories, SK-4200, Peterborough, United Kingdom) was used. Slides were counterstained with heamatoxylin. Pictures were taken with a Nikon digital camera DMX1200 and ACT-1 v2.63 software (Nikon Instruments Europe, Amstelveen, The Netherlands). Immune cells were counted in 6 microscopical views (original magnification, 200x) and were noted as cells/square millimeter.

\section{Kupffer cell isolation}

Whole liver $(n=4)$ of each experimental group were digested individually in digestion buffer $\left(33.9 \mu \mathrm{g} / \mathrm{ml}\right.$ Liberase TM, $0.002 \%$ DNasel) for $20 \mathrm{~min}$ at $37^{\circ} \mathrm{C}$. The digested liver solution was further disrupted by pushing it through a $100 \mu \mathrm{m}$ cell strainer using wash buffer (PBS, 1\% FCS and 2.5 mM EDTA). Cells were then centrifuged at $1500 \mathrm{rpm}$ for $10 \mathrm{~min}$ at $4^{\circ} \mathrm{C}$. Pellet was resuspended in wash buffer, removal of hepatocytes was accomplished by one low-spin centrifugation step at $300 \mathrm{rpm}$ for $3 \mathrm{~min}$. Supernatant, which was lysed from red blood cells, was collected and centrifuged. Next, Kupffer cells were isolated from the supernatant by using magnetic beads coated with a macrophage-specific monoclonal antibody (F4/80-APC, $1 \mu \mathrm{l} / 80 \times 10^{6}$ cells) (Biolegend) and incubated for $20 \mathrm{~min}$ at $4^{\circ} \mathrm{C}$. Afterwards, cells were washed and incubated with anti-APC microbeads ( $200 \mu \mathrm{l} / 100 \times 10^{6}$ cells) (Militenyi Biotec, Auburn, CA) for 20 min at $4^{\circ} \mathrm{C}$ in the dark. After washing, samples were run into $L S$ columns, put on a Quadro MACS magnet (Militenyi Biotec, Auburn, CA) and rinsed with wash buffer. Positively selected cells were flushed using wash buffer and collected for further analysis. 


\section{RNA isolation and quantitative polymerase chain reaction}

Total RNA was isolated from frozen mouse liver and Kupffer cells as described previously $(17,18)$. To isolate total RNA from BMDM, FavorPrep ${ }^{\text {TM }}$ Blood/Culture cell total RNA purification mini kit (FABRK001, Favorgen, Vienna, Switzerland) was used. First-strand complementary DNA (cDNA) was made from 500 ng total RNA of each mouse according to the manufacturer's protocol (iScript ${ }^{\mathrm{TM}}$ cDNA Synthesis Kit (1708891), Bio-Rad, Veenendaal, The Netherlands). As for total RNA of isolated Kupffer cells, approximately $50 \mathrm{ng}$ of total RNA was used. Relative quantitative gene expressions of inflammatory markers were measured by quantitative PCR on an SDS 7900HT by using SensiMix SYBR HIROX (Cat No QT605-05 Bioline, London, United Kingdom) and $10 \mathrm{ng}$ of cDNA template. For normalization, the geometric mean of two references genes were used (Cyclophillin A and ribosomal protein S12). Primers sets were developed with Primer Express version 2.0 (Applied Biosystems) using default settings. The primer sequences can be found in Table 1. Data from qPCR were analyzed with the LinRegPCR, Analysis of RT PCR data, Version 2015.3 (19-21).

Table 1: Primer sequences

Gene Primer forward $\quad$ Primer reverse

\begin{tabular}{|c|c|c|}
\hline Cyclophillin A & TTCСТССТTTCACAGAATTATTCCA & CCGCCAGTGCCATTATGG \\
\hline S12 & GGAAGGCATAGCTGCTGGAGGTGT & CCTTCGATGACATCCTTGGCCTGA \\
\hline$A b c a 1$ & CCCAGAGCAAAAAGCGACTC & GGTCATCATCACTTTGGTCCTTG \\
\hline$A b c g 1$ & TCGGACGCTGTGCGTTTT & CCCACAAATGTCGCAACCT \\
\hline$C d 36$ & GCCAAGCTATTGCGACATGA & AAAAGAATCTCAATGTCCGAGACTTT \\
\hline$L X R \alpha$ & CAACAGTGTAACAGGCGCT & TGCAATGGGCCAAGGC \\
\hline Notch-1 & AGGACCTCATCAACTCACACGC & TCTTTGTTAGCCCCGTTCTTCAG \\
\hline Notch-2 & CCGTGTTGACTTCTGCTCTCTCAC & ССTACTACCCTTGGCATCCTTTG \\
\hline Notch-3 & TCTCAGACTGGTCCGAATCCAC & ACACTTGCCTCTTGGGGGTAAC \\
\hline Notch-4 & ATGCGAGGAAGATACGGAGTGG & TCGGAATGTTGGAGGCAGAAC \\
\hline DII1 & СTACTACGGAGAGGGCTGCT & CCAGGGTTGCACACTTTCTC \\
\hline DII4 & ACAACTTGTCGGACTTCCAG & CAGCTCCTTCTTCTGGTTTG \\
\hline Jagged-1 & ATCGTGCTGCCTTTCAGTTT & ACTGTCAGGTTGAACGGTGTC \\
\hline
\end{tabular}




$\begin{array}{lcc}\text { Jagged-2 } & \text { GTCGTCATCCCCTTCCAGT } & \text { CTCCTCATTCGGGGTGGTAT } \\ \text { Hey1 } & \text { GAAACTTGAGTTCGGCTCTAGG } & \text { GCTTAGCAGATCCTTGCTCCAT } \\ \text { Hes } 1 & \text { AGGCGGACATTCTGGAAATG } & \text { CGGTACTTCCCCAGCACACTT } \\ \text { Tnf- } \boldsymbol{\alpha} & \text { CATCTTCTCAAAATTCGAGTGACAA } & \text { TGGGAGTAGACAAGGTACAACCC } \\ \text { Itgam } & \text { ACTTTCAGAAGATGAAGGAGTTTGTCT } & \text { TGTGATCTTGGGCTAGGGTTC } \\ \text { Icam } & \text { CTACCATCACCGTGTATTCGTTTC } & \text { CGGTGCTCCACCATCCA }\end{array}$

\section{Cell Culture}

Bone marrow was isolated from hind limbs of DLL4 ${ }^{\mathrm{f} / \mathrm{f}}$ LySMCre $^{\mathrm{WT}}(\mathrm{Wt} ; \mathrm{n}=3)$ and $\mathrm{DLL}^{\mathrm{f} / \mathrm{f}}$ LysMCre $^{+/ 0}$ (DLL4 ${ }^{\text {del }} ; \mathrm{n}=3$ ) mice. In short, the femur and tibiae were flushed with cold PBS. Bone marrow cells were cultured for 8 days in RPMI1640 cell culture medium (10\% Fetal Calf Serum (FCS) (Bodinco BV, Alkmaar, The Netherlands), 1\% penicillin/streptomycin, 1\% L-Glutamine, 20mM HEPES) (GIBCO by Life technologies, Bleiswijk, the Netherlands) supplemented with 20\% LCM (L929 cell conditioned medium which contains M-CSF) to differentiate into BMDM. All cells were cultured at $37^{\circ} \mathrm{C}$ in the presence of $5 \% \mathrm{CO} 2$ atmosphere. Cells were seeded in a 24-wells plate (Greiner, 662102, Alphen a/d Rijn) (350,000 cells/well) and stimulated for 4 hours with LPS $(100 \mathrm{ng} / \mathrm{ml})$. For experiments with immobilized DLL4, cells were coated overnight with recombinant DLL4 $(1 \mu \mathrm{g} / \mathrm{ml}$; R\&D Systems) and $0.2 \%$ gelatin in PBS at 4 ${ }^{\circ} \mathrm{C}$. Wells were rinsed once with PBS before plating Wt BMDM (350.000 cells/well) followed by $4 \mathrm{hrs}$ incubation at $37^{\circ} \mathrm{C}$. Tumor necrosis factor alpha (TNF $\alpha$ ) protein was measured via ELISA (88-7324-88; Affymetrix, eBioscience, Vienna, Austria) according to the manufacturer's protocol.

\section{Western Blot}

BMDM of Wt and DLL4 ${ }^{\text {del }}$ mice were lysed in RIPA buffer (50 mM Tris-HCL pH 7.5, 150 $\mathrm{mM} \mathrm{NaCl}, 0.5 \%$ Sodium deoxycholate, 1\% Triton X-100, 0.1\% SDS) supplemented with protease and phosphatase inhibitor mixture. For making liver homogenates, about 40 $50 \mathrm{mg}$ of frozen liver tissue was homogenized in $1 \mathrm{ml}$ RIPA About 40-50 mg of frozen liver tissue was homogenized in $1 \mathrm{ml} \mathrm{SET}$ buffer (250 mM Sucrose, $2 \mathrm{mM}$ EDTA, 10 mMTris) with $1 \mathrm{~mm}$ glass beads (art. 11079110) on the max setting of the Biospec Mini Bead Beater-1. To optimize cell destruction, samples were taken through a 25Gx5/8" needle several times and a final thaw cycle was added. Total protein content was measured via bicinchoninic acid (BCA) assay (23225; Pierce, Rockford, IL). For western blot analysis, equal amounts of protein $(30 \mu \mathrm{g})$ were loaded on the gel. 
After SDS/PAGE electrophoresis, protein was transferred on nitrocellulose membrane (Biorad). The membrane was blockade with $5 \%$ non-fat dry milk for $1 \mathrm{hr}$ at room temperature. Afterwards, the membrane was incubated overnight at $4^{\circ} \mathrm{C}$ with primary antibody against DLL4 (0.3 ug/ml, ab183532, Cambridge, United Kingdom) or $\beta$-actin (1:1000 dilution, Cell Signaling Technology, Danvers, MA, USA) which was us as a reference protein. Detection was performed according to its primary antibody using anti-goat (Santa Cruz) or anti-rabbit (Cell Signaling) horse-radish peroxidase (HRP)conjugated secondary antibodies, followed by chemiluminescence.

\section{Statistical analysis}

Significant differences between the experimental groups were analyzed with the twoway ANOVA followed by a Tukey post-hoc test using the IBM ${ }^{\circledR}$ SPSS Statistics program (Version 22.0.0.). In vitro results were analyzed for significant differences with the two-tailed unpaired t-test using GraphPad Prism (Version 5.03). Outliers were determined via the Grubbs' Test. Data were expressed as the mean \pm SEM and considered significant at $\mathrm{p}<0.05$. $* * *$ and $* * *$ indicate $\mathrm{p}<0.05,0.01$ and 0.001 resp. 


\section{Results}

\section{Myeloid DLL4 deficiency has no effect on plasma and liver lipid levels}

To investigate the effect of myeloid DLL4 deficiency on the health status of Wt-tp and

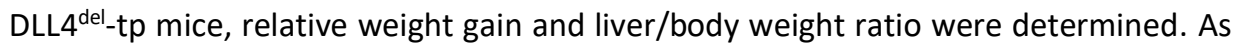
expected, upon HFC, both the relative weight gain and liver/body weight ratio were increased compared to chow. No differences were observed between Wt-tp and

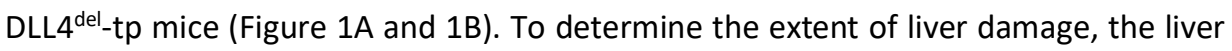
enzyme alanine aminotransferase (ALT) was measured. Upon HFC feeding, ALT levels

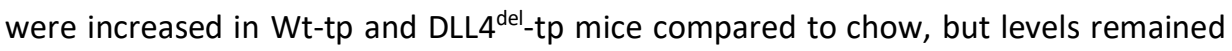
similar between both groups (Figure 1C).

A

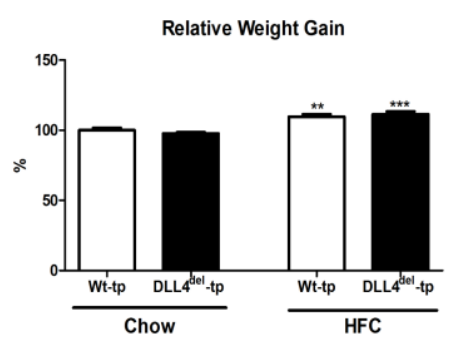

C

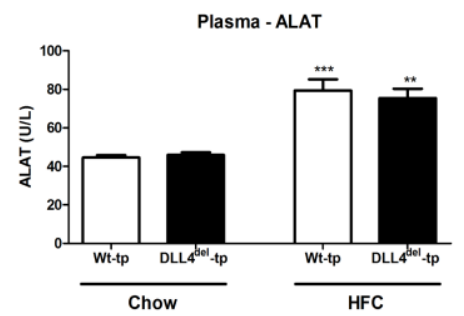

B

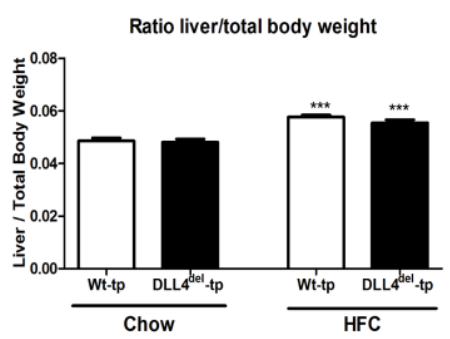

Figure 1: Body and liver weights of Wt-tp and DLL4del-tp mice. Relative weight gain was calculated from the body weights of Wt-tp and DLL4del-tp mice (A). Relative liver/total body ratio was measured from the liver and body weights of Wt-tp and DLL4del-tp mice (B). Plasma ALT levels

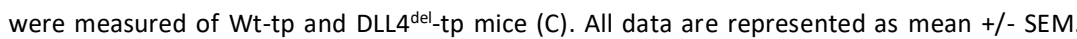
Data are significant at ${ }^{*} p<0.05,{ }^{* *} p<0.01,{ }^{* * *} p<0.001$. Significance is compared to the chow group of the respective genotype. 
Next, we investigated the effect of myeloid DLL4 on plasma and liver lipid levels. Upon HFC feeding, cholesterol and triglyceride levels were increased in Wt-tp and DLL4 ${ }^{\text {del }}$-tp mice. However, no significant differences were observed between both groups in both plasma and liver (Figure 2A-D). To further determine the effects of myeloid DLL4 deficiency on cholesterol metabolism, gene expression of ATP-binding cassette subfamily A member 1 (Abca1), ATP-binding cassette subfamily $\mathrm{G}$ member 1 (Abcg1), Liver $X$ receptor alpha $(L x r \alpha)$ and Cluster of Differentiation $36(C d 36)$ were analyzed in the livers of Wt-tp and DLL4 ${ }^{\text {del }}$-tp mice. Gene expression of Abca1 and Cd36 were significantly upregulated in the livers of Wt-tp and DLL4 ${ }^{\text {del-tp }}$ mice on an HFC diet compared to chow-fed mice. Similar hepatic mRNA levels were detected between Wt-

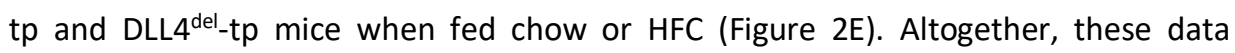
suggest that myeloid DLL4 signaling has no effect on lipid metabolism.

\section{Hepatic inflammation is not changed in myeloid DLL4-deficient mice.}

To investigate that DLL4 is knocked down specifically in myeloid cells, we first determined DLL4 expression in whole livers of Wt- and DLL4 ${ }^{\text {del-tp }}$ mice. We found that DI/4 expression both on mRNA and protein level in whole livers was similar between

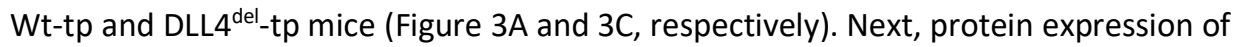
DLL4 was assessed in Wt and DLL4 ${ }^{\text {del }}$ BMDM. In line with our gene expression data regarding DLL4 in Kupffer cells (Figure 3D), DLL4 protein expression was reduced in DLL4 ${ }^{\text {del }}$ BMDM compared to Wt BMDM (Figure 3B). Altogether, these data indicate that DLL4 deficiency is selective for myeloid cells. To determine the effect on myeloid DLL4 deficiency on Notch signaling, the expression of Notch target genes was investigated in the livers of Wt-tp and DLL4 ${ }^{\text {del }}$-tp mice. Gene expression analysis of the downstream targets of DLL4, Hairy/enhance of split-1 (Hes1) and Hairy/enhancer-ofsplit related with YRPW motif protein 1 (Hey1), was analyzed. Upon HFC feeding, Hey 1 and Hes1 expression was increased in Wt-tp and DLL4 ${ }^{\text {del }}$-tp mice, indicative for increased Notch signaling activation. However, no changes in Hey1 and Hes1 were observed between both groups (Figure 3F-G). Additionally, Hes1 gene expression in KCs of Wt-tp and DLL4 ${ }^{\text {del }}$-tp mice on chow and HFC diet was determined. No differences were observed in Hes1 gene expression between KCs of Wt and DLL4 ${ }^{\text {del }}$-tp mice (Figure 3E). 
A

Cholesterol - Plasma

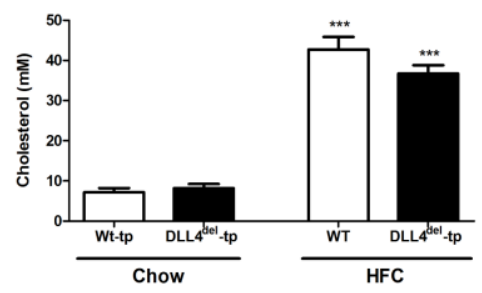

C

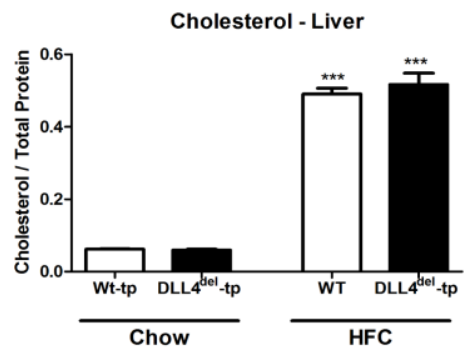

E

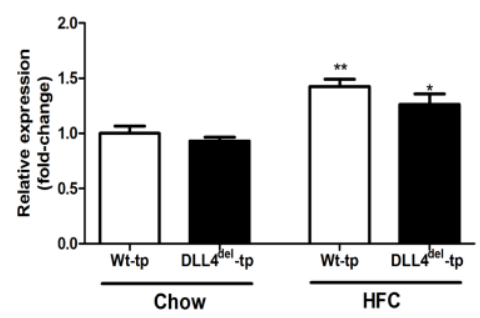

Liver mRNA - Cd36

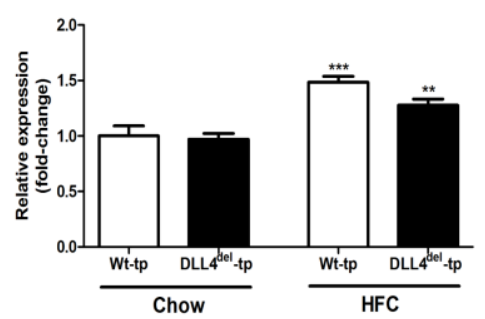

B

Triglycerides - Plasma

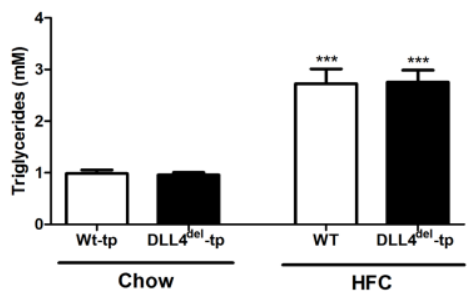

D

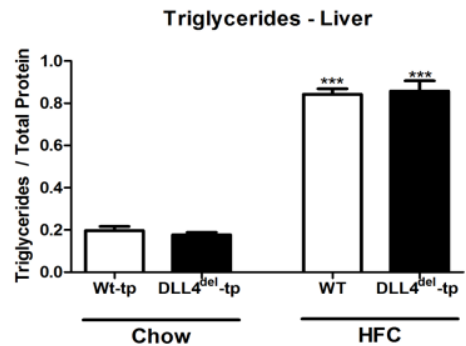

Liver mRNA - Abcg1

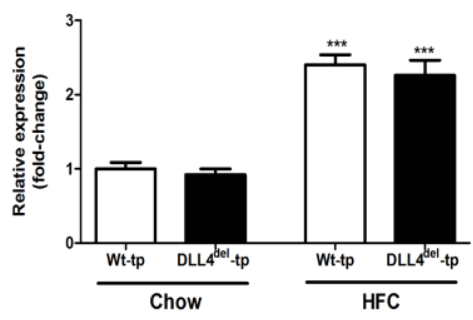

Liver mRNA - Lxr $\alpha$

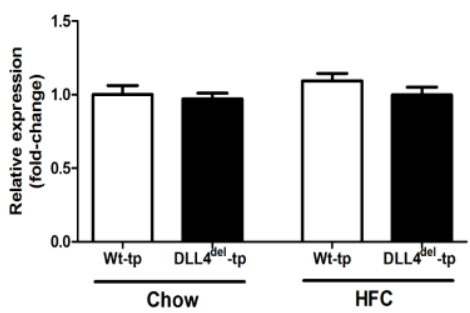

Figure 2: Lipid level measurements in Wt-tp and DLL4 ${ }^{\text {del }}$-tp mice. Cholesterol and triglyceride levels were measured in plasma (A-B) and in the liver (C-D) of Wt-tp and DLL4 ${ }^{\text {del-tp }}$ mice. E. Gene expression of $A b c a 1, A b c g 1, C d 36$ and Lxra were measured in the liver of Wt-tp and DLL4del-tp mice. All data are represented as mean $+/$ - SEM. Data are significant at $* p<0.05,{ }^{* *} p<0.01$, $* * * p<0.001$. Significance is compared to the chow group of the respective genotype. 
A

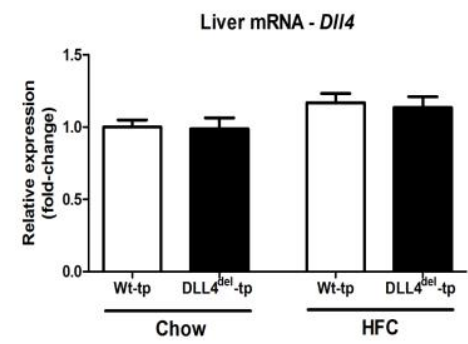

B

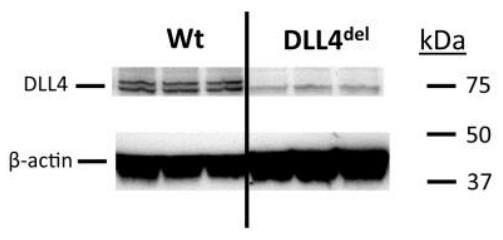

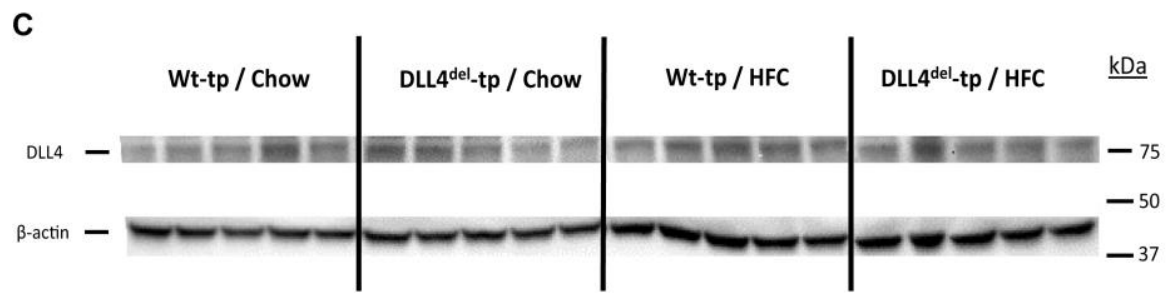

D

Kupffer Cells mRNA - DII4

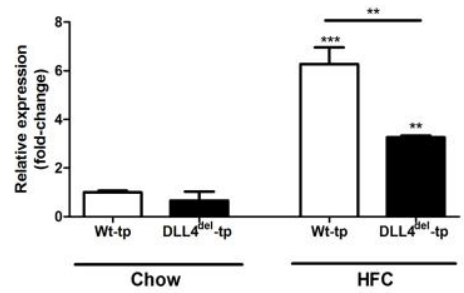

$\mathbf{F}$

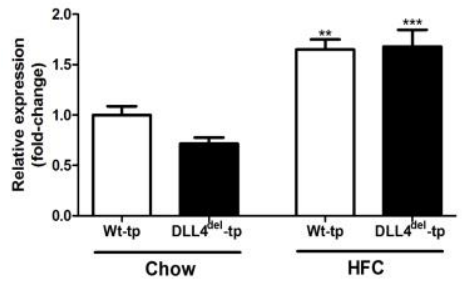

E

Kupffer Cells mRNA - Hes1

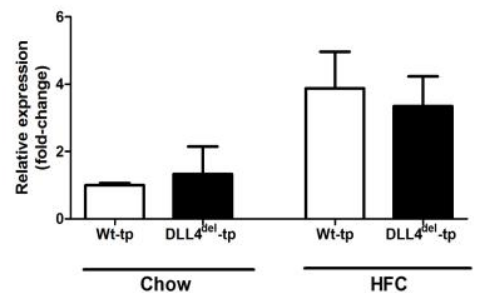

G Liver mRNA - Hes1

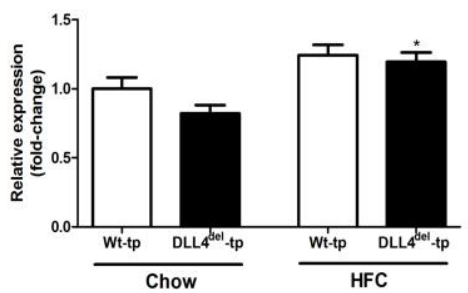

Figure 3: Hepatic gene and protein expression analysis of DLL4 and its downstream targets. Gene

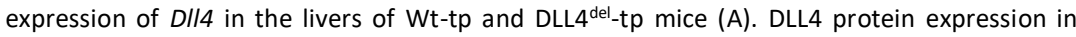
BMDM and livers of mice, respectively (B-C). Gene expression analysis of DII4 and Hes1 in

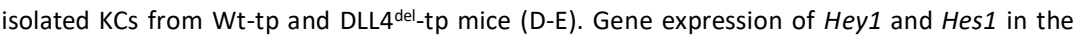
livers of Wt-tp and DLL4del-tp mice (F-G). All data are represented as mean +/- SEM. Data are significant at $* p<0.05, * * p<0.01, * * * p<0.001$. Significance is compared to the chow group of the respective genotype. 
Next, gene expression of Notch-receptors and ligands were measured in the livers of

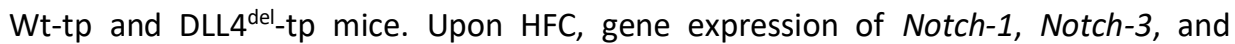
Jagged-1 was increased compared to chow-fed mice in both Wt-tp and DLL4 ${ }^{\text {del-tp }}$ mice, whereas DIl1 gene expression was reduced. However, no differences were

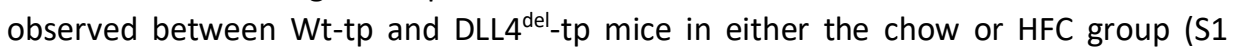
Figure). Similar findings were observed in BMDM of Wt and DLL4 ${ }^{\text {del }}$ mice; upon LPS stimulation, the expression of Notch-1, Notch-2 and DII1 was increased in both Wt and DLL4 ${ }^{\text {del }}$ BMDM, whereas Jagged-2 gene expression was reduced compared to nonstimulated conditions. No differences in Notch ligands and receptors were observed between Wt and DLL4 ${ }^{\text {del }}$ BMDM (S2 Figure). Altogether, these findings suggest that hematopoietic deletion of DLL4 is not associated with changes in the expression of other Notch receptors or ligands.

Next, to investigate whether myeloid DLL4 deficiency lowers hepatic inflammation, immunohistological stainings and gene expression analysis were performed on liver tissue of Wt-tp and DLL4 ${ }^{\text {del }}$-tp mice. First, we performed an H\&E staining on liver sections of Wt-tp and DLL4 ${ }^{\text {del }}$-tp mice. These sections were scored for steatosis and liver cell injury (e.g. necrosis, inflammation, bile duct formation) by an experienced mouse pathologist in a blinded manner. Histological analysis revealed that, upon an HFC diet, steatosis and liver cell injury was pronounced in both Wt-tp and DLL4 ${ }^{\text {del }}$-tp mice. These findings were also supported by ALAT plasma levels, which is a marker for liver injury (Figure 1C). In line with our previously obtained results, no differences were observed between the two genotypes (S3 Figure). These data further support the conclusion that myeloid DLL4 deficiency does not affect liver steatosis and hepatic inflammation. Additionally, liver sections were stained for infiltrated macrophages (MAC-1 staining) and neutrophils (NIMP staining). Upon HFC feeding, infiltrated macrophages were increased in Wt-tp and DLL4 ${ }^{\text {del }}$-tp mice compared to chow-fed mice. Similar effects were observed for neutrophils. However, no differences were observed between the two genotypes in the chow- and HFC-fed group for infiltrated macrophages and neutrophils (Figure 4A-C). Moreover, gene expression levels of Tnfa, Integrin Alpha M (Itgam) and Intercellular Adhesion Molecule 1 (Icam) were similar between Wt-tp and DLL4 ${ }^{\text {del }}$-tp mice (Figure 4D). To determine foam cell formation a CD68 staining was performed on livers of Wt-tp and DLL4 ${ }^{\text {del }}$-tp mice. There were no differences in foam cell formation between Wt-tp and DLL4 ${ }^{\text {del- }}$-tp HFC fed mice (data not shown). Overall, these results suggest that myeloid DLL4 deficiency does not lower hepatic inflammation. 


\section{MAC-1}

A
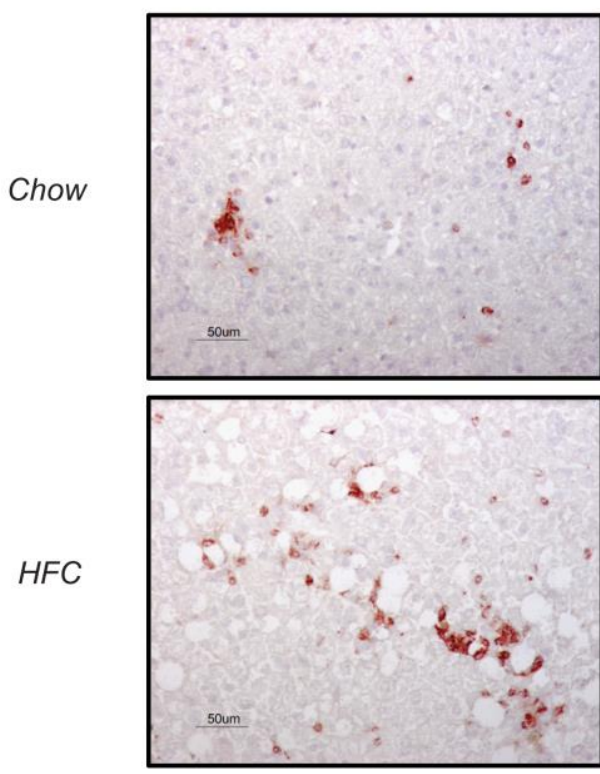

B

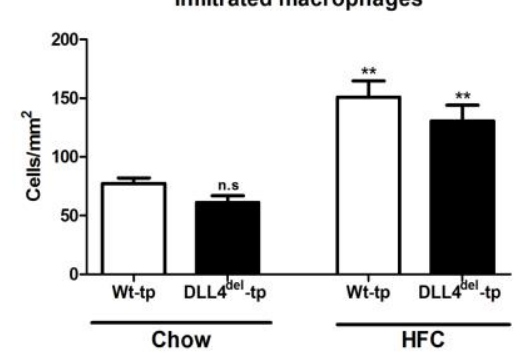

DLL4del-tp
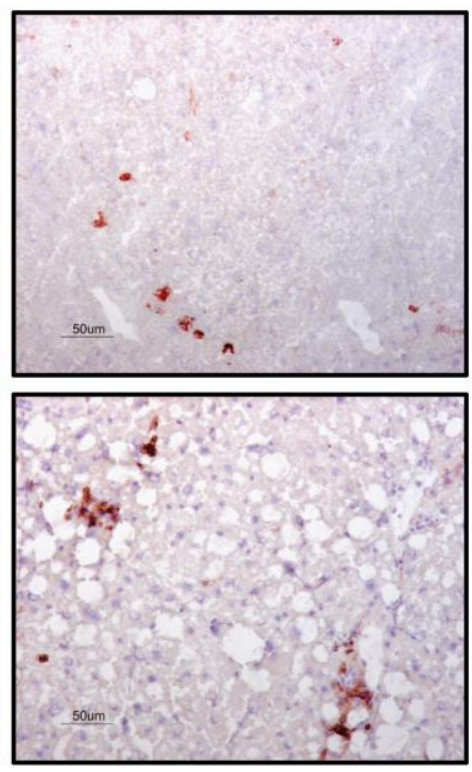

C

Neutrophils

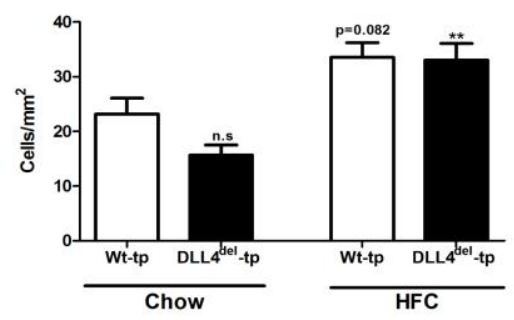

D
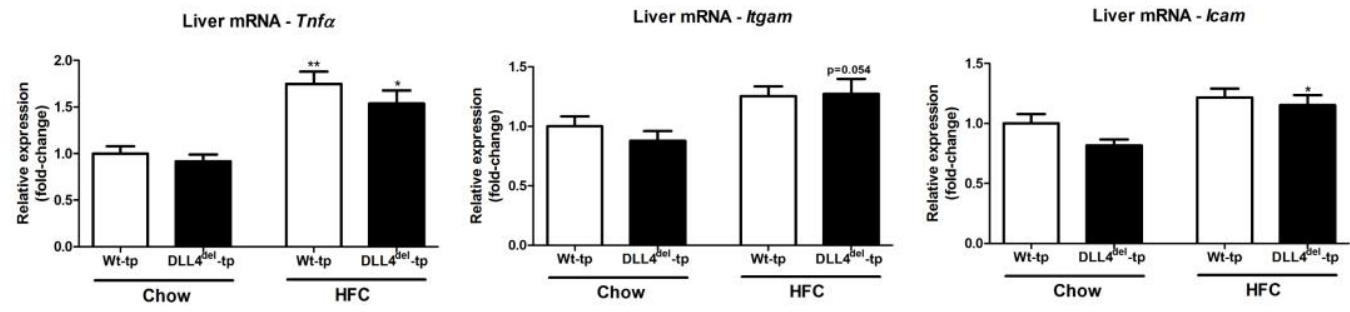
Figure 4: Hepatic inflammation in Wt-tp and DLL4 ${ }^{\text {del-tp }}$ mice. Representative pictures of the MAC-1 staining on the livers of Wt-tp and DLL4 ${ }^{\text {del-tp }}$ mice. Original magnification: 200x (A). Quantification of the MAC-1 and NIMP staining for infiltrated macrophages and amount of neutrophils, respectively (B-C). Gene expression of Tnfo, Itgam and Icam were measured in the

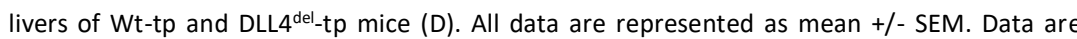
significant at $* p<0.05, * * p<0.01, * * * p<0.001$. Significance is compared to the chow group of the respective genotype.

\section{DLL4 deficiency does not affect inflammatory gene expression in bone marrow-derived macrophages.}

As we did not observe differences on hepatic inflammation in vivo, we next investigated whether bone marrow-derived macrophages (BMDM) of myeloid DLL4deficient mice are less susceptible for inflammation. Bone marrow from $\operatorname{DLL}^{f / f}$ LysMCre $^{\mathrm{Wt}}(\mathrm{Wt})$ and DLL4/f LysMCre ${ }^{+/ 0}$ (DLL4 ${ }^{\text {del }}$ ) was isolated and differentiated to BMDM followed by an LPS stimulus. As expected, DLL4 ${ }^{\text {del }}$ BMDM showed a significant reduction of DLL4 expression when compared to Wt macrophages (Figure 5A). However, no significant differences in TNF $\alpha$ cytokine production, Tnfo and Itgam expression were detected when compared to Wt BMDM upon LPS stimulation (Figure 5B-D). While the differences between the groups for Dll4 and Itgam gene expression remain similar in the condition without LPS, TNF $\alpha$ cytokine production was not detectable. Tnf $\alpha$ gene expression levels were increased significantly in Wt and DLL4 del BMDM due to the LPS stimulus. These data show that DLL4 ${ }^{\text {del }}$ BMDM can contribute to inflammation to the same extent as compared to Wt BMDM. To investigate the relative contribution of DLL4 to LPS-induced inflammation, DLL4 was immobilized in culture plates, where it acts as an inflammatory stimulus on Wt BMDM in the absence of LPS. Upon DLL4 stimulation, gene expression of Tnf $\alpha$ was significantly increased. A similar trend was observed in TNF $\alpha$ cytokine production. However, in the absence of LPS, the levels of TNF $\alpha$ cytokine production are extremely low $( \pm 1.5-3.0 \mathrm{pg} / \mathrm{ml}$ ) (Figure $5 \mathrm{E})$. These data suggest a minor role for myeloid DLL4 in triggering inflammation.

A

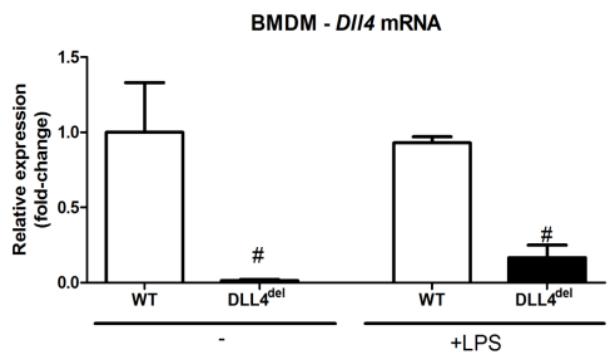

B

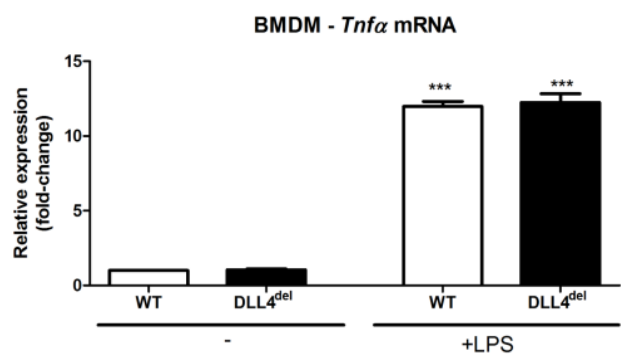


C

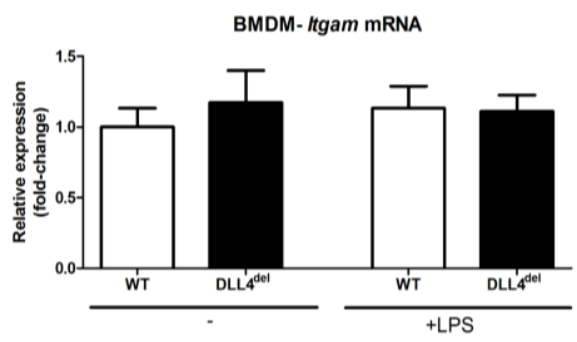

D

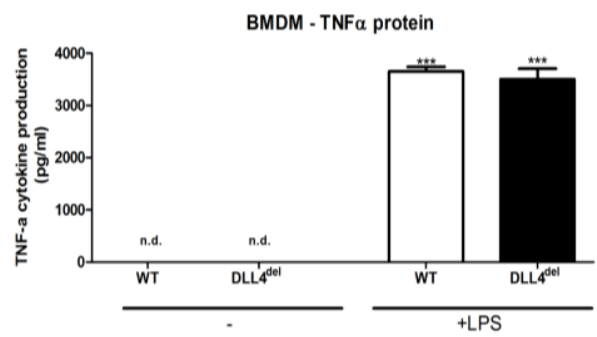

E

BMDM - Tnf $\alpha$ mRNA

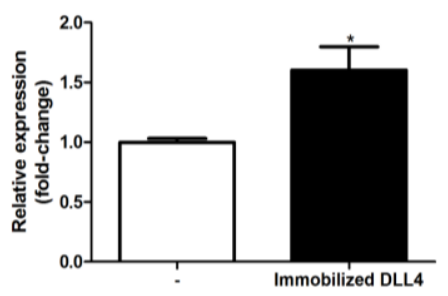

BMDM - TNF $\alpha$ protein

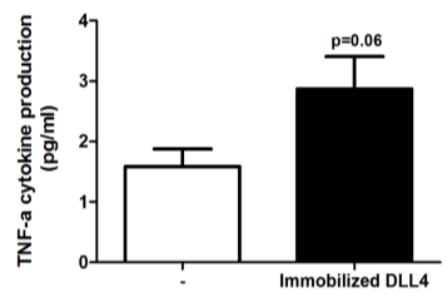

Figure 5:

Inflammatory response of bone marrow-derived macrophages from Wt and DLL4 del mice. Gene expression of DI/4 was measured in BMDM of Wt and DLL4 ${ }^{\text {del }}$ mice (A). Gene expression of Tnfa and Itgam were measured in BMDM of Wt and DLL4 ${ }^{\text {del }}$ mice (B-C). TNF $\alpha$ cytokine production was measured in BMDM of Wt and DLL4 ${ }^{\text {del }}$ mice (D). Wt BMDM stimulated with immobilized recombinant DLL4 (E). All data are represented as mean $+/$ - SEM. Data are significant at $* p<0.05, * * p<0.01, * * * p<$ 0.001 . Significance is compared to Wt BMDM. 


\section{Discussion}

Notch signaling is involved in various metabolic diseases $(7,9,13,22)$ and has been described as an essential modulator for inflammation and macrophage function (7,2327). While many Notch ligands have been investigated thoroughly, in the current study, we investigated for the first time the contribution of myeloid DLL4 in the context of hepatic inflammation.

Macrophage activation is essential for atherosclerotic plaque development (28-31) and recent studies have implicated Notch signaling in this process $(9,23,32)$. These studies showed that DLL4 ligand-expressing macrophages are found in human atherosclerotic lesions and that pro-inflammatory stimuli can increase DLL4 expression in macrophages (23). Furthermore, it has been shown in vivo that plaque progression was reduced in apolipoprotein E-deficient mice after treatment with a $\mathrm{Y}$ secretase, in order to inhibit Notch signaling (32). Taken into account the prominent role of Notch signaling in atherosclerosis, and since NASH and atherosclerosis share similar disease mechanisms (8), the results obtained in the current study were unexpected. In contrast to our results, global inhibition of DLL4 using specific antibodies resulted in a reduction in plaque development and decreased fat accumulation in $\mathrm{Ldll}^{-1}$ - mice. Next to that, they showed that F4/80 gene expression in the liver was reduced in these mice $(9,10)$, while our result showed no differences in hepatic inflammation. In vitro data from our group and others demonstrated the proinflammatory role of DLL4 on macrophages. However, data regarding the role of DLL4 on cells other than macrophages is lacking. In our experimental design, the DLL4 deletion is restricted to myeloid cells. In contrast, Fukuda et al. used a global inhibition of DLL4 (via anti-DLL4 antibodies) (9). It is therefore possible that in vivo, the contribution of DLL4 on myeloid cells is minor and cells other than macrophages contribute to the inflammatory response, as observed by Hoebe et al. (33). For example, when stromal cells, that express DLL4, were co-cultured with macrophages, the inflammatory response was increased, compared to stromal cells without DLL4 coincubated with macrophages (23). These data demonstrate the contribution of other DLL4-expressing cells to inflammation. In line, there is evidence that Notch receptors can be activated through other Notch ligands (34-37). Furthermore, Notch-1, -2 and -3 are highly expressed on monocytes and macrophages and in vitro studies have shown that these cells can undergo cytokine specific apoptosis by interaction of DLL1 which could influence the macrophage inflammatory response $(23,25,38)$. Next to that, it can be speculated that DLL4-expressing hepatocytes may also affect myeloid DLL4Notch signaling, as myeloid DLL4 signaling is mediated through all four Notch receptors $(23,39,40)$. Additionally, DLL4 induces Notch-1, $-2,-3$ cleavages (41). As such 
it is likely that, macrophages in DLL4 ${ }^{\text {del }}$-tp mice could still be activated via hepatic DLL4. Interestingly, Koga et al, showed that $L d / r^{\prime}$ hyperlipidemic mice showed high levels of soluble DLL4 in the plasma compared to Wt mice (42). Fung et al, already showed that soluble DLL4 is able to activate Notch signaling in macrophages (23). Based on these observations it can be suggested that in our model hepatocytes could still be functioning as suitable donor for DLL4 activation as they still express DLL4.

In conclusion, our data suggest that the inhibition of one single Notch-ligand in the myeloid linage is not sufficient to overcome hepatic inflammation. Nevertheless, since the macrophage-DII4 expression in our model was not completely suppressed, it can't be totally excluded that complete DLL4 deletion in macrophages might lead to different results. Furthermore, there is a possibility that Kupffer cell isolation using magnetic beads may contain other cells such as endothelial cells, which could explain for these findings. Finally, the contribution of non-myeloid Kupffer cells to notch signaling with regard to the pathogenesis of steatohepatitis is unknown and as such it is possible that, DLL4 on Kupffer cells promote the pathogenesis of steatohepatitis. Therefore, further research should emphasize on the effects of complete DLL4 deletion in myeloid cells and the contribution of non-myeloid cells to DLL4-Notch signaling. 


\section{References}

1. Clark JM (2006) The epidemiology of nonalcoholic fatty liver disease in adults. J Clin Gastroenterol 40 Suppl 1: S5-10.

2. Kopec KL, Burns D (2011) Nonalcoholic fatty liver disease: a review of the spectrum of disease, diagnosis, and therapy. Nutr Clin Pract 26: 565-576.

3. Portincasa P, Grattagliano I, Palmieri VO, Palasciano G (2005) The emerging problem of nonalcoholic steatohepatitis (NASH). Rom J Gastroenterol 14: 43-51.

4. Radtke F, MacDonald HR, Tacchini-Cottier F (2013) Regulation of innate and adaptive immunity by Notch. Nat Rev Immunol 13: 427-437.

5. Jin C, Henao-Mejia J, Flavell RA (2013) Innate immune receptors: key regulators of metabolic disease progression. Cell Metab 17: 873-882.

6. Sell H, Habich C, Eckel J (2012) Adaptive immunity in obesity and insulin resistance. Nat Rev Endocrinol 8: 709-716.

7. Bi P, Kuang S (2015) Notch signaling as a novel regulator of metabolism. Trends Endocrinol Metab 26: 248-255.

8. Bieghs V, Rensen PC, Hofker MH, Shiri-Sverdlov R (2012) NASH and atherosclerosis are two aspects of a shared disease: central role for macrophages. Atherosclerosis 220: 287-293.

9. Fukuda D, Aikawa E, Swirski FK, Novobrantseva TI, Kotelianski V, et al. (2012) Notch ligand deltalike 4 blockade attenuates atherosclerosis and metabolic disorders. Proc Natl Acad Sci U S A 109: E1868-1877.

10. Niida T, Lok LL, Zheng CY, Koga JI, Fukuda D, et al. (2013) Delta-like 4/Notch Signaling Promotes Fatty Liver Disease in Mice. Circulation 128.

11. Bieghs V, Wouters K, van Gorp PJ, Gijbels MJ, de Winther MP, et al. (2010) Role of scavenger receptor $A$ and $C D 36$ in diet-induced nonalcoholic steatohepatitis in hyperlipidemic mice. Gastroenterology 138: 2477-2486, 2486 e2471-2473.

12. Bieghs V, Verheyen F, van Gorp PJ, Hendrikx T, Wouters K, et al. (2012) Internalization of modified lipids by CD36 and SR-A leads to hepatic inflammation and lysosomal cholesterol storage in Kupffer cells. PLoS One 7: e34378.

13. Valenti L, Mendoza RM, Rametta R, Maggioni M, Kitajewski C, et al. (2013) Hepatic notch signaling correlates with insulin resistance and nonalcoholic fatty liver disease. Diabetes 62 : 4052-4062.

14. Pajvani UB, Qiang L, Kangsamaksin T, Kitajewski J, Ginsberg HN, et al. (2013) Inhibition of Notch uncouples Akt activation from hepatic lipid accumulation by decreasing mTorc1 stability. Nat Med 19: 1054-1060

15. Koch U, Fiorini E, Benedito R, Besseyrias V, Schuster-Gossler K, et al. (2008) Delta-like 4 is the essential, nonredundant ligand for Notch1 during thymic T cell lineage commitment. J Exp Med 205: 2515-2523.

16. Clausen BE, Burkhardt C, Reith W, Renkawitz R, Forster I (1999) Conditional gene targeting in macrophages and granulocytes using LysMcre mice. Transgenic Res 8: 265-277.

17. Shiri-Sverdlov R, Wouters K, van Gorp PJ, Gijbels MJ, Noel B, et al. (2006) Early diet-induced nonalcoholic steatohepatitis in APOE2 knock-in mice and its prevention by fibrates. $\mathrm{J}$ Hepatol 44: 732-741.

18. Bieghs V, Hendrikx T, van Gorp PJ, Verheyen F, Guichot YD, et al. (2013) The cholesterol derivative 27-hydroxycholesterol reduces steatohepatitis in mice. Gastroenterology 144: 167-178 e161.

19. Ruijter JM, Ramakers C, Hoogaars WM, Karlen Y, Bakker O, et al. (2009) Amplification efficiency: linking baseline and bias in the analysis of quantitative PCR data. Nucleic Acids Res 37: e45. 
20. Tuomi JM, Voorbraak F, Jones DL, Ruijter JM (2010) Bias in the Cq value observed with hydrolysis probe based quantitative PCR can be corrected with the estimated PCR efficiency value. Methods 50: 313-322.

21. Ruijter JM, Lorenz P, Tuomi JM, Hecker M, van den Hoff MJ (2014) Fluorescent-increase kinetics of different fluorescent reporters used for qPCR depend on monitoring chemistry, targeted sequence, type of DNA input and PCR efficiency. Mikrochim Acta 181: 1689-1696.

22. Quillard T, Charreau B (2013) Impact of notch signaling on inflammatory responses in cardiovascular disorders. Int J Mol Sci 14: 6863-6888.

23. Fung E, Tang SM, Canner JP, Morishige K, Arboleda-Velasquez JF, et al. (2007) Delta-like 4 induces notch signaling in macrophages: implications for inflammation. Circulation 115: 29482956.

24. Monsalve E, Perez MA, Rubio A, Ruiz-Hidalgo MJ, Baladron V, et al. (2006) Notch-1 up-regulation and signaling following macrophage activation modulates gene expression patterns known to affect antigen-presenting capacity and cytotoxic activity. J Immunol 176: 5362-5373.

25. Ohishi K, Varnum-Finney B, Flowers D, Anasetti C, Myerson D, et al. (2000) Monocytes express high amounts of Notch and undergo cytokine specific apoptosis following interaction with the Notch ligand, Delta-1. Blood 95: 2847-2854.

26. Monsalve E, Ruiz-Garcia A, Baladron V, Ruiz-Hidalgo MJ, Sanchez-Solana B, et al. (2009) Notch1 upregulates LPS-induced macrophage activation by increasing NF-kappaB activity. Eur J Immunol 39: 2556-2570.

27. Palaga T, Buranaruk C, Rengpipat S, Fauq AH, Golde TE, et al. (2008) Notch signaling is activated by TLR stimulation and regulates macrophage functions. Eur J Immunol 38: 174-183.

28. Libby P, Ridker PM, Hansson GK (2011) Progress and challenges in translating the biology of atherosclerosis. Nature 473: 317-325.

29. Hansson GK, Hermansson A (2011) The immune system in atherosclerosis. Nat Immunol 12: 204 212.

30. Hansson GK, Libby P (2006) The immune response in atherosclerosis: a double-edged sword. Nat Rev Immunol 6: 508-519.

31. Libby P, Ridker PM, Hansson GK, Leducq Transatlantic Network on A (2009) Inflammation in atherosclerosis: from pathophysiology to practice. J Am Coll Cardiol 54: 2129-2138.

32. Aoyama T, Takeshita K, Kikuchi R, Yamamoto K, Cheng XW, et al. (2009) gamma-Secretase inhibitor reduces diet-induced atherosclerosis in apolipoprotein E-deficient mice. Biochem Biophys Res Commun 383: 216-221.

33. Hoebe KH, Witkamp RF, Fink-Gremmels J, Van Miert AS, Monshouwer M (2001) Direct cell-tocell contact between Kupffer cells and hepatocytes augments endotoxin-induced hepatic injury. Am J Physiol Gastrointest Liver Physiol 280: G720-728.

34. Lu R, Gao H, Wang H, Cao L, Bai J, et al. (2013) Overexpression of the Notch3 receptor and its ligand Jagged1 in human clinically non-functioning pituitary adenomas. Oncol Lett 5: 845-851.

35. Lin L, Mernaugh R, Yi F, Blum D, Carbone DP, et al. (2010) Targeting specific regions of the Notch3 ligand-binding domain induces apoptosis and inhibits tumor growth in lung cancer. Cancer Res 70: 632-638.

36. Purow BW, Haque RM, Noel MW, Su Q, Burdick MJ, et al. (2005) Expression of Notch-1 and its ligands, Delta-like-1 and Jagged-1, is critical for glioma cell survival and proliferation. Cancer Res 65: 2353-2363.

37. Kume T (2009) Novel insights into the differential functions of Notch ligands in vascular formation. J Angiogenes Res 1: 8.

38. Zhou D, Huang C, Lin Z, Zhan S, Kong L, et al. (2014) Macrophage polarization and function with emphasis on the evolving roles of coordinated regulation of cellular signaling pathways. Cell Signal 26: 192-197. 
39. Martinez JC, Muller MM, Turley H, Steers G, Choteau L, et al. (2009) Nuclear and membrane expression of the angiogenesis regulator delta-like ligand 4 (DLL4) in normal and malignant human tissues. Histopathology 54: 598-606.

40. Shutter JR, Scully S, Fan W, Richards WG, Kitajewski J, et al. (2000) DIl4, a novel Notch ligand expressed in arterial endothelium. Genes \& Development 14: 1313-1318.

41. Groot AJ, Habets R, Yahyanejad S, Hodin CM, Reiss K, et al. (2014) Regulated proteolysis of NOTCH2 and NOTCH3 receptors by ADAM10 and presenilins. Mol Cell Biol 34: 2822-2832.

42. Koga JI, Wang JG, Tang JJ, Wilson CL, Raines EW, et al. (2013) Activated Macrophages Release Delta-like 4: A Potential New Biomarker of Cardiometabolic Disorders. Circulation 128. 


\section{Supplementary Figures}

A

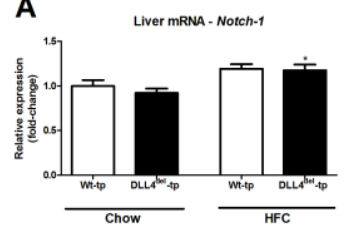

D

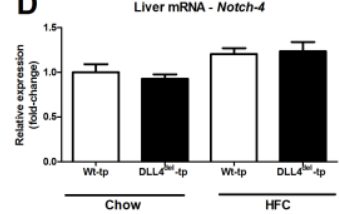

G

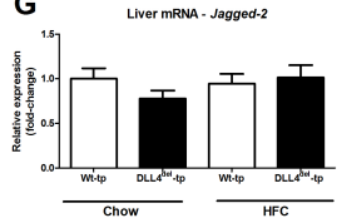

B

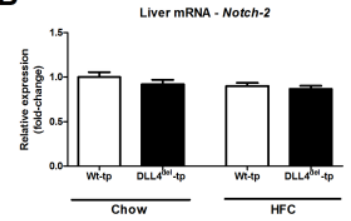

E

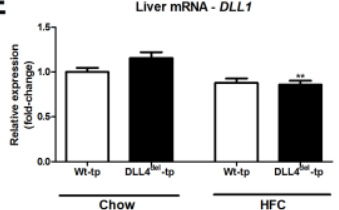

C

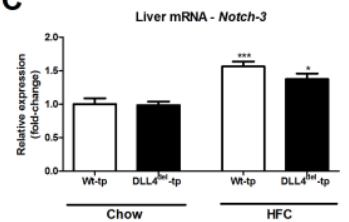

$\mathbf{F}$

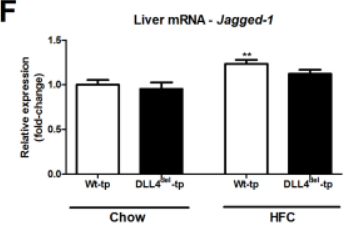

Supplementary figure 1: Gene expression of Notch receptors/ligands in the livers of Wt-tp and DLL4 ${ }^{\text {del-tp }}$ mice.

A

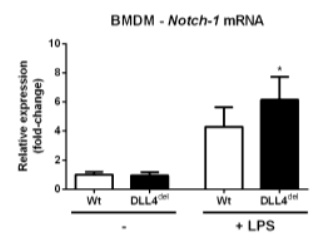

D BMDM - Notch-4 MRNA

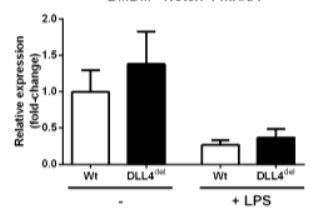

G $\quad$ BMDM - Jagged. 2 mRNA

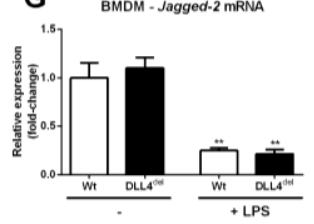

B

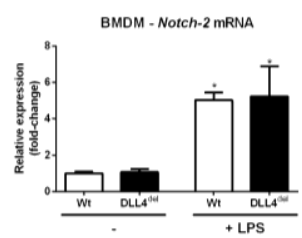

E

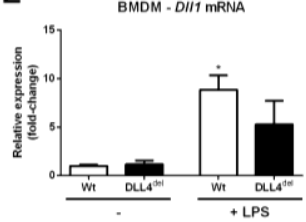

C

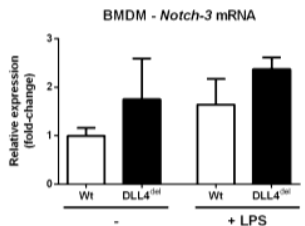

$\mathbf{F}$

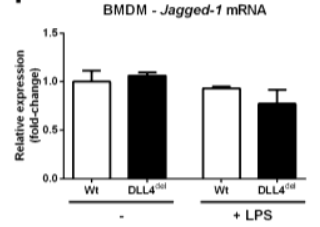

Supplementary figure 2: Gene expression of Notch receptors/ligands in BMDM from Wt and DLL4 ${ }^{\text {del }}$ mice. 

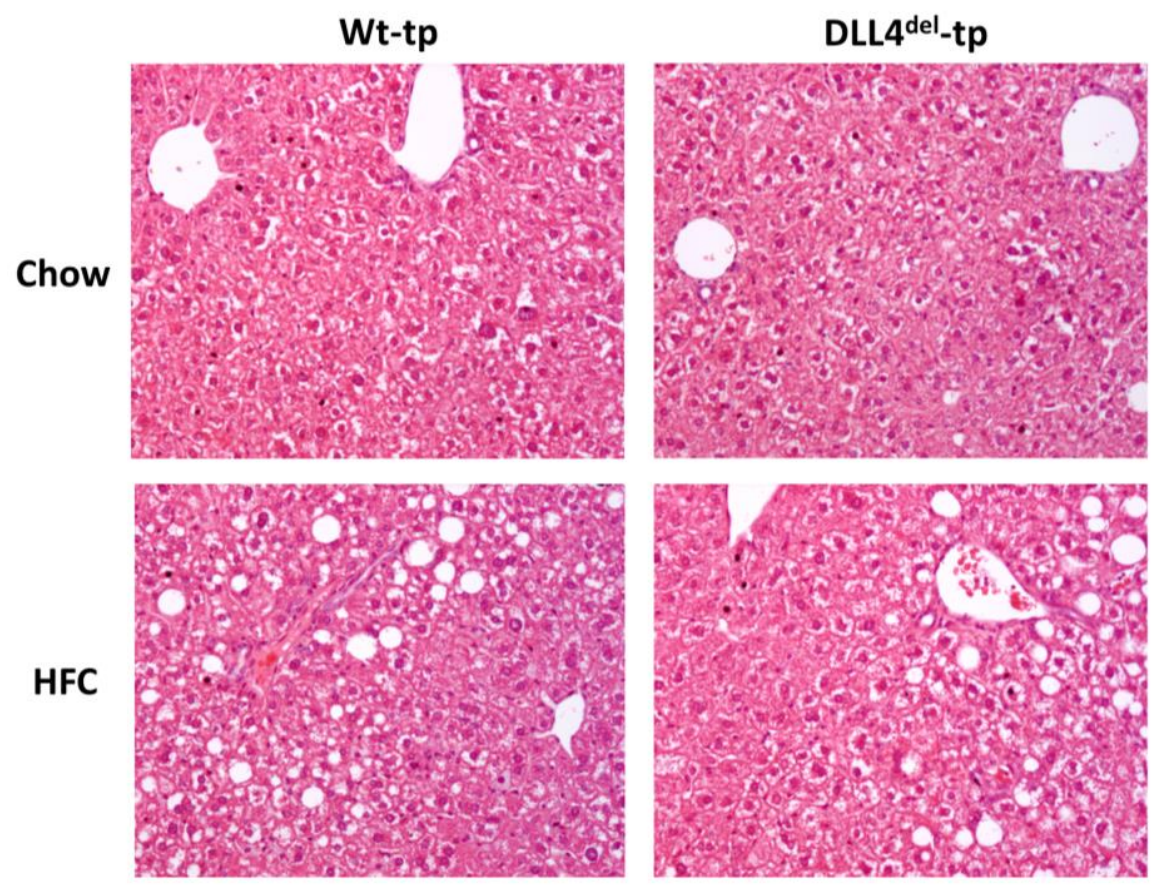

Supplementary Figure 3: Representative pictures of H\&E staining on the livers of Wt-tp and DLL4 ${ }^{\text {del-tp }}$ mice. 


\section{Chapter 5}

\section{Hematopoietic overexpression of CYP27A1 reduces}

hepatic inflammation independently of 27hydroxycholesterol levels in $\mathrm{LdII}^{/-}$mice

T. Hendrikx, M.L.J. Jeurissen, V. Bieghs, S.M.A. Walenbergh, P.J. van Gorp, F. Verheyen, T. Houben, Y. D. Guichot, M.J.J. Gijbels, E. Leitersdorf, M.H. Hofker, D. Lütjohann, R. Shiri-Sverdlov 


\section{Abstract}

Background \& Aims: Non-alcoholic steatohepatitis (NASH) is characterized by hepatic lipid accumulation and inflammation. Currently, the underlying mechanisms, leading to hepatic inflammation, are still unknown. The breakdown of free cholesterol inside Kupffer cells (KCs) by the mitochondrial enzyme CYP27A1 produces 27hydroxycholesterol $(27 \mathrm{HC})$. We recently demonstrated that administration of $27 \mathrm{HC}$ to hyperlipidemic mice reduced hepatic inflammation. In line, hematopoietic deletion of Cyp27a1 resulted in increased hepatic inflammation. In the current manuscript, the effect of hematopoietic overexpression of Cyp27a1 on the development of NASH and cholesterol trafficking was investigated. We hypothesized that Cyp27a1 overexpression in $\mathrm{KCs}$ will lead to reduced hepatic inflammation.

Methods: Irradiated $L d l r^{-/}$mice were transplanted (tp) with bone marrow from mice overexpressing Cyp27a1 (Cyp27a1 ${ }^{\text {over }}$ ) and wild type $(\mathrm{Wt})$ mice and fed either chow or a high-fat, high-cholesterol (HFC) diet for 3 months. Additionally, gene expression was assessed in bone marrow-derived macrophages (BMDM) from Cyp27a1over and $\mathrm{Wt}$ mice.

Results: In line with our hypothesis, hepatic inflammation in HFC-fed Cyp27a1over-tp mice was reduced and KCs were less foamy compared to Wt-tp mice. Remarkably, these changes occurred even though plasma and liver levels of $27 \mathrm{HC}$ did not differ between both groups. BMDM from Cyp27a $1^{\text {over }}$ mice revealed reduced inflammatory gene expression and increased expression of cholesterol transporters compared to $\mathrm{Wt}$ BMDM after lipopolysaccharide (LPS) stimulation.

Conclusions: Our data suggest that overexpression of Cyp27a1 in KCs reduces hepatic inflammation independently of $27 \mathrm{HC}$ levels in plasma and liver, further pointing towards KCs as specific target for improving the therapy of NASH. 


\section{Introduction}

Non-alcoholic fatty liver disease (NAFLD) is considered the hepatic event of the metabolic syndrome and is characterized by the deposition of fat in the liver (steatosis). NAFLD covers a broad spectrum of diseases ranging from steatosis to nonalcoholic steatohepatitis (NASH). NASH is distinguished from simple steatosis by the added presence of inflammation in the liver. Whereas steatosis is generally considered a relatively benign and reversible condition, inflammation adversely affects the long-term prognosis of liver diseases as this enables the development of more advanced stages of the disease, including fibrosis, cirrhosis or hepatocellular carcinoma, ultimately requiring liver transplantation (1). So far, the intracellular mechanisms that trigger the inflammatory response are not known. Hence, therapy options are very poor and lack specificity. The uptake of dietary cholesterol by Kupffer cells (KCs), the resident macrophages of the liver, was found to play an important role during NASH development (2). Similar to previously reported observations during atherosclerosis $(3,4)$, the accumulation of cholesterol leading to a swollen appearance of macrophages, termed foam cells, was associated with an increased inflammatory response in the liver (5). Upon uptake by macrophages, cholesterol is initially directed to lysosomes for hydrolyzation and then further transported to the cytoplasm. Here, cholesterol can be converted into 27 -hydroxycholesterol $(27 \mathrm{HC})$ by the action of the mitochondrial enzyme CYP27A1 as the first step in the alternative pathway of bile acid formation (6). Recently, we demonstrated that exogenous administration of $27 \mathrm{HC}$ dramatically reduced hepatic inflammation in hyperlipidemic $L d l r^{-/}$mice upon highfat, high-cholesterol (HFC) feeding (7). In line with this observation, hematopoietic deletion of Cyp27a1 resulted in increased hepatic inflammation (7). We hypothesized that hematopoietic overexpression of Cyp27a1 will lead to reduced hepatic inflammation. In order to investigate the effect of overexpression of Cyp27a1 in KCs on hepatic inflammation, bone marrow chimeras were generated by injecting bone marrow cells from mice overexpressing Cyp27a1 (Cyp27a1 ${ }^{\text {over }}$ ) into lethally irradiated Ldlr/- hyperlipidemic host mice. In the current study we show that overexpression of Cyp27a1 in KCs reduces hepatic inflammation, independently of hepatic and plasma 27HC levels. 


\section{Materials and methods}

\section{Bone marrow-derived macrophages}

Bone marrow-derived macrophages were isolated from the tibiae and femurs of C57BL/6 or Cyp27a $1^{\text {over }}$ mice (kindly provided by E. Leitersdorf (8)). Cells were cultured in RPMI-1640 (GIBCO Invitrogen, Breda, the Netherlands) with 10\% heat-inactivated foetal calf serum (Bodinco B.V. Alkmaar, the Netherlands), penicillin (100 U/ml), streptomycin $(100 \mu \mathrm{g} / \mathrm{ml})$ and L-glutamine $2 \mathrm{mM}$ (all GIBCO Invitrogen, Breda, the Netherlands), supplemented with 20\% L929-conditioned medium (LCM) for 8-9 days to generate bone marrow-derived macrophages. After attachment, macrophages were seeded at 350,000 cells per well in 24-well plates and incubated for $24 \mathrm{~h}$ with medium (control), cyclodextrin (carrier control) or $27 \mathrm{HC}(0.25 \mu \mathrm{M} ; 1 \mu \mathrm{M})$. Then cells were washed and stimulated with LPS $(100 \mathrm{ng} / \mathrm{ml})$ for $4 \mathrm{~h}$. Finally, cells were lysed for mRNA expression analysis. For protein expression analysis and electron microscopy analysis, cells were seeded at 2,000,000 cells per well in 6-well plates and incubated under the same conditions.

\section{Mice, diet, and bone marrow transplantation}

Mice were housed under standard conditions and given free access to food and water. Experiments were performed according to the Dutch regulations and approved by the Committee for Animal Welfare of the Maastricht University. Female 12-week-old Ldlr - mice were lethally irradiated and transplanted with Wt or Cyp27a1 ${ }^{\text {over }}$ bone marrow as previously described (9). After a recovery period of 9 weeks, the mice were given either chow or HFC diet for 3 months (chow: $n=5$; HFC: $n=10$ ). The HFC diet contained $21 \%$ milk butter, $0.2 \%$ cholesterol, $46 \%$ carbohydrates, and $17 \%$ casein. Collection of blood and tissue specimens, biochemical determination of lipids in plasma and liver, liver histology, electron microscopy, RNA isolation, cDNA synthesis, qPCR and oxysterol levels were determined as described previously $(7,10)$.

\section{Statistical analysis}

Data were analysed using the Graphpad Prism 4.0.3 software. Groups were compared using the unpaired t test for comparing two groups or one-way ANOVA for comparing multiple groups. Data were expressed as the mean and standard error of the mean and were considered significantly different at ${ }^{*} p<0.05 ; * *<<0.01$; or $* * * p<0.001$. 


\section{Results}

\section{Cyp27a $1^{\text {over }}$-tp mice have less hepatic inflammation compared to $\mathrm{Wt}$ - tp mice}

The effect of hematopoietic overexpression of Cyp27a1 in diet induced NASH was investigated by transplanting bone marrow from wild type (Wt) and Cyp27a1 overexpressing (Cyp27a ${ }^{\text {over }}$ ) mice into $L d l r^{-/}$mice. After a recovery period of 9 weeks, mice received chow or HFC diet for 3 months. Body weight did not differ significantly between the groups (data not shown). To investigate the effect of hematopoietic overexpression of Cyp27a1 on hepatic inflammation, liver sections were stained with antibodies against several inflammatory markers including macrophages and neutrophils. Lower numbers of infiltrating macrophages $(p=0.0206)$ and neutrophils ( $p=0.0146$ ) were observed in the livers of Cyp27a1 ${ }^{\text {over }}$-tp mice compared to Wt-tp mice after HFC (Figure 1A), as further illustrated by representative pictures from Mac1 staining for infiltrating macrophages and neutrophils (Figure 1B). These findings were confirmed by reduced hepatic gene expression of the monocyte chemoattractant protein 1 (Mcp1) ( $p=0.0083)$, chemokine ( $-X-C$ motif) ligand 1 ( $C x c / 1)(p=$ 0.046), and $C x c / 2$ ( $p=0.039$ ) in Cyp27a $1^{\text {over }}$-tp mice compared to Wt-tp mice upon HFC (Figure 1C), whereas gene expression for tumor necrosis factor-alpha (Tnfo) showed the same trend, although it did not reach significance $(p=0.07)$. Taken together, these data indicate that hematopoietic overexpression of Cyp27a1 reduces hepatic inflammation. To investigate the effect of overexpression of Cyp27a1 in hematopoietic cells on apoptosis, hepatic expression of genes important during apoptosis was determined. Compared to animals on chow, expression of the apoptotic genes Bfl1 and Traf1 was increased after 3 months of HFC diet. However, no

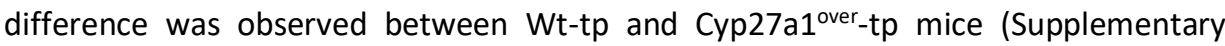
Figure $1 \mathrm{~A})$. In line with these findings, no difference between Wt-tp and Cyp27a1 $1^{\text {over }}$ tp mice was found in hepatic expression of catalase (Cat), SOD2, Hmox, and Cyp2E1, markers for oxidative stress (Supplementary Figure 1B). To further characterize these two genotypes, markers for liver damage and fibrosis were analysed. As expected, plasma alanine transaminase (ALT) levels were increased in mice after 3 months of HFC feeding. Similar ALT levels were observed in Wt-tp and Cyp27a ${ }^{\text {over }}$-tp mice. Additionally, hepatic gene expression of $T g f B$, a marker for fibrosis development, was unchanged between Wt-tp and Cyp27a $1^{\text {over }}$-tp mice upon HFC diet (Supplementary Figure $1 \mathrm{C}$ ). To evaluate macrophage polarization in the livers of both transplanted groups, hepatic gene expression analysis of $I L 12$, an $M_{1}$ macrophage marker, was measured and revealed no difference between the two groups. Likewise, no difference was observed in the expression of the $M_{2}$ macrophage markers arginase-1 (Arg1) and IL10 after 3 months of HFC feeding (Supplementary Figure 1D). Taken together, these data indicate that hematopoietic overexpression of Cyp27a1 reduces hepatic inflammation independent of the level of apoptosis, oxidative stress, liver damage or macrophage subset polarization. 

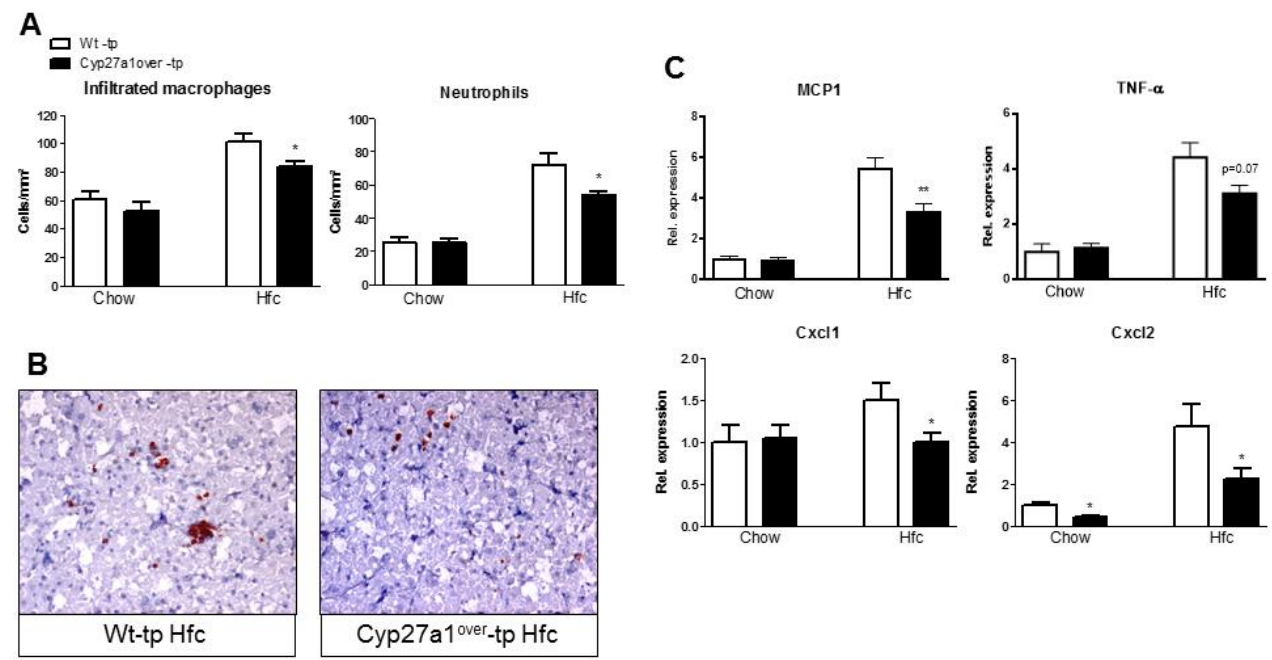

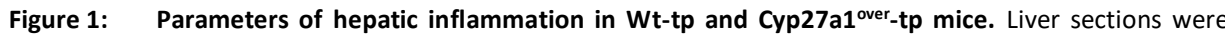
stained for infiltrating macrophages and neutrophils (Mac-1), neutrophils (NIMP) and positive cells were counted (A). Representative pictures of Mac-1 staining (200x magnification) after 3

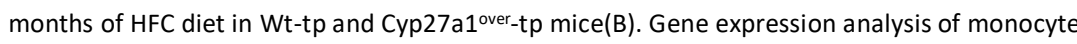
chemoattractant protein 1 (Mcp1), tumor necrosis factor alpha (Tnf $\alpha)$, chemokine (C-X-C motif) ligand $1\left(C_{x C l}\right)$ and $C_{x C} / 2$. Gene expression data were set relative to Wt-tp mice on chow diet (C). * Indicates $\mathrm{p}<0.05$ and ${ }^{* *} \mathrm{p}<0.01$.

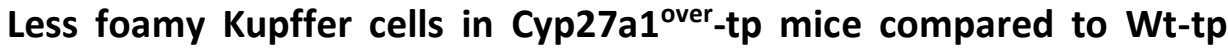 mice}

To analyse the effect of Cyp27a1 overexpression on the foamy appearance of KCs, a CD68 staining (for $\mathrm{KC}$ ) was performed and revealed a clear difference between Cyp27a $1^{\text {over }}$-tp mice and Wt-tp mice upon HFC diet. In Cyp27a $1^{\text {over }}$-tp mice, KCs are less swollen and foamy compared to KCs in Wt-tp animals (Supplementary Figure 4A). These data are in line with reduced gene expression of $C d 68$ in the livers of Cyp27a10ver-tp mice compared to Wt-tp mice after 3 months of HFC feeding (Supplementary Figure 4B). To investigate whether the difference in foamy appearance of KCs is related to changes in cholesterol uptake or cholesterol efflux, gene expression analysis was performed. For cholesterol uptake, hepatic expression of $C d 36$, scavenger receptor a $(S R-A)$, low density lipoprotein receptor-related protein 1 (LRP1) and SR-B1 did not differ between Wt-tp and Cyp27over-tp mice upon HFC (Supplementary Figure $4 C$ ). Next to that, no difference in hepatic expression of two well-known cholesterol efflux transporters, Abca1 and Abcg1, was observed between

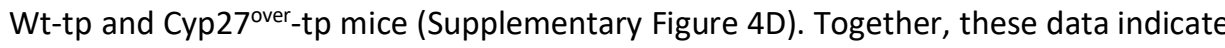
that changes in the foamy appearance of KCs are not related to cholesterol uptake and reverse cholesterol transport in total liver. 


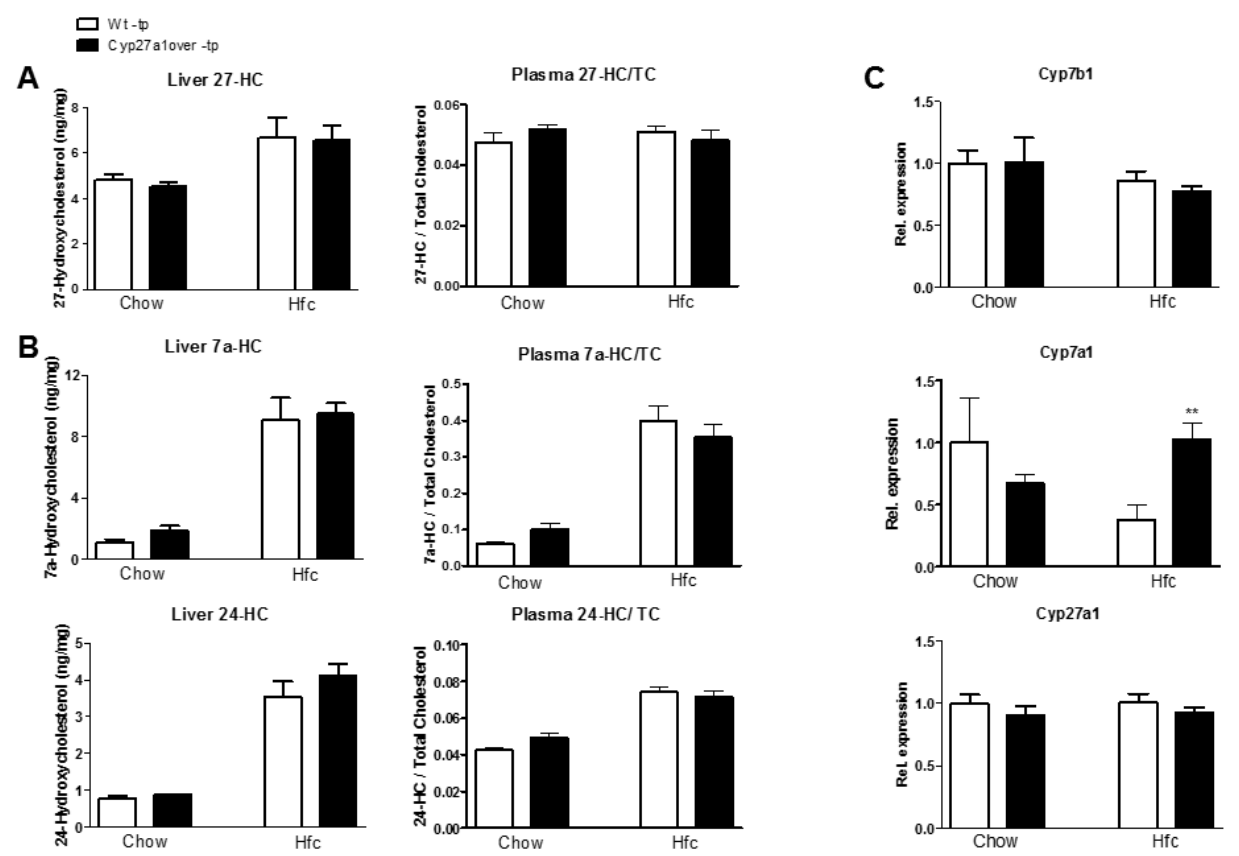

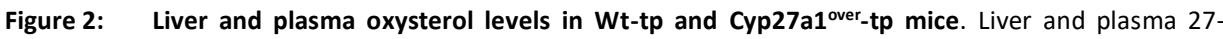
hydroxycholesterol levels after chow and HFC diet (A). Liver and plasma 7a-hydroxycholesterol and 24-hydroxycholesterol levels after chow and HFC diet (B). Gene expression analysis of

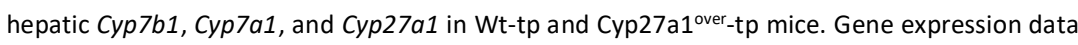
were set relative to $\mathrm{Wt}$-tp mice on chow $\operatorname{diet}(\mathrm{C})$. ${ }^{*}$ Indicates $\mathrm{p}<0.05$.

\section{Bone marrow-derived macrophages (BMDM) from Cyp27a1 ${ }^{\text {over }}$ mice have increased intracellular cholesterol trafficking}

In order to investigate the mechanism by which Cyp27a1 reduces inflammation, bone marrow cells were isolated from $\mathrm{Wt}$ and Cyp27a1 $1^{\text {over }}$ mice and cultured to macrophages. After stimulation with lipopolysaccharide (LPS) for $4 \mathrm{~h}$, the expression of Tnf $\alpha$ was significantly lower in BMDM from Cyp27a $1^{\text {over }}$ mice compared to those from Wt mice, confirming our in vivo findings that Cyp27a1 overexpression in macrophages results in a reduced inflammatory response (Figure $3 \mathrm{~A}$ ). To study the specific effect of Cyp27a1 overexpression on cholesterol uptake by macrophages, the expression of $C d 36$ and $S R-A$ was analysed with and without LPS stimulation. No difference was observed between BMDM from Wt and from Cyp27a $1^{\text {over }}$ mice (Figure $3 B)$. On the other hand, expression of liver $X$ receptor alpha $(L X R \alpha)(p=0.025), A b c a 1$ ( $p=0.0094)$, and Abcg1 ( $p=0.0462)$, genes involved in cholesterol efflux, was increased in BMDM from Cyp27a1 $1^{\text {over }}$ mice compared to Wt BMDM after LPS stimulation (Figure 3C). These data indicate that Cyp27a1 overexpression in 
macrophages leads to an increase of cholesterol efflux transport during an inflammatory response.
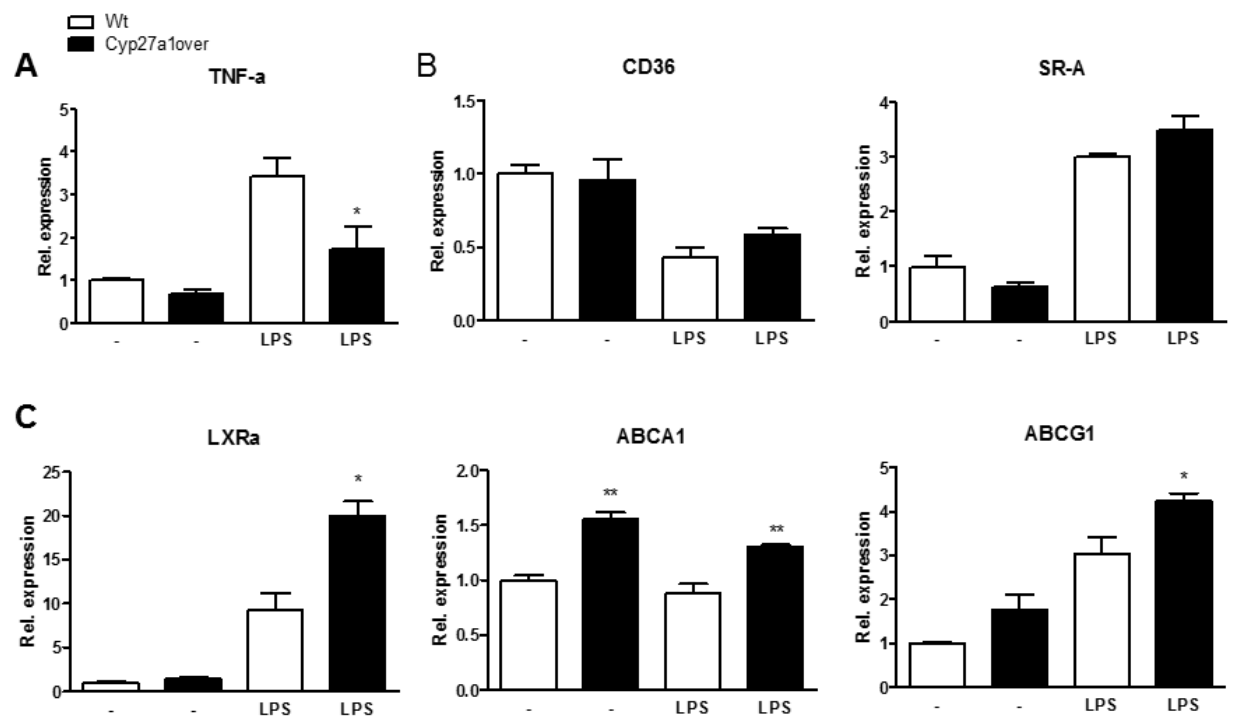

Figure 3. Gene expression in bone marrow-derived macrophages from Wt and Cyp27a1 ${ }^{\text {over }}$ mice after LPS stimulation. Gene expression analysis of the inflammatory marker tumor necrosis factor alpha (Tnfa) (A), scavenger receptors $C d 36$ and $S R-A(B)$, liver $X$ receptor alpha ( $L X R a)$ and ATPbinding cassette transporter $\mathrm{A} 1$ (Abca1) and G1 (Abcg1) (C) in BMDM from Wt and Cyp27a1 ${ }^{\text {over }}$ mice after $4 \mathrm{~h}$ LPS stimulation. Data were set relative to BMDM from Wt mice incubated with medium. ${ }^{*}$ Indicates $\mathrm{p}<0.05$ and $* * \mathrm{p}<0.01$.

To further examine the effect of Cyp27a1 overexpression on intracellular cholesterol trafficking in macrophages, gene expression analysis for genes important for lysosomal cholesterol transport (Npc1 and Npc2) was assessed. Whereas Npc1 expression was not affected by LPS stimulation, the expression of $N p c 2$ increased dramatically after stimulation with LPS in both BMDM from Wt and Cyp27a $1^{\text {over }}$ mice (Figure 4A). Notably, macrophages overexpressing Cyp27a1 showed increased expression of Npc2 compared to Wt BMDM after LPS stimulation (Figure 4A). Additionally, in order to study specifically the effect of $27 \mathrm{HC}$ on macrophages, protein levels of Npc1 and Npc2 were determined in BMDM from Wt mice that were incubated with $27 \mathrm{HC}$ and cyclodextrin (carrier control). Interestingly, $27 \mathrm{HC}$ incubation led to a significant induction of NPC1 and NPC2 protein levels compared to control condition (Figure 4B). This increase was accompanied by a reduction in lysosomal cholesterol accumulation in BMDM, incubated with $27 \mathrm{HC}$ as shown in the electron microscopy pictures (Figure 4C). While adding cyclodextrin to macrophages resulted in a trend towards a reduction in lysosomal cholesterol accumulation, adding $27 \mathrm{HC}$ was 
able to dramatically reduce lysosomal cholesterol accumulation in comparison to control and compared to the cyclodextrin condition. Thus, $27 \mathrm{HC}$ is more effective in reducing lysosomal cholesterol accumulation than its vehicle cyclodextrin. Taken together, these data suggest that Cyp27a1 and 27HC are able to modulate intracellular cholesterol trafficking in macrophages via NPC proteins.
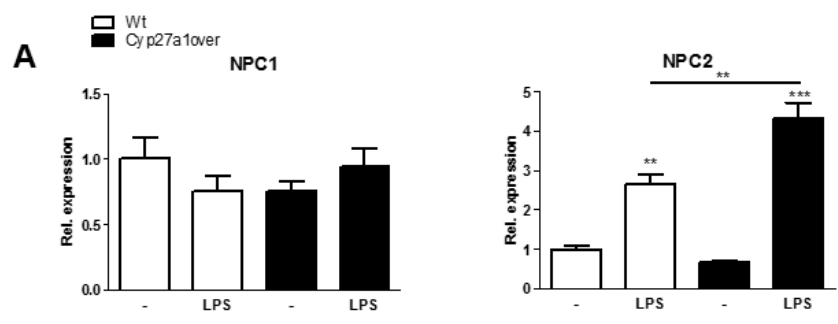

B
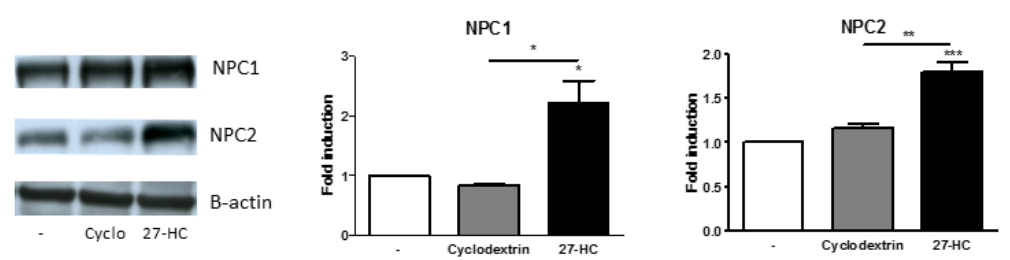

C

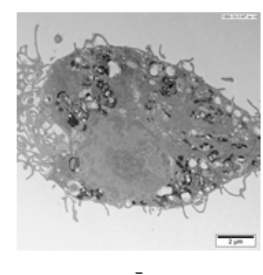

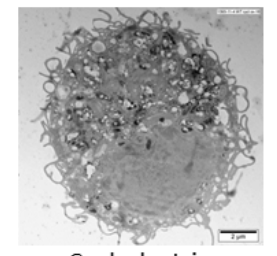

Cyclodextrin

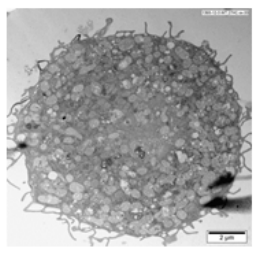

27-HC

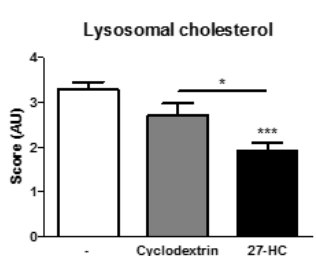

Figure 4: Gene expression and protein levels in bone marrow-derived macrophages from Wt and Cyp27a1 ${ }^{\text {over }}$ mice of genes important in intracellular cholesterol trafficking. Niemann-Pick C1 (Npc1) and Npc2 gene expression in BMDM from Wt and Cyp27a1 over mice after $4 \mathrm{~h}$ LPS stimulation (A). Representative pictures of 5 independent Western blot measurements. Western blot analysis of $\mathrm{Npc1}$ and $\mathrm{Npc2}$ proteins in BMDM from Wt mice after $4 \mathrm{~h}$ of LPS stimulation and incubation with cyclodextrin (carrier control) and 27-hydroxycholesterol. Betaactin was used as loading control (B). Representative electron microscopy pictures (acid phosphatase staining) of Wt BMDM incubated with medium, cyclodextrin, or 27HC. Pictures of approximately 25 BMDM were scored for lysosomal cholesterol accumulation (C). Data were set relative to BMDM from Wt mice incubated with medium. ${ }^{*}$ Indicates $p<0.05 ;{ }^{* *} p<0.01$; $* * * p<0.001$. 


\section{Discussion}

Our results indicate that Cyp27a1 overexpression in hematopoietic cells reduces dietinduced hepatic inflammation. Remarkably, the reduction in hepatic inflammation was independent of plasma and liver levels of 27-hydroxycholesterol and other oxysterols. Mechanistically, our data suggest that Cyp27a1 can reduce hepatic inflammation via modulation of intracellular cholesterol trafficking in macrophages. Furthermore, our data provide further evidence to the importance of KCs in triggering hepatic inflammation.

\section{CYP27A1 is able to reduce hepatic inflammation independent of circulating $27 \mathrm{HC}$ levels}

Currently, most data are highly controversial regarding the activities of oxysterols. Although some in vitro studies have demonstrated that oxysterols have some cytotoxic, oxidative, and/or inflammatory effects (11), the most abundant oxysterol, being $27 \mathrm{HC}$, is considered as a potential candidate for the reduction of inflammation during NASH (7). Daily injection of $27 \mathrm{HC}$ was found to result in reduced hepatic inflammation in a dietary model for NASH. As expected, in addition to the reduced inflammatory response upon $27 \mathrm{HC}$ administration, increased levels of $27 \mathrm{HC}$ in liver and plasma were detected (7). Importantly, 27HC was found to be a selective oestrogen receptor modulator that can serve as a competitive antagonist for the oestrogen receptor $(12,13)$. As such, circulating levels of $27 \mathrm{HC}$ levels may directly antagonize the functions of oestrogen receptors in vascular endothelial and smooth muscle cells, thereby leading to a loss of the cardioprotective effect of oestrogen (14). Furthermore, increased levels of $27 \mathrm{HC}$, which occur during hypercholesterolemia, have recently been shown to be involved in different pathologies. In a mouse model for breast cancer, it was shown that $27 \mathrm{HC}$ increases oestrogen receptor-dependent growth and LXR-dependent metastasis (15). Mice that demonstrated increased circulating levels of $27 \mathrm{HC}$ showed increased metastasis of breast cancer cells to the lung. Besides involvement in breast cancer, it was shown that increased concentrations of $27 \mathrm{HC}$ led to decreased bone mineral density that was associated with decreased bone formation and increased bone resorption (12). Our current data indicate that increased Cyp27a1 expression, specifically in hematopoietic cells, does not alter circulating $27 \mathrm{HC}$ levels while inflammation is reduced. Our data suggest that the increased systemic and hepatic production of $27 \mathrm{HC}$ is prevented by upregulation of the classical pathway. Another explanation for the similar levels of systemic and hepatic levels of $27 \mathrm{HC}$ between the groups is the fact that parenchymal cells compromise about $80 \%$ of all liver cells. In our study, gene expression of Cyp27a1 in

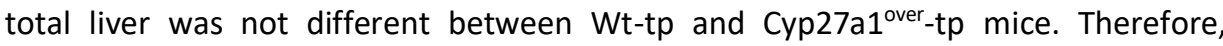
hematopoietic overexpression of Cyp27a1 is not likely to be reflected in increased $27 \mathrm{HC}$ levels in plasma and liver. Therefore, our data further point towards therapy options wherein CYP27A1 is specifically targeted in KCs. 


\section{CYP27A1 modulates intracellular cholesterol trafficking via NPC proteins}

The observation that hematopoietic Cyp27a1 overexpression leads to a reduced foamy appearance of KCs while neither cholesterol uptake, nor reverse cholesterol transport was modulated in total liver suggests that overexpression of Cyp27a1 only affected intracellular cholesterol trafficking inside KCs. Our current observations are in line with our previous findings that indicated that the agonistic effect of $27 \mathrm{HC}$ on the liver $X$ receptor (LXR) in KCs is not dominant in all liver cells, but is restricted to KCs (7). In line with our data it was shown that introducing the expression of Cyp27a1 in vitro, by transfecting cells, stimulated cholesterol efflux compared to un-transfected control cells (16). Additionally, pre-incubation of non-transfected cells with $27 \mathrm{HC}$ led to increased cholesterol efflux by $24-60 \%$ (16). Others have reported that this process may occur via LXR-stimulation, as it is known that $27 \mathrm{HC}$ and possibly another product of CYP27A1, cholestenoic acid, may be ligands of LXR, regulating a number of genes involved in lipid metabolism including Abca1 (17). Interestingly, hepatic levels of cholesteryl esters were dramatically reduced in Cyp27a $1^{\text {over }}$-tp mice compared to the levels in Wt-tp mice in our study. In line with our findings, it was demonstrated that reduced cholesteryl esters, by transgenic overexpression of the cholesteryl ester hydrolase (CEH) in macrophages, polarizes Kupffer cells to a more anti-inflammatory phenotype that attenuates hepatic lipid synthesis and accumulation (18). Furthermore, macrophage $\mathrm{CEH}$ overexpression was found to reduce atherosclerosis and necrosis in $\mathrm{Ld} / \mathrm{r}^{-/}$mice, while free cholesterol levels were unchanged $(19,20)$. In addition, accumulation of cholesteryl esters during cholesteryl ester storage disease is known to be associated with increased inflammation in different tissues and accelerated atherosclerosis (21). Although $27 \mathrm{HC}$ was previously shown to be able to influence intracellular cholesterol transport from lysosomes to the cytoplasm $(7,22)$, the mechanism involved is not yet known. The two main proteins that are involved in cholesterol transport from lysosomes to the cytoplasm are Niemann-Pick C1 (NPC1) and NPC2. While NPC1 is a multiple membrane spanning domain protein containing a sterol sensing domain, NPC2 is a small intra-lysosomal protein that has been characterized biochemically as a cholesterol-binding and transport protein (23). A defect in either of these proteins results in Niemann-Pick disease type $C$, characterized by lysosomal cholesterol accumulation and inflammation in different tissues including the liver. Interestingly, it was shown that NPC1 and NPC2-deficient cells have a severely reduced production of $27 \mathrm{HC}$, and that upon incubation with $27 \mathrm{HC}$ the lysosomal cholesterol pool in $\mathrm{NPC1}^{-/-}$fibroblasts is dramatically reduced (22). In line with these data, we observed for the first time that Cyp27a1 overexpression is able to increase NPC1 and NPC2 gene expression and protein levels. After binding, NPC2 is able to deliver cholesterol intracellular via interaction with the phospholipid bilayer, thereby reaching a putative transmembrane transporter via lateral diffusion in the plane of the membrane, or it could flip across the limiting lysosomal membrane 
and become accessible for transportation to the plasma membrane (24). Alternatively, NPC2 is able to directly interact with NPC1 or other lysosomal membrane proteins, resulting in the removal of cholesterol from the lysosome (25). In this way, NPC1 and NPC2 function as a tag team duo to mobilize cholesterol $(24,26)$. Our data suggest that $27 \mathrm{HC}$ can stimulate NPC mediated cholesterol binding and transportation to the lysosomal membrane, where it can be released out of lysosomes. Taken together, our studies provide a new mechanism by which Cyp27a1 can modulate intracellular cholesterol trafficking in macrophages, thereby leading to reduced inflammation.

While both intracellular cholesterol trafficking and cholesterol efflux can modulate inflammation, the increased NPC expression observed in Cyp27a $1^{\text {over }}$-tp mice is probably the main reason for the reduced inflammatory response observed in Cyp27a $1^{\text {over }}$-tp mice. Increased cholesterol efflux was shown to modulate the immune response and inflammation through direct and indirect anti-inflammatory mechanisms (17). However, it was reported previously that the total amount of cholesterol in cells is not correlated directly with inflammation, but rather the amount of cholesterol trapped inside lysosomes (2), suggesting an important role for NPC proteins in the inflammatory response. Moreover, studies in both arteries and in cell culture have shown that accumulated cholesterol in lysosomes cannot be decreased simply by inhibiting further uptake of lipoproteins or by increasing efflux of extralysosomal cholesterol stores (27-29). On the other hand, increasing the expression of the NPC1 protein led to increased cholesterol efflux and the inhibition of atherosclerosis (30). Thus, increased cholesterol efflux can also be a consequence of increased NPC expression. To conclude, while both pathways contributes to the reduced inflammatory response observed in the Cyp27a $1^{\text {over }}$-tp mice, stimulating cholesterol transport out of lysosomes seems to play a more dominant role.

In summary, we have shown for the first time that overexpression of Cyp27a1, specifically in macrophages, is able to reduce hepatic inflammation. Mechanistically, our data suggest that Cyp27a1 can modulate intracellular cholesterol trafficking by increasing NPC1 and NPC2 expression. This effect is likely regulated via increased intracellular levels of $27 \mathrm{HC}$, while circulating levels of $27 \mathrm{HC}$ are unchanged between the transplanted groups. Taken together, our data point towards the potential of targeted therapy options during the development of NASH and other inflammatoryrelated disorders, such as atherosclerosis. 


\section{References}

1. Wree A, Broderick L, Canbay A, Hoffman HM, Feldstein AE. From NAFLD to NASH to cirrhosisnew insights into disease mechanisms. Nat Rev Gastroenterol Hepatol. 2013;10(11):627-36.

2. Bieghs V, Verheyen F, van Gorp PJ, Hendrikx T, Wouters K, Lutjohann D, et al. Internalization of modified lipids by CD36 and SR-A leads to hepatic inflammation and lysosomal cholesterol storage in Kupffer cells. PloS one. 2012;7(3):e34378.

3. Cox BE, Griffin EE, Ullery JC, Jerome WG. Effects of cellular cholesterol loading on macrophage foam cell lysosome acidification. J Lipid Res. 2007;48(5):1012-21.

4. Jerome WG, Cox BE, Griffin EE, Ullery JC. Lysosomal cholesterol accumulation inhibits subsequent hydrolysis of lipoprotein cholesteryl ester. Microsc Microanal. 2008;14(2):138-49.

5. Wouters K, van Gorp PJ, Bieghs V, Gijbels MJ, Duimel H, Lutjohann D, et al. Dietary cholesterol, rather than liver steatosis, leads to hepatic inflammation in hyperlipidemic mouse models of nonalcoholic steatohepatitis. Hepatology. 2008;48(2):474-86.

6. Hall E, Hylemon P, Vlahcevic Z, Mallonee D, Valerie K, Avadhani N, et al. Overexpression of CYP27 in hepatic and extrahepatic cells: role in the regulation of cholesterol homeostasis. Am J Physiol Gastrointest Liver Physiol. 2001;281(1):G293-301.

7. Bieghs V, Hendrikx T, van Gorp PJ, Verheyen F, Guichot YD, Walenbergh SM, et al. The cholesterol derivative 27-hydroxycholesterol reduces steatohepatitis in mice. Gastroenterology. 2013;144(1):167-78 e1.

8. Meir K, Kitsberg D, Alkalay I, Szafer F, Rosen H, Shpitzen S, et al. Human sterol 27-hydroxylase (CYP27) overexpressor transgenic mouse model. Evidence against 27-hydroxycholesterol as a critical regulator of cholesterol homeostasis. J Biol Chem. 2002;277(37):34036-41.

9. Bieghs V, Wouters K, van Gorp PJ, Gijbels MJ, de Winther MP, Binder CJ, et al. Role of scavenger receptor $A$ and $\mathrm{CD} 36$ in diet-induced nonalcoholic steatohepatitis in hyperlipidemic mice. Gastroenterology. 2010;138(7):2477-86, 86 e1-3.

10. Hendrikx T, Bieghs V, Walenbergh SM, van Gorp PJ, Verheyen F, Jeurissen ML, et al. Macrophage specific caspase-1/11 deficiency protects against cholesterol crystallization and hepatic inflammation in hyperlipidemic mice. PloS one. 2013;8(12):e78792.

11. Vejux A, Montange T, Martine L, Zarrouk A, Riedinger JM, Lizard G. Absence of oxysterol-like side effects in human monocytic cells treated with phytosterols and oxyphytosterols. J Agric Food Chem. 2012;60(16):4060-6.

12. DuSell CD, Nelson ER, Wang X, Abdo J, Modder UI, Umetani M, et al. The endogenous selective estrogen receptor modulator 27-hydroxycholesterol is a negative regulator of bone homeostasis. Endocrinology. 2010;151(8):3675-85.

13. DuSell CD, Umetani M, Shaul PW, Mangelsdorf DJ, McDonnell DP. 27-hydroxycholesterol is an endogenous selective estrogen receptor modulator. Mol Endocrinol. 2008;22(1):65-77.

14. Umetani M, Domoto H, Gormley AK, Yuhanna IS, Cummins CL, Javitt NB, et al. 27Hydroxycholesterol is an endogenous SERM that inhibits the cardiovascular effects of estrogen. Nat Med. 2007;13(10):1185-92. 
15. Nelson ER, DuSell CD, Wang X, Howe MK, Evans G, Michalek RD, et al. The oxysterol, 27 hydroxycholesterol, links cholesterol metabolism to bone homeostasis through its actions on the estrogen and liver $X$ receptors. Endocrinology. 2011;152(12):4691-705.

16. Escher G, Krozowski Z, Croft KD, Sviridov D. Expression of sterol 27-hydroxylase (CYP27A1) enhances cholesterol efflux. J Biol Chem. 2003;278(13):11015-9.

17. Fu X, Menke JG, Chen Y, Zhou G, MacNaul KL, Wright SD, et al. 27-hydroxycholesterol is an endogenous ligand for liver $X$ receptor in cholesterol-loaded cells. J Biol Chem. 2001;276(42):38378-87.

18. Bie J, Zhao B, Marqueen KE, Wang J, Szomju B, Ghosh S. Macrophage-specific transgenic expression of cholesteryl ester hydrolase attenuates hepatic lipid accumulation and also improves glucose tolerance in ob/ob mice. Am J Physiol Endocrinol Metab. 2012;302(10):E128391.

19. Zhao B, Song J, Chow WN, St Clair RW, Rudel LL, Ghosh S. Macrophage-specific transgenic expression of cholesteryl ester hydrolase significantly reduces atherosclerosis and lesion necrosis in Ldlr mice. J Clin Invest. 2007;117(10):2983-92.

20. Zhao B, Song J, St Clair RW, Ghosh S. Stable overexpression of human macrophage cholesteryl ester hydrolase results in enhanced free cholesterol efflux from human THP1 macrophages. Am J Physiol Cell Physiol. 2007;292(1):C405-12.

21. Bernstein DL, Hulkova H, Bialer MG, Desnick RJ. Cholesteryl ester storage disease: review of the findings in 135 reported patients with an underdiagnosed disease. J Hepatol. 2013;58(6):1230 43.

22. Frolov A, Zielinski SE, Crowley JR, Dudley-Rucker N, Schaffer JE, Ory DS. NPC1 and NPC2 regulate cellular cholesterol homeostasis through generation of low density lipoprotein cholesterolderived oxysterols. J Biol Chem. 2003;278(28):25517-25.

23. Ramirez CM, Liu B, Aqul A, Taylor AM, Repa JJ, Turley SD, et al. Quantitative role of LAL, NPC2, and NPC1 in lysosomal cholesterol processing defined by genetic and pharmacological manipulations. J Lipid Res. 2011;52(4):688-98.

24. Infante RE, Wang ML, Radhakrishnan A, Kwon HJ, Brown MS, Goldstein JL. NPC2 facilitates bidirectional transfer of cholesterol between NPC1 and lipid bilayers, a step in cholesterol egress from lysosomes. Proc Natl Acad Sci U S A. 2008;105(40):15287-92.

25. Storch J, Xu Z. Niemann-Pick C2 (NPC2) and intracellular cholesterol trafficking. Biochim Biophys Acta. 2009;1791(7):671-8.

26. Subramanian K, Balch WE. NPC1/NPC2 function as a tag team duo to mobilize cholesterol. Proc Natl Acad Sci U S A. 2008;105(40):15223-4.

27. Jerome WG, Lewis JC. Early atherogenesis in White Carneau pigeons: effect of a short-term regression diet. Exp Mol Pathol. 1990;53(3):223-38.

28. Yancey PG, Jerome WG. Lysosomal cholesterol derived from mildly oxidized low density lipoprotein is resistant to efflux. J Lipid Res. 2001;42(3):317-27.

29. Yancey PG, Miles S, Schwegel J, Jerome WG. Uptake and trafficking of mildly oxidized LDL and acetylated LDL in THP-1 cells does not explain the differences in lysosomal metabolism of these two lipoproteins. Microsc Microanal. 2002;8(2):81-93. 
30. Ma X, Hu YW, Mo ZC, Li XX, Liu XH, Xiao J, et al. NO-1886 up-regulates Niemann-Pick C1 protein (NPC1) expression through liver $X$ receptor alpha signaling pathway in THP-1 macrophagederived foam cells. Cardiovasc Drugs Ther. 2009;23(3):199-206. 


\section{Supplementary Materials and methods}

\section{Liver cholesterol and cholesteryl-ester concentration measurements}

To investigate the effect of hematopoietic overexpression of CYP27a1 on cholesterol and cholesteryl-ester in the liver, liver homogenates of Wt-tp and Cyp27a $1^{\text {over-tp mice }}$ were analysed according to the manufacturing protocol using the cholesterol/cholesteryl-ester quantitation kit (ab65359; Abcam).

\section{Supplementary Figures:}

A

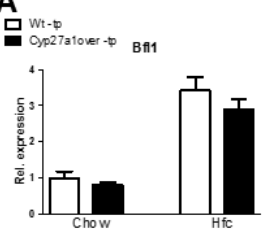

B
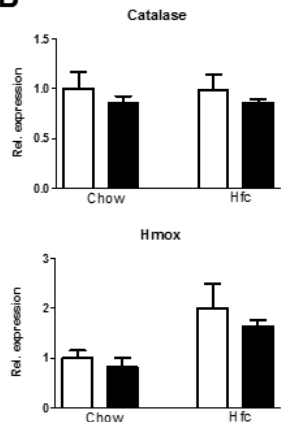

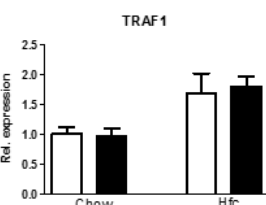

SOD2

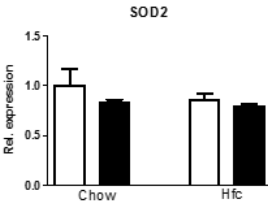

Cyp2e1

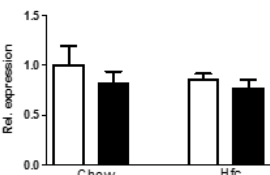

C
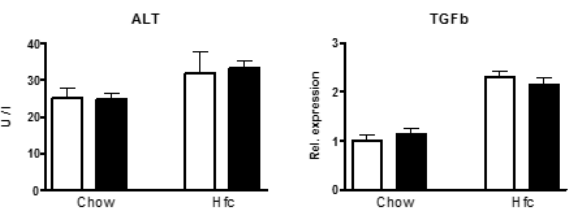

D
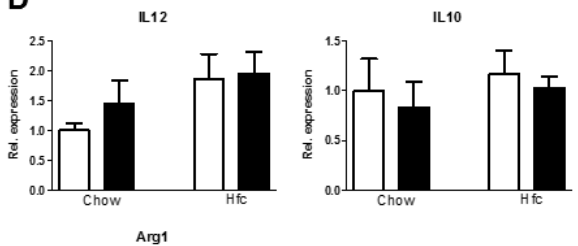

Supplementary Figure 1.

Characterization for apoptosis, oxidative stress, liver damage and macrophage polarization of $\mathrm{Wt}$-tp and Cyp27a1 ${ }^{\text {over-tp }}$ mice. Hepatic expression analysis of apoptotic genes $B f I 1$ and TRAF1 in Wt-tp and

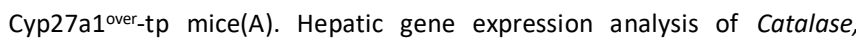
SOD2, Hmox and Cyp2E1, markers for oxidative stress(B). Plasma alanine transaminase (ALT) levels and hepatic gene expression of Tgf-beta in Wt-tp

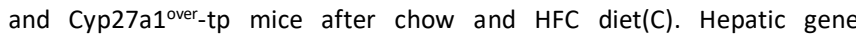
expression analysis of IL-12, IL-10 and Arginase- 1 (Arg-1) as markers for

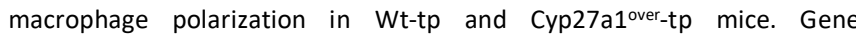
expression data were set relative to Wt-tp mice on chow diet (D). 
$\mathbf{A}$ Cyp27a10ver-tp
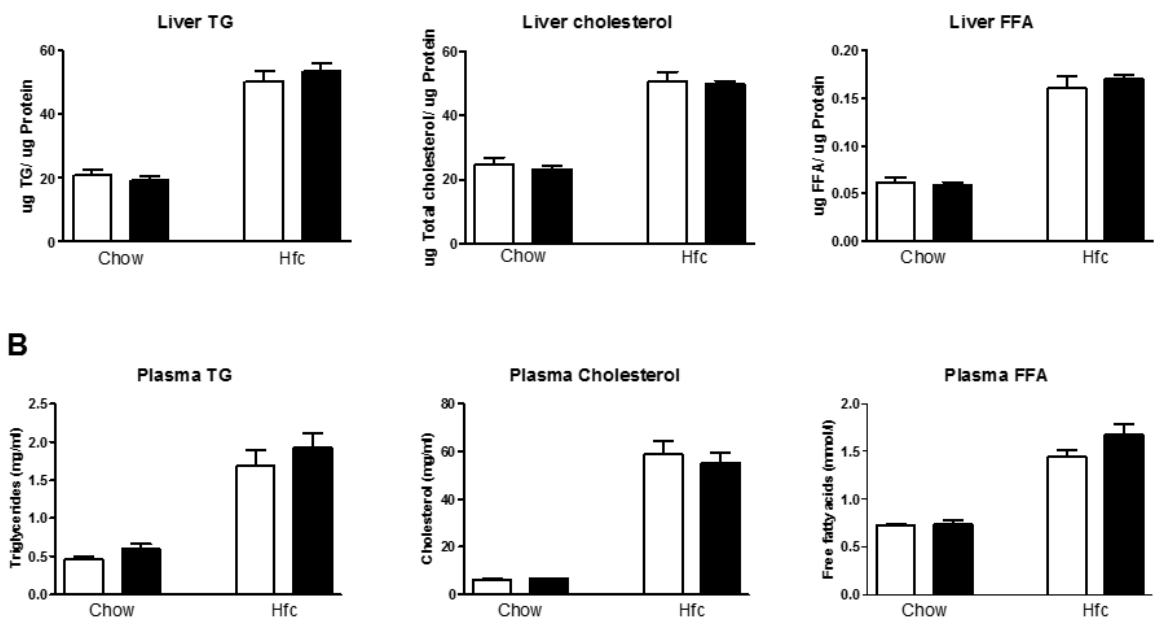

Supplementary Figure 2.

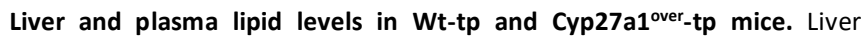
triglyceride, cholesterol and free fatty acid levels after chow and HFC diet

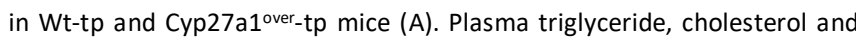
free fatty acid levels after chow and HFC diet in Wt-tp and Cyp27a $1^{\text {over-tp }}$ mice (B).

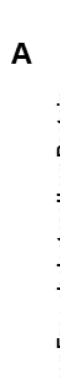

$\square \mathrm{Wt}-\mathrm{tp}$

A $\square$ Cyp27a1over -tp
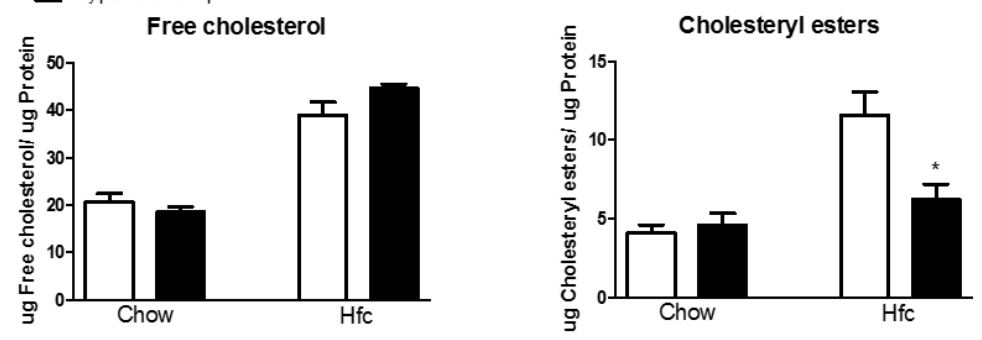

B ACAT2

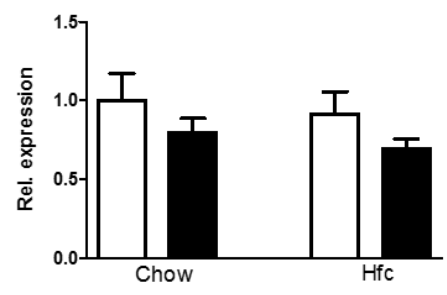




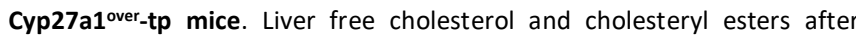

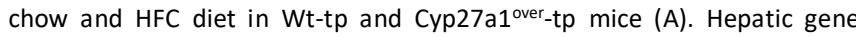
expression analysis of ACAT2 in liver of Wt-tp and Cyp27a1over-tp mice (B). Gene expression data were set relative to Wt-tp mice on chow diet. *indicates $\mathrm{p}<0.05$

A

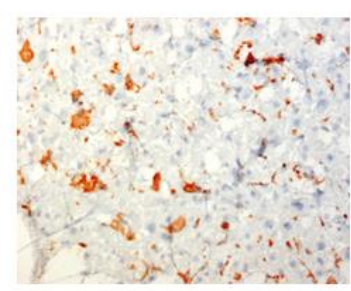

Wt-tp Hfc

C

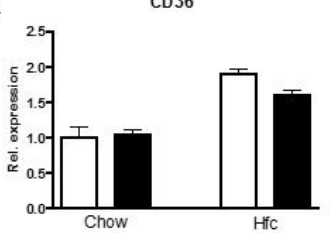

LRP1

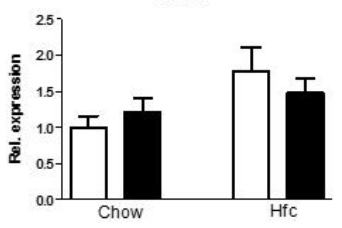

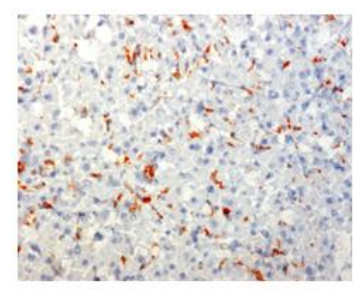

Cyp27 $7^{\text {over-tp Hfc }}$

SRA

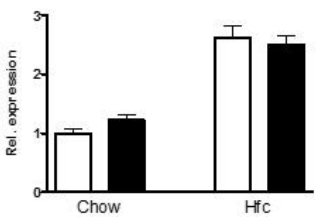

SR-B1

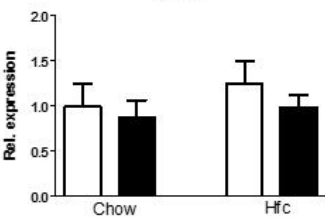

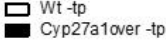

B CD68

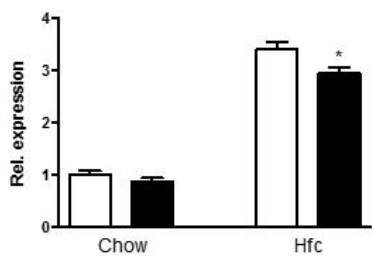

D
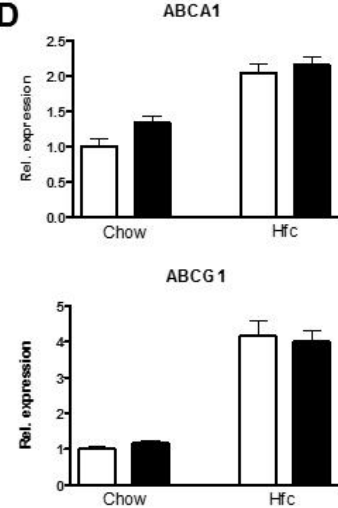

Supplementary Figure. 4.

Foamy appearance of $\mathrm{KCs}$ and hepatic cholesterol metabolism gene

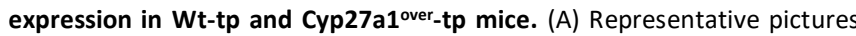
of Cd68 staining (200x magnification) after 3 months of HFC diet in Wt-tp and Cyp27a $1^{\text {over }}$-tp mice. Hepatic gene expression analysis of macrophage marker Cd68 (B), scavenger receptors Cd36, SR-A, LRP1 and SR-B1 (C), and ATP-binding cassette transporter A1 (Abca1) and G1 (Abcg1) (D) in liver of Wt-tp and Cyp27a1\%-tp mice. Gene expression data were set relative to Wt-tp mice on chow diet. *indicates $p<0.05$ 


\section{Chapter 6}

General Discussion 
While it was previously suggested that atherosclerosis and NASH are two aspects of a shared disease, evidence of a shared mechanism remained to be elucidated. In this thesis, I focused on the role of macrophages in both atherosclerosis and NASH by investigating mechanisms related to the crosstalk between lipids and inflammation. In this chapter, our novel findings are summarized below and will be discussed in detail.

\section{Novel findings of this thesis:}

- The shared etiology of NASH and atherosclerosis is linked via several mechanisms that are influenced by

- Iysosomal accumulation of oxidized cholesterol (Chapter 2)

o inflammasome activation (Chapter 3)

- The oxidation of lysosomal cholesterol, rather than the accumulated amount, is important as a trigger for inflammation (Chapter 2).

- Hematopoietic caspase-1/11 plays an important role as inflammatory mediator in atherosclerosis development (Chapter 3).

- Myeloid DLL4 does not contribute to the progression of NASH development (Chapter 4).

- Lysosomal cholesterol accumulation can be reduced by the oxysterol 27hydroxycholesterol, which increases the expression of lysosomal NPC proteins, thereby consequently reducing hepatic inflammation (Chapter 5). 


\section{NASH and atherosclerosis: shared features of a macrophage-specific response}

Foam cell formation is defined as the excessive uptake of modified lipids by macrophages due to a vicious circle of increased oxidative stress and cytokine production. These processes will stimulate atherogenesis by endothelial activation, increased LDL oxidation/retention and uptake of oxLDL by macrophages (1-4). Similarly, this process of foam cell formation has also been described in NASH where Kupffer cells show a similar foamy-like morphology (5). In line, multiple studies indicate an association between atherosclerosis and NASH (6), and it was suggested that both diseases share features of a similar mechanism (7). The uptake of oxidized lipids by scavenger receptors was one of the first features found to be involved in both atherosclerosis and NASH. Mice lacking these receptors show reduced hepatic inflammation $(8,9)$ and atherosclerosis development $(10)$. Another shared feature between atherosclerosis and NASH is macrophage inflammation, since both diseases are driven by macrophage cytokine production. For example, TNF is a major proinflammatory cytokine which is produced by plaque macrophages as well as Kupffer cells. Additionally, TNF is predominantly expressed in livers of NASH patients and stimulates atherosclerotic lesion progression and lesional foam cell formation $(11,12)$. Similar findings have been obtained for IL-12 which has been shown to be an important regulator of inflammation in early lesion development and to contribute to a fatty liver $(13,14)$. Furthermore, mouse models originally generated to investigate atherosclerosis such as $\mathrm{Ldll}^{-/}$mice are nowadays widely used to investigate NASH development when fed a Western type diet (15). Relevantly, although chronic inflammation affects the liver and the arteries simultaneously, hepatic inflammation is already pronounced after 7 days whereas atherosclerosis development is only observed after 1 month on a Western-type diet in $\mathrm{Ldll}^{-/}$mice. As NASH develops earlier it may contribute to atherosclerosis development $(5,7,16)$. In conclusion, these findings clearly show that the inflammatory processes in NASH and atherosclerosis are similar, play a major role in disease progression and influence each other. In this thesis, several shared mechanisms related to atherosclerosis and NASH were investigated, which focused on the uptake of oxidized lipids (Chapter 2), cholesterol-induced inflammation (Chapter 3 and 4) and modulation of intracellular cholesterol accumulation (Chapter 5). 


\section{Oxidized LDL as the main culprit in lysosomal cholesterol- induced inflammation}

The uptake of oxidized lipids, mainly oxidized LDL (oxLDL) is considered to be the main culprit responsible for initiating foam cell formation in macrophages (4, 17-19). Several studies have shown that uptake of oxLDL by macrophages, leading to foam cell formation, contributes to inflammation (20-22). Relevantly, recent evidence suggests that the inflammatory response triggered by foam cells may not so much depend on the amount of cholesterol taken up by macrophages but rather more on the distribution of the cholesterol within the cell $(8,23,24)$. These observations support a defective mechanism in intracellular lipid trafficking in macrophages leading to foam cell formation and inflammation. Normally, native LDL is endocytosed upon binding to the LDL receptor and is then transferred to the lysosomes for degradation. Within the lysosomal compartment, cholesteryl esters are released from the LDL particles and hydrolysed to free cholesterol by the enzyme lysosomal acid lipase. The transport of free cholesterol out of the lysosomes and into the cytoplasm is facilitated by NPC proteins (25-28). In comparison to native LDL, in vitro studies have shown that oxLDL is poorly degraded and is resistant to efflux from the lysosome into the cytoplasm and thereby therefore accumulates in lysosomes (29-32). Since the transport of free cholesterol is mainly facilitated by NPC proteins, it is likely that dysregulation of these proteins contributes to lysosomal cholesterol accumulation. Indeed, non-modified as well as modified oxLDL will accumulate within lysosomes of cells with dysfunctional NPC1 protein $(33,34)$. Lysosomal cholesterol accumulation has also been affiliated with NASH. Mice with CD36 and SR-A-deficient macrophages display normal foam cell formation when challenged with a high-fat diet, but lysosomal cholesterol accumulation and hepatic inflammation were reduced. This suggests that oxLDL accumulation is normally restricted to the lysosomal compartment, but that in these cells cholesterol metabolism and trafficking was altered $(8,9)$. Additionally, oxLDL injected in $\mathrm{Ldll}^{-/}$mice was trapped in Kupffer cells resulting in increased hepatic inflammation (35). Accordingly, pneumococcal vaccinations of these mice (as applied in Chapter 2) to increase anti-oxLDL antibody titers that prevent oxLDL uptake, led to decreased lysosomal cholesterol accumulation and reduced hepatic inflammation (23). NPC1 has been proven to protect against atherosclerosis as NPC1 mutant mice, which display lysosomal cholesterol accumulation are susceptible to atherogenesis (36). Several studies even propose that atherosclerosis displays features of an acquired lysosomal storage disorder (37). Indeed, Binder et al showed that pneumococcal vaccinations are also atheroprotective in hyperlipidemic mice (38).

In Chapter 2, we examined the specific contribution of oxLDL to macrophagedependent lysosomal cholesterol-mediated atherogenesis using pneumococcal vaccination in NPC ${ }^{\text {mut }}$-tp mice. We found that the vaccination resulted in a moderate decrease in atherosclerosis and vascular inflammation (Chapter 2). Relevantly, plaque 
progression was more advanced in immunized NPC1 ${ }^{\text {mut }}$-tp mice than in the study with hyperlipidemic mice (38) which could be explained by the fact that oxidation of cholesterol can also occur within lysosomes (39). Non-oxLDL lipids trapped within lysosomes in immunized NPC1 ${ }^{\text {mut }}$-tp mice could still be partly oxidized leading to more advanced plaques. In a previous study, we demonstrated that immunization of NPC1 ${ }^{\text {mut }}$-tp mice also lead to reduced hepatic inflammation and improved lysosomal function (Walenbergh et al, submitted). The findings in Chapter 2 highlight the importance of oxLDL in lysosomes since individuals with an impaired lipid metabolism shown only a very small increase $(0.20 \%)$ of circulating oxLDL (relative to LDL) when compared to healthy individuals (40). Overall, the findings in this thesis clearly show that oxLDL in lysosomes are causally linked to inflammation in both NASH and atherosclerosis. Several mechanisms have been proposed as to how lysosomal cholesterol accumulation can trigger inflammation (Figure 1) (41). One of them is by the inhibition of autophagy, a process involved in the degradation of cellular proteins and organelles. Autophagy plays an important role in atherosclerosis development and is also associated with NASH $(42,43)$. Additionally, dysfunctional autophagy has been implicated in lysosomal storage disorders, where improper fusion of lysosomes and autophagosomes results in inflammatory processes, as extensively reviewed by others (44-48). Furthermore, release of lysosomal enzymes, such as cathepsins into the cytoplasm upon lysosomal membrane damage or into the extracellular space as a consequence of disturbed lysosomal trafficking can lead to apoptosis and extracellular matrix degradation (49-51). Finally, inflammasome activation by cholesterols crystals also contributes to lysosomal cholesterol-induced inflammation $(52,53)$. Its role in atherosclerosis was examined in Chapter $\mathbf{3}$ and will be discussed further.

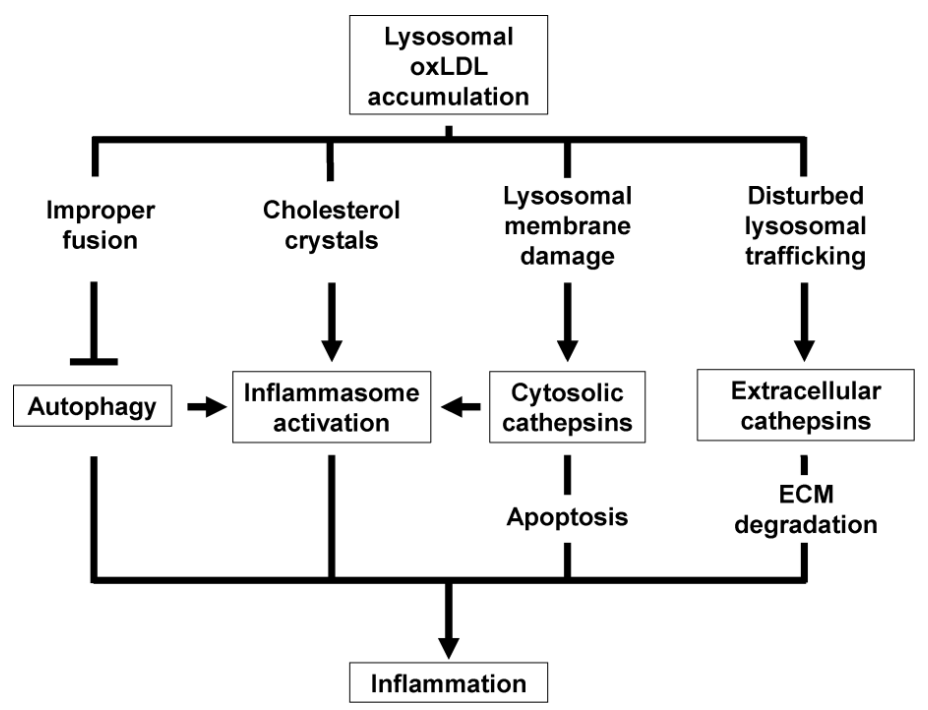


Figure 1: Proposed mechanisms for the induction of inflammation through the lysosomal accumulation of oxidized cholesterol. Several mechanisms have been proposed by Hendrikx et al. on how lysosomal cholesterol accumulation can trigger inflammation, including disturbed autophagy, inflammasome activation and the release of lysosomal enzymes such as cathepsins (41).

\section{The accumulation of lysosomal cholesterol as trigger for inflammasome-induced inflammation.}

The inflammasome is a multi-protein complex leading to caspase- 1 activation and subsequent release of mature IL-1 $\beta$ and IL-18 cytokines (54-56). Pro-inflammatory stimuli, which can induce inflammasome activation, are cholesterol crystals, reactive oxygen species and metabolic stress $(41,57,58)$. Lysosomal accumulation of free cholesterol can contribute to cholesterol crystal formation within lipid-loaded lysosomes (59). These observations indicate that lysosomal cholesterol accumulation can act as contributing factor to inflammasome activation.

Cholesterol crystals have been implicated in the progression of both atherosclerosis and NASH. Cholesterol crystals are present in atherosclerotic lesions and were associated with plaque rupture in human atherosclerotic lesions $(60,61)$. Relevantly, lysosomal damage induced by cholesterol crystals, which were identified in early atherosclerotic lesions, contributes to NLRP3 inflammasome activation in mice (52, 53). Inflammasome activation may also play an important role during $\mathrm{NASH}$, as cholesterol crystals were identified in the livers of $\mathrm{Ldll}^{-/}$mice and were associated with increased hepatic inflammation and lysosomal cholesterol accumulation $(23,24)$. Importantly, cholesterol crystal formation and lysosomal cholesterol accumulation are reduced upon pneumococcal immunization (23). In line, caspase-1 expression was reduced in immunized NPC1 ${ }^{\text {mut }}$-tp mice in the aortic, which indicates an inflammasome/caspase-1 mediated inflammatory response upon lysosomal oxLDL accumulation (Chapter 2). Indeed, oxLDL has been found to bind to toll-like receptors (TLRs) and scavenger receptors, which can result in inflammasome activation leading to caspase-1 activation $(52,60,62)$. Overall, these observations suggest a role for inflammasome activation in NASH and atherosclerosis. Since caspase-1 activation is regulated through the inflammasome, its role in atherosclerosis has been investigated. Indeed, complete caspase-1 deletion in $\mathrm{Apoe}^{-/}$mice reduced inflammation and atherosclerosis development $(63,64)$. The activation of caspase- 1 leads to the release of pro-inflammatory cytokine IL-1 $\beta$ and IL-18 mainly produced by monocytes and macrophages $(65,66)$. In this thesis, it was shown that caspase-1/11 deletion in hematopoietic cells leads to reduced atherosclerosis development and plays an important role in vascular inflammation (Chapter $\mathbf{3}$ ). In the context of NASH, complete caspase-1 deficiency protects against inflammatory responses and fibrosis during NASH development $(67,68)$. In line with our observation in Chapter $\mathbf{3}$, 
hematopoietic deletion of caspase-1/11 reduced liver inflammation by reducing the foamy cell appearance of $\mathrm{KCS}$, and the accumulation of lysosomal cholesterol. Additionally, increased cholesterol efflux and restored autophagy function were observed in $\mathrm{KCs}$ in hematopoietic caspase-1/11 mice. In conclusion, these results show that macrophage caspase-1/11 activation plays an important role in both atherosclerosis development and NASH. The production of IL-1 $\beta$ occurs downstream of caspase-1 activation through regulation of the inflammasome. Inflammatory processes which are regulated through IL-1 $\beta$ signalling are contributing to the progression of $\operatorname{NASH}(55,69)$. The naturally occurring IL-1 receptor antagonist (IL-1Ra) plays an important role in the regulation of IL- $1 \beta$ signalling by competing with IL- $1 \beta$ for its receptor $(55,70,71)$. Previous findings of our group demonstrated that IL-1Ra was elevated in plasma of NASH patients and had increased diagnostic value in combination with commonly used markers to detect NASH (72). Similar findings have been reported for atherosclerosis (73). Overall, these data clearly indicate that IL-1Ra can be used to improve diagnosis of both NASH and atherosclerosis.

\section{Notch signaling as a central regulator of metabolic function}

Notch signaling is crucial for the regulation of homeostasis within many metabolic organs (74). Metabolic processes such as lipid metabolism and glucose homeostasis are regulated by Notch signaling, as inhibition of notch leads to reduced lipid accumulation and improved insulin sensitivity in mice (75-80). In humans, downstream targets of Notch have been found to correlate well with insulin resistance and NAFLD (81). Relevantly, DLL4-induced Notch signaling has been implicated in macrophage inflammatory responses and is co-localizes with macrophages in human atherosclerotic lesions (82). In this thesis it was shown that myeloid DLL4 deficiency could not reduce hepatic inflammation in Ldlr-/- mice (Chapter 4). This is in contrast with previous findings, where global inhibition of Notch ligand Delta-Like Ligand-4 (DLL4) attenuated atherosclerosis by altering the macrophage-mediated inflammatory response in mice (75). Furthermore, lipid and macrophage content were also reduced upon global inhibition of DLL4, suggesting an important role for DLL4-Notch signaling in macrophages. Supported by co-culture experiments by Fung et al, our findings can be explained by the contribution of other DLL4 expressing to inflammation cells as in our model only myeloid DLL4 is ablated (82). As macrophages comprise only a small part of the liver, the contribution of hepatocytes, which also can express DLL4, could explain our findings. DLL4 signaling is mediated through all four Notch receptors which are known to be expressed on macrophages (82-85). Alternatively, the effect seen in myeloid DLL4 deficient mice could be obscured by the $A$ disintegrin and metalloproteinase (ADAM)-mediated shedding of DLL4, releasing a soluble DLL4 that could in turn activate macrophage Notch signaling $(82,86)$. ADAMs play an important role in the regulation of Notch as they catalyze the proteolytic cleavage of Notch receptors and their ligands $(87,88)$. 
Apart from their role in Notch signaling, ADAMs are also involved in the release or "shedding" of other surface molecules (89-91). It is well known that the infiltration of inflammatory cells such as monocytes/macrophages in the context of atherosclerosis is controlled by cytokine and chemokine release $(1,92,93)$. Some of these processes are regulated through Notch signaling since it was demonstrated that ADAM10 is an important mediator in Notch-DLL4 dependent regulation of IL- 6 in human endothelial cells, indicating that ADAM10 plays an important role in vascular inflammation (94). Relevantly, in human atherosclerotic lesions, ADAM10 is highly expressed in lesional foam cells and is increased during plaque progression (95). Myeloid ADAM10 influences plaque stability by regulating leukocyte recruitment, production of inflammatory mediators and affecting extracellular matrix degradation, demonstrating a causal role for the proteinase in atherosclerosis (96). With regard to extracellular matrix degradation it was reported that global inhibition of DLL4 led to reduced expression levels of matrix metallopeptidase 9 (MMP-9) in peritoneal macrophages (75), which may suggest again a link in ADAM10-DLL4 signaling as ADAM10 deficiency also reduces MMP-9 levels (96). ADAM17, also known as TNF $\alpha$ converting enzyme (TACE), is highly expressed in atherosclerotic lesions, has also been associated with metabolic processes in the liver and suggested to play role in NASH development (97-100). Moreover, ADAMs may be associated with lysosomes and are upon stimulation directed to lipid rafts within cell membrane (101). Lysosomal function is linked to Notch signaling as impaired acidification of the lysosomal compartment reduces Notch signaling (102). OxLDL stimulated macrophages display similarities as lysosomal $\mathrm{pH}$ is increased upon stimulation (103) but its effect on Notch signaling in response to inflammation is unknown. Overall, the influences of lysosomal $\mathrm{pH}$ on Notch signaling with regard to inflammation could be interesting to investigate further as well as the contribution of soluble DLL4 to atherosclerosis and NASH development and progression. In addition, it would be very interesting to further elucidate the role of both ADAM and Notch signaling in relation to atherosclerosis and NASH. 


\section{Modulating intracellular cholesterol transport influences lysosomal cholesterol-induced inflammation.}

We not only demonstrated that the oxidation of lysosomal cholesterol, rather than the total amount of accumulated lysosomal cholesterol, contributes to inflammatory processes in atherosclerosis (Chapter 2) but we also showed this to be the case in NASH (Walenbergh et al, submitted). It is likely that reducing lysosomal cholesterol accumulation by stimulating cholesterol efflux from the lysosomes to the cytoplasm will reduce lysosomal cholesterol-induced inflammation in both diseases.

Oxidation of LDL, leads to the formation of oxysterols which are believed to be one of the biological components of oxLDL. These oxysterols show biological activities ranging from inhibition of sterol synthesis and sterol efflux thereby affecting cholesterol metabolism or even macrophage activation (104-107). It was reported that foam cell formation is promoted upon oxysterol stimulation, e.g. 25hydroxycholesterol and 7-ketocholesterol stimulate the formation and accumulation of cholesterol esters (108). Additionally, 7-ketocholesterol was found to promote monocyte differentiation (109). Furthermore, 25-hydroxycholesterol has the ability to induce IL-1 $\beta$ production in human macrophages, i.e. stimulating inflammasome activation and caspase-1 mediated processes (110). Some oxysterols also have the ability to induce Notch signaling in osteogenic processes (111). With regard to DLL4, global inhibition of DLL4 has been shown to reduce osteogenic regulators and bone morphogenetic proteins (BMPs) leading to reduced calcification of the aortas (75). In addition, early atherosclerotic lesions showed features of osteogenic processes and were associated with inflammation (112). Overall, these findings show that oxysterols play an important role in cholesterol metabolism and inflammation. One of the abundant oxysterols found in the human circulation is 27-hydroxycholesterol (27-HC), an oxysterol that plays an important role in the bile acid synthesis pathway. The mitochondrial enzyme CYP27A1 is responsible for the conversion of cholesterol to 27$\mathrm{HC}$ in macrophages (104). In atherosclerotic lesions high amounts of $27-\mathrm{HC}$ can be found, whereas NPC1mut fibroblasts/macrophages display reduced synthesis of 27-HC which reflex in reduced LXR-regulated cholesterol efflux. (36, 104, 113-115). Patients with cerebrotendinous xanthomatosis (CTX) who lack the mitochondrial enzyme CYP27A1 develop premature atherosclerosis, suggesting for a protective role for 27HC and CYP27A1 $(115,116)$. Indeed, Frolov et al. demonstrated that the increase in total cholesterol content observed in NPC1mut fibroblasts can be reduced by 27-HC stimulation (113). This observation suggests that 27-HC could lower lysosomal cholesterol content; a hypothesis that can supported by previous findings of our group showing that hematopoietic deletion of CYP27A1 led to increased hepatic inflammation and was associated with increased lysosomal cholesterol accumulation in KCs (24). Relevantly, daily administration of 27-HC in Ldlr-/- mice led to a significant reduction in hepatic inflammation and foam cell size of $\mathrm{KCs}$ in combination with a reduction in lysosomal cholesterol accumulation and cholesterol crystals (24). 
Additionally, 27-HC can modulate macrophage polarization to a more antiinflammatory phenotype by promoting $\mathrm{IL}-10$ secretion and liver $\mathrm{X}$ receptor (LXR) expression (117). Based on these findings it is proposed that 27-HC stimulates the transport of cholesterol from the lysosomes to the cytoplasm and consequently reduces inflammation. The mechanisms involved in modulating intracellular cholesterol metabolism are unknown. As demonstrated in Chapter 5, hematopoietic CYP27A1 overexpression reduces hepatic inflammation, independently of 27-HC levels. Additionally, we found that CYP27A1 modulates intracellular cholesterol trafficking via NPC proteins. Overall, these data clearly indicate that $27-\mathrm{HC}$ has antiinflammatory effects by lowering intracellular cholesterol content via NPC1 proteins. Besides its role in modulating intracellular cholesterol by affecting lysosomal transport proteins (Chapter 5), 27-HC is also a well-known ligand for LXR. LXRs are important regulators for maintaining cholesterol homeostasis and can be described as functional cholesterol sensors. Their biological activity is broad and can affect cholesterol transport from the circulation, regulate cholesterol efflux and uptake in the liver and modulate cellular uptake by activating their downstream targets such as SREBP, ABCA1 and ABCG1 (118, 119). Therefore, the high concentrations $27-H C$ found in atherosclerotic plaques and foam cells may be of a protective nature (104) as discussed previously. In contrast, oxysterols are suggested to have antagonistic effects on LXR (120). Bieghs et al clearly demonstrated that the antagonistic effects of 27-HC on LXR were effective in whole liver (i.e. hepatocytes and KCs) whereas the agonistic effects of 27-HC were limited to KCs (24) which may explain the discrepancy observed in atherosclerotic lesions. The findings that mainly oxidized cholesterol is trapped in lysosomes and that total cholesterol uptake does not contribute to inflammation (Chapter 2; Walenbergh et al, manuscript submitted), together with the antiinflammatory effect of 27-HC mediated by NPC proteins, provides valuable information for the development of therapeutic strategies to lower lysosomal cholesterol accumulation.

In vitro studies, however, have found that $27-\mathrm{HC}$ can also have pro-inflammatory effects on macrophages and other tissues (121-125), which contradicts our findings in Chapter 5. One possible explanation for these observations is that $27-\mathrm{HC}$ also functions as of a selective estrogen receptor modulator. Therefore, 27-HC can exert both agonistic as well as antagonistic functions on estrogen receptors (ER) which are divergent from natural occurring ER ligands (126-128). The cell lines (THP-1, U937) or human tissue used in these studies were mainly of male origin $(129,130)$, whereas the mice used in Chapter 5 or by Bieghs et al. (24) were all female, i.e. with higher estrogen levels. As estrogen can modulate macrophage inflammation independently of the LXR pathway (131-133), we speculate that 27-HC may function as an ER modulator leading to the differences between literature and Chapter 5. Further research is necessary to characterize the influence of 27-HC on ER-mediated effects on macrophage inflammation before $27-\mathrm{HC}$ can be used as therapeutic agent for lowering intracellular cholesterol. 
In conclusion, this thesis provides novel insights in macrophage specific mechanisms of lysosomal oxidized lipid accumulation, leading to inflammatory processes that contribute to the progression of both atherosclerosis and NASH. These diseases do not only display similar inflammatory mechanisms, but also mutually influence each other's progression. Such mechanistic insights provide valuable information for the development of novel therapeutic interventions or even diagnostic tools. 


\section{Reference:}

1. Hansson GK, Libby P. The immune response in atherosclerosis: a double-edged sword. Nature reviews Immunology. 2006 Jul;6(7):508-19. PubMed PMID: 16778830.

2. Libby P. Atherosclerosis: the new view. Sci Am. 2002 May;286(5):46-55. PubMed PMID: 11951331. Epub 2002/04/16. eng.

3. Libby P, Ridker PM, Hansson GK. Progress and challenges in translating the biology of atherosclerosis. Nature. 2011 May 19;473(7347):317-25. PubMed PMID: 21593864.

4. Linton MF, Yancey PG, Davies SS, Vickers KC, Jerome WGJ, Linton EF. The Role of Lipids and Lipoproteins in Atherosclerosis. In: De Groot LJ, Beck-Peccoz P, Chrousos G, Dungan K, Grossman A, Hershman JM, et al., editors. Endotext. South Dartmouth (MA)2000.

5. Wouters K, van Gorp PJ, Bieghs V, Gijbels MJ, Duimel H, Lutjohann D, et al. Dietary cholesterol, rather than liver steatosis, leads to hepatic inflammation in hyperlipidemic mouse models of nonalcoholic steatohepatitis. Hepatology. 2008 Aug;48(2):474-86. PubMed PMID: 18666236.

6. Xu X, Lu L, Dong Q, Li X, Zhang N, Xin Y, et al. Research advances in the relationship between nonalcoholic fatty liver disease and atherosclerosis. Lipids in health and disease. 2015;14:158. PubMed PMID: 26631018. Pubmed Central PMCID: 4668687.

7. Bieghs V, Rensen PC, Hofker MH, Shiri-Sverdlov R. NASH and atherosclerosis are two aspects of a shared disease: central role for macrophages. Atherosclerosis. 2012 Feb;220(2):287-93. PubMed PMID: 21930273.

8. Bieghs V, Verheyen F, van Gorp PJ, Hendrikx T, Wouters K, Lutjohann D, et al. Internalization of modified lipids by CD36 and SR-A leads to hepatic inflammation and lysosomal cholesterol storage in Kupffer cells. PloS one. 2012;7(3):e34378. PubMed PMID: 22470565. Pubmed Central PMCID: 3314620.

9. Bieghs V, Wouters K, van Gorp PJ, Gijbels MJ, de Winther MP, Binder CJ, et al. Role of scavenger receptor $A$ and $\mathrm{CD} 36$ in diet-induced nonalcoholic steatohepatitis in hyperlipidemic mice. Gastroenterology. 2010 Jun;138(7):2477-86, 86 e1-3. PubMed PMID: 20206177. Pubmed Central PMCID: 3114629.

10. Manning-Tobin JJ, Moore KJ, Seimon TA, Bell SA, Sharuk M, Alvarez-Leite Jl, et al. Loss of SR-A and CD36 activity reduces atherosclerotic lesion complexity without abrogating foam cell formation in hyperlipidemic mice. Arteriosclerosis, thrombosis, and vascular biology. 2009 Jan;29(1):19-26. PubMed PMID: 18948635. Pubmed Central PMCID: 2666043.

11. Xanthoulea S, Gijbels MJ, van der Made I, Mujcic H, Thelen M, Vergouwe MN, et al. P55 tumour necrosis factor receptor in bone marrow-derived cells promotes atherosclerosis development in low-density lipoprotein receptor knock-out mice. Cardiovasc Res. 2008 Nov 1;80(2):309-18. PubMed PMID: 18628255.

12. Crespo J, Cayon A, Fernandez-Gil P, Hernandez-Guerra M, Mayorga M, Dominguez-Diez A, et al. Gene expression of tumor necrosis factor alpha and TNF-receptors, p55 and p75, in nonalcoholic steatohepatitis patients. Hepatology. 2001 Dec;34(6):1158-63. PubMed PMID: 11732005.

13. Kremer M, Thomas E, Milton RJ, Perry AW, van Rooijen N, Wheeler MD, et al. Kupffer cell and interleukin-12-dependent loss of natural killer T cells in hepatosteatosis. Hepatology. 2010 Jan;51(1):130-41. PubMed PMID: 20034047. Pubmed Central PMCID: 3761962. 
14. Lee TS, Yen HC, Pan CC, Chau LY. The role of interleukin 12 in the development of atherosclerosis in ApoE-deficient mice. Arteriosclerosis, thrombosis, and vascular biology. 1999 Mar;19(3):73442. PubMed PMID: 10073981.

15. Bieghs V, Van Gorp PJ, Wouters K, Hendrikx T, Gijbels MJ, van Bilsen M, et al. LDL receptor knock-out mice are a physiological model particularly vulnerable to study the onset of inflammation in non-alcoholic fatty liver disease. PloS one. 2012;7(1):e30668. PubMed PMID: 22295101. Pubmed Central PMCID: 3266276.

16. Ma Y, Wang W, Zhang J, Lu Y, Wu W, Yan H, et al. Hyperlipidemia and atherosclerotic lesion development in Ldlr-deficient mice on a long-term high-fat diet. PloS one. 2012;7(4):e35835. PubMed PMID: 22558236. Pubmed Central PMCID: 3338468. Epub 2012/05/05. eng.

17. Morel DW, Hessler JR, Chisolm GM. Low density lipoprotein cytotoxicity induced by free radical peroxidation of lipid. Journal of lipid research. 1983 Aug;24(8):1070-6. PubMed PMID: 6415194.

18. Steinbrecher UP, Parthasarathy S, Leake DS, Witztum JL, Steinberg D. Modification of low density lipoprotein by endothelial cells involves lipid peroxidation and degradation of low density lipoprotein phospholipids. Proceedings of the National Academy of Sciences of the United States of America. 1984 Jun;81(12):3883-7. PubMed PMID: 6587396. Pubmed Central PMCID: 345326.

19. Quinn MT, Parthasarathy S, Fong LG, Steinberg D. Oxidatively modified low density lipoproteins: a potential role in recruitment and retention of monocyte/macrophages during atherogenesis. Proceedings of the National Academy of Sciences of the United States of America. 1987 May;84(9):2995-8. PubMed PMID: 3472245. Pubmed Central PMCID: 304787

20. Groeneweg $M$, Kanters E, Vergouwe MN, Duerink H, Kraal G, Hofker MH, et al. Lipopolysaccharide-induced gene expression in murine macrophages is enhanced by prior exposure to oxLDL. Journal of lipid research. 2006 Oct;47(10):2259-67. PubMed PMID: 16840796.

21. Chen C, Khismatullin DB. Oxidized low-density lipoprotein contributes to atherogenesis via coactivation of macrophages and mast cells. PloS one. 2015;10(3):e0123088. PubMed PMID: 25811595. Pubmed Central PMCID: PMC4374860.

22. Walenbergh SM, Koek GH, Bieghs V, Shiri-Sverdlov R. Non-alcoholic steatohepatitis: the role of oxidized low-density lipoproteins. J Hepatol. 2013 Apr;58(4):801-10. PubMed PMID: 23183522.

23. Bieghs V, van Gorp PJ, Walenbergh SM, Gijbels MJ, Verheyen F, Buurman WA, et al. Specific immunization strategies against oxidized low-density lipoprotein: a novel way to reduce nonalcoholic steatohepatitis in mice. Hepatology. 2012 Sep;56(3):894-903. PubMed PMID: 22334337. Pubmed Central PMCID: PMC3374908.

24. Bieghs V, Hendrikx T, van Gorp PJ, Verheyen F, Guichot YD, Walenbergh SM, et al. The cholesterol derivative 27-hydroxycholesterol reduces steatohepatitis in mice. Gastroenterology. 2013 Jan;144(1):167-78 e1. PubMed PMID: 23041327.

25. de Duve C. Lysosomes revisited. European journal of biochemistry / FEBS. 1983 Dec 15;137(3):391-7. PubMed PMID: 6319122.

26. Dell'Angelica EC, Mullins C, Caplan S, Bonifacino JS. Lysosome-related organelles. FASEB journal : official publication of the Federation of American Societies for Experimental Biology. 2000 Jul;14(10):1265-78. PubMed PMID: 10877819. 
27. Kwon HJ, Abi-Mosleh L, Wang ML, Deisenhofer J, Goldstein JL, Brown MS, et al. Structure of Nterminal domain of NPC1 reveals distinct subdomains for binding and transfer of cholesterol. Cell. 2009 Jun 26;137(7):1213-24. PubMed PMID: 19563754. Pubmed Central PMCID: 2739658.

28. Sugii S, Reid PC, Ohgami N, Du H, Chang TY. Distinct endosomal compartments in early trafficking of low density lipoprotein-derived cholesterol. The Journal of biological chemistry. 2003 Jul 18;278(29):27180-9. PubMed PMID: 12721287.

29. Griffin EE, Ullery JC, Cox BE, Jerome WG. Aggregated LDL and lipid dispersions induce lysosomal cholesteryl ester accumulation in macrophage foam cells. Journal of lipid research. 2005 Oct;46(10):2052-60. PubMed PMID: 16024919.

30. Jerome WG, Cash C, Webber R, Horton R, Yancey PG. Lysosomal lipid accumulation from oxidized low density lipoprotein is correlated with hypertrophy of the Golgi apparatus and transGolgi network. Journal of lipid research. 1998 Jul;39(7):1362-71. PubMed PMID: 9684738.

31. Jerome WG, Cox BE, Griffin EE, Ullery JC. Lysosomal cholesterol accumulation inhibits subsequent hydrolysis of lipoprotein cholesteryl ester. Microscopy and microanalysis : the official journal of Microscopy Society of America, Microbeam Analysis Society, Microscopical Society of Canada. 2008 Apr;14(2):138-49. PubMed PMID: 18312718. Pubmed Central PMCID: 2837357.

32. Yancey PG, Jerome WG. Lysosomal cholesterol derived from mildly oxidized low density lipoprotein is resistant to efflux. Journal of lipid research. 2001 Mar;42(3):317-27. PubMed PMID: 11254742.

33. Beltroy EP, Richardson JA, Horton JD, Turley SD, Dietschy JM. Cholesterol accumulation and liver cell death in mice with Niemann-Pick type C disease. Hepatology. 2005 Oct;42(4):886-93. PubMed PMID: 16175610.

34. Loftus SK, Morris JA, Carstea ED, Gu JZ, Cummings C, Brown A, et al. Murine model of NiemannPick C disease: mutation in a cholesterol homeostasis gene. Science. 1997 Jul 11;277(5323):232 5. PubMed PMID: 9211850.

35. Bieghs V, Walenbergh SM, Hendrikx T, van Gorp PJ, Verheyen F, Olde Damink SW, et al. Trapping of oxidized LDL in lysosomes of Kupffer cells is a trigger for hepatic inflammation. Liver Int. 2013 Aug;33(7):1056-61. PubMed PMID: 23617943. Pubmed Central PMCID: PMC4040540.

36. Zhang JR, Coleman T, Langmade SJ, Scherrer DE, Lane L, Lanier MH, et al. Niemann-Pick C1 protects against atherosclerosis in mice via regulation of macrophage intracellular cholesterol trafficking. The Journal of clinical investigation. 2008 Jun;118(6):2281-90. PubMed PMID: 18483620. Pubmed Central PMCID: 2381744.

37. Jerome WG. Advanced atherosclerotic foam cell formation has features of an acquired lysosomal storage disorder. Rejuvenation research. 2006 Summer;9(2):245-55. PubMed PMID: 16706652.

38. Binder CJ, Horkko S, Dewan A, Chang MK, Kieu EP, Goodyear CS, et al. Pneumococcal vaccination decreases atherosclerotic lesion formation: molecular mimicry between Streptococcus pneumoniae and oxidized LDL. Nature medicine. 2003 Jun;9(6):736-43. PubMed PMID: 12740573.

39. Wen Y, Leake DS. Low density lipoprotein undergoes oxidation within lysosomes in cells. Circulation research. 2007 May 11;100(9):1337-43. PubMed PMID: 17446432. 
40. Holvoet P, Kritchevsky SB, Tracy RP, Mertens A, Rubin SM, Butler J, et al. The metabolic syndrome, circulating oxidized LDL, and risk of myocardial infarction in well-functioning elderly people in the health, aging, and body composition cohort. Diabetes. 2004 Apr;53(4):1068-73. PubMed PMID: 15047623.

41. Hendrikx T, Walenbergh SM, Hofker MH, Shiri-Sverdlov R. Lysosomal cholesterol accumulation: driver on the road to inflammation during atherosclerosis and non-alcoholic steatohepatitis. Obes Rev. 2014 May;15(5):424-33. PubMed PMID: 24629059.

42. Liao X, Sluimer JC, Wang Y, Subramanian M, Brown K, Pattison JS, et al. Macrophage autophagy plays a protective role in advanced atherosclerosis. Cell Metab. 2012 Apr 4;15(4):545-53. PubMed PMID: 22445600. Pubmed Central PMCID: PMC3322248.

43. Hendrikx T, Bieghs V, Walenbergh SM, van Gorp PJ, Verheyen F, Jeurissen ML, et al. Macrophage specific caspase-1/11 deficiency protects against cholesterol crystallization and hepatic inflammation in hyperlipidemic mice. PloS one. 2013;8(12):e78792. PubMed PMID: 24312444. Pubmed Central PMCID: PMC3846469.

44. Choi AM, Ryter SW, Levine B. Autophagy in human health and disease. N Engl J Med. 2013 Feb 14;368(7):651-62. PubMed PMID: 23406030.

45. Raben N, Shea L, Hill V, Plotz P. Monitoring autophagy in lysosomal storage disorders. Methods Enzymol. 2009;453:417-49. PubMed PMID: 19216919. Pubmed Central PMCID: PMC2669416.

46. Settembre C, Fraldi A, Jahreiss L, Spampanato C, Venturi C, Medina D, et al. A block of autophagy in Iysosomal storage disorders. Hum Mol Genet. 2008 Jan 1;17(1):119-29. PubMed PMID: 17913701.

47. Settembre C, Fraldi A, Rubinsztein DC, Ballabio A. Lysosomal storage diseases as disorders of autophagy. Autophagy. 2008 Jan;4(1):113-4. PubMed PMID: 18000397.

48. Tessitore A, Pirozzi M, Auricchio A. Abnormal autophagy, ubiquitination, inflammation and apoptosis are dependent upon lysosomal storage and are useful biomarkers of mucopolysaccharidosis VI. PathoGenetics. 2009;2(1):4. PubMed PMID: 19531206. Pubmed Central PMCID: 2708151.

49. Li W, Yuan XM, Olsson AG, Brunk UT. Uptake of oxidized LDL by macrophages results in partial lysosomal enzyme inactivation and relocation. Arteriosclerosis, thrombosis, and vascular biology. 1998 Feb;18(2):177-84. PubMed PMID: 9484981.

50. Porter K, Lin Y, Liton PB. Cathepsin B is up-regulated and mediates extracellular matrix degradation in trabecular meshwork cells following phagocytic challenge. PloS one. 2013;8(7):e68668. PubMed PMID: 23844232. Pubmed Central PMCID: PMC3700899.

51. Sukhova GK, Shi GP, Simon DI, Chapman HA, Libby P. Expression of the elastolytic cathepsins S and $\mathrm{K}$ in human atheroma and regulation of their production in smooth muscle cells. The Journal of clinical investigation. 1998 Aug 1;102(3):576-83. PubMed PMID: 9691094. Pubmed Central PMCID: PMC508918.

52. Duewell P, Kono H, Rayner KJ, Sirois CM, Vladimer G, Bauernfeind FG, et al. NLRP3 inflammasomes are required for atherogenesis and activated by cholesterol crystals. Nature. 2010 Apr 29;464(7293):1357-61. PubMed PMID: 20428172. Pubmed Central PMCID: 2946640.

53. Rajamaki K, Lappalainen J, Oorni K, Valimaki E, Matikainen S, Kovanen PT, et al. Cholesterol crystals activate the NLRP3 inflammasome in human macrophages: a novel link between 
cholesterol metabolism and inflammation. PloS one. 2010;5(7):e11765. PubMed PMID: 20668705. Pubmed Central PMCID: 2909263. Epub 2010/07/30. eng.

54. Schroder K, Tschopp J. The inflammasomes. Cell. 2010 Mar 19;140(6):821-32. PubMed PMID: 20303873.

55. Szabo G, Petrasek J. Inflammasome activation and function in liver disease. Nature reviews Gastroenterology \& hepatology. 2015 Jul;12(7):387-400. PubMed PMID: 26055245.

56. Man SM, Kanneganti TD. Converging roles of caspases in inflammasome activation, cell death and innate immunity. Nature reviews Immunology. 2016 Jan;16(1):7-21. PubMed PMID: 26655628.

57. Latz E. The inflammasomes: mechanisms of activation and function. Curr Opin Immunol. 2010 Feb;22(1):28-33. PubMed PMID: 20060699. Pubmed Central PMCID: PMC2844336.

58. Zhou R, Yazdi AS, Menu P, Tschopp J. A role for mitochondria in NLRP3 inflammasome activation. Nature. 2011 Jan 13;469(7329):221-5. PubMed PMID: 21124315.

59. Tangirala RK, Jerome WG, Jones NL, Small DM, Johnson WJ, Glick JM, et al. Formation of cholesterol monohydrate crystals in macrophage-derived foam cells. Journal of lipid research. 1994 Jan;35(1):93-104. PubMed PMID: 8138726.

60. Grebe A, Latz E. Cholesterol crystals and inflammation. Current rheumatology reports. 2013 Mar;15(3):313. PubMed PMID: 23412688. Pubmed Central PMCID: 3623938.

61. Small DM. George Lyman Duff memorial lecture. Progression and regression of atherosclerotic lesions. Insights from lipid physical biochemistry. Arteriosclerosis. 1988 Mar-Apr;8(2):103-29. PubMed PMID: 3348756.

62. Stewart CR, Stuart LM, Wilkinson K, van Gils JM, Deng J, Halle A, et al. CD36 ligands promote sterile inflammation through assembly of a Toll-like receptor 4 and 6 heterodimer. Nature immunology. 2010 Feb;11(2):155-61. PubMed PMID: 20037584. Pubmed Central PMCID: 2809046.

63. Usui F, Shirasuna K, Kimura H, Tatsumi K, Kawashima A, Karasawa T, et al. Critical role of caspase-1 in vascular inflammation and development of atherosclerosis in Western diet-fed apolipoprotein E-deficient mice. Biochem Biophys Res Commun. 2012 Aug 24;425(2):162-8 PubMed PMID: 22819845. Epub 2012/07/24. eng.

64. Gage J, Hasu M, Thabet M, Whitman SC. Caspase-1 deficiency decreases atherosclerosis in apolipoprotein E-null mice. Can J Cardiol. 2012 Mar-Apr;28(2):222-9. PubMed PMID: 22265992. Epub 2012/01/24. eng.

65. Netea MG, Nold-Petry CA, Nold MF, Joosten LA, Opitz B, van der Meer JH, et al. Differential requirement for the activation of the inflammasome for processing and release of IL-1beta in monocytes and macrophages. Blood. 2009 Mar 5;113(10):2324-35. PubMed PMID: 19104081. Pubmed Central PMCID: 2652374.

66. Granowitz EV, Clark BD, Vannier E, Callahan MV, Dinarello CA. Effect of interleukin-1 (IL-1) blockade on cytokine synthesis: I. IL-1 receptor antagonist inhibits IL-1-induced cytokine synthesis and blocks the binding of IL-1 to its type II receptor on human monocytes. Blood. 1992 May 1;79(9):2356-63. PubMed PMID: 1533322.

67. Dixon LJ, Berk M, Thapaliya S, Papouchado BG, Feldstein AE. Caspase-1-mediated regulation of fibrogenesis in diet-induced steatohepatitis. Laboratory investigation; a journal of technical 
methods and pathology. 2012 May;92(5):713-23. PubMed PMID: 22411067. Pubmed Central PMCID: 3808241.

68. Dixon LJ, Flask CA, Papouchado BG, Feldstein AE, Nagy LE. Caspase-1 as a central regulator of high fat diet-induced non-alcoholic steatohepatitis. PloS one. 2013;8(2):e56100. PubMed PMID: 23409132. Pubmed Central PMCID: 3567081.

69. Ganz M, Szabo G. Immune and inflammatory pathways in NASH. Hepatol Int. 2013 Dec;7 Suppl 2:771-81. PubMed PMID: 24587847. Pubmed Central PMCID: PMC3918407.

70. Dinarello CA. Immunological and inflammatory functions of the interleukin-1 family. Annu Rev Immunol. 2009;27:519-50. PubMed PMID: 19302047.

71. Dinarello CA. The role of the interleukin-1-receptor antagonist in blocking inflammation mediated by interleukin-1. N Engl J Med. 2000 Sep 7;343(10):732-4. PubMed PMID: 10974140.

72. Hendrikx T, Walenbergh SM, Jeurissen ML, Houben T, van Gorp PJ, Lindsey PJ, et al. Plasma IL-1 receptor antagonist levels correlate with the development of non-alcoholic steatohepatitis. Biomark Med. 2015;9(12):1301-9. PubMed PMID: 26612588.

73. Olofsson PS, Sheikine Y, Jatta K, Ghaderi M, Samnegard A, Eriksson P, et al. A functional interleukin-1 receptor antagonist polymorphism influences atherosclerosis development. The interleukin-1beta:interleukin-1 receptor antagonist balance in atherosclerosis. Circ J. 2009 Aug;73(8):1531-6. PubMed PMID: 19574724.

74. Bi P, Kuang $\mathrm{S}$. Notch signaling as a novel regulator of metabolism. Trends in endocrinology and metabolism: TEM. 2015 May;26(5):248-55. PubMed PMID: 25805408. Pubmed Central PMCID: 4435535.

75. Fukuda D, Aikawa E, Swirski FK, Novobrantseva TI, Kotelianski V, Gorgun CZ, et al. Notch ligand delta-like 4 blockade attenuates atherosclerosis and metabolic disorders. Proceedings of the National Academy of Sciences of the United States of America. 2012 Jul 3;109(27):E1868-77. PubMed PMID: 22699504. Pubmed Central PMCID: 3390871.

76. Fukuda D, Aikawa M. Expanding role of delta-like 4 mediated notch signaling in cardiovascular and metabolic diseases. Circ J. 2013;77(10):2462-8. PubMed PMID: 24025398. Pubmed Central PMCID: 4545641.

77. Niida T, Lok LL, Zheng CY, Koga JI, Fukuda D, Banks A, et al. Delta-like 4/Notch Signaling Promotes Fatty Liver Disease in Mice. Circulation. 2013 Nov 26;128(22). PubMed PMID: WOS:000332162903199. English.

78. Song NJ, Yun UJ, Yang S, Wu C, Seo CR, Gwon AR, et al. Notch1 deficiency decreases hepatic lipid accumulation by induction of fatty acid oxidation. Sci Rep. 2016;6:19377. PubMed PMID: 26786165. Pubmed Central PMCID: PMC4726366.

79. Pajvani UB, Qiang L, Kangsamaksin T, Kitajewski J, Ginsberg HN, Accili D. Inhibition of Notch uncouples Aug;19(8):1054-60. PubMed PMID: 23832089. Pubmed Central PMCID: 3737382.

80. Bi P, Shan T, Liu W, Yue F, Yang X, Liang XR, et al. Inhibition of Notch signaling promotes browning of white adipose tissue and ameliorates obesity. Nature medicine. 2014 Aug;20(8):911-8. PubMed PMID: 25038826. Pubmed Central PMCID: 4181850.

81. Valenti L, Mendoza RM, Rametta R, Maggioni M, Kitajewski C, Shawber CJ, et al. Hepatic notch signaling correlates with insulin resistance and nonalcoholic fatty liver disease. Diabetes. 2013 Dec;62(12):4052-62. PubMed PMID: 23990360. Pubmed Central PMCID: 3837035. 
82. Fung E, Tang SM, Canner JP, Morishige K, Arboleda-Velasquez JF, Cardoso AA, et al. Delta-like 4 induces notch signaling in macrophages: implications for inflammation. Circulation. 2007 Jun 12;115(23):2948-56. PubMed PMID: 17533181.

83. Martinez JC, Muller MM, Turley H, Steers G, Choteau L, Li JL, et al. Nuclear and membrane expression of the angiogenesis regulator delta-like ligand 4 (DLL4) in normal and malignant human tissues. Histopathology. 2009 Apr;54(5):598-606. PubMed PMID: 19413639.

84. Shutter JR, Scully S, Fan W, Richards WG, Kitajewski J, Deblandre GA, et al. Dll4, a novel Notch ligand expressed in arterial endothelium. Gene Dev. 2000 Jun 1;14(11):1313-8. PubMed PMID: WOS:000087454900003. English.

85. Hendriks HF, Brouwer A, Knook DL. Isolation, purification, and characterization of liver cell types. Methods Enzymol. 1990;190:49-58. PubMed PMID: 1965003.

86. Koga JI, Wang JG, Tang JJ, Wilson CL, Raines EW, Aikawa M. Activated Macrophages Release Delta-like 4: A Potential New Biomarker of Cardiometabolic Disorders. Circulation. 2013 Nov 26;128(22). PubMed PMID: WOS:000332162903460. English.

87. Kopan R. Notch signaling. Cold Spring Harbor perspectives in biology. 2012;4(10). PubMed PMID: 23028119. Pubmed Central PMCID: 3475170.

88. D'Souza B, Meloty-Kapella L, Weinmaster G. Canonical and non-canonical Notch ligands. Curr Top Dev Biol. 2010;92:73-129. PubMed PMID: 20816393. Pubmed Central PMCID: PMC4286395.

89. Edwards DR, Handsley MM, Pennington CJ. The ADAM metalloproteinases. Mol Aspects Med. 2008 Oct;29(5):258-89. PubMed PMID: 18762209. Epub 2008/09/03. eng.

90. Duffy MJ, McKiernan E, O'Donovan N, McGowan PM. The role of ADAMs in disease pathophysiology. Clin Chim Acta. 2009 May;403(1-2):31-6. PubMed PMID: 19408347. Epub 2009/05/02. eng.

91. Reiss K, Saftig P. The "a disintegrin and metalloprotease" (ADAM) family of sheddases: physiological and cellular functions. Semin Cell Dev Biol. 2009 Apr;20(2):126-37. PubMed PMID: 19049889. Epub 2008/12/04. eng.

92. Virmani R, Kolodgie FD, Burke AP, Farb A, Schwartz SM. Lessons from sudden coronary death: a vascular biology. 2000 May;20(5):1262-75. PubMed PMID: 10807742.

93. Hansson GK. Inflammation, atherosclerosis, and coronary artery disease. N Engl J Med. 2005 Apr 21;352(16):1685-95. PubMed PMID: 15843671.

94. Pabois A, Devalliere J, Quillard T, Coulon F, Gerard N, Laboisse C, et al. The disintegrin and endothelial cells. Biochemical pharmacology. 2014 Oct 15;91(4):510-21. PubMed PMID: 25130545.

95. Donners MM, Wolfs IM, Olieslagers S, Mohammadi-Motahhari Z, Tchaikovski V, Heeneman S, et al. A disintegrin and metalloprotease 10 is a novel mediator of vascular endothelial growth factor-induced endothelial cell function in angiogenesis and is associated with atherosclerosis. Arteriosclerosis, thrombosis, and vascular biology. 2010 Nov;30(11):2188-95. PubMed PMID: 20814017. Epub 2010/09/04. eng.

96. van der Vorst EP, Jeurissen M, Wolfs IM, Keijbeck A, Theodorou K, Wijnands E, et al. Myeloid A disintegrin and metalloproteinase domain 10 deficiency modulates atherosclerotic plaque composition by shifting the balance from inflammation toward fibrosis. Am J Pathol. 2015 Apr;185(4):1145-55. PubMed PMID: 25659879. 
97. Fiorentino L, Vivanti A, Cavalera M, Marzano V, Ronci M, Fabrizi M, et al. Increased tumor necrosis factor alpha-converting enzyme activity induces insulin resistance and hepatosteatosis in mice. Hepatology. 2010 Jan;51(1):103-10. PubMed PMID: 19877183.

98. Jiang JX, Chen X, Fukada H, Serizawa N, Devaraj S, Torok NJ. Advanced glycation endproducts induce fibrogenic activity in nonalcoholic steatohepatitis by modulating TNF-alpha-converting enzyme activity in mice. Hepatology. 2013 Oct;58(4):1339-48. PubMed PMID: 23703665. Pubmed Central PMCID: PMC3897213.

99. Kaneko H, Anzai T, Horiuchi K, Morimoto K, Anzai A, Nagai T, et al. Tumor necrosis factor-alpha converting enzyme inactivation ameliorates high-fat diet-induced insulin resistance and altered energy homeostasis. Circ J. 2011;75(10):2482-90. PubMed PMID: 21785222.

100. Canault M, Peiretti F, Kopp F, Bonardo B, Bonzi MF, Coudeyre JC, et al. The TNF alpha converting enzyme (TACE/ADAM17) is expressed in the atherosclerotic lesions of apolipoprotein E-deficient mice: possible contribution to elevated plasma levels of soluble TNF alpha receptors. Atherosclerosis. 2006 Jul;187(1):82-91. PubMed PMID: 16214147. Epub 2005/10/11. eng.

101. Ebsen $H$, Lettau M, Kabelitz D, Janssen O. Subcellular localization and activation of ADAM proteases in the context of FasL shedding in T lymphocytes. Mol Immunol. 2015 Jun;65(2):41628. PubMed PMID: 25745808.

102. Valapala M, Hose S, Gongora C, Dong L, Wawrousek EF, Samuel Zigler J, Jr., et al. Impaired endolysosomal function disrupts Notch signalling in optic nerve astrocytes. Nat Commun. 2013;4:1629. PubMed PMID: 23535650. Pubmed Central PMCID: PMC3718029.

103. Cox BE, Griffin EE, Ullery JC, Jerome WG. Effects of cellular cholesterol loading on macrophage foam cell lysosome acidification. Journal of lipid research. 2007 May;48(5):1012-21. PubMed PMID: 17308299.

104. Brown AJ, Jessup W. Oxysterols and atherosclerosis. Atherosclerosis. 1999 Jan;142(1):1-28. PubMed PMID: 9920502.

105. Harkewicz R, Hartvigsen K, Almazan F, Dennis EA, Witztum JL, Miller YI. Cholesteryl ester hydroperoxides are biologically active components of minimally oxidized low density lipoprotein. The Journal of biological chemistry. 2008 Apr 18;283(16):10241-51. PubMed PMID: 18263582. Pubmed Central PMCID: PMC2447632.

106. Levitan I, Volkov S, Subbaiah PV. Oxidized LDL: diversity, patterns of recognition, and pathophysiology. Antioxidants \& redox signaling. 2010 Jul 1;13(1):39-75. PubMed PMID: 19888833. Pubmed Central PMCID: 2877120.

107. Patel RP, Diczfalusy U, Dzeletovic S, Wilson MT, Darley-Usmar VM. Formation of oxysterols during oxidation of low density lipoprotein by peroxynitrite, myoglobin, and copper. Journal of lipid research. 1996 Nov;37(11):2361-71. PubMed PMID: 8978488.

108. Brown MS, Dana SE, Goldstein JL. Cholesterol ester formation in cultured human fibroblasts. Stimulation by oxygenated sterols. The Journal of biological chemistry. 1975 May 25;250(10):4025-7. PubMed PMID: 1126942.

109. Hayden JM, Brachova L, Higgins K, Obermiller L, Sevanian A, Khandrika S, et al. Induction of monocyte differentiation and foam cell formation in vitro by 7-ketocholesterol. Journal of lipid research. 2002 Jan;43(1):26-35. PubMed PMID: 11792719. 
110. Rosklint T, Ohlsson BG, Wiklund O, Noren K, Hulten LM. Oxysterols induce interleukin-1beta production in human macrophages. European journal of clinical investigation. 2002 Jan;32(1):35 42. PubMed PMID: 11851725.

111. Kim WK, Meliton V, Tetradis S, Weinmaster G, Hahn TJ, Carlson M, et al. Osteogenic oxysterol, 20(S)-hydroxycholesterol, induces notch target gene expression in bone marrow stromal cells. Journal of bone and mineral research : the official journal of the American Society for Bone and Mineral Research. 2010 Apr;25(4):782-95. PubMed PMID: 19839776. Pubmed Central PMCID: 3153332.

112. Aikawa E, Nahrendorf M, Figueiredo JL, Swirski FK, Shtatland T, Kohler RH, et al. Osteogenesis associates with inflammation in early-stage atherosclerosis evaluated by molecular imaging in vivo. Circulation. 2007 Dec 11;116(24):2841-50. PubMed PMID: 18040026.

113. Frolov A, Zielinski SE, Crowley JR, Dudley-Rucker N, Schaffer JE, Ory DS. NPC1 and NPC2 regulate cellular cholesterol homeostasis through generation of low density lipoprotein cholesterolderived oxysterols. The Journal of biological chemistry. 2003 Jul 11;278(28):25517-25. PubMed PMID: 12719428.

114. Lange $\mathrm{Y}, \mathrm{Ye} J$, Rigney M, Steck T. Cholesterol movement in Niemann-Pick type C cells and in cells treated with amphiphiles. The Journal of biological chemistry. 2000 Jun 9;275(23):17468-75. PubMed PMID: 10751394.

115. Bjorkhem I, Andersson O, Diczfalusy U, Sevastik B, Xiu RJ, Duan C, et al. Atherosclerosis and sterol 27-hydroxylase: evidence for a role of this enzyme in elimination of cholesterol from human macrophages. Proceedings of the National Academy of Sciences of the United States of America. 1994 Aug 30;91(18):8592-6. PubMed PMID: 8078928. Pubmed Central PMCID: 44652.

116. Oftebro H, Bjorkhem I, Skrede S, Schreiner A, Pederson JI. Cerebrotendinous xanthomatosis: a defect in mitochondrial 26-hydroxylation required for normal biosynthesis of cholic acid. The Journal of clinical investigation. 1980 Jun;65(6):1418-30. PubMed PMID: 7410549. Pubmed Central PMCID: 371480.

117. Marengo B, Bellora F, Ricciarelli R, De Ciucis C, Furfaro A, Leardi R, et al. Oxysterol mixture and, in particular, 27-hydroxycholesterol drive M2 polarization of human macrophages. BioFactors. 2015 Dec 16. PubMed PMID: 26669587.

118. Hong C, Tontonoz P. Liver $X$ receptors in lipid metabolism: opportunities for drug discovery. Nature reviews Drug discovery. 2014 Jun;13(6):433-44. PubMed PMID: 24833295.

119. Ory DS. Nuclear receptor signaling in the control of cholesterol homeostasis: have the orphans found a home? Circulation research. 2004 Oct 1;95(7):660-70. PubMed PMID: 15459087.

120. Song C, Hiipakka RA, Liao S. Auto-oxidized cholesterol sulfates are antagonistic ligands of liver $X$ receptors: implications for the development and treatment of atherosclerosis. Steroids. 2001 Jun;66(6):473-9. PubMed PMID: 11182136.

121. Heo W, Kim SM, Eo SK, Rhim BY, Kim K. FSL-1, a Toll-like Receptor 2/6 Agonist, Induces Expression of Interleukin-1alpha in the Presence of 27-hydroxycholesterol. The Korean journal of physiology \& pharmacology : official journal of the Korean Physiological Society and the Korean Society of Pharmacology. 2014 Dec;18(6):475-80. PubMed PMID: 25598661. Pubmed Central PMCID: 4296036. 
122. Gargiulo S, Gamba P, Testa G, Rossin D, Biasi F, Poli G, et al. Relation between TLR4/NF-kappaB signaling pathway activation by 27-hydroxycholesterol and 4-hydroxynonenal, and atherosclerotic plaque instability. Aging cell. 2015 Aug;14(4):569-81. PubMed PMID: 25757594. Pubmed Central PMCID: 4531071.

123. Kikuchi T, Sugiura H, Koarai A, Ichikawa T, Minakata Y, Matsunaga K, et al. Increase of 27hydroxycholesterol in the airways of patients with COPD: possible role of 27-hydroxycholesterol in tissue fibrosis. Chest. 2012 Aug;142(2):329-37. PubMed PMID: 22281802.

124. Kim SM, Jang H, Son Y, Lee SA, Bae SS, Park YC, et al. 27-hydroxycholesterol induces production of tumor necrosis factor-alpha from macrophages. Biochem Biophys Res Commun. 2013 Jan 11;430(2):454-9. PubMed PMID: 23246833.

125. Kim SM, Lee CW, Kim BY, Jung YS, Eo SK, Park YC, et al. 27-Oxygenated cholesterol induces expression of CXCL8 in macrophages via NF-kappaB and CD88. Biochem Biophys Res Commun. 2015 Aug 7;463(4):1152-8. PubMed PMID: 26086093.

126. DuSell CD, Umetani M, Shaul PW, Mangelsdorf DJ, McDonnell DP. 27-hydroxycholesterol is an endogenous selective estrogen receptor modulator. Molecular endocrinology. 2008 Jan;22(1):65-77. PubMed PMID: 17872378. Pubmed Central PMCID: 2194632.

127. Umetani M, Domoto $\mathrm{H}$, Gormley AK, Yuhanna IS, Cummins CL, Javitt NB, et al. 27Hydroxycholesterol is an endogenous SERM that inhibits the cardiovascular effects of estrogen. Nature medicine. 2007 Oct;13(10):1185-92. PubMed PMID: 17873880.

128. Umetani M, Shaul PW. 27-Hydroxycholesterol: the first identified endogenous SERM. Trends in endocrinology and metabolism: TEM. 2011 Apr;22(4):130-5. PubMed PMID: 21353593. Pubmed Central PMCID: 3070823.

129. Tsuchiya S, Yamabe M, Yamaguchi Y, Kobayashi Y, Konno T, Tada K. Establishment and characterization of a human acute monocytic leukemia cell line (THP-1). International journal of cancer. 1980 Aug;26(2):171-6. PubMed PMID: 6970727.

130. Sundstrom C, Nilsson K. Establishment and characterization of a human histiocytic lymphoma cell line (U-937). International journal of cancer. 1976 May 15;17(5):565-77. PubMed PMID: 178611.

131. Calippe B, Douin-Echinard V, Laffargue M, Laurell H, Rana-Poussine V, Pipy B, et al. Chronic estradiol administration in vivo promotes the proinflammatory response of macrophages to TLR4 activation: involvement of the phosphatidylinositol 3-kinase pathway. Journal of immunology. 2008 Jun 15;180(12):7980-8. PubMed PMID: 18523261.

132. Campbell L, Emmerson E, Williams H, Saville CR, Krust A, Chambon P, et al. Estrogen receptoralpha promotes alternative macrophage activation during cutaneous repair. The Journal of investigative dermatology. 2014 Sep;134(9):2447-57. PubMed PMID: 24769859.

133. Harkonen PL, Vaananen HK. Monocyte-macrophage system as a target for estrogen and selective estrogen receptor modulators. Annals of the New York Academy of Sciences. 2006 Nov;1089:218-27. PubMed PMID: 172617 



\section{Summary}


Common features as foam cell formation and inflammation play an important role in the progression of NASH and atherosclerosis. While NASH and atherosclerosis share a similar etiology evidence for a shared mechanism remained to be elucidated. Within this thesis, I focused on the role of macrophages in both atherosclerosis and NASH by investigating mechanism related to crosstalk between lipids and inflammation. This thesis has provided novel insights in macrophage specific mechanism of lysosomal oxidized lipid accumulation, leading to inflammatory processes that contribute to the progression of both atherosclerosis and NASH.

Chapter 1 provides a global overview regarding the pathophysiology of the metabolic syndrome and its two major contributors; NASH and atherosclerosis. This chapter focuses on several studies which demonstrated that foam cell formation and inflammation are shared characteristics of two chronic inflammatory diseases. Furthermore, this chapter brings forward the view that atherosclerosis and NASH display features of an acquired lysosomal storage defect. Finally, serval downstream effects of foamy macrophages on inflammatory pathways and the modulation of cholesterol content are described.

Chapter 2 provides evidence for the importance of lysosomal oxLDL accumulation inside macrophages by using a macrophage specific NPC1 mutant mouse model in combination with pneumococcal immunization. Here is it was demonstrated that plaque development was reduced in NPC1 ${ }^{\text {mut }}$-tp mice after immunization, independently of plasma lipid levels. Furthermore, inflammatory gene expression was reduced in the aortic arch of NPC1 ${ }^{\text {mut }}$-tp mice after immunization. These findings demonstrate that lysosomal oxLDL accumulation inside macrophages contributes to murine atherosclerosis.

Chapter 3 provides novel insight in one of macrophage specific mechanisms, the inflammasome, that can induce inflammatory processes as consequence of excessive cholesterol accumulation in macrophages. Here it was hypothesized that hematopoietic caspase-1/11 deficiency leads to reduced atherosclerosis development. In line with our hypothesis, hematopoietic deletion of caspase-1/11 resulted in strong reduction in atherosclerotic plaque size. Overall, our data indicated that hematopoietic caspase-1/11 activation is involved in vascular inflammation and atherosclerosis, and plays an important role in cardiovascular disease progression. 
In Chapter 4, we elucidated the contribution of Notch signaling which has been considered to be an important regulator of metabolic processes and macrophage inflammation in atherosclerosis. As a potential shared mechanism, it was hypothesized that myeloid DLL4 deficiency in LdI $^{-/}$mice can reduce hepatic inflammation. In contrast to our hypothesis, hepatic inflammation was not reduced in myeloid DLL4 deficient mice. In line with these findings, no differences were observed, in vitro, in expression of inflammatory genes between DLL4-deficient and wildtype bone marrow-derived macrophages. Overall, these results suggest that myeloid DLL4 deficiency does not contribute to hepatic inflammation in vivo.

In Chapter 5, we investigated the possible effects of modulating intracellular cholesterol transport as possible mechanism to reduce lysosomal cholesterol-induced inflammation. It was hypothesized that CYP27a1 overexpression in Kupffer cells will lead to reduced hepatic inflammation as it was previously demonstrated that 27hydroxycholesterol, produced by the mitochondrial enzyme CYP27a1, reduces hepatic inflammation in hyperlipidemic mice. In this chapter it was shown that hematopoietic overexpression of CYP27a1 reduces hepatic inflammation, independently of 27hydroxycholesterol levels, by modulating intracellular cholesterol trafficking via lysosomal NPC proteins.

In Chapter 6, our novel findings were discussed in detailed and I elaborated on how these mechanisms affect NASH and atherosclerosis development. 



\section{Samenvatting}


De vorming van schuimcellen en daarbij de ontwikkelde inflammatie zijn gemeenschappelijk kenmerken die een belangrijke bijdrage leveren aan de ontwikkeling van NASH en atherosclerose. Al hoewel NASH en atherosclerose een vergelijkbare etiologie hebben, bewijs voor een gedeeld mechanisme is echter nog niet bekend. In dit proefschrift heb ik mijn voornamelijk gefocust op de rol van macrofagen in NASH en atherosclerose. Hierbij is specifiek gekeken naar verschillende mechanismes die gerelateerd waren aan de communicatie over en weer tussen lipiden en inflammatie. Dit proefschrift verschaft nieuwe inzichten in macrofaag specifieke mechanismes die betrekking hebben op de opname van lysosomaal geoxideerd cholesterol. Deze mechanismes dragen bij aan de ontwikkeling van inflammatie in NASH en atherosclerose.

Hoofdstuk 1 biedt één globale weergaven van de pathofysiologie van het metabool syndroom en zijn twee grote riscofactoren; NASH en atherosclerose. Dit hoofdstuk richten zich op verschillende studies die de ontwikkeling van schuimcellen en inflammatie beschrijft als een gedeeld feature van twee chronische ontstekingsziektes. Bovendien beschrijft dit hoofdstuk ook het standpunt dat NASH en atherosclerose gemeenschappelijk kenmerken vertoond van een lysosomaal stapelingsziekte. Tot slot, de verschillende effecten van schuimcellen op het ontstekingsprocessen en de modulatie van cholesterol transport wordt beschreven.

Hoofdstuk 2 levert het bewijs voor het belang van lysosomale oxLDL accumulatie in macrofagen. Dit proces is beschreven in een macrofaag-specifiek muismodel in combinatie met pneumococci immunisatie. In dit hoofdstuk is aangetoond dat plaque ontwikkeling in NPC1 ${ }^{\text {mut }}$-tp muizen is verlaagd na immunisatie, ongeacht van plasma lipiden niveaus. Daarnaast was er een afname in genexpressie van inflammatoire markers in de aortaboog van NPC1mut-tp muizen na immunisatie. Deze bevindingen tonen aan dat lysosomaal oxLDL accumulatie in macrofagen bijdraagt aan de ontwikkeling van atherosclerose in muizen.

Hoofdstuk 3 biedt nieuw inzichten in een van de nieuwe macrofaag specifieke mechanisme, de inflammasome. De inflammasome kan ontstekingsprocessen veroorzaken als gevolg van overmatige opeenhoping van cholesterol in macrofagen. Onze hypothese in dit hoofdstuk was dat hematopoetisch caspase-1/11 deficiënt leidt tot verminderde ontwikkeling van atherosclerose. In lijn met onze hypothese, hematopoetisch deletie van caspase-1/11 resulteert in een sterke verlaging van atherosclerotisch plaque oppervlak. Kortom, onze resultaten geven weer dat hematopoetisch caspase-1/11 activatie betrokken is bij vasculaire inflammatie en atherosclerose, en bijdraagt in de ontwikkeling van cardiovasculaire ziekten. 
In hoofdstuk 4 droegen we bij aan de opheldering van de bijdrage van Notch signalering. Notch signalering wordt beschouwd als een belangrijke regulator van metabole processen en macrofaag gerelateerde ontstekingen bij atherosclerose. Als een potentiële gemeenschappelijk mechanisme, name we de hypothese aan dat myeloïde DLL4 deficiëntie in $\mathrm{Ldll}^{/}$- muizen leidt tot een verlaging van leverontsteking. In tegenstelling tot onze hypothese, leverontsteking was niet verlaagde in myeloïde DLL4 deficiënte muizen. In lijn met deze bevindingen, geen verschillen waren aangetoond, in vitro, in de expressie van inflammatoire genen tussen DLL4-deficiente en wildtype beenmerg-specifieke macrofagen. Kortom, deze resultaten suggereren dat myeloïde DLL4 deficiëntie niet bijdraagt aan ontwikkeling van leverontsteking in vivo.

In hoofdstuk 5 onderzochten we de mogelijk effecten van modulering van het intracellulair cholesterol transport als een middel om lysosomale cholesterol geïnduceerde ontstekingen te verlagen. Eerdere resultaten hebben aangetoond dat 27-hydroxycholesterol, geproduceerd door het mitochondriale enzym CYP27A1, leverontsteking remt in hyperlipidemische muizen. De hypothese in dit hoofdstuk was dat CYP27A1 overexpressie in Kupffer cellen zal leiden tot een verminder leverontsteking zoals eerder aangetoond. We hebben kunnen aantonen dat overexpressie van hematopoetisch CYP27A1 leverontsteking verminderd, onafhankelijk van 27-hydroxycholesterol niveaus, door het moduleren van intracellulaire cholesterol transport via de lysosomale NPC-eiwitten.

In hoofdstuk 6, heb ik deze bevindingen in detail besproken en ben ik ingegaan op hoe deze mechanismen van invloed kunnen hebben op de ontwikkeling van NASH en atherosclerose. 

Valorisation 


\section{Socio-economic relevance}

Nowadays it is well recognized that diet, together with lifestyle and environment, are important risk factors for the development of non-alcoholic fatty liver disease (NAFLD). NAFLD is one of the important contributors for the continuous rise of chronic liver disease in the Western society. NAFLD can be divided into two sub-types: fatty liver disease and non-alcoholic steatohepatitis (NASH), which is a chronic inflammatory condition of the liver. The fatty liver is a benign condition and reversible condition, the presence of inflammation in a fatty liver is irreversible and only treatment is a liver transplantation $(1,2)$. Epidemiological studies reveal that about $20 \%$ of the Western population has NAFLD. Approximately $15-30 \%$ of these NAFLD patients will ultimately develop NASH. NASH is associated with liver-related death, with a mortality rate between $30-40 \%$ in NASH patients (3). The prevalence of steatosis is estimated to be ranging from $84 \%$ to $96 \%$ whereas in this population the prevalence of NASH is ranging from $25 \%$ to $55 \%$ (4).

In addition to the association between NAFLD and hepatic-related morbidity and mortality, NAFLD is also related to increased cardiovascular-associated mortality. In support of this, NAFLD has been associated with increased cardiovascular disease (CVD) risk in patients with obesity and diabetes $(5,6)$. Moreover, multiple clinical studies have found a link between NAFLD and atherosclerosis and shows that NAFLD may act as an important contributor to CVD. However, although NAFLD/NASH and CVD share a common etiology, the precise underlying pathophysiological mechanisms are not fully understood yet (7). This thesis provides for the first time novel insights in the pathophysiological mechanisms of NAFLD and CVD, focusing particular on macrophage responses related to the crosstalk between lipids and inflammation. Our findings reveal novel therapeutic strategies, related to the inhibition of the inflammasome and redistribution of intracellular cholesterol, that consequently inhibit the progression of NASH and atherosclerosis. As such, our findings could positively affect the economic burden related to NASH and atherosclerosis, as therapeutic strategies could target both NASH and atherosclerosis simultaneously. Hereby, healthcare costs can be reduced, for example hospitalisation costs and the development of affordable medicine. 


\section{Innovation and future directions}

A clear association between NASH and atherosclerosis has been established, as they display features of a shared etiology. Yet, evidence for a shared mechanism related to the progression of NASH and atherosclerosis are lacking and remain unclear. In this aspect, this thesis is innovative as it provides novel insights in a macrophage-specific mechanism that contributes to the progression of NASH and atherosclerosis. One of the most important take-home messages is that NASH and atherosclerosis do not only display inflammatory mechanisms but also mutually influence each other's progression. Knowledge utilization with regard to this insight could lead to the discovery of novel therapeutic interventions or diagnostic tools, applicable to both diseases.

\section{Intervention strategies:}

Several targets are identified within this thesis that potentially could lead to novel therapeutic targets. The inflammasome was identified as an important activator for inflammation in NASH and atherosclerosis (Chapter 3). Strong collaboration with the pharmaceutical industry could lead to promising novel drug target therapies to inhibit the inflammasome activation thereby tackling the disease progression of both NASH and atherosclerosis. Furthermore, pneumococcal vaccination described in this thesis was used as a proof of concept to abolish oxidative cholesterol uptake within lysosomes (Chapter 2). The therapeutic properties of pneumococcal vaccinations with regard to NASH and atherosclerosis have been shown, but is limited with regard to clinical data in human patients $(8,9)$. Therefore, more investments should be made to investigate the added value of pneumococcal vaccinations to NASH and CVD in a clinical setting. In addition, this thesis provides evidence that the distribution of intracellular cholesterol content can be modulated, i.e. by redirecting cholesterol from the lysosome to the cytoplasm, consequently reducing inflammation. Therefore, novel therapeutic interventions should not only focus on reducing cholesterol levels alone but rather focus on modulating intracellular cholesterol content to reduce inflammation and should be investigated more thoroughly. As such, intracellular cholesterol modulation, for example via gene modulation of CYP27A1 (Chapter 5), is a good novel therapeutic intervention to redirect intracellular cholesterol and should be tested in NASH and atherosclerosis patients. Important to note is that throughout this thesis it is repeatedly mentioned that NASH and atherosclerosis display features of an acquired lysosomal storage defect, suggesting that similar mechanism are applicable to lysosomal storage diseases. Besides targeting CYP27A1, the use of $27 \mathrm{HC}$ has been shown to improve hepatic inflammation (10) and should be tested in a clinical setting. However, it is important to note, as $27-\mathrm{HC}$ may function as a selective estrogen receptor (ER) modulator, its proposed anti-inflammatory effects may differ between tissues (11). Therefore, future research is necessary to identify the function of 27-HC ER-mediated effects in macrophage-induced inflammation and in other tissues, before 
27-HC could be used as therapeutic agent for lowering intracellular cholesterol. Finally, future research may be directed to lysosomal-induced inflammation. By using a NPC1 mutant mouse model, an innovative way can be established to investigate the inflammatory mechanism related to lysosomal function. More importantly, bone marrow transplantation of NPC1 mutant mice to hyperlipidemic $L d / r^{-/}$mice would be a great model to investigate lysosomal function under metabolic conditions.

\section{Screening procedures for risk factors in CVD and NAFLD}

As NASH and atherosclerosis mutually influence each other's progression, the findings in this thesis may be beneficial and could raise awareness among clinicians with regard to screening methods in patients with risk factors for NASH and CVD. Screening for cardiovascular risk factors in NALFD patients would be highly beneficial to detect early development of CVD, and vice versa. This point of view is also supported by Francque et al., who proposed to screen for cardiovascular risk factors in NAFLD patients. Here it was stated that several questions should be addressed first; as what to screen for and which screening techniques should be used and which disease populations should be screened (5). To address these questions, a strong collaboration between hepatic and cardiovascular clinicians is needed. Currently used biomarkers to identify NASH are limited to the liver enzymes ALAT, ASAT and gammaglutamyl transferase (GGT), but lack accuracy. As such, the golden standard for the detection of NASH is still a liver biopsy $(3,6)$. As such, the need for new biomarkers for NASH holds high potential to be investigated in the future. Several studies also address an association between these liver enzymes and cardiovascular outcome but appear to be not that strong (6). Our group has now identified cathepsin D as a new biomarker for hepatic inflammation (12). As such, future directions could be taken to show how cathepsin $\mathrm{D}$ could function as potential biomarker for cardiovascular risk factors in combination with hepatic manifestations, as cathepsins D is involved in endothelial permeability and is associated with coronary events $(13,14)$. This knowledge could be implemented into new screening protocols, whereby CVD patients should be screened for NASH and the other way around. 


\section{Potential target groups and activities}

\section{Scientific value}

The findings described in this thesis will increase our knowledge about the macrophage-specific mechanisms which are contributing to the progression of NASH and atherosclerosis. Next to identifying new macrophage-specific mechanisms, the goal of these studies was to identify therapeutic targets which can benefit society in reducing NASH and atherosclerosis development. As such, besides its socioeconomic relevance, our results also have a high scientific value, as they are very appealing to clinicians, healthcare workers, pharmacological industry, patient groups, society and other scientific researchers. To get this knowledge to the scientific community and beyond, our findings are published in peer-reviewed scientific journals, such as PLoS One, FEBS Journal, Journal of Hepatology and Atherosclerosis. In addition, our findings are presented by means of an oral presentation at highly esteemed national (Dutch Liver Retreat, Spier, 2013-2015; Dutch Lipoprotein Club, Leiden the Netherlands, 2012-2013; 25th Genetics Retreat, Kerkrade, 2015; 5th Joint Diabetes and Metabolism Research Symposium, Maastricht, 2015) and international conferences (20th Annual Scandinavian Atherosclerosis Conferences, Humlebæk Denmark, 2014) and via poster presentations (Annual Symposium School of Nutrition and Translational Research in Metabolism (NUTRIM), Maastricht, the Netherlands, 2014-2015 and British Atherosclerosis Society Autumn Meeting, Cambridge, United Kingdom, 2015).

Knowledge transfer to the patients and the clinic

Before novel therapeutic strategies can be utilized in the clinic, strong valorisation procedures should be followed in collaboration with clinicians, patient groups and pharmacological industry. Additionally, collaborations between patient groups, foundations, clinicians and health care workers are needed to raise awareness for cardiovascular and hepatic risk factors in patients. For example, advances could be made by clinicians and foundations, to prepare one general brochure to make NAFLD and CVD patients aware that both diseases are closely linked to each other and as such, that potential risk factors should not be underestimated. In addition, the view that NAFLD and CVD are closely linked with each other could be quickly spread by presenting on national and international scientific conferences. These conferences should not be limited to scientists and clinicians, but also include people from hepatic and cardiovascular foundations. Sharing information between clinicians and fellow scientists to these foundations would improve collaborations between these groups, thereby foundations could better asses where funding is needed. The creation of new grants that focus on the hepatic-cardiovascular axis would be innovative and would improve the accessibility for scientists to invest specifically on this topic. These investments may not only benefit patient outcome, quality of life but also improve healthcare costs. As our findings focus on reducing systemic inflammation in general and contribute to intracellular cholesterol redistribution, these findings are not only 
limited to NASH and atherosclerosis, but could also be implemented to other chronic inflammatory diseases, such as lysosomal storage diseases.

\section{The need for a systemic research approach and treatment}

Relevantly, one of the features of macrophages is that their response to inflammation is diverse and not limited to one specific tissue. As such, macrophage-specific mechanisms may not only influence the progression of NASH and atherosclerosis, but also other chronic inflammatory diseases. Therefore, it is important to determine whether these responses are seen in other tissues and not only in the liver and vessel wall. It would be useful to investigate the effects of macrophage-driven mechanisms during inflammation, such as inflammasome activation, distribution of intracellular cholesterol and the anti-inflammatory effects of $27-\mathrm{HC}$ in other tissues, e.g. the adipose tissue, lung and brain.

To summarize, these findings described in this thesis have high socioeconomic and scientific relevance. Good collaborations between different agencies are necessary to utilize the findings of this thesis to the field. Additionally, future research should focus on the intervention strategies regarding inflammasome activation and intracellular cholesterol distribution. Furthermore, reforming screening protocols in NAFLD and CVD patients is essential in reducing the economic burden for both and NASH and atherosclerosis. Overall, future research should not only focus on lowering cholesterol levels in general but rather focus on the lowering intracellular cholesterol levels in macrophages. Additionally, future research can be expanded by investing more in fundamental research by investigating lysosomal-induced inflammation in chronic inflammatory diseases. 


\section{References}

1. Kopec KL, Burns D. Nonalcoholic fatty liver disease: a review of the spectrum of disease, diagnosis, and therapy. Nutrition in clinical practice : official publication of the American Society for Parenteral and Enteral Nutrition. 2011;26(5):565-76.

2. Portincasa P, Grattagliano I, Palmieri VO, Palasciano G. The emerging problem of nonalcoholic steatohepatitis (NASH). Rom J Gastroenterol. 2005;14(1):43-51.

3. Koek GH. [Treatment of non-alcoholic fatty liver disease]. Ned Tijdschr Geneeskd. 2011;155:A3181.

4. Clark JM. The epidemiology of nonalcoholic fatty liver disease in adults. Journal of clinical gastroenterology. 2006;40 Suppl 1:S5-10.

5. Francque SM, van der Graaff D, Kwanten WJ. Non-alcoholic fatty liver disease and cardiovascular risk: Pathophysiological mechanisms and implications. J Hepatol. 2016.

6. Satapathy SK, Sanyal AJ. Epidemiology and Natural History of Nonalcoholic Fatty Liver Disease. Semin Liver Dis. 2015;35(3):221-35.

7. $\mathrm{Xu} \mathrm{X,} \mathrm{Lu} \mathrm{L,} \mathrm{Dong} \mathrm{Q,} \mathrm{Li} \mathrm{X,} \mathrm{Zhang} \mathrm{N,} \mathrm{Xin} \mathrm{Y,} \mathrm{et} \mathrm{al.} \mathrm{Research} \mathrm{advances} \mathrm{in} \mathrm{the} \mathrm{relationship} \mathrm{between}$ nonalcoholic fatty liver disease and atherosclerosis. Lipids in health and disease. 2015;14:158.

8. Bieghs V, van Gorp PJ, Walenbergh SM, Gijbels MJ, Verheyen F, Buurman WA, et al. Specific immunization strategies against oxidized low-density lipoprotein: a novel way to reduce nonalcoholic steatohepatitis in mice. Hepatology. 2012;56(3):894-903.

9. Binder CJ, Horkko S, Dewan A, Chang MK, Kieu EP, Goodyear CS, et al. Pneumococcal vaccination decreases atherosclerotic lesion formation: molecular mimicry between Streptococcus pneumoniae and oxidized LDL. Nature medicine. 2003;9(6):736-43.

10. Bieghs V, Hendrikx T, van Gorp PJ, Verheyen F, Guichot YD, Walenbergh SM, et al. The cholesterol derivative 27-hydroxycholesterol reduces steatohepatitis in mice. Gastroenterology. 2013;144(1):167-78 e1.

11. Umetani M, Shaul PW. 27-Hydroxycholesterol: the first identified endogenous SERM. Trends in endocrinology and metabolism: TEM. 2011;22(4):130-5.

12. Walenbergh SM, Houben T, Hendrikx T, Jeurissen ML, van Gorp PJ, Vreugdenhil AC, et al. Plasma cathepsin D levels: a novel tool to predict pediatric hepatic inflammation. Am J Gastroenterol. 2015;110(3):462-70.

13. Goncalves I, Hultman K, Duner P, Edsfeldt A, Hedblad B, Fredrikson GN, et al. High levels of cathepsin $D$ and cystatin $B$ are associated with increased risk of coronary events. Open Heart. 2016;3(1):e000353.

14. Monickaraj F, McGuire PG, Nitta CF, Ghosh K, Das A. Cathepsin D: an Mvarphi-derived factor mediating increased endothelial cell permeability with implications for alteration of the bloodretinal barrier in diabetic retinopathy. FASEB journal : official publication of the Federation of American Societies for Experimental Biology. 2016;30(4):1670-82. 

Dankwoord 


\section{Dankwoord}

Hatseflats!!!!! Daar is ie dan. Na vier jaar met ups en downs is mijn proefschrift klaar! Dit proefschrift is natuurlijk niet tot stand gekomen zonder de hulp van een aantal mensen. Daarom wil ik deze mensen bedanken voor hun hulp en steun gedurende deze jaren.

Allereerst wil ik mijn beoordelingscommissie bedanken dat ze de gelegenheid hebben genomen om mijn proefschrift te beoordelen en waar nodig te corrigeren. Bedankt!

I want to thank my promotor and supervisor Ronit, without her this thesis would not lay in front of you. Ronit, I am very grateful, pleased and honoured that you were my promotor and supervisor during this period. I still remember that day that you walked towards me and said that there was a vacancy within your group. I did not hesitate for a moment and applied the next day! Thank you for giving me the opportunity to be a part of the Liver Lovers Club. Your motivation, enthusiasm, caring and love for not only research but also for the group itself was and still is an inspiration for me. I really enjoyed our trip to Cambridge and the discussions we had during that time. The last year of being a PhD student was the hardest. Thank you being there for me and for all your help, especially during this last period!

Daarnaast wil ik ook mijn andere promotor bedanken. Jan, bedankt voor alle levendige discussies tijdens de labchat en de suggesties en input die je hebt gegeven.

Marjo, bedankt dat je op het laatste moment mijn co-promotor wilde worden. Ik denk dat het niet meer dan gepast is dat wij samen dit PhD traject afsluiten, aangezien ik bij jou ook mijn afstudeerstage voor de Master heb afgerond. Bedankt voor alle hulp in het laatste jaar van mijn PhD, het nakijken van alle hoofdstukken, de suggesties die je gedaan hebt en alle steun die je hebt gegeven!

Dan mijn paranimfen, Sofie, jou kan ik niet genoeg bedanken voor alle hulp die je me gegeven heb bij het afronden van mijn twee laatste hoofdstukken van dit proefschrift. Jouw frisse blik op een nieuwe versie van een manuscript is altijd van grote waarde geweest. Je bent altijd de rust zelve, stress zie ik nooit bij jou en dat straal je over op de gehele groep. Jouw gedrevenheid en behulpzaamheid waardeer ik zeer.

Tom, herinner je je nog de eerste keer bij de Dutch Liver Retreat? Nou ik wel en de jenevers ook volgens mij, hahaha. Jou wil ik ook hartelijk bedanken voor alle hulp die je geboden hebt gedurende deze 4 jaar! Vooral gedurende de periode met injecteren van de NPC1 muizen. Jouw enthousiasme en gedrevenheid voor onderzoek en kennis van literatuur is van onschatbare waarde voor de groep en een inspiratie voor iedereen. Jouw Belgische humor ga ik zeker missen. Veel succes met het afronden van jouw PhD, het gaat je zeker lukken. 
Daarnaast wil ik ook de andere leden van de Liver Lovers Club bedanken:

Yvonne, na je promotie ben je lid geworden van ons clubje en ik denk dat je een grote aanwinst bent voor het team. Je ben één van de meest hardwerkende personen die ik ken. Dat waardeer ik zeer, maar gun jezelf ook eens af en toe wat rust ;) Bedankt voor al je hulp en suggesties! Tim, ook al ben je niet meer fysiek aanwezig in onze groep, je bent er toch op een of andere manier altijd bij. Ook jij bedankt voor alle hulp die je geboden hebt tijdens mijn PhD. Veel succes in Amerika samen met Sabrina! Patrick, bij jou kon ik altijd langskomen als ik in de knoop zat met een technisch probleem. Daarnaast ga ik ook de discussies over onze studies missen. Veel succes verder! Then Jieyi, I also want to thank you for all your help! I enjoyed our conversations about China. I wish you all the best for the future together with Junfang. And last but definitely not least: Albert, ook jij bedankt voor alle inzet die je in het laatste jaar hebt getoond om het $27 \mathrm{HC}$ verhaal opgang te brengen. Je bent van grote waarde geweest voor het team en ik wens je heel veel succes met je PhD! Vervolgens wil ik alle studenten bedanken die me geholpen hebben tijdens mijn promotie traject: Rick, Robin, Isabel, Ilona, Paula, Angel, Mitch, Joris en Samantha.

Vervolgens wil ik ook mijn kamergenootjes bedanken voor alle hulp tussen door. Ilvy, aangezien we samen de labchat sessie goed hebben kunnen regelen, ben ik ervan overtuigd dat het ook helemaal goed zal komen met je $\mathrm{PhD}$;) Heel veel succes met het afronden daarmee. Yilin, yes this time I said your name right. Good luck will all the things you have planned for the future. I hope that you will find a new job that suits you.

Daarnaast wil ook mijn andere collega's bedanken. Diebert en Willem, bedankt voor jullie input en suggesties tijdens de labchat en seminars gedurende deze 4 jaar. Ik stelde dat altijd zeer op prijs. Joost, bedankt dat je onderdeel wil uitmaken van de Corona en voor jouw input en discussies tijdens de labchat en andere meetings. Petra, mijn lunch buddy. Jij bent van onschatbare waarde voor MolGen. Ik kon altijd terecht bij je met administratief gerelateerde vragen en je bent een grote hulp geweest gedurende de laatste maanden. Ik ga onze gesprekken tijdens de lunch missen. Henny, ook jij bedankt voor al je hulp me het sturen en maken van de juiste brieven. Marion, ik waardeer zeer je hulp tijdens de experimenten en onze discussies achter de microscoop. Jouw directheid en eerlijkheid stelde ik altijd erg op prijs. Vivian en Wil, jullie ondersteuning in het lab en kennis over Western blotting was van onschatbare waarde! Bedankt! Dip, thanks for all your suggestions during the labchats and meetings. Good luck for the future! Karin, I wish you all the best with your new job in America. Good luck! Miranda, ook jou wil ik bedanken voor de suggesties en input die je gegeven heb tijdens het laatste jaar. Onze lunchgesprekken ga ik zeker missen. Daarnaast zal ik het leuke labuitje naar Bobbejaanland, helaas gevolgd door ons ritje naar de Belgische politie, niet snel vergeten! 
Jan Theys, ook jij bedankt dat je onderdeel van de Corona wil zijn. Jouw hulp die je geboden hebt met het DLL4 project en de discussies die we er samen met Ronit over gevoerd hebben, waardeer ik zeer. Al met al hebben we dit project met succes afgerond!

Ook wil ik al mijn collega's die in deze periode van 4 jaar de afdeling hebben verlaten bedanken. Emiel en Kosta, ik heb altijd genoten van ons gezamenlijke macrofaag clubje. Emiel nogmaals veel succes in München en Kosta jij veel succes met het afronden van je PhD. Ook wil ik Ine, Peggy, Nadine, Yeliz, Marie en Guus bedanken voor jullie collegialiteit en gezelligheid!

Daarnaast wil ook alle medewerkers van het CPV bedanken voor hun ondersteunde hulp.

Aan alle familieleden en schoonfamilie, bedankt voor jullie steun. Ik stelde de interesse die jullie toonden voor mijn onderzoek zeer op prijs. Bedankt!

Pap en Mam, dit boekje was niet zonder jullie tot stand gekomen. Jullie hebben me altijd gesteund in de keuzes die ik gemaakt heb gedurende de afgelopen jaren en dat waardeer ik zeer. Bedankt dat ik altijd bij jullie terecht kon om te relaxen, om er de volgende dag weer vol voor te gaan. Bedankt voor de motiverende woorden en steun die jullie gegeven hebben tijdens deze periode. Debbie en Roy ook jullie bedankt voor jullie steun en interesse in mijn onderzoek.

Monique, sjattie, jouw steun en onvoorwaardelijke liefde is gedurende deze periode van onschatbare waarde geweest en is nog steeds mijn grootste drijfkracht. Bedankt dat je er altijd voor me bent en dat je al dat gemopper hebt moeten aanhoren. Ik hoop dat we na het afsluiten van onze PhD's een mooie tijd en toekomst tegemoet kunnen gaan en dat we nieuwe avonturen tegemoet kunnen gaan. Ik hou van je! 


\section{Curriculum Vitae}


Mike Jeurissen was born on November $15^{\text {th }}, 1985$ in Lelystad, the Netherlands. In 2003, he acquired his high school diploma at the Zorgcentrum Broekhin in Roermond, the Netherlands. Afterwards, he followed the MLO education to became a clinical technician at the Gilde Opleidingen in Venlo-Blerick, the Netherlands. He received his Bachelor in Biology and Medical Laboratory Sciences in September 2012 at the Zuyd University in Heerlen, the Netherlands. Later that year he enrolled into the master program of Cardiovascular Biology and Medicine at Maastricht University, the Netherlands. For his master, he performed an internship at the Department of Pathology, where he investigated the effect of hypoxia on plague development. For his master thesis, he performed an internship at the Department of Molecular Genetics at Maastricht University, investigating ADAM activity in regulating macrophage function and polarization in atherosclerosis, and graduated in July, 2012.

In October 2012, he started his PhD program at the Department of Molecular Genetics within the school of Nutrition and Translation Research in Metabolism under supervision of Prof. Dr. Ronit Shiri-Sverdlov, Prof. Dr. Jan Glatz and Dr. Marjo Donners. The topic of his research was focused on the role of macrophages in NASH and atherosclerosis. Different mechanisms were investigated in relation to the crosstalk between lipids and inflammation. During this period main activities were to design, plan and organize research projects; mentoring of several Bachelor and Master students during their internship and conducting various teaching activities as a tutor. He also attended several national and international conferences such as Dutch Liver Retreat, Spier, 2013-2015; Dutch Lipoprotein Club, Leiden, 2012-2013; 25th Genetics Retreat, Kerkrade, 2015; 5th Joint Diabetes and Metabolism Research Symposium, Maastricht, 2015; 20th Annual Scandinavian Atherosclerosis Conferences, Humlebæk Denmark, 2014 and British Atherosclerosis Society Autumn Meeting, Cambridge, United Kingdom, 2015. During these conferences, he presented his research both via oral and poster presentations. 


\section{List of Publications}

1. Myeloid DLL4 does not contribute to the pathogenesis of Non-Alcoholic Steatohepatitis in Ldlr-/- mice. Jeurissen ML, Walenbergh, SMA, Houben T, Hendrikx T, Li J, Oligschläger Y, van Gorp PJ, Gijbels MJJ, Bitorina A, Nessel I, Radtke F, Vooijs M, Theys J, Shiri-Sverdlov R. In Press at PlosOne

2. Prevention of oxLDL uptake leads to a moderate decrease of atherosclerosis in hematopoietic NPC1-deficient Ldlr $^{-/}$mice. Jeurissen ML*, Walenbergh SMA*, Houben T, Gijbels MJJ, Li J, Hendrikx T, Oligschläger Y, van Gorp PJ, Binder CJ, Donners MMPC, Shiri-Sverdlov R. Atherosclerosis. 2016 Oct 20;255:59-65. doi: 10.1016/j.atherosclerosis.2016.10.038*Shared first

3. Plasma cathepsin $D$ correlates with histological classifications of fatty liver disease in adults and responds to intervention. Walenbergh SMA, Houben T, Rensen SS, Bieghs V, Hendrikx T, van Gorp PJ, Jeurissen MLJ, Buurman WA, Greve JWM, Plat J, Hofker MH, Kalhan S, Lindsey P, Koek GH, Shiri-Sverdlov R. In press in Scientific Reports

4. Macrophage stimulating protein enhances Hepatic inflammation in a NASH model. Li J, Chanda D, van Gorp PJ, Jeurissen MLJ, Houben T, Walenbergh SM, Debets J, Oligschlaeger Y, Gijbels MJ, Neumann D, Shiri-Sverdlov R. PLoS One. 2016 Sep 29;11(9):e0163843. doi: 10.1371/journal.pone.0163843. eCollection 2016

5. MSP is a negative regulator of inflammation and lipogenesis in ex vivo models of non-alcoholic steatohepatitis. Chanda D, Li J, Oligschlaeger $Y$, Jeurissen ML, Houben T, Walenbergh SM, Shiri-Sverdlov R, Neumann D Exp Mol Med. 2016 Sep 9;48:e258. doi: 10.1038/emm.2016.79.

6. Plasma IL-1 receptor antagonist levels correlate with the development of non-alcoholic steatohepatitis. Hendrikx T, Walenbergh SM, Jeurissen ML, Houben T, van Gorp PJ, Lindsey PJ, Koek GH, Kalhan S, Pihlajamaki J, Hofker MH, Shiri-Sverdlov R. Biomark Med. 2015 Dec;9(12):1301-9. doi: 10.2217/bmm.15.71. Epub 2015 Nov 19.

7. Weekly Treatment of 2-Hydroxypropyl- $\beta$-cyclodextrin Improves Intracellular Cholesterol Levels in LDL Receptor Knockout Mice. Walenbergh SM, Houben T, Hendrikx T, Jeurissen MLJ, van Gorp PJ, Vaes N, Olde Damink SW, 
Verheyen F, Koek GH, Lütjohann D, Grebe A, Latz E, Shiri-Sverdlov R. Int J Mol Sci. 2015 Sep 2;16(9):21056-69. doi: 10.3390/ijms160921056.

8. Bone marrow-specific caspase-1/11 deficiency inhibits atherosclerosis development in Ldlr $^{-/}$mice. Jeurissen MLJ*, Hendrikx T*, van Gorp PJ, Gijbels MJ, Walenbergh SM, Houben T, van Gorp R, Pöttgens CC, Stienstra R, Netea MG, Hofker MH, Donners MM, Shiri-Sverdlov R. FEBS J. 2015 Jun;282(12):2327-38. doi: 10.1111/febs.13279. Epub 2015 Apr 20. *Shared first

9. Plasma cathepsin D levels: a novel tool to predict pediatric hepatic inflammation. Walenbergh SM, Houben $T$, Hendrikx $T$, Jeurissen ML, van Gorp PJ, Vreugdenhil AC, Adriaanse MP, Buurman WA, Hofker MH, Mosca A, Lindsey PJ, Alisi A, Liccardo D, Panera N, Koek GH, Nobili V, Shiri-Sverdlov R. Am J Gastroenterol. 2015 Mar;110(3):462-70. doi: 10.1038/ajg.2015.29. Epub 2015 Mar 3.

10. Myeloid A disintegrin and metalloproteinase domain 10 deficiency modulates atherosclerotic plaque composition by shifting the balance from inflammation toward fibrosis. van der Vorst EP, Jeurissen MLJ, Wolfs IM, Keijbeck A, Theodorou K, Wijnands E, Schurgers L, Weber S, Gijbels MJ, Hamers AA, Dreymueller D, Rose-John S, de Winther MP, Ludwig A, Saftig P, Biessen EA, Donners MM. Am J Pathol. 2015 Apr;185(4):1145-55. doi: 10.1016/j.ajpath.2014.11.028. Epub 2015 Feb 7.

11. Protective role of plant sterol and stanol esters in liver inflammation: insights from mice and humans. Plat J, Hendrikx T, Bieghs $V$, Jeurissen $M U$, Walenbergh SM, van Gorp PJ, De Smet E, Konings M, Vreugdenhil AC, Guichot YD, Rensen SS, Buurman WA, Greve JW, Lütjohann D, Mensink RP, Shiri-Sverdlov R. PLoS One. 2014 Oct 30;9(10):e110758. doi: 10.1371/journal.pone.0110758. eCollection 2014.

12. Hematopoietic overexpression of Cyp27a1 reduces hepatic inflammation independently of 27-hydroxycholesterol levels in $\mathrm{Ldlr}^{-/-}$mice. Hendrikx T, Jeurissen MLJ, Bieghs V, Walenbergh SM, van Gorp PJ, Verheyen F, Houben T, Guichot YD, Gijbels MJ, Leitersdorf E, Hofker MH, Lütjohann D, ShiriSverdlov R. J Hepatol. 2015 Feb;62(2):430-6. doi: 10.1016/j.jhep.2014.09.027. Epub 2014 Oct 2. 
13. Reversal of hypoxia in murine atherosclerosis prevents necrotic core expansion by enhancing efferocytosis. Marsch E, Theelen TL, Demandt JA, Jeurissen MLJ, van Gink $M$, Verjans $R$, Janssen $A$, Cleutjens JP, Meex SJ, Donners MM, Haenen GR, Schalkwijk CG, Dubois LJ, Lambin P, Mallat Z, Gijbels MJ, Heemskerk JW, Fisher EA, Biessen EA, Janssen BJ, Daemen MJ, Sluimer JC. Arterioscler Thromb Vasc Biol. 2014 Dec;34(12):2545-53. doi: 10.1161/ATVBAHA.114.304023. Epub 2014 Sep 25.

14. Macrophage specific caspase-1/11 deficiency protects against cholesterol crystallization and hepatic inflammation in hyperlipidemic mice. Hendrikx $T$, Bieghs V, Walenbergh SM, van Gorp PJ, Verheyen F, Jeurissen MLJ, Steinbusch MM, Vaes N, Binder CJ, Koek GH, Stienstra R, Netea MG, Hofker MH, Shiri-Sverdlov R. PLoS One. 2013 Dec 2;8(12):e78792. doi: 10.1371/journal.pone.0078792. eCollection 2013.

15. Oxidised plant sterols as well as oxycholesterol increase the proportion of severe atherosclerotic lesions in female LDL receptor+/- mice. Plat J, Theuwissen E, Husche C, Lütjohann D, Gijbels MJ, Jeurissen MLJ, ShiriSverdlov R, van der Made I, Mensink RP. Br J Nutr. 2014 Jan 14;111(1):64-70. doi: 10.1017/S0007114513002018. Epub 2013 Jun 18.

16. The cholesterol derivative 27-hydroxycholesterol reduces steatohepatitis in mice. Bieghs V, Hendrikx T, van Gorp PJ, Verheyen F, Guichot YD, Walenbergh SM, Jeurissen MLJ, Gijbels M, Rensen SS, Bast A, Plat J, Kalhan SC, Koek GH, Leitersdorf E, Hofker MH, Lütjohann D, Shiri-Sverdlov R. Gastroenterology. 2013 Jan;144(1):167-178.e1. doi: 10.1053/j.gastro.2012.09.062. Epub 2012 Oct 3. 


\section{Submitted / in preparation}

1. Lysosomal cholesterol in Kupffer cells, particularly when oxidized, contributes to murine steatohepatitis.

Walenbergh SMA, Houben T, Hendrikx T, van Gorp PJ, Jeurissen MLJ, Lenders MH, Gijbels MJJ, Plat J, Hofker MH, Binder CJ, Lütjohann D, Verheyen F, Koek $\mathrm{GH}$, Shiri-Sverdlov R. Submitted

2. Cellular gender identity - The inflammatory effects of 27-hydroxycholesterol are sex dependent.

Bitorina A, Jeurissen ML, Houben T, Walenbergh SMA, Oligschläger $Y$, Plat J, Lütjohann D, Romano A, Shiri-Sverdlov $\mathrm{R}$, In preparation.

\section{Oral Presentations}

1. March 2016: Plenary meeting 2016, Department of Genetics and Cell Biology, Maastricht University Medical Center (MUMC+), the Netherlands

Title: The Inflammasome: the role of hematopoietic capsase-1/11 in atherosclerosis development

2. October 2015: $6^{\text {th }}$ Dutch Liver Retreat, Spier the Netherlands

Title: Myeloid DLL4 does not contribute to the pathogenesis of Non-alcoholic steatohepatitis in Ldlr/- mice

3. June, 2015: The $5^{\text {th }}$ Joint Diabetes and Metabolism Research Symposium

Title: Hematopoietic overexpression of CYP27A reduces hepatic inflammation, independently of 27-hydroxycholesterol levels in LdIr/- mice

4. April 2015: $25^{\text {th }}$ Genetics Retreat, Kerkrade, the Netherlands

5. Title: Title: Hematopoietic overexpression of CYP27A reduces hepatic inflammation, independently of 27-hydroxycholesterol levels in LdIr-- mice

6. March 2015: $5^{\text {th }}$ Maastricht Inflammation in the Metabolic Syndrome and Atheroslcerosis (MIMSA) mini-symposium, Maastricht, the Netherlands

Title: Hematopoietic overexpression of CYP27A reduces hepatic inflammation, independently of 27-hydroxycholesterol levels in Ldlr/- mice 
7. October 2014: $5^{\text {th }}$ Dutch Liver Retreat, Spier, the Netherlands

Title: Hematopoietic overexpression of CYP27A reduces hepatic inflammation, independently of 27-hydroxycholesterol levels in Ldlr/- mice

8. April 2014: 20 th Annual Scandinavian Atherosclerosis Conference 2014, Humlebæk, Denmark

Title: The inflammasome: The role of hematopoietic caspase-1/11 in atherosclerosis development

9. February 2014: Metabolic Syndrome Course 2014, Maastricht, the Netherlands

Title: Regulation and dysregulation of metabolic homeostasis by the liver

10. September 2013: 4th Dutch Liver Retreat, Spier, The Netherlands

Title: Plant sterol and stanol esters as a novel treatment for hepatic inflammation

11. November 2012: Dutch Lipoproteïne Club, Leiden, The Netherlands

Title: The inflammasome: The role of hematopoietic caspase-1/11 in atherosclerosis development.

\section{Poster Presentations}

1. December 2015: The $23^{\text {st }}$ Annual Symposium School of Nutrition and Translational Research in Metabolism (NUTRIM), Maastricht, the Netherlands Title: Myeloid DLL4 does not contribute to the pathogenesis of non-alcoholic steatohepatitis in Ldlr ${ }^{-1}$ mice

2. September 2015: British Atherosclerosis Society Autumn Meeting 2015, Cambridge, United Kingdom

Title: Lysosomal cholesterol in plaque, particularly when oxidized, contributes to the development of atherosclerosis.

3. December 2014: The $22^{\text {st }}$ Annual Symposium School of Nutrition and Translational Research in Metabolism (NUTRIM), Maastricht, the Netherlands Title: Hematopoietic overexpression of CYP27A reduces hepatic inflammation, independently of 27-hydroxycholesterol levels in $\mathrm{Ldll}^{-/}$mice 


\section{Other contributions}

1. Organizer of the weekly meetings of the department of Molecular Genetics (2015-Present)

Molecular Genetics, Maastricht, the Netherlands

2. Committee Member Seminar ${ }^{+}$(2015)

Molecular Genetics, Maastricht, the Netherlands

3. Invited scientific chair of the session 'Lipid Metabolism'

$1^{\text {st }}$ European Fatty Liver Conference (EFLC), Maastricht, the Netherlands

4. Invited scientific chair of the session 'Liver biology and diseases'

$6^{\text {th }}$ Dutch Liver Retreat, Spier, the Netherlands (2015) 
